NUREG/CR-6412

SAND97-3170

\title{
Aging and Loss-of-Coolant Accident (LOCA) Testing of Electrical Connections
}

Prepared by

C.F. Nelson

Sandia National Laboratories

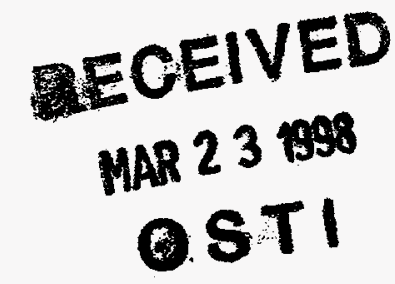

Prepared for

U.S. Nuclear Regulatory Commission

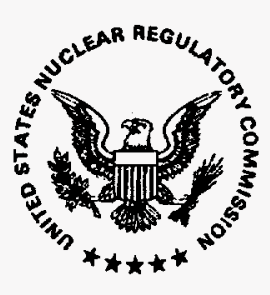




\section{AVAILABILITY NOTICE}

Availability of Reference Materials Cited in NRC Publications

Most documents cited in NRC publications will be available from one of the following sources:

1. The NRC Public Document Room, 2120 L Street, NW., Lower Level, Washington. DC 20555-0001

2. The Superintendent of Documents, U.S. Government Printing Office, P. O. Box 37082, Washington, DC 20402-9328

3. The National Technical Information Service, Springfield, VA 22161-0002

Although the listing that follows represents the majority of documents cited in NRC publications, it is not intended to be exhaustive.

Referenced documents available for inspection and copying for a fee from the NRC Public Document Room include NRC correspondence and internal NRC memoranda; NRC bulletins, circulars, information notices, inspection and investigation notices; licensee event reports; vendor reports and correspondence: Commission papers; and applicant and licensee documents and correspondence.

The following documents in the NUREG series are available for purchase from the Government Printing Office: formal NRC staff and contractor reports, NRC-sponsored conference proceedings, international agreement reports, grantee reports, and NRC booklets and brochures. Also available are regulatory guides, NRC regulatlons in the Code of Federal Regulations, and Nuclear Regulatory Commission issuances.

Documents avaliable from the National Technical Information Service include NUREG-series reports and technical reports prepared by other Federal agencies and reports prepared by the Atomic Energy Commission, forerunner agency to the Nuclear Regulatory Commission.

Documents available from public and special technical libraries include all open literature items, such as books, journal articles, and transactions. Federal Register notices. Federal and State legislation. and congressional reports can usually be obtained from these libraries.

Documents such as theses, dissertations, foreign reports and translations, and non-NRC conference proceedings are available for purchase from the organization sponsoring the publication cited.

Single coples of NRC draft reports are available free. to the extent of supply. upon written request to the Office of Administration, Distribution and Mail Services Section. U.S. Nuclear Regulatory Commission, Washington, DC 20555-0001.

Coples of industry codes and standards used in a substantive manner in the NRC regulatory process are maintained at the NRC Library, Two White Flint North, 11545 Rockville Pike, Rockville, MD 20852-2738, for use by the public. Codes and standards are usually copyrighted and may be purchased from the originating organization or, if they are American National Standards, from the American National Standards Institute. 1430 Broadway, New York, NY 10018-3308.

\section{DISCLAIMER NOTICE}

This report was prepared as an account of work sponsored by an agency of the United States Government. Neither the United States Government nor any agency thereof, nor any of their employees, makes any warranty, expressed or implied, or assumes any legal liability or responsibility for any third panty's use, or the results of such use, of any information, apparatus, product, or process disclosed in this report, or represents that its use by such third party would not infringe privately owned rights. 


\section{Aging and Loss-of-Coolant Accident (LOCA) Testing of Electrical Connections}

Manuscript Completed: December 1997

Date Published: January 1998

Prepared by

C.F. Nelson

Sandia National Laboratories

Albuquerque, NM 87185

S.K. Aggarwal, NRC Program Manager DISTRIBUTION OF THIS DOCUMENT IS UNLIMITED th

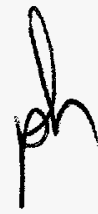

Prepared for

Division of Engineering Technology Office of Nuclear Regulatory Research U.S. Nuclear Regulatory Commission Washington, DC 20555-0001 NRC Job Code A1818

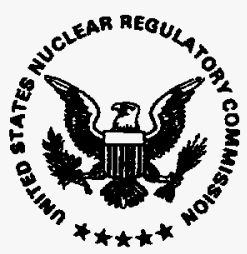




\section{DISCLAIMER}

This report was prepared as an account of work sponsored by an agency of the United States Government. Neither the United States Government nor any agency thereof, nor any of their employees, makes any warranty, express or implied, or assumes any legal liability or responsibility for the accuracy, completeness, or usefulness of any information, apparatus, product, or process disclosed, or represents that its use would not infringe privately owned rights. Reference herein to any specific commercial product, process, or service by trade name, trademark, manufacturer, or otherwise does not necessarily constitute or imply its endorsement, recommendation, or favoring by the United States Government or any agency thereof. The views and opinions of authors expressed herein do not necessarily state or reflect those of the United States Government or.any agency thereof. 


\section{DISCLAIMER}

Portions of this document may be illegible electronic image products. Images are produced from the best available original document. 


\begin{abstract}
This report presents the results of an experimental program to determine the aging and loss-of-coolant accident (LOCA) behavior of electrical connections in order to obtain an initial scoping of their performance. Ten types of connections commonly used in nuclear power plants were tested. These included 3 types of conduit seals, 2 types of cable-to-device connectors, 3 types of cable-to-cable connectors, and 2 types of in-line splices. The connections were aged for 6 months under simultaneous thermal $\left(99^{\circ} \mathrm{C}\right)$ and radiation $(46 \mathrm{~Gy} / \mathrm{hr}$ ) conditions. A simulated LOCA consisting of sequential high dose-rate irradiation $(3 \mathrm{kGy} / \mathrm{hr})$ and high-temperature steam exposures followed the aging. Connection functionality was monitored using insulation resistance measurements during the aging and LOCA exposures. Because only 5 of the 10 connection types passed a post-LOCA, submerged dielectric withstand test, further detailed investigation of electrical connections and the effects of cable jacket integrity on the cable-connection system is warranted.
\end{abstract}





\section{Contents}

Abstract

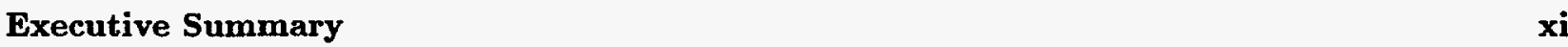

$\begin{array}{lc}\text { Acknowledgements } & \text { xiii }\end{array}$

Abbreviations $\quad$ xv

1 INTRODUCTION AND OBJECTIVES 1

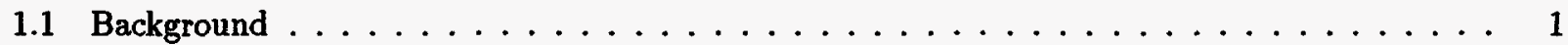

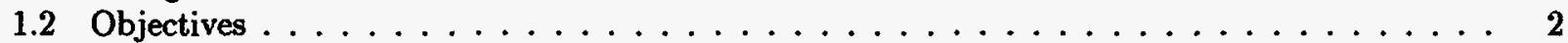

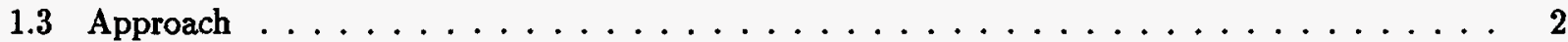

2 EXPERIMENTAL APPARATUS AND TECHNIQUE 3

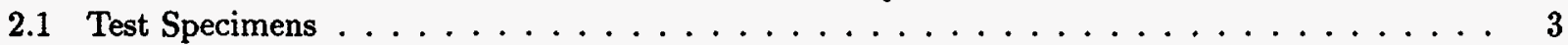

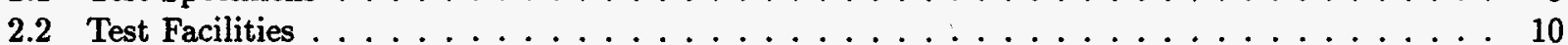

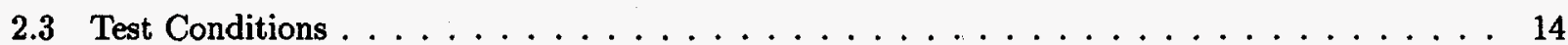

2.3.1 Simultaneous Radiation and Thermal Aging . . . . . . . . . . . . . 14

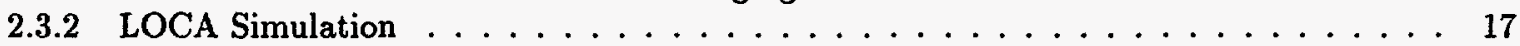

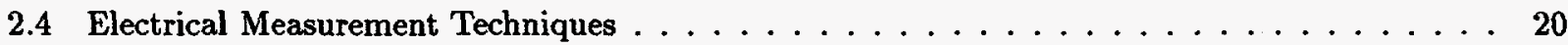

2.4 .1 Dielectric Withstand . . . . . . . . . . . . . . . . . . 22

2.4 .2 Insulation Resistance . . . . . . . . . . . . . . . . 23

2.4.3 Time Domain Reflectometry . . . . . . . . . . . . . . . . . . 24

3 EXPERIMENTAL RESULTS $\quad 27$

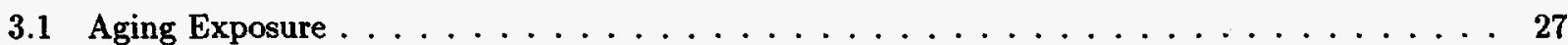

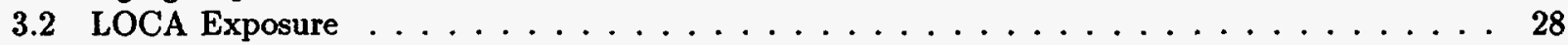

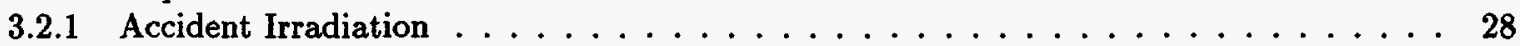

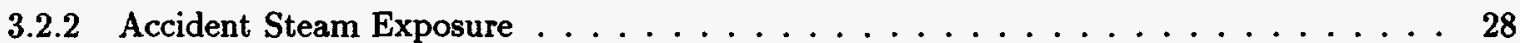

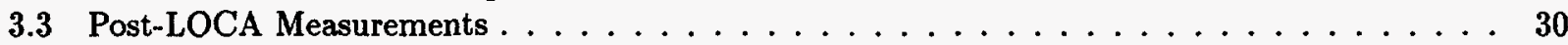

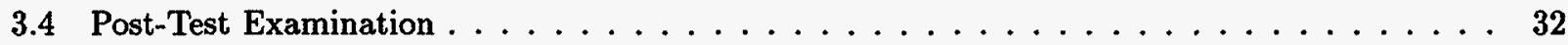

4 SUMMARY AND CONCLUSIONS $\quad 51$

$\begin{array}{lc}\text { REFERENCES } & 53\end{array}$

A TERMINAL BLOCKS $\quad \mathbf{5 7}$

A.1 Experimental Apparatus and Technique $\ldots \ldots \ldots \ldots \ldots \ldots \ldots \ldots$

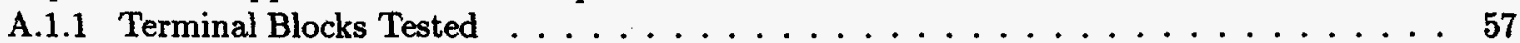

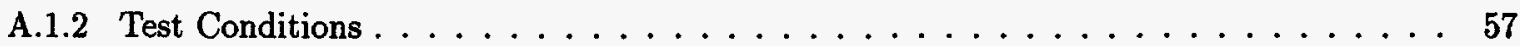

A.1.3 Electrical Measurement Techniques . . . . . . . . . . . . . . 61

A.2 Experimental Results . . . . . . . . . . . . . . . . . . . 61

B TEST FACILITIES AND RADIATION DOSIMETRY

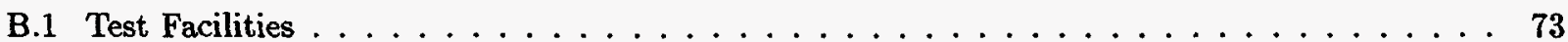

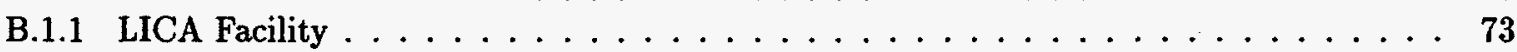

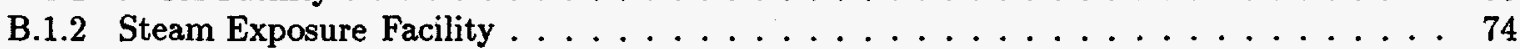

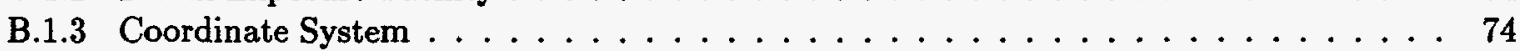

B.2 Radiation Dosimetry . . . . . . . . . . . . . . . . . . . . . 76

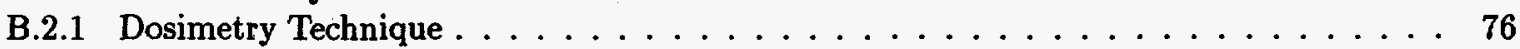

B.2.2 Aging Irradiation $\ldots \ldots \ldots \ldots \ldots \ldots \ldots \ldots \ldots \ldots \ldots$ 
Contents

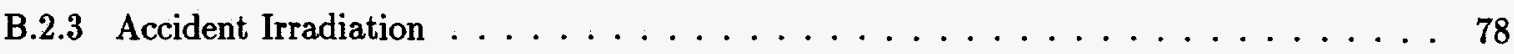

C TIME DOMAIN REFLECTOMETRY RESULTS 


\section{List of Figures}

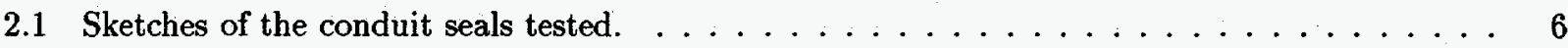

2.2 Sketches of the cable-to-device and cable-to-cable connectors tested. . . . . . . . . . 7

2.3 Sketch of the Amphenol coaxial connector tested showing the actual connectors and the arrangement of Raychem heat-shrinkable tubing applied for environmental protection. . . . . 8

2.4 Sketch of the device enclosures used for installation of conduit seals and cable-to-device con-

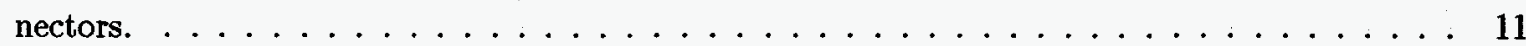

2.5 Detail of the test chamber and a sketch of the mandrel on which the electrical connections were mounted. . . . . . . . . . . . . . . . . . . . . 13

2.6 Top view of the test chamber and mandrel showing how the test specimens were arranged. . . 14

2.7 Required aging temperature as a function of activation energy, $E_{a} \ldots \ldots \ldots \ldots$

2.8 Curves of equivalent thermal exposures for the activation energies listed in Table 2.5 . . . . . 16

2.9 Schematic of the system used to monitor test chamber conditions during aging and accident

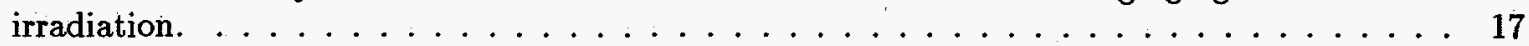

2.10 Temperature, airflow, and cable excitation during the simultaneous radiation and thermal

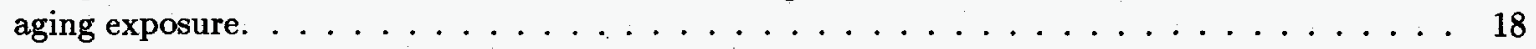

2.11 Temperature, airflow, and cable excitation during the accident radiation exposure. . . . . . 19

2.12 Pressure and temperature during the accident steam exposure. . . . . . . . . . . 21

2.13 Schematic of the system used to measure ac leakage currents. . . . . . . . . . . . 23

2.14 Schematic of the system used to perform discrete insulation resistance measurements. . . . . 24

2.15 Circuitry used to measure continuous insulation resistance during the accident steam exposure. 25

3.1 IR of the Amphenol coaxial connector conductors during aging and accident irradiation. . . . 36

3.2 IR of the Conax Buffalo ECSA conduit seal conductors during aging and accident irradiation. 36

3.3 IR of the Rockbestos coaxial cable conductors during aging and accident irradiation. . . . . . 37

3.4 IR of the EGS conduit seal conductors during aging and accident irradiation. . . . . . . . 37

3.5 IR of the EGS Grayboot connector conductors during aging and accident irradiation. . . . . . 38

3.6 IR of the EGS quick-disconnect connector conductors during aging and accident irradiation. . 38

3.7 IR of the Rockbestos Firewall III cable conductors during aging and accident irradiation. . . 39

3.8 IR of the Litton-VEAM connector conductors during aging and accident irradiation. . . . . . 39

3.9 IR of the NAMCO EC210 connector conductors during aging and accident irradiation. . . . . 40

3.10 IR of the Okonite tape splice conductors during aging and accident irradiation. . . . . . . . 40

3.11 IR of the Raychem heat-shrink splice conductors during aging and accident irradiation. . . . 41

3.12 IR of the Rosemount $353 \mathrm{C}$ conduit seal conductors during aging and accident irradiation. . . 41

3.13 IR of the Amphenol coaxial connector conductors during the accident steam exposure. . . . . 42

3.14 IR of the Conax Buffalo ECSA conduit seal conductors during the accident steam exposure. . 42

3.15 IR of the Rockbestos coaxial cable conductors during the accident steam exposure. . . . . . 43

3.16 IR of the EGS conduit seal conductors during the accident steam exposure. . . . . . . . . 43

3.17 IR of the EGS Grayboot connector conductors during the accident steam exposure. . . . . . . 44

3.18 IR of the EGS quick-disconnect connector conductors during the accident steam exposure. . . 44

3.19 IR of the Rockbestos Firewall III cable conductors during the accident steam exposure. . . . 45

3.20 IR of the Litton-VEAM connector conductors during the accident steam exposure. . . . . . 45

3.21 IR of the NAMCO EC210 connector conductors during the accident steam exposure. . . . . . 46

3.22 IR of the Okonite tape splice conductors during the accident steam exposure. . . . . . . . 46

3.23 IR of the Raychem heat-shrink splice conductors during the accident steam exposure. . . . . 47

3.24 IR of the Rosemount $353 \mathrm{C}$ conduit seal conductors during the accident steam exposure. . . . 47

A.1 Sketch of the two terminal blocks inside an enclosure. . . . . . . . . . . . . 59

A.2 Circuit used for dc and ac excitation of the terminal block conductors and to measure their "continuous" IRs during the accident steam exposure. . . . . . . . . . . . . 59

A.3 Direct current excitation for the terminal block conductors during the accident steam exposure. 60 
List of Figures

A.4 Alternating current excitation for the terminal block conductors during the accident steam exposure.

A.5 IR of the 7 Marathon terminal block conductors during aging and accident irradiation. . . . 63

A.6 IR of the 7 States terminal block conductors during aging and accident irradiation. . . . . . 63

A.7 IR of conductor 66 during the accident steam exposure (Marathon dc ground plane, enclosure 1). 64

A.8 IR of conductor 67 during the accident steam exposure (States ac ground plane, enclosure 1). 64

A.9 IR of conductor 68 during the accident steam exposure (States ac adjacent terminal, enclosure 1). 65

A.10 IR of conductor 69 during the accident steam exposure (Marathon dc adjacent terminal,

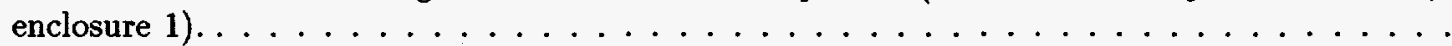

A.11 IR of conductor 70 during the accident steam exposure (Marathon dc adjacent terminal, enclosure 1) . . . . . . . . . . . . . . . . . . . 66

A.12 IR of conductor 71 during the accident steam exposure (States ac energization, enclosure 1). . 66

A.13 IR of conductor 72 during the accident steam exposure (Marathon dc energization, enclosure 1). 67

A.14 IR of conductor 73 during the accident steam exposure (States dc ground plane, enclosure 2). 67

A.15 IR of conductor 74 during the accident steam exposure (Marathon ac ground plane, enclosure 2). 68

A.16 IR of conductor 75 during the accident steam exposure (Marathon ac adjacent terminal,

enclosure 2) . . . . . . . . . . . . . . . . . . . 68

A.17 IR of conductor 76 during the accident steam exposure (States dc adjacent terminal, enclosure 2). 69

A.18 IR of conductor 77 during the accident steam exposure (States dc adjacent terminal, enclosure 2). 69

A.19 IR of conductor 78 during the accident steam exposure (Marathon ac energization, enclosure 2). 70

A.20 IR of conductor 79 during the accident steam exposure (States dc energization, enclosure 2). $\quad 70$

B.1 Plan view of the LICA pool and fixtures. $\ldots \ldots \ldots \ldots \ldots \ldots \ldots$

B.2 Sketch of a test chamber and large chamber cobalt fixture. . . . . . . . . . . 75

B.3 Plan view of large chamber cobalt fixture showing the fixture coordinate system and possible

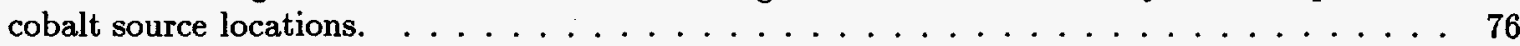

B.4 Steam Exposure Facility-steam generation and storage. . . . . . . . . . . . . . . 77

B.5 Steam Exposure Facility-superheaters and steam delivery. . . . . . . . . . . . . 77

B.6 Cobalt-60 source configuration for aging irradiation (black circles are guide tubes filled with a Co-60 source and white circles are empty guide tubes) . . . . . . . . . . 79

B.7 Aging radiation dose rate-spline fit through data $\left(0^{\circ}\right.$ corresponds to $x=6.75$ inches, $y=$ 0 inches).

B.8 Cobalt-60 source configuration for accident irradiation (black circles are guide tubes filled with a Co-60 source and white circles are empty guide tubes) . . . . . . . . . . . .

B.9 Accident radiation dose rate-spline fit through data $\left(0^{\circ}\right.$ corresponds to $x=6.75$ inches, $y=0$ inches). . . . . . . . . . . . . . . . . . 80

C.1 TDR of the Amphenol coaxial connector conductors before and after the accident steam exposure.

C.2 TDR of the Conax Buffalo ECSA conduit seal conductors before and after the accident steam exposure. . . . . . . . . . . . . . . . . . 83

C.3 TDR of the Rockbestos coaxial cable conductors before and after the accident steam exposure. 84

C.4 TDR of the EGS conduit seal conductors before and after the accident steam exposure. . . . 85

C.5 TDR of the EGS Grayboot connector conductors before and after the accident steam exposure. 86

C.6 TDR of the EGS quick-disconnect connector conductors before and after the accident steam

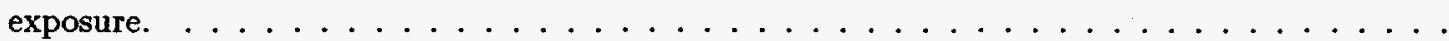

C.7 TDR of the Rockbestos Firewall III cable conductors before and after the accident steam

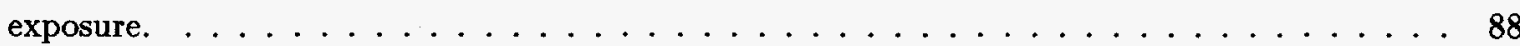

C. 8 TDR of the Litton-VEAM connector conductors before and after the accident steam exposure. 89

C.9 TDR of the NAMCO EC210 connector conductors before and after the accident steam exposure. 90

C.10 TDR of the Okonite tape splice conductors before and after the accident steam exposure. . . 91

C.11 TDR of the Raychem heat-shrink splice conductors before and after the accident steam exposure. 92 
List of Figures

C.12 TDR of the Rosemount 353C conduit seal conductors before and after the accident steam

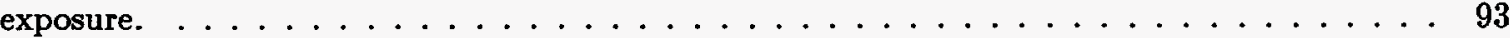




\section{List of Tables}

2.1 Electrical Connections Tested-Conduit Seals and Cable-to-Device Connectors. . . . . . . . 4

2.2 Electrical Connections Tested-Cable-to-Cable Connectors, In-Line Splices, and Cable Runs. 5

2.3 Conductor Numbers for the Connections. . . . . . . . . . . . . . . . . . 9

2.4 Installation Instructions and Activation Energies for the Test Specimens. . . . . . . . . . 11

2.5 Equivalent Thermal Aging to 6 Months at $98.8^{\circ} \mathrm{C}$ for the Test Specimens. . . . . . . . . . 15

2.6 Target Accident Steam Exposure Profile and IEEE Std. 323-1974 Combined PWR/BWR Profile. 22

3.1 Conax Buffalo ECSA Conduit Seal Conductor Fuses Replaced During the Accident Steam Exposure. . . . . . . . . . . . . . . . . . . . . 30

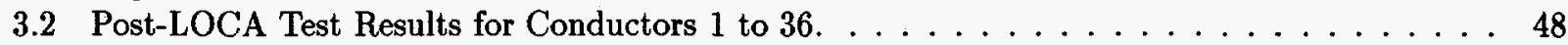

3.3 Post-LOCA Test Results for Conductors 37 to $65 . \ldots \ldots \ldots \ldots \ldots$

A.1 Terminal Blocks Tested. . . . . . . . . . . . . . . . . . . . . 58

A.2 Activation Energies and Equivalent Thermal Aging to 6 Months at $98.8^{\circ} \mathrm{C}$ for the Terminal

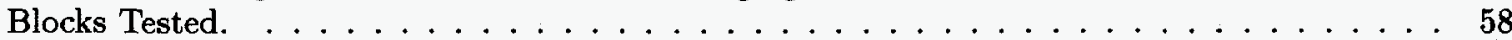

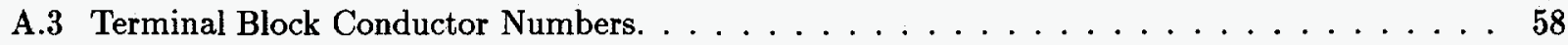

A.4 Alternating Current Excitation for Terminal Block Conductors During the Accident Steam Exposure. . . . . . . . . . . . . . . . . . . . . 61

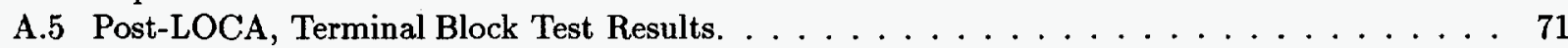




\section{Executive Summary}

This report presents the results of an experimental program to determine the aging and loss-of-coolant accident (LOCA) behavior of electrical connections in order to obtain an initial scoping of their performance. Ten types of connections commonly used in nuclear power plants were tested. These included 3 types of conduit seals, 2 types of cable-to-device connectors, 3 types of cable-to-cable connectors, and 2 types of in-line splices.

While the 6-month period of simultaneous radiation and thermal aging at $99^{\circ} \mathrm{C}\left(210^{\circ} \mathrm{F}\right)$ and $46 \mathrm{~Gy} / \mathrm{hr}(4.6 \mathrm{krad} / \mathrm{hr})$ was chosen to nominally simulate a plant environment for 60 years at $55^{\circ} \mathrm{C}$ $\left(131^{\circ} \mathrm{F}\right)$ and a dose of $200 \mathrm{kGy}(20 \mathrm{Mrad})$, the actual equivalent thermal aging ranged from 60 years at $28^{\circ} \mathrm{C}\left(82^{\circ} \mathrm{F}\right)$ for the Okonite tape splice to 60 years at $85^{\circ} \mathrm{C}\left(185^{\circ} \mathrm{F}\right)$ for the Conax Buffalo ECSA conduit seal (a complete listing of the equivalent aging for all the connections is included in the report). While it would have been desirable to age each of the connections to exactly 60 years at $55^{\circ} \mathrm{C}$ based upon each manufacturer's claimed activation energy, this was not possible because of time and scope considerations. Instead, a compromise was made by aging all of the connections at the same time in a single test chamber; this led to some of the connections being aged to less than, and some being aged to more than, the nominal conditions of 60 years at $55^{\circ} \mathrm{C}$. The simultaneous aging was followed by a LOCA simulation consisting of a 1000-kGy (100-Mrad) accident radiation exposure followed by an accident steam exposure.

In general, there was no meaningful degradation in the measured insulation resistance (IR) of the connections during the aging and accident irradiation exposures. Of the 55 connection conductors, only the IR of one Conax Buffalo ECSA conduit seal conductor and two Rosemount 353C conduit seal conductors fell below $10^{7} \Omega$ during aging and the accident irradiation exposure. In addition, the snap-on plastic covers used on the EGS Grayboot connector quickly became very brittle during aging, and will easily break apart and fall off. This had no effect on the measured IR values and the covers are not required by the manufacturer. However, if the covers are required for seismic reasons or to prevent the connector from pulling apart, then premature aging could lead to problems.

The IR for most of the connections also remained high during the accident steam exposure. Only the four Conax Buffalo ECSA conduit seal conductors gave extremely low IR values $(<100 \Omega)$; the two nongrounded conductors repeatedly blew 1-A fuses when energized at $110 \mathrm{Vdc}$. However, post-test examination showed that these low IR values were produced by degraded Kapton-insulated cable leads; the IR of the actual conduit seals remained at levels above $10^{10} \Omega$. After the initial steam transients, only 3 of 6 Litton-VEAM connector conductors and all four Amphenol coaxial connector conductors had IR values that fell below $10^{7} \Omega$ (in addition to the four Conax Buffalo ECSA conduit seal conductors).

Post-test examination showed that the O-ring seals used in the Litton-VEAM connector were brittle and had experienced compression set, thereby reducing their sealing ability and allowing moisture to enter the connector body. The Rockbestos coaxial cable used with the Amphenol coaxial connector appears to allow moisture to permeate its jacket and then get into the unsealed connector by wicking along the braided shield. No explanation for the behavior of the Rosemount 353C conduit seal was found during the post-test examination.

After completion of the LOCA exposure, a large fraction of the cable jackets were cracked, allowing easy ingress of moisture into the cables and possibly into the connections. While the connections are designed to stop this from occurring, the moisture in the cables is an additional environmental stressor and also makes any failure of the connection's internal seals more likely to affect circuit performance. Generally, the main function of a cable jacket is to protect the insulation during cable installation and no credit is taken for the jacket during environmental qualification testing. In fact, cracks or other breaches of the cable jacket may not be reported during such tests because they do not affect the cable's functionality. Situations where cable jacket integrity may be significant include beta radiation shielding, retention of shield integrity for shielded cables, and the possibility of jacket-insulation 
interactions for bonded-jacket cables. The results of the tests indicate that cable jacket integrity may also be important for connections because of possible intrusion of moisture into the connection.

After completion of the aging and accident exposures, submerged dielectric withstand testing was performed on the connections as required in IEEE 383-1974, which also requires that equipment be installed in a manner that simulates its expected installation when in actual use.

Because research testing does not apply to any specific installation, it must be performed using environments and device configurations that represent a reasonable expectation of what might actually be encountered in a plant; there are many plausible scenarios where connections could be subjected to submergence. Splices and cable-to-cable connectors can be installed anywhere along a cable run; thus these devices are as likely as a cable to be subjected to submergence. Because conduits are normally vented to the environment through a junction box, conduit seals are used as a moisture barrier between the conduit and the inside of a component. Anecdotes abound of incidents where trapped water poured out when a conduit was opened.

Half of the 10 connection types did not pass the post-LOCA, submerged dielectric withstand test:

- Essentially all the conductors in the Conax Buffalo ECSA conduit seals, Rosemount 353C conduit seals, EGS quick-disconnect connectors, Amphenol coaxial connectors, and Litton-VEAM connectors tripped the dielectric test set.

- None of the conductors in the EGS conduit seals, NAMCO EC210 connectors, EGS Grayboot connectors, Okonite tape splices, or Raychem heat-shrink splices tripped the test set.

Note that the problems were not limited to any one family of electrical connections; at least one connection from each of several of the families (conduit seals, cable-to-device connectors, and cable-to-cable connectors) was unable to pass the submerged dielectric withstand test.

If connections are used in applications where there is no possibility of submergence, the results of the submerged dielectric withstand testing are not relevant to the connection's ability to perform its intended functions. One must always know what specific applications and environmental conditions are relevant before using the results of a specific test for all possible uses of a device. It should also be noted that:

- If the environmental conditions of interest are less severe than those described in this report, then conclusions based upon these results cannot be substantiated. By their very nature, connections are usually easy to replace or service and thus in many applications they will be exposed to much less aging than complete cable runs, which are usually intended to remain in service for the entire life of a plant.

- Even though some of the problems identified in this report appear to be caused by cabling instead of the connection itself, it is important to remember that a problem anywhere in the entire cable-connection system will keep a system from being able to perform its intended function. Connections with Kapton-insulated cable leads may be more susceptible to such system-level problems because Kapton is relatively fragile.

Further detailed investigation of electrical connections is warranted and is being initiated because of the reduced IR values that occurred during the simulated nominal life of 60 years and the ensuing LOCA exposure, and the fact that $50 \%$ of the connection types were unable to successfully pass the subsequent submerged dielectric withstand test. This additional research will provide information on the accident performance of unaged cable-connection systems and also systems aged to conditions less severe than those used in this report. 


\section{Acknowledgements}

I would like to thank all of the people who have contributed to this project and the writing of this report. This work has been sponsored by the NRC Office of Nuclear Regulatory Research under the project management of Bill Farmer, Milt Vagins, and Satish Aggarwal. Ed Baynes and Mike Ramirez prepared the test specimens and operated the experimental apparatus; they also performed many of the insulation resistance measurements throughout the test program. In addition, Mark Jacobus provided advice on the overall test program and Gary Fuehrer helped debug the computer programs used to acquire experimental data. 



\section{Abbreviations}

Acronyms

ac

ANSI

ASTM

BWR

CSPE

dc

EPR

Hypalon

IEEE

IR

Kapton

LICA

LOCA

NIST

NPT

NRC

NRC/NRR

NRC/RES

NUREG

PWR

rms

TDR

TLD

XLPE

XLPO alternating current

American National Standards

Institute

American Society for Testing and Materials

boiling water reactor

chlorosulfonated polyethylene

direct current

ethylene propylene rubber

trademark of DuPont's CSPE

formulation

Institute of Electrical and

Electronics Engineers

insulation resistance

trademark of DuPont's polyimide film

Low Intensity Cobalt Array

loss-of-coolant accident

National Institute of Standards and

Technology

American National Standard Taper

Pipe Thread (ANSI B2.1-1968)

United States Nuclear Regulatory

Commission

NRC Office of Nuclear Reactor

Regulation

NRC Office of Nuclear Regulatory

Research

nuclear regulatory (document series published by the NRC)

pressurized water reactor

root-mean-square, abbreviation for square root of the mean of the square

time domain reflectometry

thermoluminescent dosimeter

cross-linked polyethylene; this is a specific type of XLPO

cross-linked polyolefin

Symbols

$x$

$y$

$z$

$Z$

$Z_{0}$

$\rho$

$\sigma$ horizontal distance along the long axis of the fixture used to hold the cobalt sources and the test chamber (see Figure B.3)

horizontal distance parallel to the short axis of the fixture used to hold the cobalt sources and the test chamber (see Figure B.3) vertical distance from the midpoint of the cobalt sources (see Figures B.2 and B.3) impedance $(\Omega)$ characteristic impedance $(\Omega)$ reflection coefficient standard deviation 


\section{INTRODUCTION AND OBJECTIVES}

This report presents the results of an experimental program to determine the aging and loss-of-coolant accident (LOCA) behavior of electrical connections. While there have been numerous studies on electrical cables, a similar body of work does not exist for the connections that are used to terminate the cables. This report summarizes an investigation of a wide range of connections that are commonly used in nuclear power plants, including conduit seals, connectors, and splices.

In this report, the word connection is used as a general term to encompass conduit seals, connectors, and splices. The word termination is often used in this context; however, a termination is the metallic pin, socket, or lug that is soldered or crimped to the end of an individual conductor.

Expressed in the simplest terms, a connector is a device used for convenient connection and disconnection between electrical terminations. In nuclear power plant applications, a connector also provides mechanical and environmental protection for the electrical terminations. A conduit seal serves as an environment boundary seal where a cable exits a conduit or enters a component. A splice is a permanent joining and reinsulating of conductors.

\subsection{Background}

This report describes testing of cable connections that was performed as part of the Aging Degradation of Cables Program (FIN A1818) for the U.S. Nuclear Regulatory Commission, Office of Nuclear Regulatory Research (NRC/RES). This program has previously produced several reports on cable tests, namely:

- NUREG/CR-5461, Aging of Cables, Connections, and Electrical Penetration Assemblies Used in Nuclear Power Plants [19]

- NUREG/CR-5655, Submergence and High Temperature Steam Testing of Class $1 \mathrm{E}$ Electrical Cables [20]

- NUREG/CR-5772, Aging, Condition Monitoring, and Loss-of-Coolant Accident Tests of Class 1E Electrical Cables
- Vol. 1, Crosslinked Polyolefin Cables [21]

- Vol. 2, Ethylene Propylene Rubber Cables [22]

- Vol. 3, Miscellaneous Cable Types [23]

While the NUREG/CR-5772 series of reports was being finalized, it was decided that an initial scoping study of connections should be performed as a follow-on to the cable testing that was just being completed.

Since this effort was an initial program to investigate electrical connections, it was decided to include as broad a range of connections as possible. Ten types of connections commonly used in nuclear power plants were tested. These included 3 types of conduit seals, 2 types of cable-to-device connectors, 3 types of cable-to-cable connectors, and 2 types of in-line splices. It was not possible to perform detailed testing on each connection type, to test enough of each type to obtain a good statistical sample, nor to investigate and develop condition monitoring techniques applicable to connections. Rather, this test program provides an initial scoping of whether more detailed testing of connections is warranted.

Because this was intended as a scoping test, the most severe aging condition investigated in the NUREG/CR-5772 series of reports was used for the aging exposure; this is why 60 years was chosen as the nominal aging equivalent and no unaged specimens were tested. Consistent with the cable testing, essentially the same test procedures and environmental exposures were used for the connections (i.e., since connections are installed on cables, the same procedure will identify the weakest link in the cable-connection system). It should be noted that depending on the specific application, the aging exposures in this report for the connections may be much greater than what would be experienced in a plant. By their very nature, connections are usually easy to replace or service and thus in many applications they will be exposed to much less aging than complete cable runs, which are usually intended to remain in service for the entire life of the plant. 


\subsection{Objectives}

The objective of this report is to provide initial information on the long-term aging degradation and LOCA behavior of nuclear-qualified electrical connections subjected to environmental exposures similar to those used for previous research testing of nuclear-qualified electrical cables. The specific program objectives were as follows:

- To assess the accident performance of electrical connections aged more slowly (i.e., at lower temperatures and radiation dose rates) than in typical industry tests and under simultaneous conditions.

- To investigate the performance of connections aged to a nominal 60-year life. If they perform well, then this provides an indication of their suitability for service for the entire life and possible extended life of the plant. If problems arise, then this indicates that additional effort to quantify their actual useful life is warranted.

\subsection{Approach}

To accomplish these objectives, an experimental program consisting of two phases was undertaken, both using the same specimens:

1. A 6-month-long, simultaneous thermal $\left(99^{\circ} \mathrm{C}\right.$ $\left.=210^{\circ} \mathrm{F}\right)$ and radiation aging $(45.6 \mathrm{~Gy} / \mathrm{hr}=$ $4.56 \mathrm{krad} / \mathrm{hr}$ ) exposure to nominally simulate 60 years in a nuclear power plant at an ambient temperature of $55^{\circ} \mathrm{C}\left(131^{\circ} \mathrm{F}\right)$ and a total radiation dose of $200 \mathrm{kGy}(20 \mathrm{Mrad})$.

2. A simulated LOCA exposure consisting of a 1000-kGy (100-Mrad), high dose-rate $(3 \mathrm{kGy} / \mathrm{hr}=300 \mathrm{krad} / \mathrm{hr})$ radiation exposure followed by a steam exposure.

In each phase, the connections were monitored electrically to assess their functionality and to determine if the electrical monitoring could detect degradation of connections. No detailed condition monitoring was performed and there was no attempt to develop or evaluate techniques that could monitor the aging degradation of the electrical connections. The test program generally followed the guidance of IEEE 323-1974 [16], IEEE 383-1974 [17], and IEEE 572-1985 [18].
As a first test of connection performance, the environmental exposures for this experimental program were chosen to be roughly equivalent to those in the NUREG/CR-5772 series of reports $[21,22,23]$. The only major difference is that the NUREG/CR-5772 reports used a 60-year aging radiation dose of $600 \mathrm{kGy}(60 \mathrm{Mrad})$ and an accident radiation dose of $1100 \mathrm{kGy}(110 \mathrm{Mrad})$, while this report uses a 60 -year aging radiation dose of $200 \mathrm{kGy}$ (20 Mrad) and an accident radiation dose of $1000 \mathrm{kGy}$ (100 Mrad). The lower doses for the current tests are more representative of reported actual nuclear power plant conditions. However, these conditions are still likely to be more severe than what would be seen by most connections in service. One should always evaluate these results for the environmental conditions expected for a specific application. 


\section{EXPERIMENTAL APPARATUS AND TECHNIQUE}

This section describes the electrical connections tested, the test conditions, and the experimental apparatus and techniques used to perform the measurements.

\subsection{Test Specimens}

Connection test specimens consisting of conduit seals, connectors, and splices were chosen on the basis of their use in commercial nuclear power plants. Information gained from the NRC Equipment Qualification Inspection Program ${ }^{1}$ was a major input for assessing plant use of connections.

The 10 types of connection specimens that were tested are:

- Conduit Seals

- Conax Buffalo Electric Conductor Seal Assembly

- Patel/EGS Conduit Seal

- Rosemount 353C Conduit Seal

- Cable-to-Device Connectors

- Namco EC210 1/2-in Series

- Patel/EGS 1/2-in Quick Disconnect

- Cable-to-Cable Connectors

- Amphenol 82-816-1000/16100/34500-1000 Coaxial Connectors

- EGS GB-1 Grayboot Connector

- Litton-VEAM CIR01/CIR06

- In-Line Splices

- Okonite T-95/No. 35 Tape Splice

- Raychem NPKC-3-31A Splice Kit

\footnotetext{
${ }^{1}$ Program from 1981-1992 (NRC FIN A1126) in which Sandia National Laboratories provided expert technical assistance to NRC/NRR (formerly NRC Office of Inspection and Enforcement) for equipment qualification inspections at nuclear power plants, test laboratories, equipment suppliers, architect/engineers, and any other facility involved in equipment qualification.
}

Detailed information on the conduit seals and cable-to-device connectors tested is given in Table 2.1, and for the cable-to-cable connectors and in-line splices in Table 2.2. Sketches of the conduit seals tested are shown in Figure 2.1, and the cable-to-device and cable-to-cable connectors are shown in Figures 2.2 and 2.3.

As indicated in Tables 2.1 and 2.2, Rockbestos Firewall III XLPE multiconductor cable and Rockbestos RSS-6-104/LE coaxial cable were used to install connections that were received from the manufacturer without a factory-installed length of cable. Both these cables are nuclear qualified and had been previously tested to the equivalent of 60 years in NUREG/CR-5772, Vol. 1 [21] $^{2}$ and Vol. 3 [23]. Since these cables performed well in the past, the effects of connection degradation can be isolated from cable degradation or failure. Two $18.3-\mathrm{m}(60-\mathrm{ft})$ long sections of each Rockbestos cable, without any connections, were included as part of the test to confirm that cable effects can be isolated:

- Other (cable runs with no connections)

- Rockbestos Firewall III multiconductor cable (12AWG)

- Rockbestos RSS-6-104/LE coaxial cable

Detailed information on the cable runs is given in Table 2.2.

Two specimens of each connection and cable type were tested, except for the 3 specimens of the EGS Grayboot connector ${ }^{3}$; thus, a total of 21 connections and 4 cable runs were tested.

As indicated in Table 2.3, a total of 23 cables ( 65 conductors) entered the test chamber. An additional 13 cables ( 39 conductors) exited the test chamber; these were the return legs of the cables that entered the chamber for the cable-to-cable connectors, the in-line splices, and the cable runs. Approximately $9.1-\mathrm{m}(30-\mathrm{ft})$ long cable leads were attached to one or both sides of the connections;

\footnotetext{
${ }^{2}$ The Rockbestos Firewall III XLPE multiconductor cable tested in NUREG/CR-5772, Vol. 1 had a neoprene jacket, not a Hypalon jacket as for the cable in this report.

${ }^{3}$ One EGS Grayboot connector is needed for each conductor; thus three Grayboot connectors were used for one 3-conductor cable.
} 
Table 2.1: Electrical Connections Tested-Conduit Seals and Cable-to-Device Connectors.

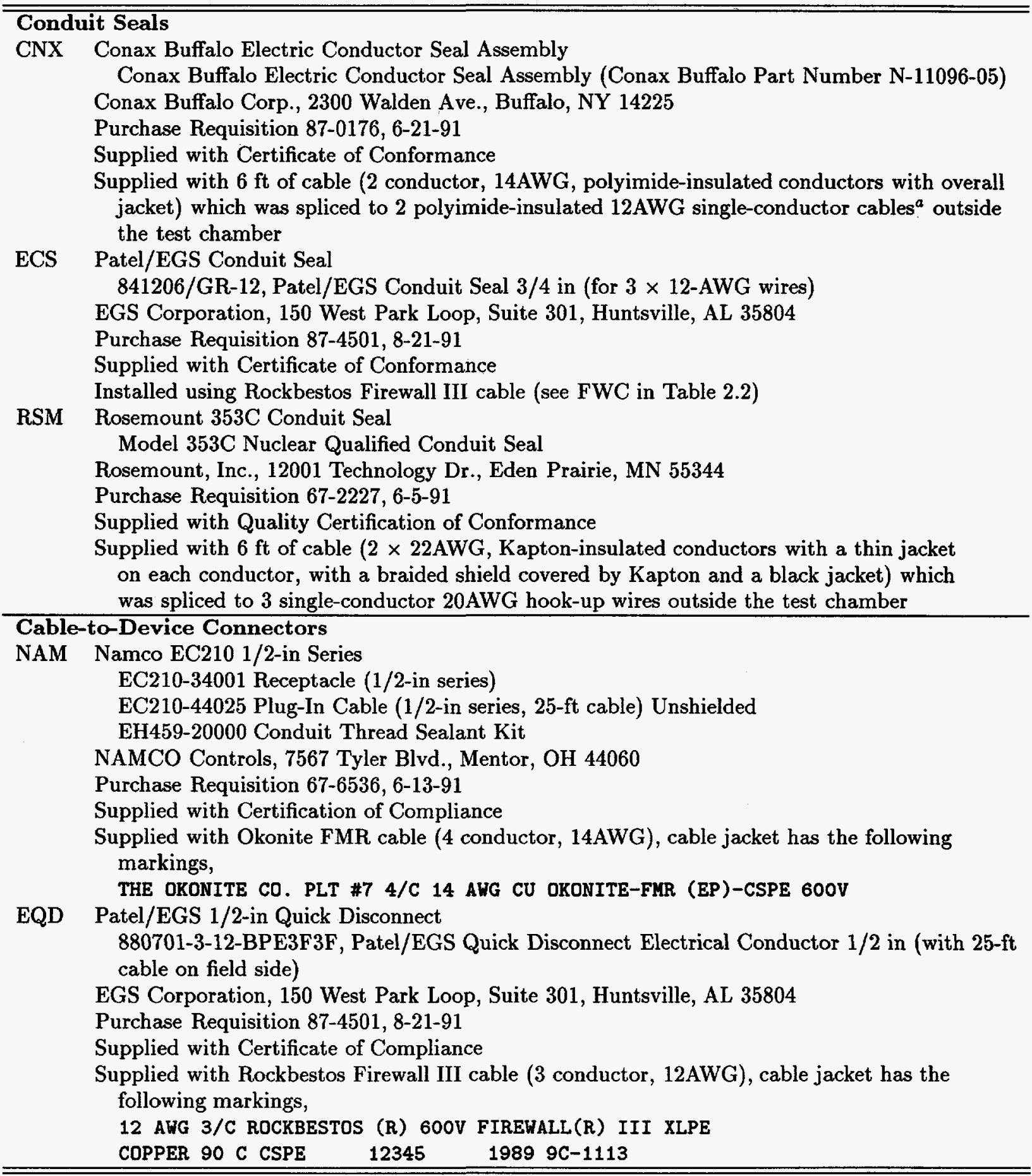

a Polyimide-insulated single-conductor cable is the same Champlain Cable Corp. cable tested in Ref. [23], Purchase Requisition 23-3238, May 1987. 
Table 2.2: Electrical Connections Tested-Cable-to-Cable Connectors, In-Line Splices, and Cable Runs.

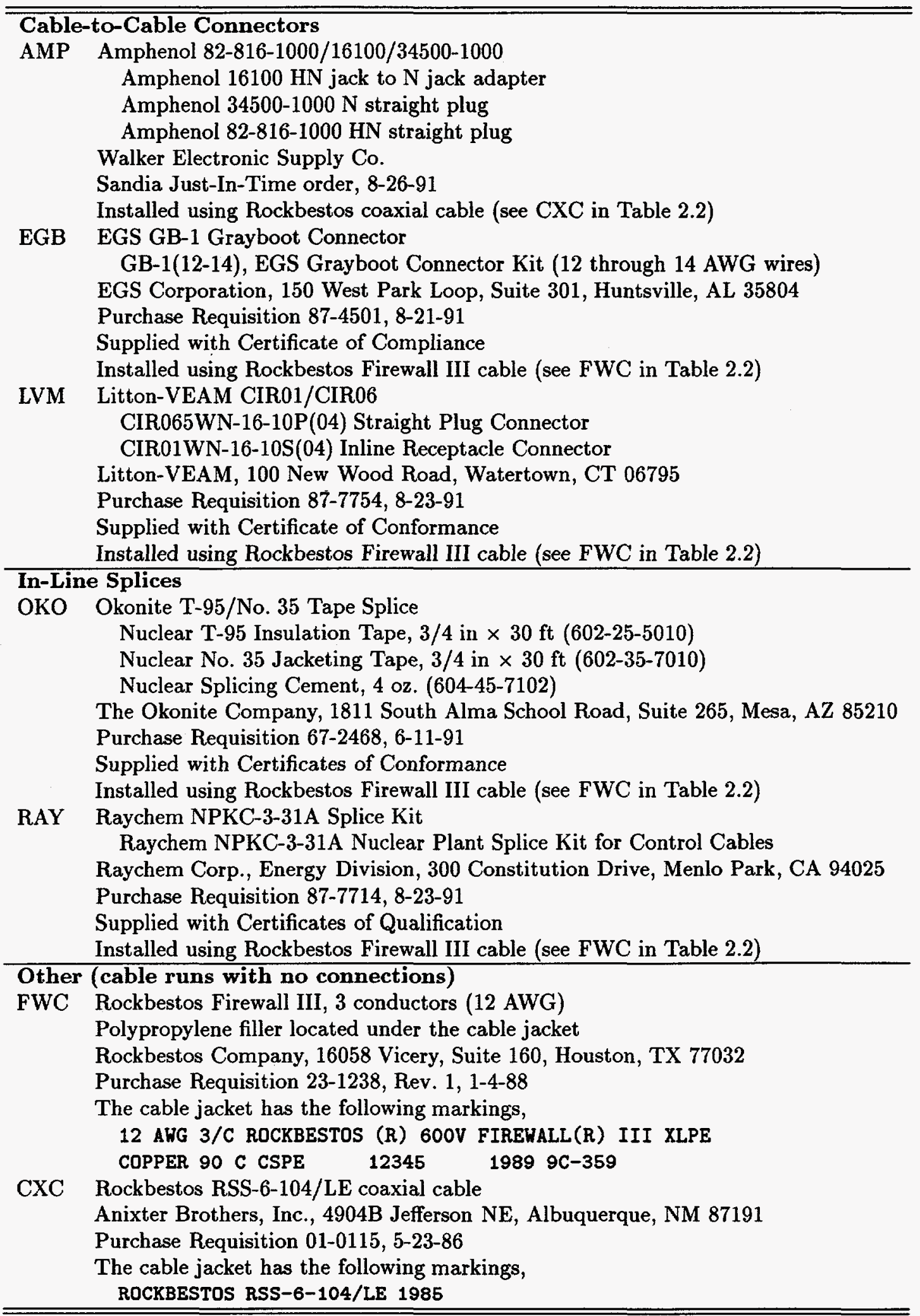



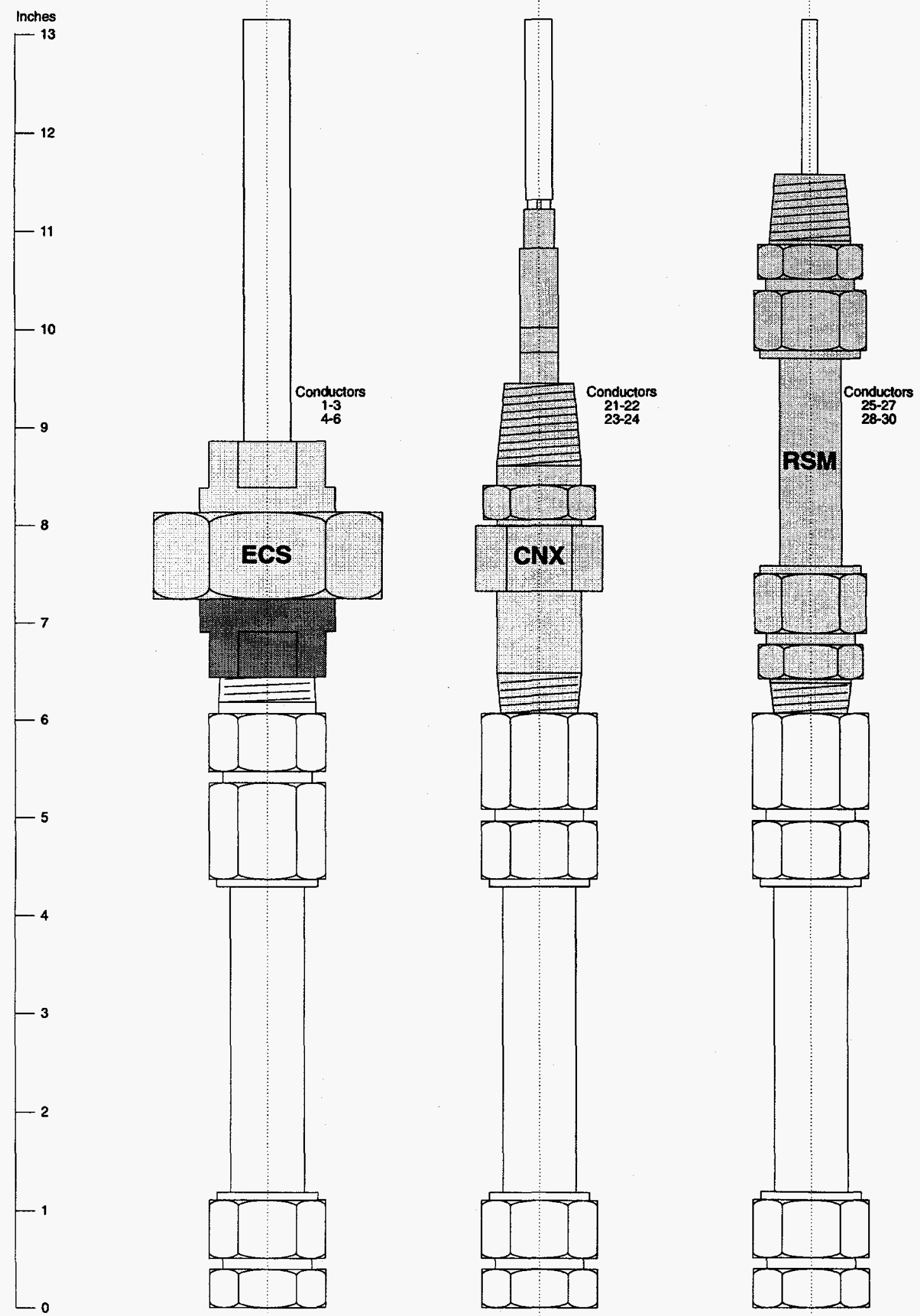

Figure 2.1: Sketches of the conduit seals tested. 

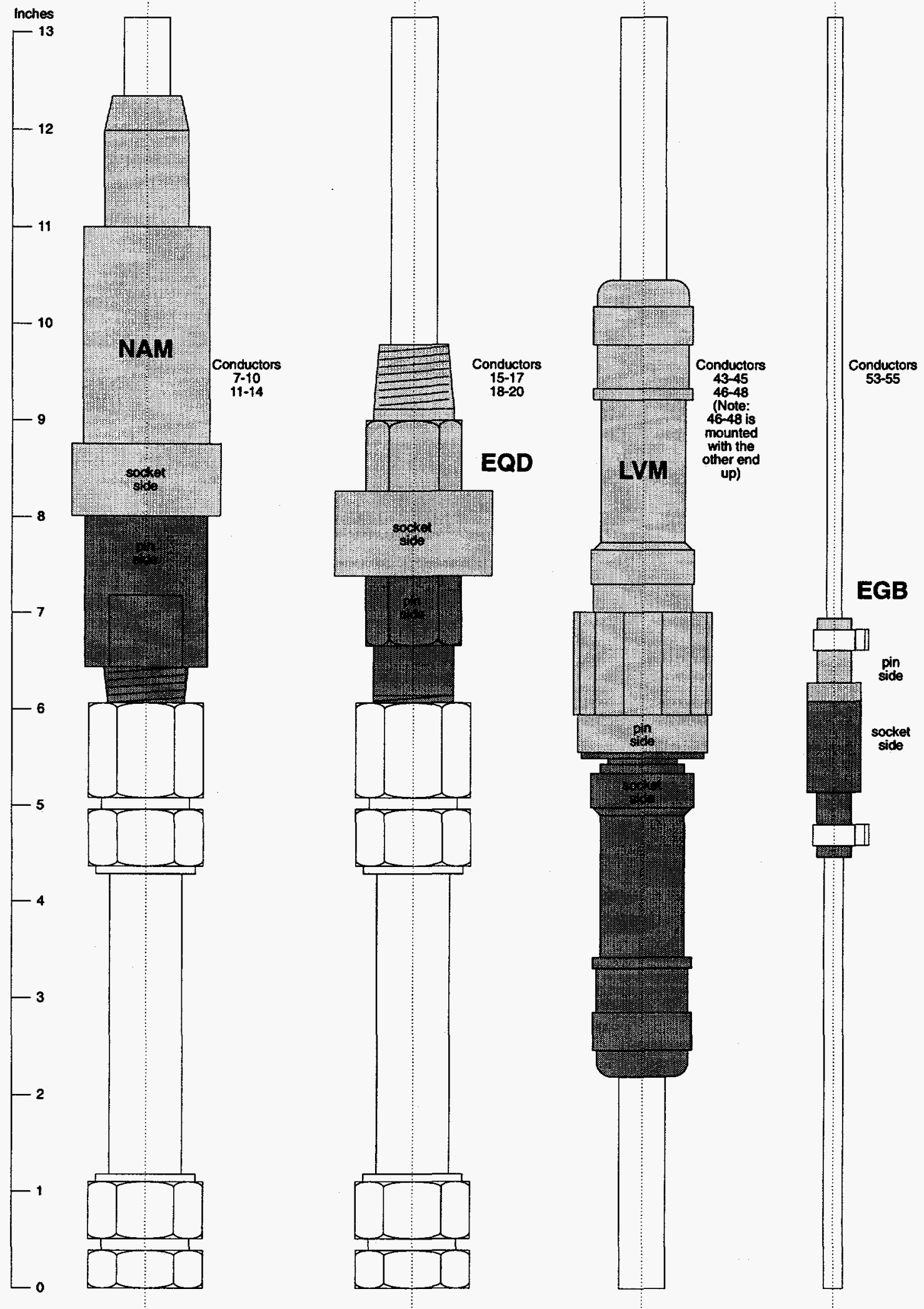

Figure 2.2: Sketches of the cable-to-device and cable-to-cable connectors tested. 

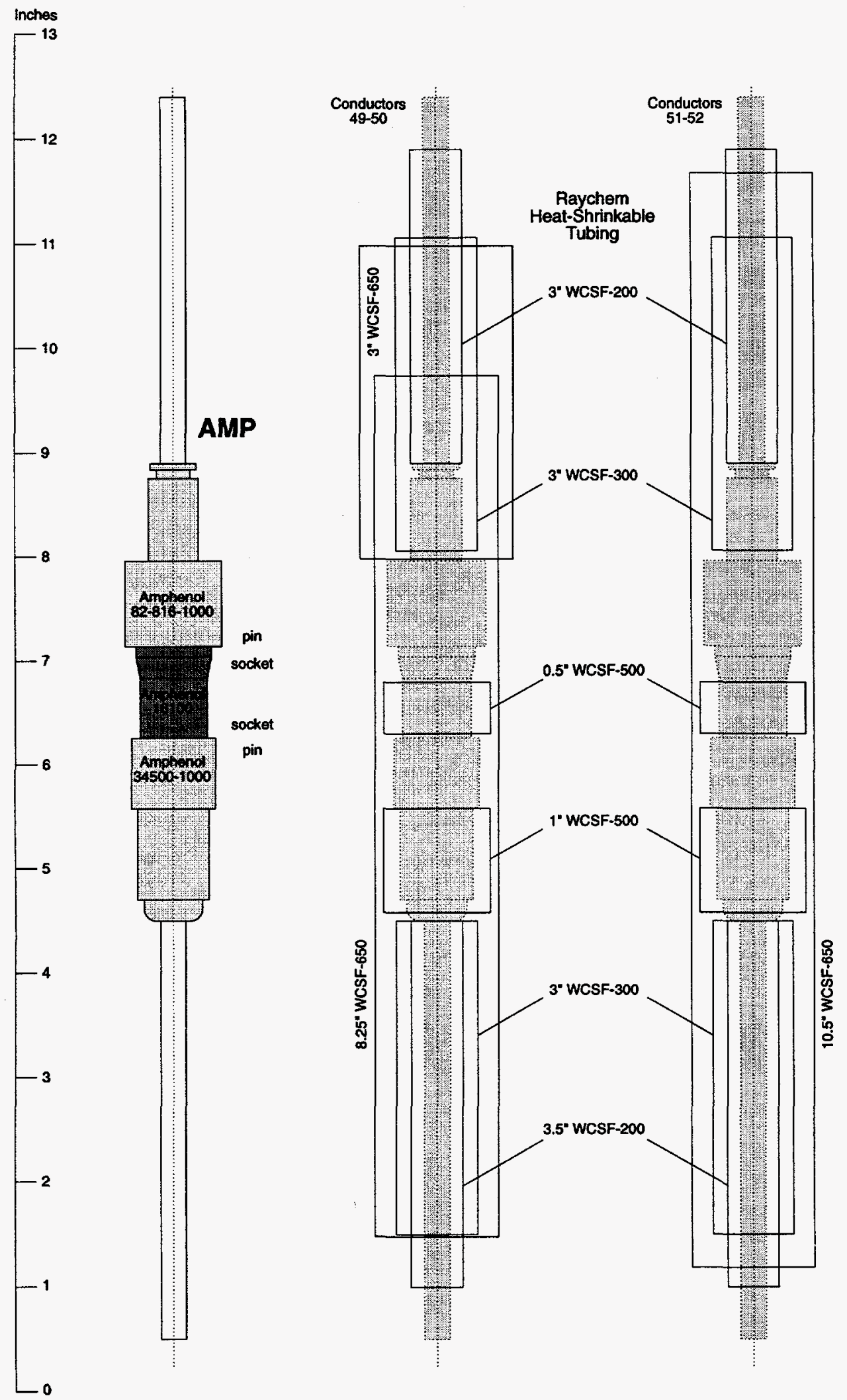

Figure 2.3: Sketch of the Amphenol coaxial connector tested showing the actual connectors and the arrangement of Raychem heat-shrinkable tubing applied for environmental protection. 
Table 2.3: Conductor Numbers for the Connections.

\begin{tabular}{|c|c|c|c|c|}
\hline $\begin{array}{l}\text { EGS Conduit Seal } \\
\text { cable } 7^{a} \\
\text { cable } 8 \\
\end{array}$ & $\begin{array}{c}\text { red conductor } \\
01 \\
04 \\
\end{array}$ & $\begin{array}{c}\text { white conductor } \\
02 \\
05 \\
\end{array}$ & $\begin{array}{c}\text { black conductor } \\
\begin{array}{|c|}03 \\
06 \\
\end{array}\end{array}$ & \\
\hline Namco EC210 & red conductor & white conductor & black conductor & green conductor \\
\hline cable 9 & 07 & 08 & 09 & 10 \\
\hline cable 10 & 11 & 12 & 13 & 14 \\
\hline EGS Quick Disconnect & red conductor & white conductor & black conductor & \\
\hline cable 11 & 15 & 16 & 17 & \\
\hline cable 12 & 18 & 19 & 20 & \\
\hline Conax Buffalo ECSA & conductor 1 & conductor 2 & & \\
\hline cable 13 & 21 & 22 & & \\
\hline cable 14 & 23 & 24 & & \\
\hline Rosemount $353 \mathrm{C}$ & striped conductor & unstriped conductor & shield & \\
\hline cable 15 & 25 & 26 & 27 & \\
\hline cable 16 & 28 & 29 & 30 & \\
\hline Raychem splice & red conductor & white conductor & black conductor & \\
\hline cable $17 \mathrm{a} / 17 \mathrm{~b}$ & $31 \mathrm{a} / 31 \mathrm{~b}^{c}$ & $32 \mathrm{a} / 32 \mathrm{~b}$ & $33 a / 33 b$ & \\
\hline cable $18 \mathrm{a} / 18 \mathrm{~b}$ & $34 a / 34 b$ & $35 \mathrm{a} / 35 \mathrm{~b}$ & $36 \mathrm{a} / 36 \mathrm{~b}$ & \\
\hline Okonite tape & red conductor & white conductor & black conductor & \\
\hline cable $19 a / 19 b$ & $37 \mathrm{a} / 37 \mathrm{~b}$ & $38 \mathrm{a} / 38 \mathrm{~b}$ & $39 a / 39 b$ & \\
\hline cable $20 \mathrm{a} / 20 \mathrm{~b}$ & $40 \mathrm{a} / 40 \mathrm{~b}$ & $41 a / 41 b$ & $42 \mathrm{a} / 42 \mathrm{~b}$ & \\
\hline Litton-VEAM & red conductor & white conductor & black conductor & \\
\hline cable $21 a / 21 b$ & $43 \mathrm{a} / 43 \mathrm{~b}$ & $44 \mathrm{a} / 44 \mathrm{~b}$ & $45 \mathrm{a} / 45 \mathrm{~b}$ & \\
\hline cable $22 \mathrm{a} / 22 \mathrm{~b}$ & $46 a / 46 b$ & $47 a / 47 b$ & $48 \mathrm{a} / 48 \mathrm{~b}$ & \\
\hline Amphenol coaxial & conductor & shield & & \\
\hline cable $23 a / 23 b$ & $49 a / 49 b$ & $50 \mathrm{a} / 50 \mathrm{~b}$ & & \\
\hline cable $24 a / 24 b$ & $51 \mathrm{a} / 51 \mathrm{~b}$ & $52 \mathrm{a} / 52 \mathrm{~b}$ & & \\
\hline EGS Grayboots $^{d}$ & red conductor & white conductor & black conductor & \\
\hline cable $25 \mathrm{a} / 25 \mathrm{~b}$ & $53 a / 53 b$ & $54 a / 54 b$ & $55 \mathrm{a} / 55 \mathrm{~b}$ & \\
\hline Firewall cable & red conductor & white conductor & black conductor & \\
\hline cable $26 a / 26 b$ & $56 \mathrm{a} / 56 \mathrm{~b}$ & $57 \mathrm{a} / 57 \mathrm{~b}$ & $58 \mathrm{a} / 58 \mathrm{~b}$ & \\
\hline cable $27 a / 27 b$ & $59 a / 59 b$ & $60 a / 60 b$ & $61 \mathrm{la} / 61 \mathrm{~b}$ & \\
\hline coaxial cable & conductor & shield & & \\
\hline cable $28 \mathrm{a} / 28 \mathrm{~b}$ & $62 \mathrm{a} / 62 \mathrm{~b}$ & $63 a / 63 b$ & & \\
\hline cable $29 a / 29 b$ & $64 a / 64 b$ & $65 a / 65 b$ & & \\
\hline
\end{tabular}

${ }^{a}$ Cables 1-6 were used to install terminal blocks in the test chamber (see Table A.3).

${ }^{b}$ Conductor numbers listed in a box were electrically grounded during aging, accident irradiation, and the accident steam exposure.

"Conductors numbered with a "b" suffix were left as an open circuit; they are the return legs of the "a" suffix conductors for the in-line splices, cable-to-cable connectors, and the cable runs with no connections.

${ }^{d}$ The EGS Grayboot connector is for a single conductor; thus three Grayboot connectors were used for one 3-conductor cable. 
only $1.2-1.5 \mathrm{~m}(4-5 \mathrm{ft})$ of each lead was located inside the test chamber. The remaining length was required for electrical connection to the test chamber when the chamber was located at the bottom of the radiation facility's water pool during the aging and accident irradiation. The Conax Buffalo ECSA conduit seals and Rosemount 353C conduit seals were each supplied with $1.8 \mathrm{~m}(6 \mathrm{ft})$ of cable on their field side, which was spliced to a 7.6-m (25-ft) cable lead outside the test chamber.

All the connections, except for the coaxial connectors mentioned below, are Class $1 \mathrm{E}$ qualified and were supplied with a Certificate of Compliance or Conformance that indicates the standards to which they have been qualified, the relevant qualification documents, and the manufacturing lot and date. The unqualified Amphenol 82-816/16100/34500 coaxial connectors were included in this test for the following reasons:

- The Amphenol 82-816-1000 type HN straight plug coaxial connector (the -1000 suffix indicates that the insert material is polystyrene) is not qualified, but is used in Class $1 E$ qualified radiation monitors such as the RD-23 detector assembly of a General Atomics High Range Radiation Monitor.

- The Amphenol 34500-1000 type N straight plug coaxial connector (the -1000 suffix indicates that the insert material is polyethylene, not polystyrene as for the 82-816-1000) was previously tested and the results described in Westinghouse Report No. PEN-TR-79-53, July 23, 1979. This connector is used in a Class $1 \mathrm{E}$ qualified Victoreen Model 877 Radiation Monitor.

- The Amphenol 16100 adapter (HN jack to N jack) was used solely to mate the two Amphenol coaxial connectors for testing purposes.

All connections were installed according to the manufacturers' instructions as listed in Table 2.4. In addition to their instructions, training was provided by Raychem on heat-shrink sizing and installation, and by EGS Corp. on proper installation of their connections. The conduit seals and cable-to-device connectors, that would normally be installed into a device such as a limit switch or pressure transmitter, had their device side terminated into a small, sealed chamber, called a "device enclosure," that simulates such devices. Each such connection had its own device enclosure, which was fabricated from stainless steel tube and Swagelok tube fittings (Swagelok Co., Solon, $\mathrm{OH}$ ) as shown in Figure 2.4. After using an Alcatel ASM 51 Helium Leak Tester to verify that all the device enclosures were "leak tight" (helium leak rate of less than $10^{-7} \mathrm{cc} / \mathrm{sec}$ ), the conductors that pass through the connection were inserted into the device enclosure. Phenolic inserts were used to separate the ends of the conductors, and the connection and device enclosure were threaded together. There was no attempt to check for connection leakage during the test. Leaking connections could be identified during the test only if the data measurements began to show anomalies, or at the conclusion of the test if the device enclosure had moisture or moisture residue inside when it was opened.

The Amphenol coaxial connectors were affixed to coaxial cable as specified in Ref. [2, pp. 12,16$]$ (the 82-816 uses a type HN typical clamp termination and the 34500 uses a type $\mathrm{N}$ standard clamp termination). To ensure an environmental seal, the Amphenol coaxial connectors were covered with Raychem WCSF-N heat-shrinkable tubing (with the necessary shims); sizing and installation were according to Raychem instructions [35, 38, 39].

\section{$2.2 \quad$ Test Facilities}

All environmental exposures were performed using the Low Intensity Cobalt Array (LICA) facility and the Steam Exposure Facility, both located in the north end of Building 867 in Technical Area I at Sandia National Laboratories in Albuquerque, NM.

The LICA facility consists of radioactive sources and various fixtures located at the bottom of a water pool and was used to perform both accident irradiation and simultaneous radiation and thermal aging of test specimens. Cobalt- 60 sources were used to provide the radiation exposure. Previous testing reported in NUREG/CR-5231 [3] has shown that accident radiation exposures are conservatively simulated by isotropic gamma ray sources such as cobalt- 60 .

The Steam Exposure Facility was used to perform the steam exposure for LOCA simulations. This 


\section{EXPERIMENTAL APPARATUS AND TECHNIQUE}

Table 2.4: Installation Instructions and Activation Energies for the Test Specimens.

\begin{tabular}{|c|c|c|c|}
\hline Connection & Installation Instructions & Activation Energy $^{a}$ & Reference \\
\hline & Conduit Seals & & \\
\hline Conax Buffalo ECSA & [4] & $3.916 \mathrm{eV}$ & {$[5, \mathrm{p} .7]$} \\
\hline Patel/EGS Conduit Seal & [9] & $2.29 \mathrm{eV}$ & {$[32$, A.1, p.10] } \\
\hline \multirow[t]{2}{*}{ Rosemount 353C Conduit Seal } & [43] & $1.29 \mathrm{eV}$ & {$[42$, p.A-3] } \\
\hline & \multicolumn{3}{|c|}{ Cable-to-Device Connectors } \\
\hline Namco EC210 1/2-in Series & {$[26,27]$} & $0.8 \mathrm{eV}$ & [51] \\
\hline Patel/EGS 1/2-in Quick Disconnect & {$[10]$} & $1.05 \mathrm{eV}$ & {$[33$, A.1, p.11] } \\
\hline \multicolumn{4}{|c|}{ Cable-to-Cable Connectors } \\
\hline Amphenol 82-816-1000/16100/34500-1000 & {$[2, \mathrm{pp} .12,16][44]$} & not Class 1E & - \\
\hline EGS GB-1 Grayboot Connector & [12] & $0.92 \mathrm{eV}$ & {$[11, \mathbf{A} .1$, p.9] } \\
\hline Litton-VEAM CIR01/CIR06 & {$[25]$} & $1.15 \mathrm{eV}$ & {$[52]$} \\
\hline \multicolumn{4}{|c|}{ In-Line Splices } \\
\hline Okonite T-95/No. 35 Tape Splice & {$[29$, pp. $2-3,10][30]$} & $0.65 \mathrm{eV}$ & {$[31]$} \\
\hline Raychem NPKC-3-31A Splice Kit & {$[36]$} & $1.34 \mathrm{eV}$ & {$[37, \text { p. } 6]^{b}$} \\
\hline \multicolumn{4}{|c|}{ Other (cable runs with no connections) } \\
\hline Rockbestos Firewall III cable & - & $1.3412 \mathrm{eV}$ (insul.) & {$[40, \mathrm{p} .49]$} \\
\hline Rockbestos RSS-6-104/LE coaxial cable & - & $2.7479 \mathrm{eV}$ (insul.) & {$[41, \mathrm{p} .44]$} \\
\hline
\end{tabular}

${ }^{a}$ For connections that consist of several materials, each with its own activation energy, the lowest activation energy is used. This ensures that all materials in the connection are aged at least the desired amount.

${ }^{b}$ Reference gives activation energy of $31 \mathrm{kcal} / \mathrm{mol}$, which was converted to $\mathrm{eV} /$ molecule using the conversion factors: $1 \mathrm{cal}=$ $4.184 \mathrm{~J}, 1 \mathrm{eV}=1.602 \times 10^{-19} \mathrm{~J}$, and 1 mole $=6.022 \times 10^{23}$ molecules (also see $[13, \mathrm{p} .8-30]$ ).

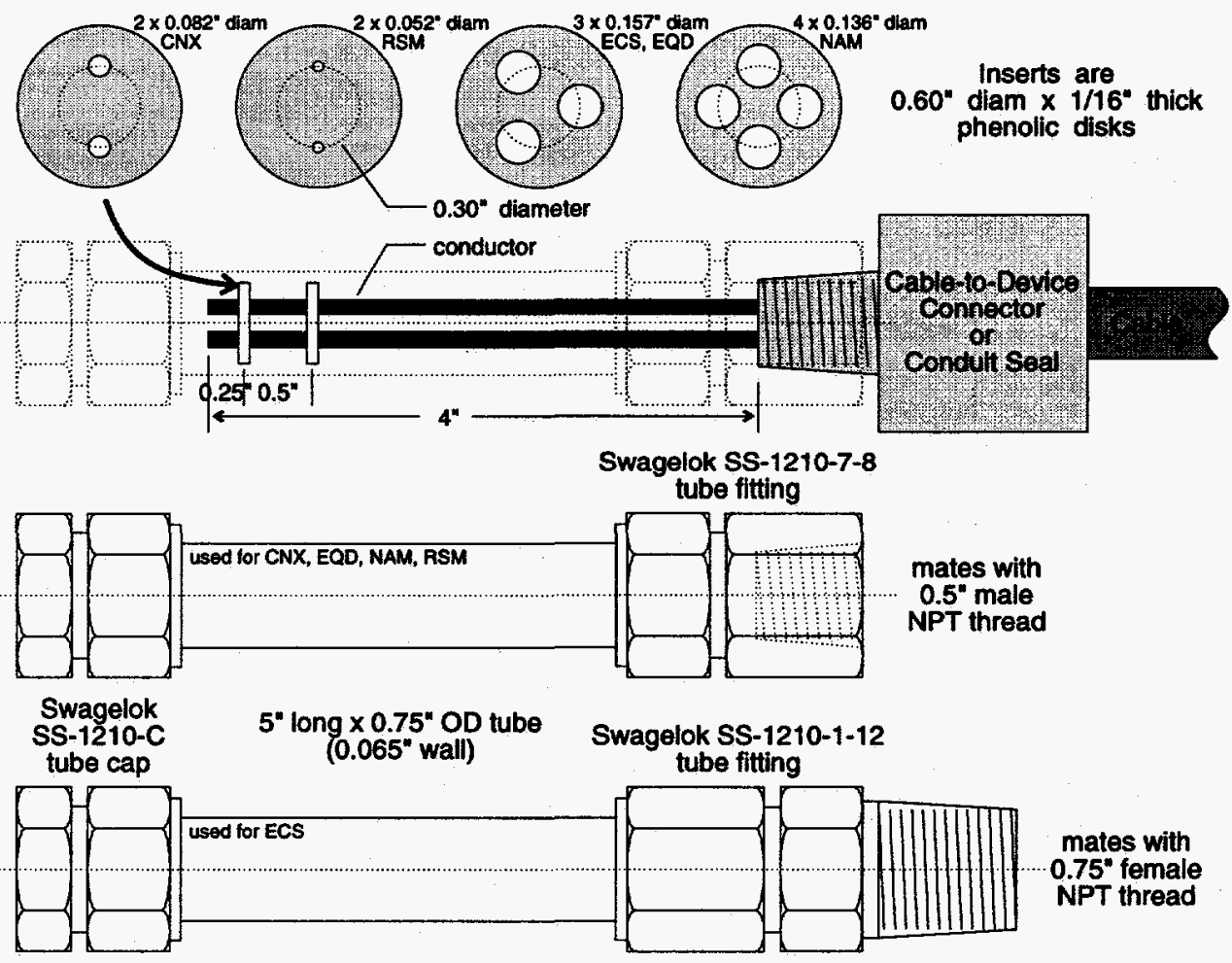

Figure 2.4: Sketch of the device enclosures used for installation of conduit seals and cable-to-device connectors. 


\section{EXPERIMENTAL APPARATUS AND TECHNIQUE}

system incorporates superheaters and a large accumulator to produce the initial temperature and pressure transients required during simulation of an accident steam exposure.

Detailed drawings of the test chamber and fixtures used for this test program are shown in Figure 2.5. One stainless steel test chamber with an inside diameter of $521 \mathrm{~mm}$ (20.5 in) was used for all parts of the test program. The test chamber head [approximately $508 \mathrm{~mm}$ (20 in) in height] contained all the penetration flanges through which the cables attached to the connections, the thermocouples, heater power lines, air, and steam enter and exit the chamber. During aging and accident irradiation, a $1651-\mathrm{mm}$ (65-in) tall chamber bottom section was used [internal height of approximately $1607 \mathrm{~mm}$ (63 in)], giving a test chamber internal volume of approximately $0.45 \mathrm{~m}^{3}$. In order to minimize the amount of steam required, a shorter test chamber bottom with a height of 38 in $(965 \mathrm{~mm})$ was used during the accident steam exposure. A ground wire was attached to the test chamber so that the chamber served as a ground for electrical measurements.

The connections were mounted on a mandrel suspended from the test chamber head; there was no attachment by either the mandrel or the test specimens to the test chamber bottom. This allowed the test chamber bottom to be removed to gain access to the test specimens without disturbing them. The specimens remained attached to the mandrel for all phases of the environmental exposure; the test chamber also served as a pressure vessel when connected to the steam system. This minimized the possibility of damage to the specimens when the test chamber was moved from the LICA facility to the steam system because the specimens did not have to be removed from one test chamber and then reinstalled in another.

As shown in Figure 2.5, the mandrel ${ }^{4}$ consisted of a pair of stainless steel rings attached to one another with eight stainless steel rods. Four stainless steel hose clamps were wrapped around the rods to provide mounting points for the connections and their associated cable leads, which were mounted vertically in the test chamber. To hold each connection in place, stainless steel

\footnotetext{
${ }^{4}$ This is the same type of mandrel around which cables would be wrapped for a cable test.
}

ribbons were loosely wrapped around each cable and tack welded to the hose clamps. The cable attached to the connection entered the test chamber through a potted penetration in the test chamber head and then was attached to the top hose clamp. The cable was positioned so that the connection was located at the middle of the cobalt- 60 sources' active region. For connections that were attached to a device, the device enclosure was held in place by stainless steel ribbon tack welded to hose clamps located below the connection. For connections that joined two lengths of cable, the return leg of the cable continued vertically down the mandrel and then looped back up through the center of the mandrel before finally exiting the test chamber through another potted penetration in the test chamber head. Figure 2.6 shows a top view of the arrangement of the test specimens in the test chamber.

As shown in Figure 2.5, the test chamber head has 9 flanged ports through which test specimens and experimental apparatus (air and steam lines, heater power, thermocouples, and a pressure tap) can enter or exit the test chamber. Each of these 9 ports has a flange cover in which various openings have been machined; the potted penetrations attach to female NPT-threaded openings. Each potted penetration consists of a stainless steel tube with a Swagelok male connector on one end and a Swagelok cap on the other; a hole is drilled in the cap to allow a cable lead to pass through. After the penetration is positioned correctly on the cable, it is filled by injecting Scotchcast Electrical Resin 9 (5240) into the tube and over the cable. Note that the electrical resin is applied over the top of the cable jacket; there is no attempt to seal the individual conductors. After the electrical resin has cured, the penetration is attached to the flange cover with the Swagelok male connector.

The two Hoffman A-806CHNF enclosures shown in Figure 2.6 each contain one Marathon and one States terminal block, which were tested at the same time as the connections. The terminal blocks were added to address issues related to a previous study of terminal blocks by Craft [6, 7]. Because these issues differed from the test program objectives, all information pertaining to the terminal blocks is contained in Appendix A. Appendix B contains a more complete description of the test facilities used for this test program. 


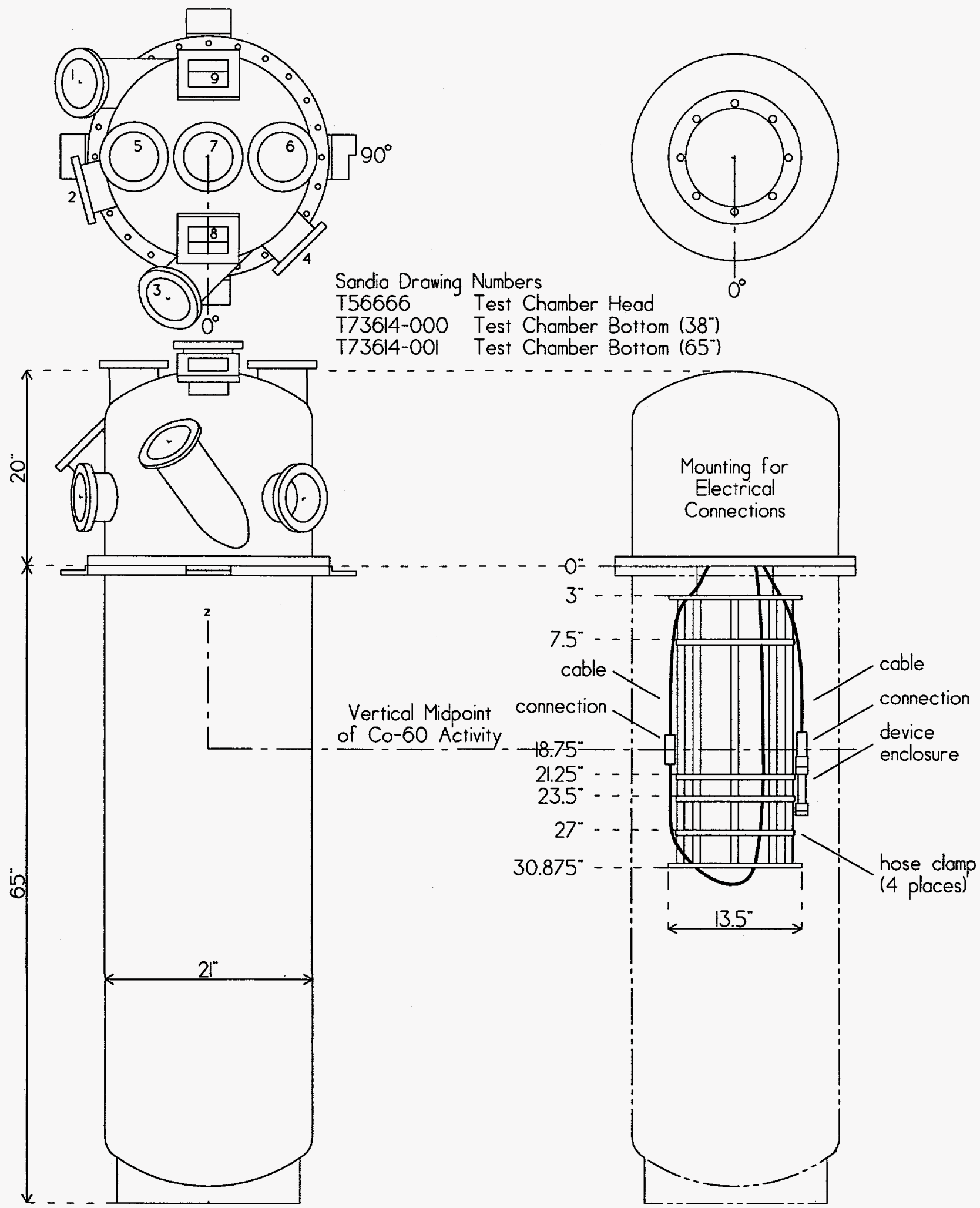

Figure 2.5: Detail of the test chamber and a sketch of the mandrel on which the electrical connections were mounted. 


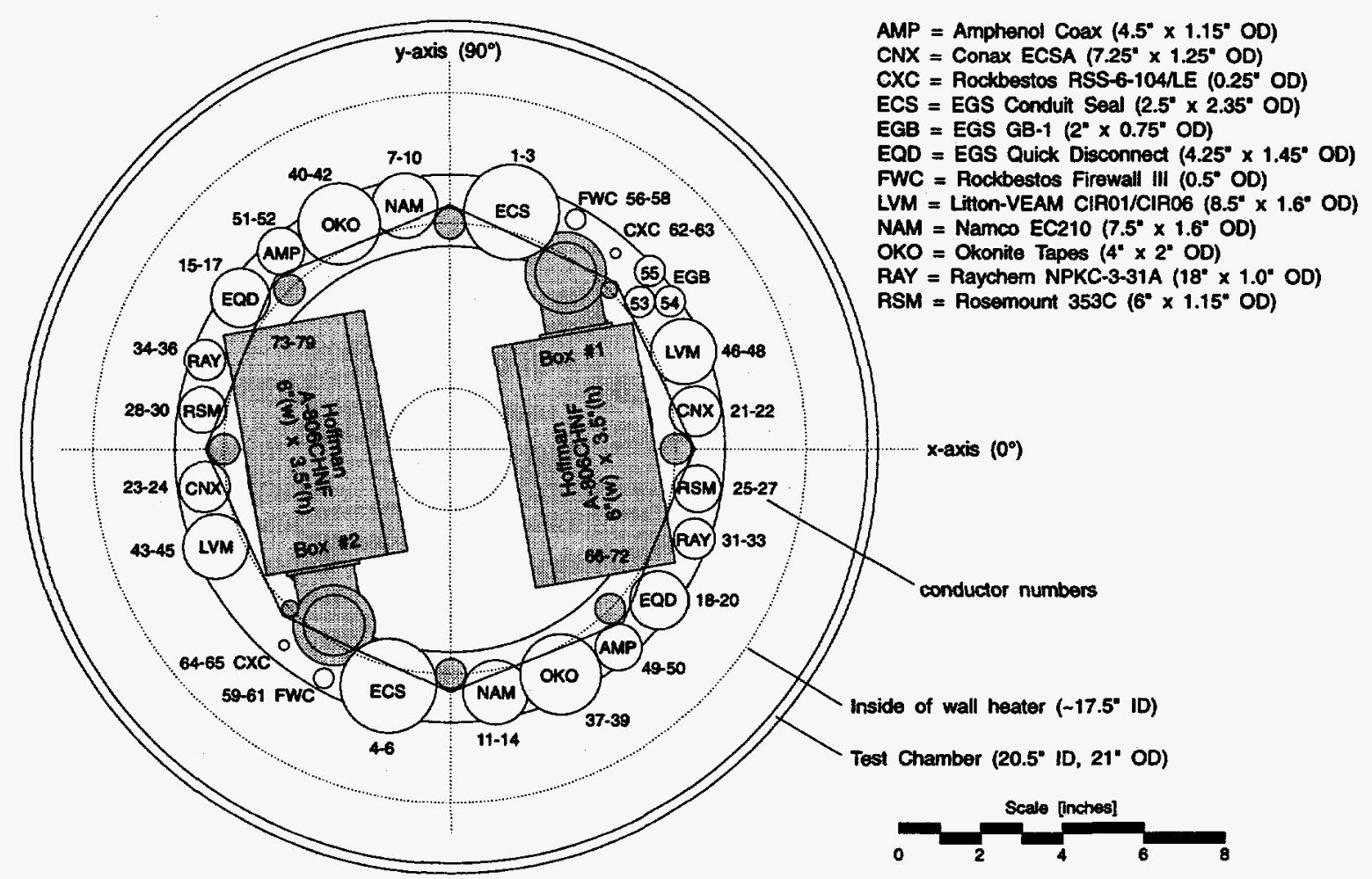

Figure 2.6: Top view of the test chamber and mandrel showing how the test specimens were arranged.

\subsection{Test Conditions}

The environmental exposure consisted of two phases:

1. Simultaneous thermal/radiation aging to simulate an end-of-life condition based on nuclear power plant operating environments.

2. A LOCA simulation consisting of an accident radiation dose sequentially followed by an accident steam exposure.

\subsubsection{Simultaneous Radiation and Thermal Aging}

The aging nominally simulated 60 years in a nuclear power plant at an ambient temperature of $55^{\circ} \mathrm{C}\left(131^{\circ} \mathrm{F}\right)$ and a total integrated aging radiation dose of $200 \mathrm{kGy}$ ( $20 \mathrm{Mrad}$ ). To accomplish this, an accelerated simultaneous aging exposure was performed for 6 months

(182.625 days) at $98.8^{\circ} \mathrm{C}\left(209.8^{\circ} \mathrm{F}\right)$ and a dose rate of $45.6 \mathrm{~Gy} / \mathrm{hr}(4.56 \mathrm{krad} / \mathrm{hr})$.
The test temperature required for the thermal aging was calculated using the Arrhenius relation [13, Eq. (4-16) and Sections 4.1, 4.4 and 8.3.2],

$$
\frac{t_{2}}{t_{1}}=\exp \left[\frac{E_{a}}{k_{b}}\left(\frac{1}{T_{2}}-\frac{1}{T_{1}}\right)\right],
$$

which can be rewritten as

$$
T_{2}=\frac{T_{1}}{1+\frac{T_{1} k_{b}}{E_{\mathrm{a}}} \ln \left(\frac{t_{2}}{t_{1}}\right)},
$$

where

$t_{1}, t_{2}=$ aging times.

$T_{1}, T_{2}=$ aging temperatures (absolute temperature).

$E_{a}=$ activation energy of the material.

$k_{b}=$ Boltzmann's constant

$\left(=1.3807 \times 10^{-23} \mathrm{~J} / \mathrm{K}\right.$

$=8.6174 \times 10^{-5} \mathrm{eV} / \mathrm{K}[24$, Appendix A]).

As shown in Figure 2.7, the aging temperature required to simulate 60 years at $55^{\circ} \mathrm{C}$ is a function of the activation energy. Using the data in Table 2.4, an activation energy of $E_{a}=1.15 \mathrm{eV}$ was chosen to give conservative data for most of 


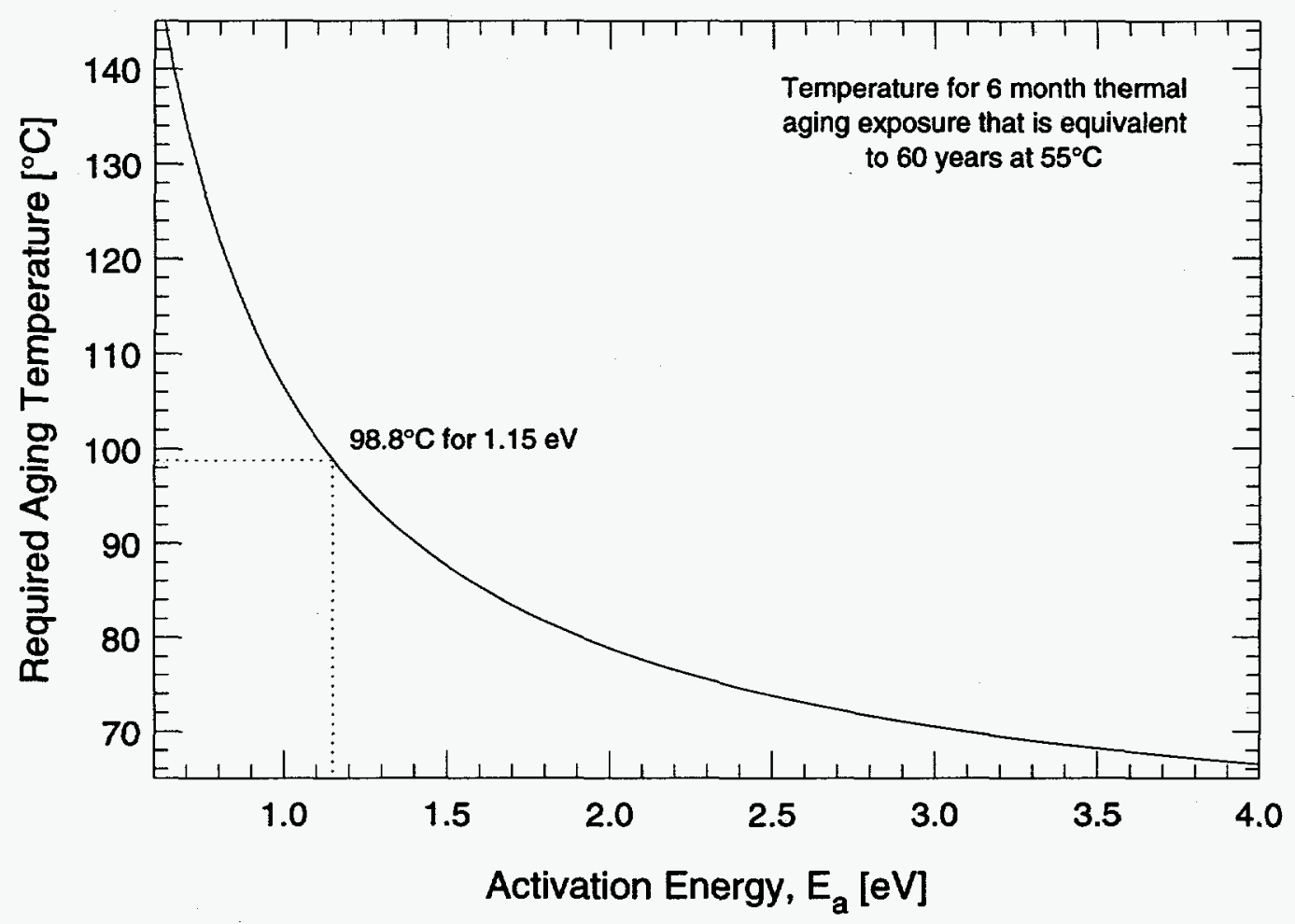

Figure 2.7: Required aging temperature as a function of activation energy, $E_{a}$.

Table 2.5: Equivalent Thermal Aging to 6 Months at $98.8^{\circ} \mathrm{C}$ for the Test Specimens.

\begin{tabular}{|c|c|c|c|}
\hline \multirow[b]{2}{*}{ Connection } & \multirow{2}{*}{$\begin{array}{l}\text { Activation Energy } \\
\text { (from Table 2.4) }\end{array}$} & \multicolumn{2}{|c|}{ Temperature $\left[{ }^{\circ} \mathrm{C}\right]$} \\
\hline & & 40 years & 60 years \\
\hline \multicolumn{4}{|c|}{ Conduit Seals } \\
\hline Conax Buffalo ECSA & $3.916 \mathrm{eV}$ & 85.9 & 84.8 \\
\hline Patel/EGS Conduit Seal & $2.29 \mathrm{eV}$ & 77.3 & 75.4 \\
\hline Rosemount 353C Conduit Seal & $1.29 \mathrm{eV}$ & 62.3 & 59.3 \\
\hline \multicolumn{4}{|c|}{ Cable-to-Device Connectors } \\
\hline Namco EC210 1/2-in Series & $0.8 \mathrm{eV}$ & 43.2 & 38.9 \\
\hline Patel/EGS 1/2-in Quick Disconnect & $1.05 \mathrm{eV}$ & 54.9 & 51.4 \\
\hline \multicolumn{4}{|c|}{ Cable-to-Cable Connectors } \\
\hline Amphenol 82-816-1000/16100/34500-1000 & not Class $1 \mathrm{E}$ & - & - \\
\hline EGS GB-1 Grayboot Connector & $0.92 \mathrm{eV}$ & 49.5 & 45.6 \\
\hline Litton-VEAM CIR01/CIR06 & $1.15 \mathrm{eV}$ & 58.3 & 55.0 \\
\hline \multicolumn{4}{|c|}{ In-Line Splices } \\
\hline Okonite T-95/No. 35 Tape Splice & $0.65 \mathrm{eV}$ & 32.7 & 27.8 \\
\hline Raychem NPKC-3-31A Splice Kit & $1.34 \mathrm{eV}$ & 63.5 & 60.6 \\
\hline \multicolumn{4}{|c|}{ Other (cable runs with no connections) } \\
\hline Rockbestos Firewall III cable & $1.3412 \mathrm{eV}$ & 63.5 & 60.6 \\
\hline Rockbestos RSS-6-104/LE cable & $2.7479 \mathrm{eV}$ & 80.7 & 79.1 \\
\hline
\end{tabular}




\section{EXPERIMENTAL APPARATUS AND TECHNIQUE}

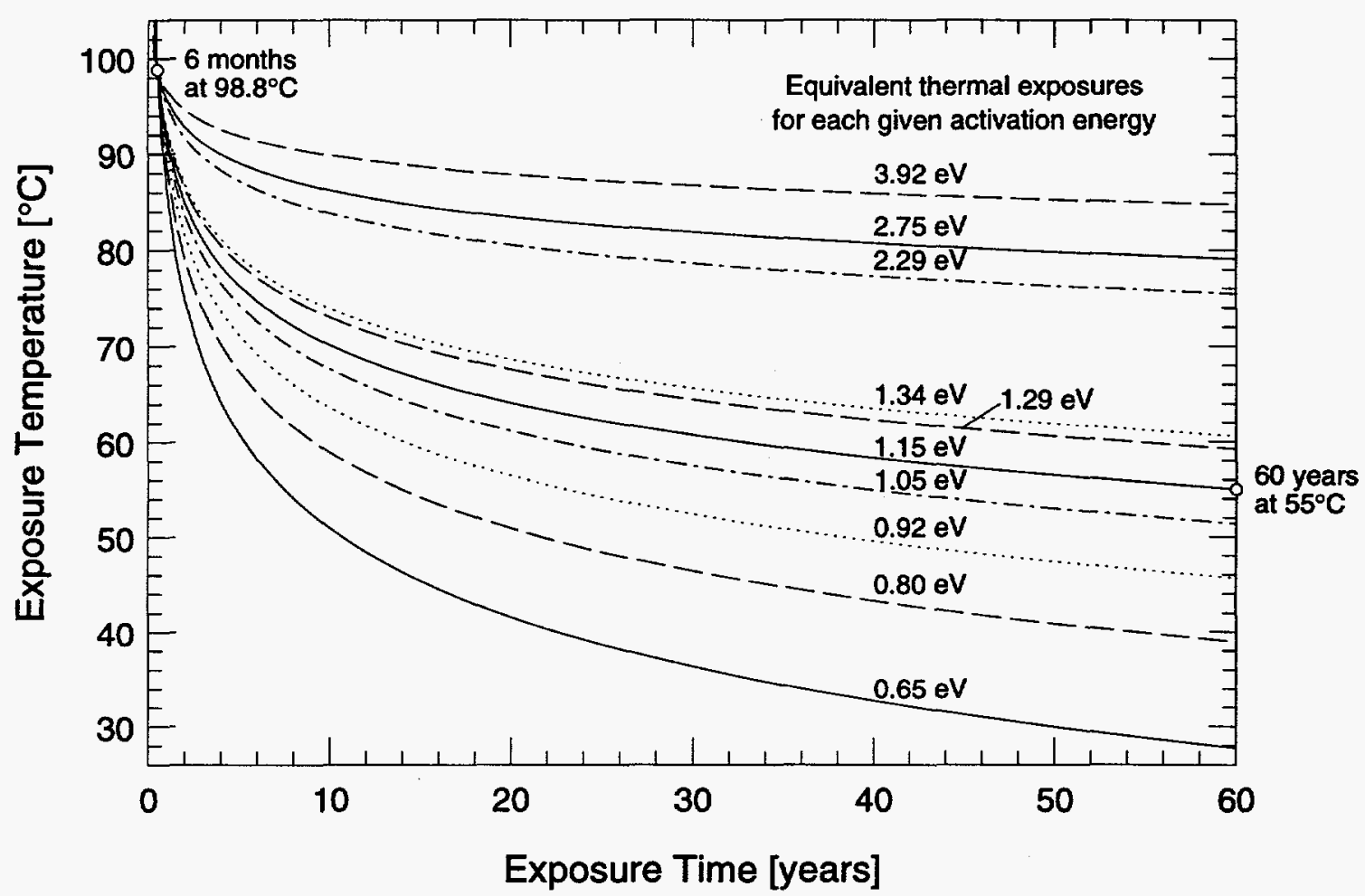

Figure 2.8: Curves of equivalent thermal exposures for the activation energies listed in Table 2.5.

the connections. For the $1.15-\mathrm{eV}$ activation energy, the Arrhenius relation gives a required aging temperature of $98.8^{\circ} \mathrm{C}\left(209.8^{\circ} \mathrm{F}\right)$. Due to differences in activation energy, the thermal aging (for any time period other than 6 months) that is equivalent to a 6 -month exposure at $98.8^{\circ} \mathrm{C}$ is different for each connection. Table 2.5 gives the equivalent aging temperatures for 40 - and 60 -year aging exposures. This is also presented by Figure 2.8, which shows curves of equivalent thermal-only exposures for the activation energies listed in Table 2.5. All these curves pass through a 6 -month exposure at $98.8^{\circ} \mathrm{C}$, and thus indicate the range of equivalent thermal exposures to which the different connections were exposed; the 40- and 60 -year values from each curve correspond to the values in Table 2.5.

Radiation dosimetry was performed to quantify the aging radiation field to which the test samples were exposed; see Appendix B for details. Because the radioactive cobalt sources were not symmetrically located around the test chamber during aging, the test chamber was rotated one-quarter turn three times during aging to ensure a uniform radiation dose for all the connections tested.

Four of the 5 types of cable-to-device and cable-to-cable connectors (NAMCO EC210 connector, EGS quick-disconnect connector, EGS Grayboot connector, and Litton-VEAM connector $)^{5}$ were subjected to periodic disconnect/connect cycling during the aging to simulate usage. One of the 2 samples of each connector remained connected for the entire duration of the test and the other underwent the periodic disconnect/connect cycling. The cycling (10 disconnect/reconnect cycles) occurred before the start of the aging and after aging exposures of 66.7 and $133.3 \mathrm{kGy}$ ( 2 and 4 months of aging). It was necessary to remove the test chamber from the radiation environment to perform the cycling.

Test chamber temperature was maintained using electric wall and inlet air heaters. The wall heater was mounted inside the test chamber bottom and was a sheet stainless steel cylinder with a wrapping of Cerra blanket insulation on the

\footnotetext{
${ }^{5}$ The Amphenol coaxial connector was not subjected to disconnect/connect cycling because it was covered with Raychem heat-shrinkable tubing which no longer allowed the connector to be taken apart.
} 


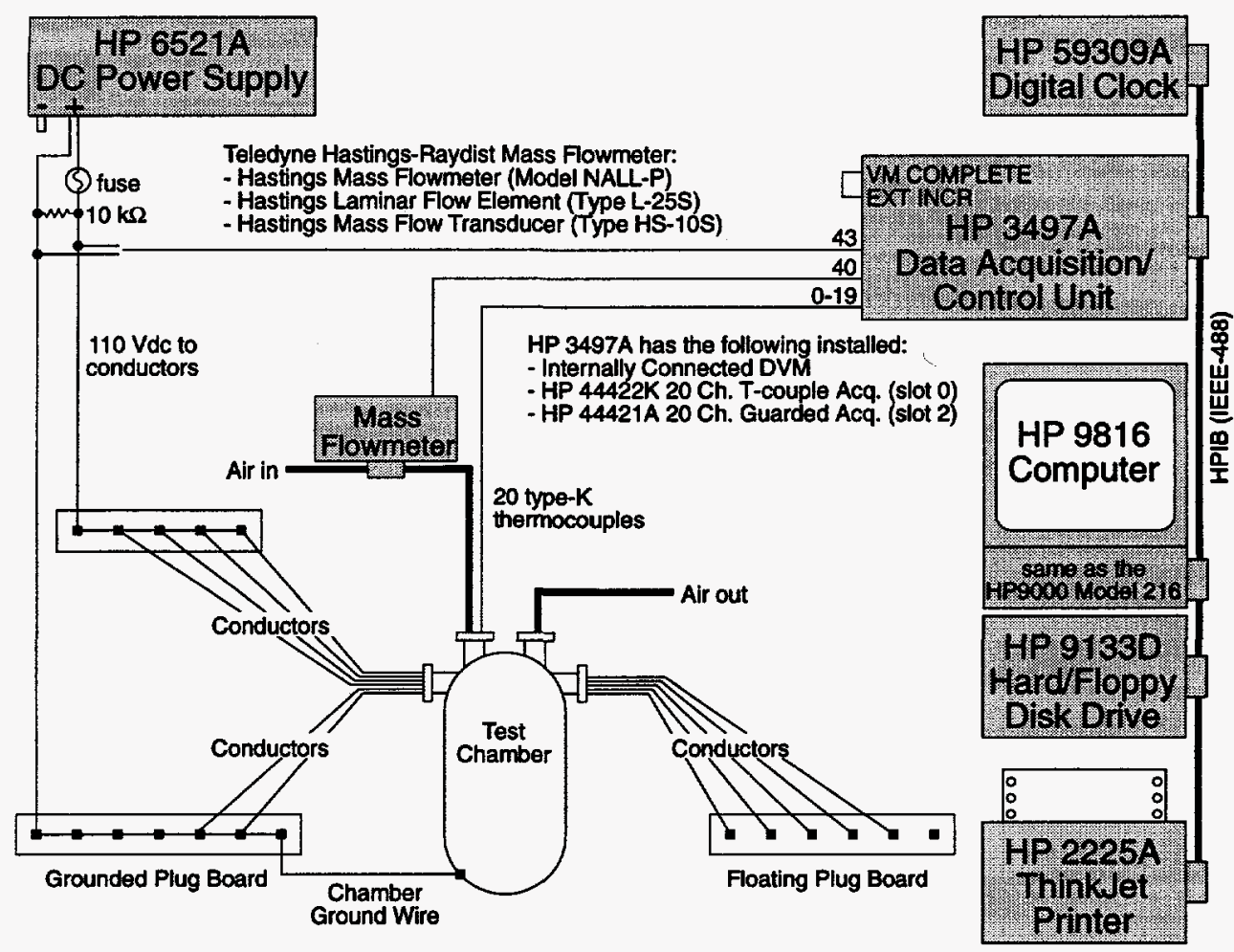

Figure 2.9: Schematic of the system used to monitor test chamber conditions during aging and accident irradiation.

outside, then a layer of uninsulated Nichrome wire, and a final layer of Cerra insulation on the outside. The chamber temperature was set using temperature controllers and type $\mathrm{K}$ thermocouples (Style AC mineral insulated thermocouples with Inconel sheathing, Gordon Co., Richmond, IL) as sensors. Temperature uniformity was improved by insulating the test chamber and providing air circulation. A flow of 5.7 liters $/ \mathrm{sec}\left(12 \mathrm{ft}^{3} / \mathrm{min}\right)$ or greater of outside air (approximately 45 air changes per hour) was supplied to the test chamber to maintain circulation and ambient oxygen concentration. Twenty thermocouples were used to monitor the temperature inside the test chamber. Aging conditions (temperature, airflow, and cable excitation) were monitored using the system shown schematically in Figure 2.9; the resulting data are shown in Figure 2.10. During the aging, all the conductors in each connection except for one ground conductor were energized with $110 \mathrm{Vdc}$ (and no current) as indicated in Table 2.3.

\subsubsection{LOCA Simulation}

A LOCA simulation consisting of an accident radiation exposure followed by an accident steam exposure was performed after completion of the aging.

\section{Accident Radiation Exposure}

The accident irradiation was performed for $338 \mathrm{hr}$ at a dose rate of $3 \mathrm{kGy} / \mathrm{hr}(300 \mathrm{krad} / \mathrm{hr})$ for an accident radiation dose of $1000 \mathrm{kGy}(100 \mathrm{Mrad})$. Radiation dosimetry was performed to quantify the accident radiation field to which the test samples were exposed; see Appendix B for details. Because of the near symmetry of the radioactive cobalt sources around the test chamber, the chamber was not rotated during the accident irradiation.

During the accident radiation exposure, the temperature was not controlled and thus was near the ambient temperature of the LICA pool water. Air circulation into the test chamber continued as 


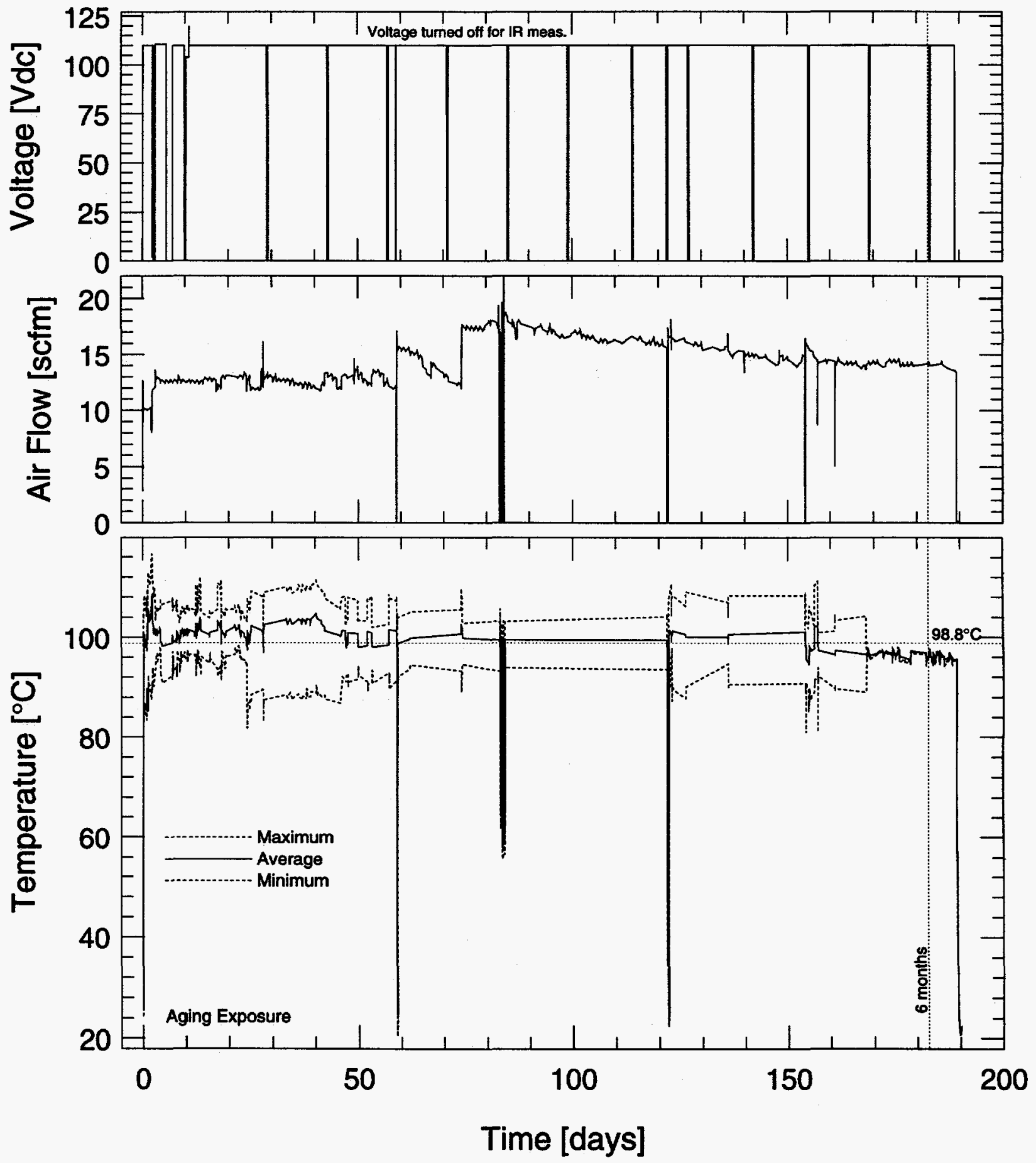

Figure 2.10: Temperature, airflow, and cable excitation during the simultaneous radiation and thermal aging exposure. 


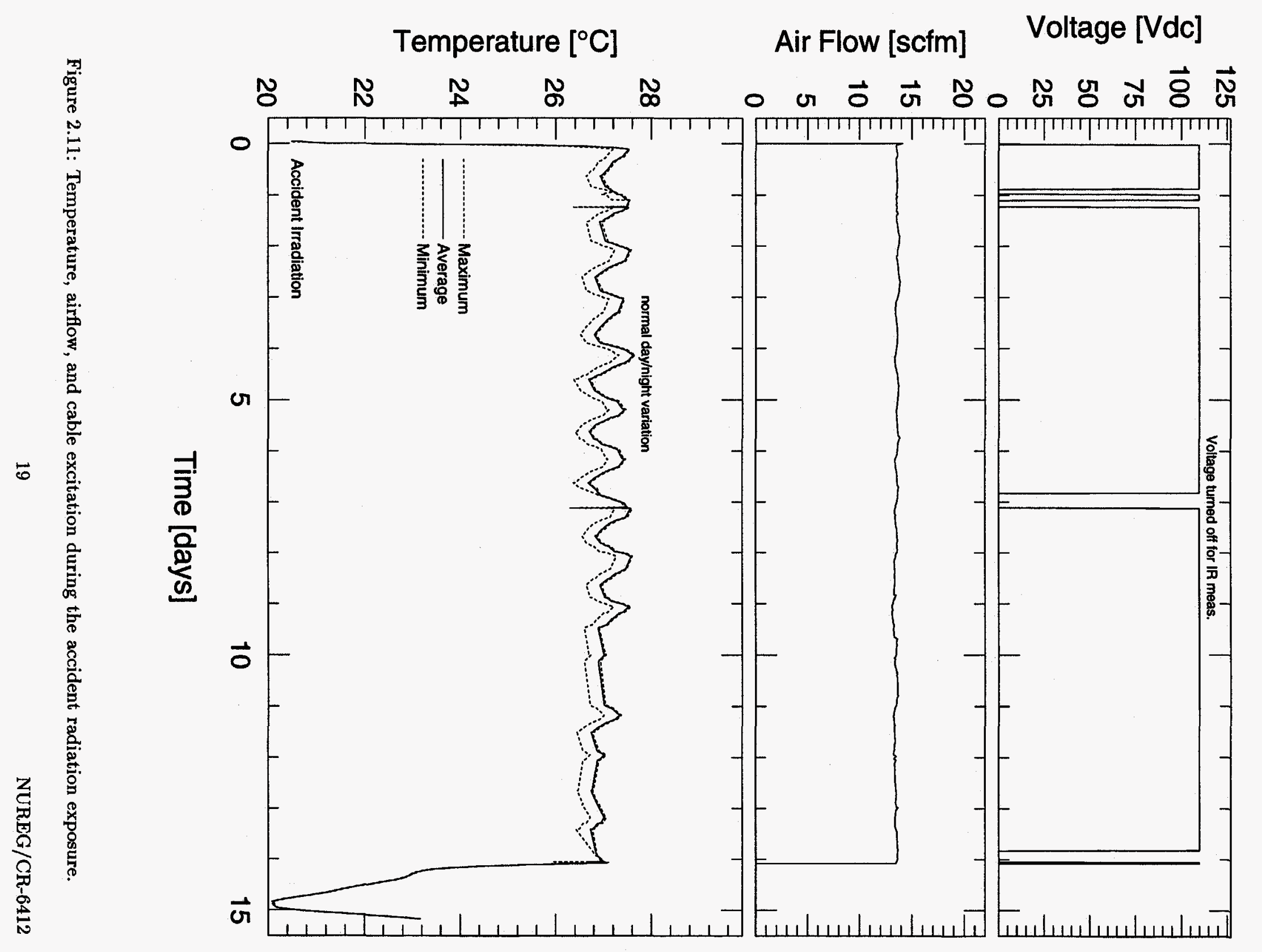

年 


\section{EXPERIMENTAL APPARATUS AND TECHNIQUE}

during the aging exposure. The conductors were energized at the same $110 \mathrm{Vdc}$ and no current as during the aging. Accident irradiation conditions (temperature, airflow, and cable excitation) were monitored using the system shown schematically in Figure 2.9; the resulting data are shown in Figure 2.11.

\section{Accident Steam Exposure}

The accident steam exposure consisted of simulated LOCA transient temperature and pressure conditions. The desired accident steam temperature and pressure profiles are given in Table 2.6 (this is the same profile used in the NUREG/CR-5772 series of reports [21, 22, 23]). The only significant difference between the desired profile and the "generic" profile given in Appendix A of IEEE Std. $323-1974^{6}$ [16, Fig. A1] is that the final portion of the desired steam test profile is at a higher temperature and for a shorter duration than the appendix to IEEE Std. 323-1974 suggests. Note that the test profile has superheated steam conditions (i.e., $P<P_{\text {sat }}$ for the given $T$, or equivalently $T>T_{\text {sat }}$ for the given $P$ ) during the initial ramp and until $6 \mathrm{hr}$ after the start of the second transient. After this, the profile continues as saturated steam. Note that the IEEE profile has a pure steam environment (i.e., the test chamber is filled only with steam, there is no air in the chamber); previous research $[14,15]$ has shown that the presence or absence of oxygen is an important parameter for LOCA simulations. The test chamber temperature and pressure were controlled manually. No chemical spray was used during the steam exposure.

The actual and target pressure and temperature during the accident steam exposure are shown in Figure 2.12. The pressure shown in Figure 2.12 was measured using a single Heise $710 \mathrm{~B}$ pressure transducer with a range of $0-1380 \mathrm{kPa}$ gauge (0-200 psig). The temperature shown in Figure 2.12 is the average value calculated from the 20 thermocouples in the test chamber.

During the accident steam exposure, the conductors were energized at approximately

\footnotetext{
${ }^{6}$ The newer standard, IEEE Std. 323-1983, is not endorsed by the NRC. It also does not include a "generic" steam condition profile like that found in Appendix $A$ of IEEE Std. 323-1974.
}

$110 \mathrm{Vdc}, 0 \mathrm{~mA}$ to allow for on-line measurement of insulation resistance. One conductor in each connection (or the shield, if present) was grounded as indicated in Table 2.3 .

Two problems occurred during the accident steam exposure. The first occurred at the start of the first transient when a port on the test chamber was left open, causing steam to be vented into the laboratory when it was introduced into the chamber. The valve controlling steam flow into the test chamber was immediately closed, the open port was then closed and the first transient was restarted approximately $24 \mathrm{~min}$ later. This can be seen in the Figure 2.12 temperature plot, which shows that the average test chamber temperature reached approximately $102^{\circ} \mathrm{C}\left(216^{\circ} \mathrm{F}\right)$ prior to the start of the first transient. The second problem was a slow drop in the test chamber temperature that occurred during days 4 and 5 . This was due to steam condensate slowly beginning to fill the test chamber after a steam trap failed so that condensate no longer drained from the chamber. The pressure remained on target because it was manually set by a pressure regulator; however, as more and more condensate collected in the bottom of the test chamber, the steam injected into the chamber was no longer able to keep it at the saturation temperature and thus the temperature began to cool. The watermark left in the test chamber indicates that the chamber filled with approximately 6 in of condensate, submerging approximately $1-1 / 8$ in of the mandrel. None of the connections was submerged, but the loop on the return legs of the cable runs and the cable-to-cable connectors were submerged.

\subsection{Electrical Measurement Techniques}

All the measurements performed were electrical in nature in order to detect if the connections had failed. It is unclear what type of mechanical, physical, or chemical testing could be nondestructively performed on an installed connection. Note that previous test programs on the aging degradation of cables [21, 22, 23] indicated that electrical measurements are not good for detecting degradation of cables. 


\section{EXPERIMENTAL APPARATUS AND TECHNIQUE}
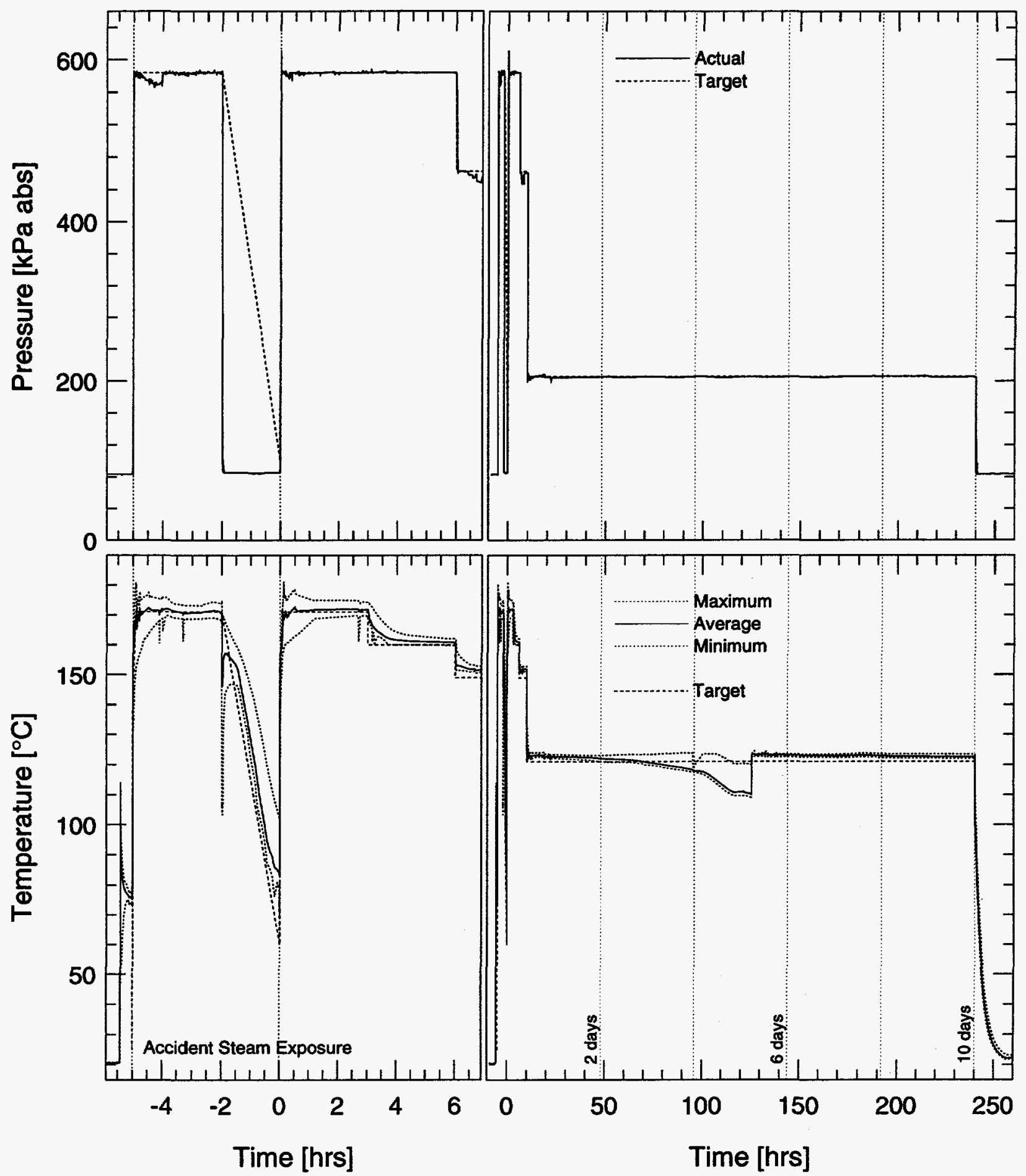

Figure 2.12: Pressure and temperature during the accident steam exposure. 
Table 2.6: Target Accident Steam Exposure Profile and IEEE Std. 323-1974 Combined PWR/BWR Profile.

\begin{tabular}{ccccc}
\hline \hline \multirow{2}{*}{ Time } & \multicolumn{2}{c}{ Intended Test Profile } & \multicolumn{2}{c}{ IEEE Std. 323-1974 Profile } \\
\cline { 2 - 5 } & Temperature & $\begin{array}{c}\text { Absolute Pressure } \\
{[\mathrm{kPa}]}\end{array}$ & $\begin{array}{c}\text { Temperature } \\
{\left[{ }^{\circ} \mathrm{C}\right]}\end{array}$ & $\begin{array}{c}\text { Absolute Pressure } \\
\left.{ }^{a} \mathrm{C}\right]\end{array}$ \\
\hline $0-10 \mathrm{~s}$ & Ambient-137.8 & Ambient-583.9 & $57.2-137.8$ & $101.3-583.9$ \\
$10 \mathrm{~s}-5 \mathrm{~min}$ & $137.8-171.1$ & 583.9 & $137.8-171.1$ & 583.9 \\
$5 \mathrm{~min}-3 \mathrm{hr}$ & 171.1 & 583.9 & 171.1 & 583.9 \\
$3-5 \mathrm{hr}$ & $171.1-60.0$ & $583.9-101.3$ & $171.1-60.0$ & $583.9-101.3$ \\
Reset time to 0 for the next portion of the profile & & \\
$0-10 \mathrm{~s}$ & $60.0-137.8$ & $101.3-583.9$ & $60.0-137.8$ & $101.3-583.9$ \\
$10 \mathrm{~s}-5 \mathrm{~min}$ & $137.8-171.1$ & 583.9 & $137.8-171.1$ & 583.9 \\
$5 \mathrm{~min}-3 \mathrm{hr}$ & 171.1 & 583.9 & 171.1 & 583.9 \\
$3-6 \mathrm{hr}$ & 160.0 & 583.9 & 160.0 & 583.9 \\
$6-10 \mathrm{hr}$ & 148.9 & 461.8 & 148.9 & 583.9 \\
$10-91 \mathrm{hr}$ & 121.1 & 205.6 & 121.1 & 273.7 \\
$91-240 \mathrm{hr}$ & 121.1 & 205.6 & & \\
$91 \mathrm{hr}-100 \mathrm{days}$ & & & 93.3 & 170.2 \\
\hline \hline
\end{tabular}

${ }^{a}$ Assuming an ambient pressure of $101.325 \mathrm{kPa}$ (sea level); note that the laboratory elevation is approximately $1646 \mathrm{~m}(5400 \mathrm{ft})$, for which the standard ambient pressure is $83.057 \mathrm{kPa}$ [28, p. 121].

\subsubsection{Dielectric Withstand}

Dielectric withstand testing measures the ac leakage current; this is also commonly known as high potential (hi-pot) testing. When an ac voltage is applied to a device, the resulting leakage current gives an indication of the device's reactive impedance (at the excitation frequency of the applied ac voltage).

Using the system shown schematically in Figure 2.13, a Hipotronics Model 750-2 AC Dielectric Test Set (Hipotronics, Inc., Brewster, NY) was used to measure leakage current on the connections. Data were acquired for dry connections at voltages of 600 and $1000 \mathrm{Vac}$ rms $(60 \mathrm{~Hz})$ and for submerged connections at 600 and $2400 \mathrm{Vac}$ rms $(60 \mathrm{~Hz})$; the $600 \mathrm{Vac}$ is a nominal value because the Hipotronics test set cannot precisely control such low ac voltages. The conductor under test was connected to the dielectric test set and all other conductors were electrically grounded before the ac voltage was applied. The opposite ends of all conductors were allowed to float electrically.

For data acquisition, the Hipotronics dielectric test set outputs dc voltages proportional to the ac excitation voltage and ac leakage current. These two dc voltage outputs were acquired using two HP 3478A Multimeters; one acquired the excitation voltage and the other the leakage current. Data acquisition utilized the following procedure:

1. Start the acquisition program; the two streams of data are acquired every half second by the multimeters and sent to the computer for storage.

2. Ramp the excitation voltage up to the desired voltage using a voltage ramp rate of $500 \mathrm{Vac} / \mathrm{sec}$.

3. Hold at the desired excitation voltage for 1 min.

4. Ramp the excitation voltage back down.

5. Stop the acquisition program.

The leakage current data point was calculated by the program based on the acquired values during the 1-min hold at the desired excitation voltage. 


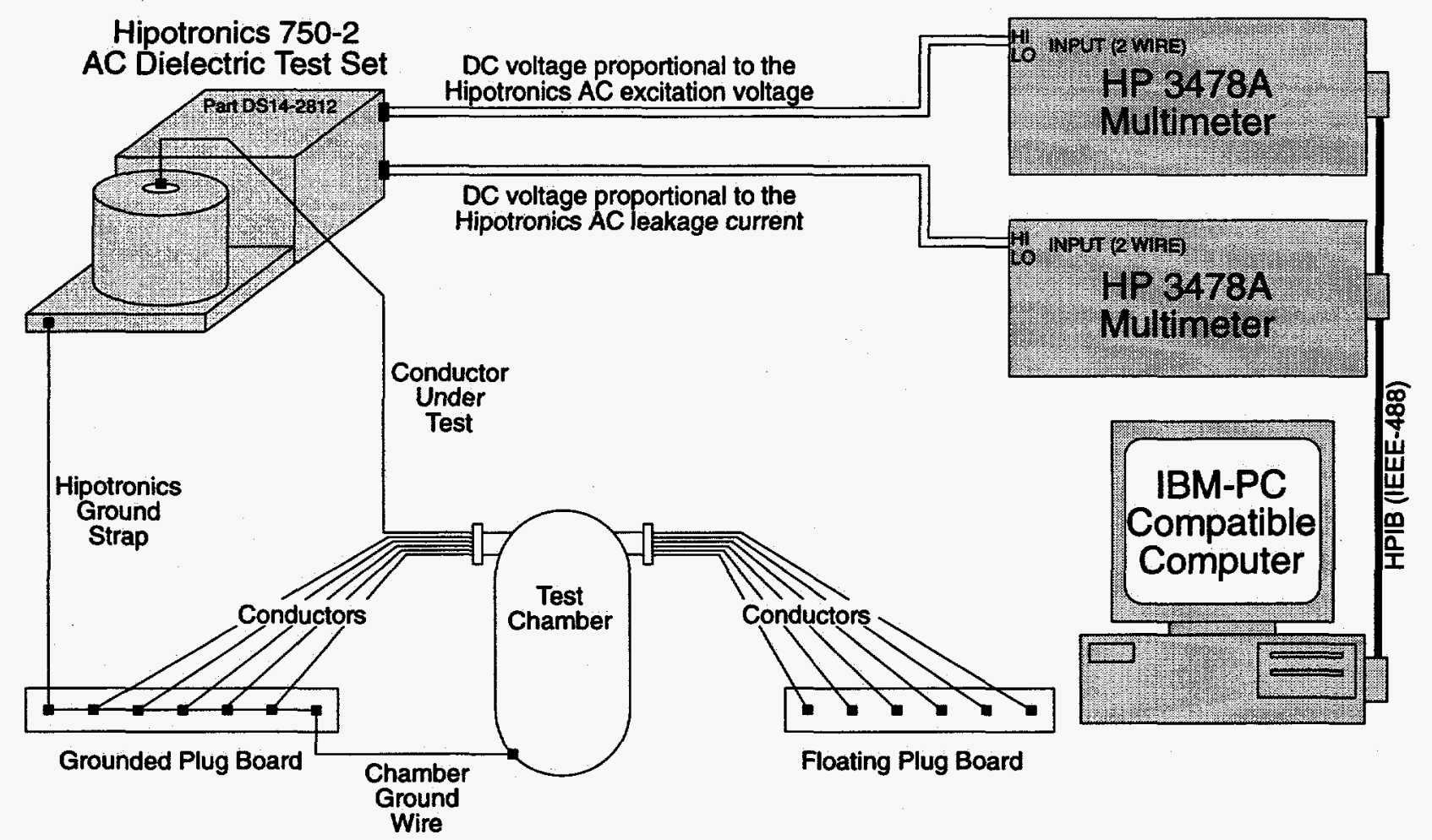

Figure 2.13: Schematic of the system used to measure ac leakage currents.

\subsubsection{Insulation Resistance}

Insulation resistance (IR) gives a measure of the resistive component of dielectric impedance. The IR value calculated from the applied dc voltage and measured current only includes resistive impedance-any initial ac effects due to the sudden application of the dc voltage have decayed by the time the IR measurement is taken. IR values are typically used by the utility industry as a go/no-go test of insulation; however, no technical basis is available to set an IR acceptance criteria for age-related degradation. Typically, an IR test is used to identify a locally damaged cable (i.e., insulation windings that are wet, or a gouged cable that is "sufficiently close" to the ground plane in the test).

The IR of all the conductors was measured at discrete times using the system shown schematically in Figure 2.14. A detailed discussion of this system appears in NUREG/CR-5772, Vol. 1 [21, Section A.2]. The conductor (or shield) under test was connected to the dc power supply through a resistor; all other conductors (and shields) were grounded before applying the dc voltage. The opposite ends of all the conductors were allowed to float electrically (i.e., open circuit). The majority of IR measurements were performed at $100 \mathrm{Vdc}$; however, some data were also acquired at $250 \mathrm{Vdc}$. A single IR measurement consisted of acquiring $\mathbf{1 5}$ samples of the voltage across the resistor at times ranging from $2 \mathrm{sec}$ to $1 \mathrm{~min}$ after the application of the power supply voltage. For each of the 15 samples, a leakage resistance value was calculated using the measured voltage across the known resistance and the power supply voltage. To reduce the effect of measurement noise, the leakage resistance values were fit using a least-squares polynomial regression; the value from the fit, rather than the leakage resistance calculated from the 1-min measurement, was used as the IR at $1 \mathrm{~min}$. Because of limitations in the accuracy of the measuring equipment, discrete IR measurements were cut off above $2.0 \times 10^{12} \Omega$.

During the accident steam exposure, IR measurements were performed using the circuit shown in Figure 2.15 in addition to the discrete IR measurements. These IRs are referred to as "continuous" IRs, even though they were not truly continuous-measurements were actually 


\section{EXPERIMENTAL APPARATUS AND TECHNIQUE}

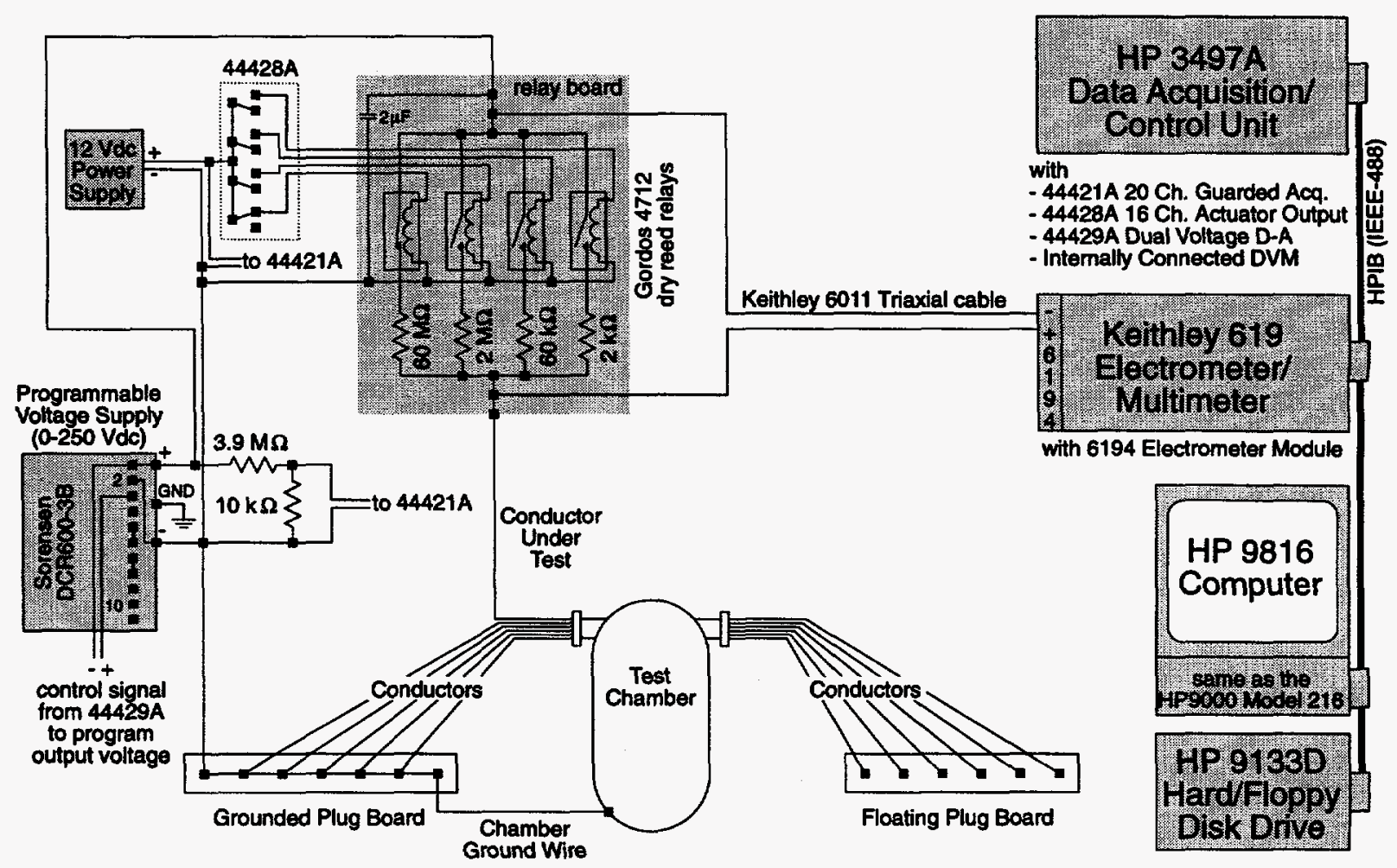

Figure 2.14: Schematic of the system used to perform discrete insulation resistance measurements.

performed at intervals ranging from 10 to $300 \mathrm{sec}$. The conductor numbers in the figure correspond to the numbers in Table 2.3. As indicated in Figure 2.15 and Table 2.3, one conductor or shield from each cable was connected to ground to provide a ground plane; no continuous IR measurements are available for these grounded conductors. Because of limitations in the accuracy of the measuring equipment, continuous IR measurements were cutoff above $1.0 \times 10^{8} \Omega$, which is several orders of magnitude less than what could be measured with the discrete IR system. The continuous IR system is most useful for identifying short-term drops in IR values, such as during the initial transient of the accident steam exposure, that would otherwise be missed by the discrete IR system. A more complete discussion of the measurement limits of the continuous IR system appears in NUREG/CR-5772, Vol. 1 [21, Section 2.4.3].

\subsubsection{Time Domain Reflectometry}

A Tektronix 1502B Time Domain Reflectometer (Tektronix, Inc., Wilsonville, OR) was used to perform time domain reflectometry (TDR) measurements on the conductors; measurements were performed before and after the accident steam exposure. The TDR data were sent to an IBM PC-compatible computer for storage via a serial port (RS-232) connection using a Tektronix SP232 serial interface that plugs into the 1502B.

The Tektronix 1502B has a female BNC connector for attaching the cable to be tested. One cable (consisting of 2 to 4 conductors) was attached to the $1502 \mathrm{~B}$ at a time. One end of the conductor under test was connected to the center pin of the 1502B input connector; the conductor's opposite end was allowed to float electrically. To provide a ground reference for the measurement, one end from each of the other conductors in the cable was shorted and attached to the shield of the 1502B input connector; the opposite ends of these conductors were also allowed to float electrically. All the conductors in cables not attached to the 1502B were left floating electrically at both ends. 


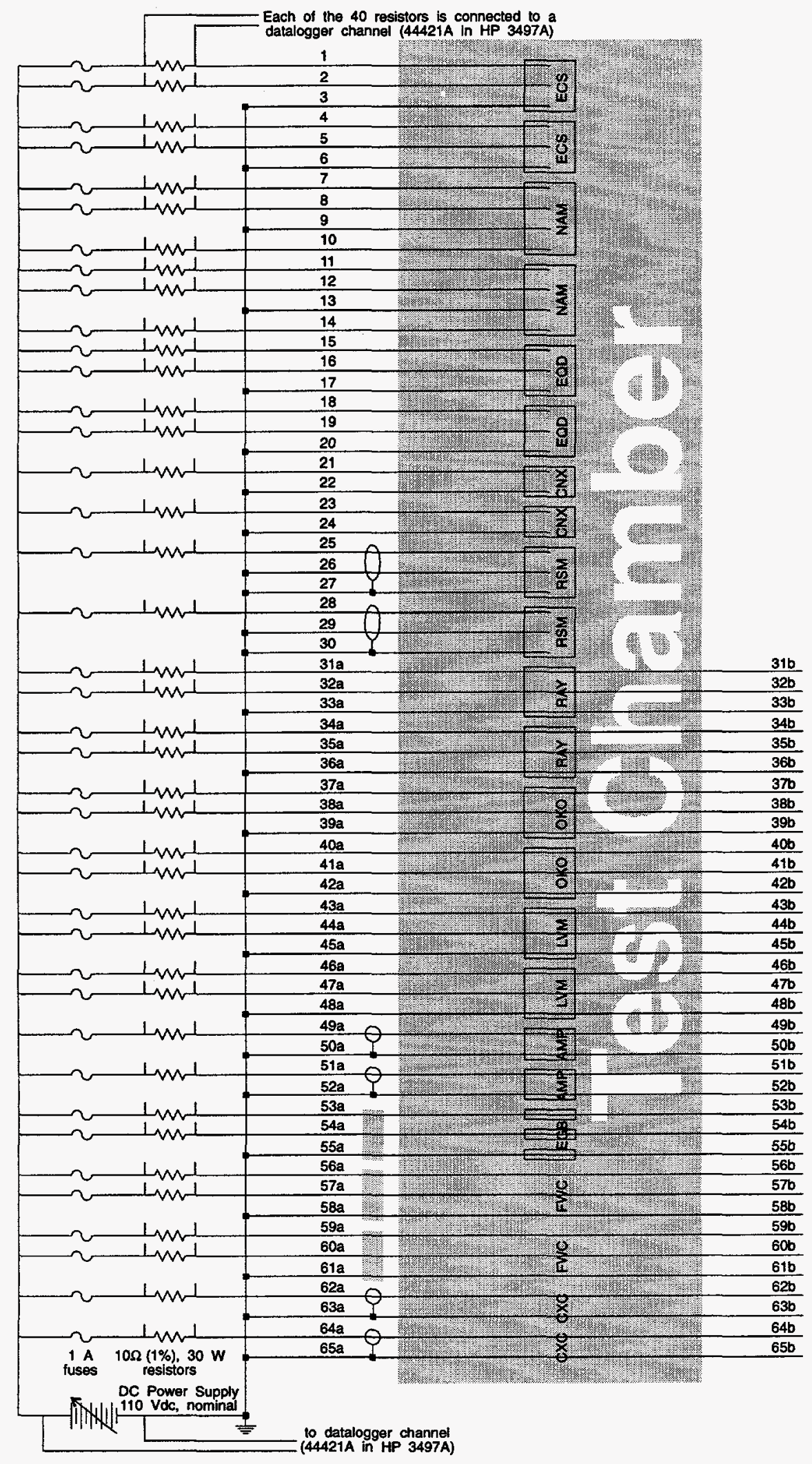

Figure 2.15: Circuitry used to measure continuous insulation resistance during the accident steam exposure. 


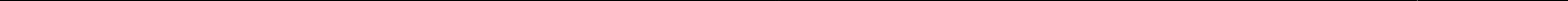




\section{EXPERIMENTAL RESULTS}

This section presents the experimental data ${ }^{1}$ acquired for the connections and cables that were tested. All the measurements performed were electrical in nature. Previous test programs on electrical cables have shown that electrical property measurements typically do not show significant changes with aging; mechanical measurements, most notably elongation at break, generally provide a better indication of aging degradation [21, 22, 23]. Electrical measurements are performed because they are simple and nondestructive.

It is unclear what type of mechanical, physical, or chemical testing could be nondestructively performed on an installed connection. For instance, tensile and elongation-at-break measurements cannot be easily performed on the connection's dielectric material because the dielectric is usually mounted permanently inside a protective metal shell. It is also much more difficult to create sample specimens from a connection because it is a discrete device, unlike a cable, which comes in a continuous length from which an unlimited number of specimens can be prepared. Even if tensile specimens could be easily prepared for a connection, the resulting measurements might not provide a direct indication of the connection's ability to perform its intended function.

For instance, a dominant failure mechanism for low-voltage instrumentation and control cables is cracking of the conductor's insulation after it has become embrittled due to thermal and/or radiation exposure. A cable with no residual elongation at break has often been found to be capable of performing its intended function in an accident scenario as long as no cracks already exist in the insulation. However, any handling of the cable, something dropping on it, or even movement of the cable tray or conduit could cause the cable to crack. An electrical test might indicate that a cable is good even though it has no remaining elongation, and any movement will cause the cable to crack and fail in the event of an accident.

This same type of failure mechanism does not

\footnotetext{
${ }^{1}$ In addition to the figures and tables included in this section, all the raw data are available upon request from the author.
}

typically occur in connections because the conductors are often encased in some sort of rigid shell that protects them and makes the insulation less susceptible to mechanical damage even after the insulation has become embrittled. Thus, the ability of a connection to perform its intended function is less dependent on the mechanical state of the conductor insulation. While electrical testing provides a direct indication of connection functionality, it must be remembered that electrical testing has not been shown to indicate degradation of connections or to predict imminent connection failure.

\subsection{Aging Exposure}

Only IR data were acquired during the simultaneous thermal and radiation aging exposure. These data are plotted against radiation dose in Figures 3.1-3.12. ${ }^{2}$ In these figures, a data point is plotted for every IR measurement (i.e., every IR measurement for each of the connection's conductors, not average data, is shown). The IR measurements during the aging exposure were performed with the test chamber and cable leads submerged in the LICA pool, except for the measurements at ambient temperature, which were performed with the test chamber and cable leads out of the LICA pool before the start of the aging exposure and between the aging exposure and accident irradiation. The ambient IR measurements were typically greater than the IR values acquired at the higher temperatures present during the aging exposure.

The measured IR values typically remained above $10^{9} \Omega$ for the duration of the aging exposure; however, the following observations should be noted:

- During baseline IR testing prior to the start of aging, one of the Rosemount $353 \mathrm{C}$ conduit seals was found to have an internal short circuit between its two conductors ( 25 and 26). There was no short to either the shield (27) or the body of the conduit seal. The

\footnotetext{
${ }^{2}$ Note that these figures also include the accident irradiation IR data.
} 
defective conduit seal was replaced with a spare, which was used for the test program.

- The lowest IR values during the aging exposure were for the Rosemount 353C conduit seal (see Figure 3.12). The IR of conductor 28 (cable shield) fell immediately from an initial value of $8.4 \times 10^{10} \Omega$ to $1.9 \times 10^{6} \Omega$ and then slowly increased to approximately $2 \times 10^{7} \Omega$ during the remainder of the aging exposure. The IR values of the other 3 conductors and 2 shields remained above $10^{8} \Omega$.

- Conductor 22 from a Conax Buffalo ECSA conduit seal also had reduced IR values during aging (see Figure 3.2); the $8.3 \times 10^{9} \Omega$ measurement at $60 \mathrm{kGy}$ fell to $7.0 \times 10^{6} \Omega$ at $75 \mathrm{kGy}$ and remained at these low levels for the remainder of the aging exposure. The other 3 conductors typically had IR values above $10^{10} \Omega$.

- Two of the three EGS Grayboot connectors were installed with a snap-on plastic cover intended to prevent the connector from pulling apart; only one of the two covered connectors was cycled. After 2 months of aging, the plastic cover was very brittle and broke apart when it was removed to cycle the connector (conductor 54). The test was continued without a plastic cover over this connector. When the 2 Grayboot connectors were cycled after 4 months of aging, the lubricant between the mating halves of the connections was dried out and had the appearance of rolled-up rubber cement. However, enough lubricant remained that the two connectors could be cycled easily. These issues had no negative effect on the IR data (see Figure 3.5), which were in the range of $10^{11} \Omega$ and above.

\subsection{LOCA Exposure}

The LOCA simulation consisted of an accident radiation exposure followed by an accident steam exposure.

\subsubsection{Accident Irradiation}

Only IR data were acquired during the accident radiation exposure. These data are plotted versus radiation dose in Figures 3.1-3.12 along with the aging IR data. In these figures, a data point is plotted for every IR measurement. The IR measurements during the accident irradiation were performed with the test chamber and cable leads submerged in the LICA pool, except for the measurements at ambient temperature, which were performed with the test chamber and cable leads out of the LICA pool between the aging exposure and accident irradiation and after the accident irradiation. The ambient IR measurements were typically greater than those acquired during the accident irradiation.

The measured IR values typically remained above $10^{9} \Omega$ for the duration of the accident irradiation; however, the following observations should be noted:

- In all cases, the IR values during the accident irradiation remained relatively constant as the dose increased.

- Just as for the aging exposure, the lowest IR values during the accident irradiation were for the Rosemount 353C conduit seal (see Figure 3.12). Conductor 25 had IR values in the range of $3 \times 10^{5}$ to $1 \times 10^{6} \Omega$ and conductor 28 had IR values near $2 \times 10^{7} \Omega$. The other 2 conductors and 2 shields typically had IR values in the range of $5 \times 10^{8} \Omega$ and above.

- Conductor 22 from a Conax Buffalo ECSA conduit seal (see Figure 3.2) also had reduced IR values of approximately $2 \times 10^{6} \Omega$ for the duration of the accident irradiation. The other 3 conductors had IR values near $2 \times 10^{9} \Omega$.

\subsubsection{Accident Steam Exposure}

IR data during the accident steam exposure are plotted against time from the start of the second steam transient for both cable conductors and shields in Figures 3.13-3.24. In these figures, a data point is plotted for every IR measurement. All the IR measurements were performed with the 
test chamber and cable leads out of the LICA pool. Measurements at ambient temperature were performed before and after the accident steam exposure. The remainder of the IR measurements were acquired at the pressures and temperatures indicated in Table 2.6 and Figure 2.12.

In general, the IR measurements inversely mirrored the environmental conditions (i.e., IR decreased as temperature and pressure increased, and IR increased when temperature and pressure decreased). For all the conductors, the measured IR decreased by at least two orders of magnitude during the transients at the start of the accident steam exposure.

Several of the connections were installed using Rockbestos Firewall III cable. Of these, the measured IR of the EGS conduit seal (Figure 3.16), EGS Grayboot connector (Figure 3.17), Okonite tape splice (Figure 3.22), and the Raychem heat-shrink splice (Figure 3.23) were all very similar to that of the Rockbestos Firewall III cable in Figure 3.19. This indicates that these connections had IR values that were comparable or better than the Rockbestos cable. The measured IR of the NAMCO EC210 connector (Figure 3.21) was also very similar even though it used a different type of cable.

The IR results for the Litton-VEAM connector (Figure 3.20), which was also installed using the Rockbestos Firewall III cable, would have also given similar results except that conductors 43 and 47 had IR values several orders of magnitude less than the other 4 conductors.

The IR results for the Rosemount 353C conduit seal (Figure 3.24) during the accident steam exposure were only slightly degraded, if at all, from the values seen during the aging exposure and accident irradiation (Figure 3.12) - the reason for this "recovery" in IR is unknown.

The IR values for the EGS quick-disconnect connector (Figure 3.18) remained relatively constant near $10^{8} \Omega$ during the steam exposure after the initial drop due to the steam transients.

The IR of the Conax Buffalo ECSA conduit seal (Figure 3.14) remained high during the first and most of the second steam transient, but then dropped rather quickly to the $10^{6} \Omega$ range about
$4 \mathrm{hr}$ into the second steam transient. The IR measurements then remained in the $10^{5}-10^{6} \Omega$ range until approximately $47 \mathrm{hr}$, after which the IR values began to fall steadily. The discrete IR measurements at $94,166,189,214$, and $237 \mathrm{hr}$ had IR values of less than $10^{3} \Omega$. The low IR values caused the $1 \mathrm{~A}$ fuses for conductors 21 and 23 on the continuous IR measurement circuit to blow repeatedly, as shown in Table 3.1 and Figure 3.14. There was a period of slight recovery in the discrete IR values; at 127 and $141 \mathrm{hr}$ the IR recovered to approximately $2.3 \times 10^{4} \Omega$; however, the IR had fallen again by the 166 -hr measurement.

The Rockbestos coaxial cable was only used to install the Amphenol coaxial connector. The coaxial cable's IR remained very high throughout the accident steam exposure, as shown in Figure 3.15. The IR of the Amphenol coaxial connector (Figure 3.13) was very high during the two transients at the start of the steam exposure, but dropped precipitously after 1 day and remained at values between $10^{4}$ and $10^{5} \Omega$ for the duration of the steam exposure.

During the accident steam exposure, water slowly dripped out the ends of a substantial fraction of the cables. This type of behavior was similar to that observed during previous cable testing and no records were kept on cable leakage. In retrospect, this lack of records is unfortunate because the presence of water inside the cable jacket may correlate with connection performance. In general, the leakage is probably due to a breach in the cable jacket; however, several of the connections were installed so that the cable jacket was not sealed after being stripped back to allow for the conductors to attach to a connection. In either case, moisture enters the portion of the cable inside the test chamber and then the high pressure inside the test chamber causes the moisture to propagate between the jacket and conductor insulation until it finally drips out at the end of the cable. A substantial fraction of the cables were filled with water during the steam exposure. The TDR measurements, described later, confirm this. 


\section{EXPERIMENTAL RESULTS}

Table 3.1: Conax Buffalo ECSA Conduit Seal Conductor Fuses Replaced During the Accident Steam Exposure.

\begin{tabular}{ccl}
\hline \hline Time & & \\
{$[\mathrm{hrs}]$} & Conductor & Description \\
\hline 68 & 23 & blown fuse \\
69 & 23 & replaced fuse, blew instantly \\
88 & 21 & blown fuse \\
93 & 21 & replaced fuse, blew instantly \\
126 & 21,23 & replaced fuses, fuses okay \\
134 & 23 & blown fuse \\
142 & 21 & blown fuse \\
142 & 21,23 & replaced fuses, blew instantly \\
162 & 21,23 & replaced fuses, blew instantly \\
210 & 21,23 & replaced fuses, 21 blew within 20 min, 23 blew immediately \\
240 & 21,23 & replaced fuses, 21 blew immediately, 23 okay \\
262 & 21 & replaced fuse, blew immediately \\
280 & 21 & replaced fuse, blew immediately \\
\hline \hline
\end{tabular}

\subsection{Post-LOCA Measurements}

After the completion of the accident steam exposure, several types of measurements were performed, including:

- IR measurements (1 min at $100 \mathrm{Vdc})$

- TDR measurements

- Submerged IR measurements (1 min at $100 \mathrm{Vdc})$

- Dielectric withstand measurements (1-min hold at 1000 Vac rms for conductors, $600 \mathrm{Vac}$ rms for shields)

- Submerged dielectric withstand measurements (1-min hold at $2400 \mathrm{Vac}$ rms for conductors, 600 Vac rms for shields)

A set of IR measurements was performed soon ( 3 days) after the completion of the accident steam exposure; these data are tabulated in Tables $\mathbf{3 . 2}$ and 3.3 and are also plotted as the ambient data at approximately $240 \mathrm{hr}$ in Figures 3.13-3.24. In general, these data show a recovery in IR from that during the steam exposure.

At this same time, TDR measurements were performed on all the conductors. These data are plotted in Appendix C as Figures C.1-C.12 along with baseline TDR data obtained prior to the start of the accident steam exposure. The pre- and poststeam TDR measurements were performed with identical test parameters; the connections were located at a distance of approximately $9.1 \mathrm{~m}$ $(30 \mathrm{ft})$ down the cable. In general, the reflection coefficient, $\rho$, of the poststeam TDR measurements was less than that of the presteam measurements, which indicates that the impedance of the connection or cable had been reduced. One possible cause of the decreased poststeam impedance could be moisture present in the cable and connection from the steam exposure, a breach in the cable jacket, or leakage into the connection. Also, the cable in the poststeam measurements appears "longer" than that of the presteam measurements. Since both measurements were performed assuming the same propagation velocity on the same cable and connection, this indicates that the actual propagation velocity was slower for the poststeam measurements than for the presteam measurements. The effect of the high temperature and pressure during the accident steam exposure might have affected the cable propagation velocity; however, it is more likely that these changes were due to moisture. ${ }^{3}$

\footnotetext{
${ }^{3}$ Because it was difficult to identify whether changes between the pre- and poststeam TDR measurements were due to cable or connection degradation, or to some other effect such as moisture or water intrusion, an additional set
} 
Because of the possibility that moisture still remained in and on the cables and connections, the IR was retested approximately 13 months later, which provided sufficient time to ensure that everything had dried out. The results are shown in Tables 3.2 and 3.3, and are similar to those obtained immediately after the accident steam exposure, except for the following observations. The IR of several NAMCO EC210 connector conductors fell substantially; the IR of conductor 7 fell by over 5 orders of magnitude and the IR of conductors 9 and 10 fell by over 2 orders of magnitude. In contrast, the IR of all the EGS quick-disconnect connector conductors increased markedly to values above $10^{10} \Omega$; the IR of Conax Buffalo ECSA conduit seal conductors 21 and 22 increased by at least 4 orders of magnitude; the IR of Rosemount $353 \mathrm{C}$ conduit seal conductors 28 and 29 increased by 2 orders of magnitude; and the IR of Amphenol coaxial connector conductors 49 and 50 increased by a factor of 40 . The IR of the Litton-VEAM connector conductors showed no consistent trend as the IR of conductors 43 and 45 increased at least 2 orders of magnitude and conductors 47 and 48 increased by at least 6 orders of magnitude; however, the IR of conductor 44 actually decreased by almost 4 orders of magnitude.

Once the dry IR test was completed, the test chamber was flooded with tap water and two additional sets of IR measurements were performed. As shown in Tables 3.2 and 3.3, they were performed after a soak period of at least 30 min for one set, and a minimum soak period of $3 \mathrm{hr}$ for the second set. Again, the submerged IR results were similar to those of the previous (dry) IR measurements, except for the following observations. The submerged IR of all the EGS quick-disconnect connector conductors decreased from values above $10^{10} \Omega$ to less than $10^{6} \Omega$. The submerged IR values of all the Conax Buffalo ECSA conduit seal conductors decreased at least 2 orders of magnitude to values of $3 \times 10^{4} \Omega$ and below. The submerged IR values of all the

of poststeam TDR measurements was performed approximately $\mathbf{2 6}$ months later (to allow time for everything to dry out). The results of this second set of poststeam TDR measurements was much closer to the presteam measurements than those performed shortly after the completion of the accident steam exposure. This suggests that moisture had a substantial impact on the earlier poststeam measurements. The differences that still remain are probably more characteristic of changes due to cable and connection degradation during the accident steam exposure.
Litton-VEAM connector conductors decreased at least 3 orders of magnitude to values of $6.9 \times 10^{4} \Omega$ and below. The submerged IR values of the Amphenol coaxial connector shield conductors (50 and 52) decreased to values in the $1 \times 10^{4}$ to $4 \times 10^{4} \Omega$ range. There were no substantial differences between the data for minimum soak times of $30 \mathrm{~min}$ and $3 \mathrm{hr}$ except for the Rosemount 353C conduit seal, where the IR of several conductors decreased by over 3 orders of magnitude between the $30-$ min and 3-hr soak times.

Following the submerged IR tests, the connections were allowed to fully dry and then dielectric withstand testing was performed. An initial withstand testing on the dry cables was performed at $1000 \mathrm{Vac}$ rms for the conductors and $600 \mathrm{Vac}$ rms for the shields to get an indication of operability before performing submerged dielectric withstand testing. As shown in Tables 3.2 and 3.3, most of the connections did not trip ${ }^{4}$ the dielectric test set ( 8 of 55 connection conductors and 0 of 10 cable conductors tripped the test set). The individual conductors either had essentially constant current during the 1-min long hold, or tripped the dielectric test set immediately during the initial ramp up to the desired voltage; none of the conductors that tripped the dielectric test set held at the desired voltage for any period of time. All the Conax Buffalo ECSA conduit seal conductors and approximately half of the Litton-VEAM connector and Amphenol coaxial connector conductors tripped the dielectric test set during the dry dielectric withstand test.

Following the dry dielectric withstand tests, the test chamber was flooded again with tap water and submerged dielectric withstand tests were performed after a minimum submergence of $2 \mathrm{hrs}^{5}$ The submerged dielectric withstand testing was performed at $2400 \mathrm{Vac}$ rms for the conductors and $600 \mathrm{Vac}$ rms for the shields. As shown in Tables 3.2 and 3.3 , half of the 10 connection types

\footnotetext{
${ }^{4}$ For the dry dielectric withstand testing, the Hipotronics test set was adjusted to trip at a current of approximately $8 \mathrm{mAac}$.

${ }^{5}$ Submerged dielectric withstand testing was performed based upon the guidance in IEEE 383-1974 [17, Section 2.3.3.4] and to mimic the testing performed in the NUREG/CR-5772 series of reports [21, 22, 23]. In addition, IEEE $572-1985$ [18, Section 6.2.4.4] requires that dielectric withstand testing be performed on Class $1 \mathrm{E}$ connections.
} 
tripped $^{6}$ the dielectric test set (22 of 55 connection conductors and 0 of 10 cable conductors tripped the test set). Just as for the dry withstand testing, individual conductors either had essentially constant current during the 1-min hold, or tripped the dielectric test set immediately during the initial ramp up to the desired voltage. Essentially all of the conductors in the EGS quick-disconnect connectors, Conax Buffalo ECSA conduit seals, Rosemount 353C conduit seals, Litton-VEAM connectors, and Amphenol coaxial connectors tripped the dielectric test set.

If a typical cable is assumed to have a capacitance of roughly $98.4 \mathrm{pF} / \mathrm{m}(30 \mathrm{pF} / \mathrm{ft})$ and the cable specimens are approximately $18.3 \mathrm{~m}(60 \mathrm{ft})$ long, then the cable impedance for $60-\mathrm{Hz}$ excitation would be:

$$
\begin{aligned}
Z & =\frac{1}{\omega C}=\frac{1}{(2 \pi f) C} \\
& =\frac{1}{(2 \pi \times 60)\left(30 \times 10^{-12} \times 60\right)}=1.47 \times 10^{6} \Omega
\end{aligned}
$$

For an excitation voltage of $2400 \mathrm{Vac}$, this results in a capacitive charging current of $1.6 \mathrm{mAac}$. The ac charging and leakage current measurement is the sum of the current actually leaking from the conductor through the insulation to a ground outside the cable plus the current necessary to charge and discharge the capacitance of the cable dielectric (insulation) as the applied cable voltage changes. This differs from an IR measurement, which only gives the dc leakage of current from the conductor through the insulation to a ground outside the cable (assuming the dc voltage has been applied long enough for initial transients to die off). At $2400 \mathrm{Vac}$, the cable IR must be less than approximately $2 \times 10^{6} \Omega$ before leakage through the conductor is comparable to a typical capacitive charging current. Because typical measured IRs are greater than $10^{8} \Omega$ (see Figures 3.1-3.24), the capacitive charging current accounts for a substantial portion of the ac charging and leakage current shown in Tables 3.2 and 3.3. Increased ac charging and leakage current is caused by a combination of increased cable capacitance or substantial decreases in the cable IR.

For the dry 1000-Vac rms excitation, typical currents were $0.4 \mathrm{mAac}$ and $0.8 \mathrm{mAac}$ for the $30-\mathrm{ft}$

\footnotetext{
${ }^{6}$ For the submerged dielectric withstand testing, the Hipotronics test set was adjusted to trip at a current of approximately $20 \mathrm{mAac}$.
}

conductors (1-30) and 60-ft conductors (30-65), respectively. This is consistent with a $60-\mathrm{Hz}$ cable impedance of $2.5 \times 10^{6} \Omega$ for the $30-\mathrm{ft}$ conductors and $1.25 \times 10^{6} \Omega$ for the 60 - $\mathrm{ft}$ conductors; these impedances correspond to a cable capacitance of approximately $35 \mathrm{pF} / \mathrm{ft}$.

For the submerged 2400 Vac rms excitation, typical currents were $1.1 \mathrm{mAac}$ and $2.2 \mathrm{mAac}$ for the $30-\mathrm{ft}$ conductors $(1-30)$ and $60-\mathrm{ft}$ conductors $(30-65)$, respectively. This is consistent with a $60-\mathrm{Hz}$ cable impedance of $2.2 \times 10^{6} \Omega$ for the $30-\mathrm{ft}$ conductors and $1.1 \times 10^{6} \Omega$ for the $60-\mathrm{ft}$ conductors; these impedances correspond to a cable capacitance of approximately $40 \mathrm{pF} / \mathrm{ft}$.

\subsection{Post-Test Examination}

Following all the measurements described previously, the connections and their cables were physically inspected and disassembled in order to determine what caused the behavior that was seen. The physical inspection found that while the majority of the connections did not have any external damage, there was damage to a large fraction of the cable jackets, namely:

- The jackets of none of the EGS conduit seal cables (conductors 1-3 and 4-6) were cracked; however, the jacket was not sealed and moisture was free to enter the cable where the jacket was stripped away so the conductors could enter each conduit seal's grommet.

- The jackets of each of the NAMCO EC210 connector cables (conductors 7-10 and 11-14) were split open and extensively cracked and brittle looking. In addition, the rubber boot at the top of the NAMCO EC210 connector was also split.

- The jackets of the EGS quick-disconnect connector cables (conductors 15-17 and 18-20) were not cracked.

- The black jackets over the Kapton-insulated conductors for both of the Conax Buffalo ECSA conduit seal cables (conductors 21-22 and 23-24) were not cracked, but were also not sealed, so moisture could enter freely. Prior to the accident steam exposure, this black jacketing material had a smooth 
surface; afterward, it had the surface texture of a dried orange peel.

- The jackets of the Rosemount 353C conduit seal cables (conductors 25-27 and 28-30) were not cracked.

- The jackets of the Raychem heat-shrink splice cables (conductors $31-33$ and 34-36) were not cracked.

- The jackets of the Okonite tape splice cables (conductors 37-39 and 40-42) were split open and cracked all the way around. The Okonite No. 35 jacketing tape was extensively cracked; however, it remained attached and the underlying T-95 insulating tape was not exposed.

- The jackets of the Litton-VEAM connector cables (conductors 43-45 and 46-48) were split open and cracked all the way around.

- The coaxial cable jackets of the Amphenol coaxial connector cables (conductors 49-50 and 51-52) were not cracked. However, the Raychem splice installed on one of the connectors had an approximately 0.25 -in-long circumferential crack and the other connector had an approximately 1-in-long longitudinal crack; neither crack appeared to go all the way through.

- The jacket of the EGS Grayboot connector cable (conductors 53-55) was split open and was also not sealed at the point where the individual conductors were spread out to install the EGS Grayboot connectors.

- The jacket for Rockbestos Firewall III cable conductors 56-58 was not cracked, but the cable jacket for conductors 59-61 had several approximately 2-in-long longitudinal cracks in the region where the cable looped back up to exit the test chamber.

- The jackets of the Rockbestos coaxial cables (conductors 62-63 and 64-65) were not cracked.

Other than the Kapton-insulated conductors for the Conax Buffalo ECSA conduit seal cables (which will be described later), there was no obvious indication that the conductor insulation had been breached for any of the cables, as no exposed metallic conductor was seen. However, the jackets of a large fraction of the cables were cracked and would allow easy ingress of moisture into the cable and possibly into the connection. After the cable jacket had split, in most cases the resulting pieces of jacket were longer than the opening from which they came.

When the test chamber was opened, there was a large quantity of light yellow-colored deposits that appeared to have melted and then run down the test chamber mandrel and test specimens before resolidifing and depositing on various surfaces in the chamber. Fourier transform infrared microspectroscopy (FTIR, useful for identifying organic constituents) was used to look at these residues, and showed that they consisted largely of polypropylene. The polypropylene is assumed to have come from a plastic insulating bushing ${ }^{7}$ that was screwed to the top of the conduit attached to each of the terminal block enclosures (see Figure A.1); this bushing was installed to ensure that the cables entering and exiting the conduit did not rub against the metal end of the conduit. The two bushings "melted" during the accident steam exposure as would be expected; the melting point of polypropylene $\left(168-171^{\circ} \mathrm{C}\right)$ is essentially the same as the peak temperatures obtained during the steam exposure. It is not believed that the melting and depositing of this polypropylene had any effect on the results obtained during this test program.

In order to isolate the cause of reduced IR values for the connection-cable systems, several IR measurements were performed with different amounts of cable lead attached to the connections, namely:

- IR for the connection and its $9.1-\mathrm{m}$ (30-ft) cable leads attached to one or both ends.

- IR for the connection and the 1.2-1.5 m (4-5 ft) of cable lead on each side of the connection that is located inside the test chamber (the cable leads were cut just outside the test chamber penetrations to remove all cable outside the chamber).

- IR for the connection and just a few inches of cable lead on one or both ends of the connection.

By comparing IR results for various amounts of cable lead attached, one can surmise where the degradation occurred. There was no significant change between the IR results for the entire test

\footnotetext{
${ }^{7}$ Commonly called "antishort" bushings by electricians.
} 
system and those for the portion inside the test chamber. However, when these IR results were compared with those for the connections alone, several of the connections had much higher IR results for the connection alone. This was especially true for the Conax Buffalo ECSA conduit seals, where the IR values increased from approximately $10^{6} \Omega$ to $10^{11} \Omega$. This indicates that the reduced IR values for the Conax Buffalo ECSA conduit seals were clearly not due to some internal degradation in the conduit seals, but to problems with the Kapton-insulated conductors in the lead wires.

When these conductors were investigated, the Kapton insulation was very soft and the wraps had loosened around the conductors. After the black heat-shrink jacketing from the cable leads was removed, blue-green copper stains ${ }^{8}$ could be seen in the Kapton wraps at several locations along the leads, including a large deposit where the conductors entered the polysulfone insulation of the Conax Buffalo ECSA conduit seal. This indicates that degraded Kapton had allowed moisture to penetrate to the conductor and this led to the substantially reduced IR values. Similar behavior has been previously observed for Kapton-insulated conductors $[45,46]$.

When the connections were disassembled, the following observations were made:

- Except for the EGS conduit seals, the device enclosures were all clean inside, indicating that no moisture had leaked past the connections. The cables inside the device enclosures were in remarkably pristine condition compared with the cable outside; the only sign of exposure was that the exposed copper ends of the conductors had turned black.

- The device enclosures for the EGS conduit seals were in a finger-tight condition; no more than $10 \mathrm{ft}-\mathrm{lb}$ of torque were required to remove them (they were tightened to $40 \mathrm{ft}-\mathrm{lb}$ when installed). When opened, each of the enclosures had approximately $0.5-0.75 \mathrm{ml}$ of fluid trapped inside. The grommets through which the individual conductors passed were

\footnotetext{
${ }^{8}$ The presence of copper was verified using electron microprobe analysis (elemental dispersive spectroscopy, EDS), which uses an electron beam to excite X-ray emissions in order to identify metals and metallic salts.
}

swollen and slightly extruded, and the holes through which the conductors passed were distended into an oval shape, no longer sealing to the conductors over their entire length. While one cannot be certain how the water got into the enclosures, the most likely path seems to be leakage through the grommet along the conductors. Note that because of the small quantity of fluid and the vertical mounting of the conductors, the water did not reduce the measured IR values.

- The pins and sockets of the two NAMCO EC210 connectors were slightly blackened with corrosion and all the O-rings had an oily residue on them.

- The pins and sockets of EGS quick-disconnect connector for conductors 15-17 had a very light amount of corrosion and remnants of a slight amount of leakage into the connector past the O-ring seal. The EGS quick-disconnect connector for conductors $18-20$ had no corrosion or leakage.

- The backnuts of the two Litton-VEAM connectors were found to be in a finger-tight configuration even though they were both initially torqued to $35 \mathrm{ft}-\mathrm{lb}$. Examination of the O-ring seal at the backnut indicates that compression setting of the O-ring may have led to the loss of torque on the backnuts. In addition, the O-ring sealing the two halves of the Litton-VEAM connector for conductors 43-45 was cracked; however, there were only minimal signs of copper deposits on the pins or leakage past the cracked O-ring. On the other hand, the Litton-VEAM connector for conductors 46-48 had corrosion on the pins and obvious signs that leakage had occurred past the O-ring. Note that NRC Information Notice 89-23 [47] addressed the issue of degraded gaskets and elastomeric inserts for this type of connection.

- The Amphenol coaxial connectors were sectioned at the completion of the test and corrosion was found both inside the connectors and outside the connectors under the Raychem heat-shrink that was used to protect them from the environment. The moisture appears to have entered to connectors via the coaxial cable's braided shield; the Raychem heat-shrink remained 
intact. Similar behavior for this coaxial cable has been reported in NRC Information Notice 97-45 [48]. 


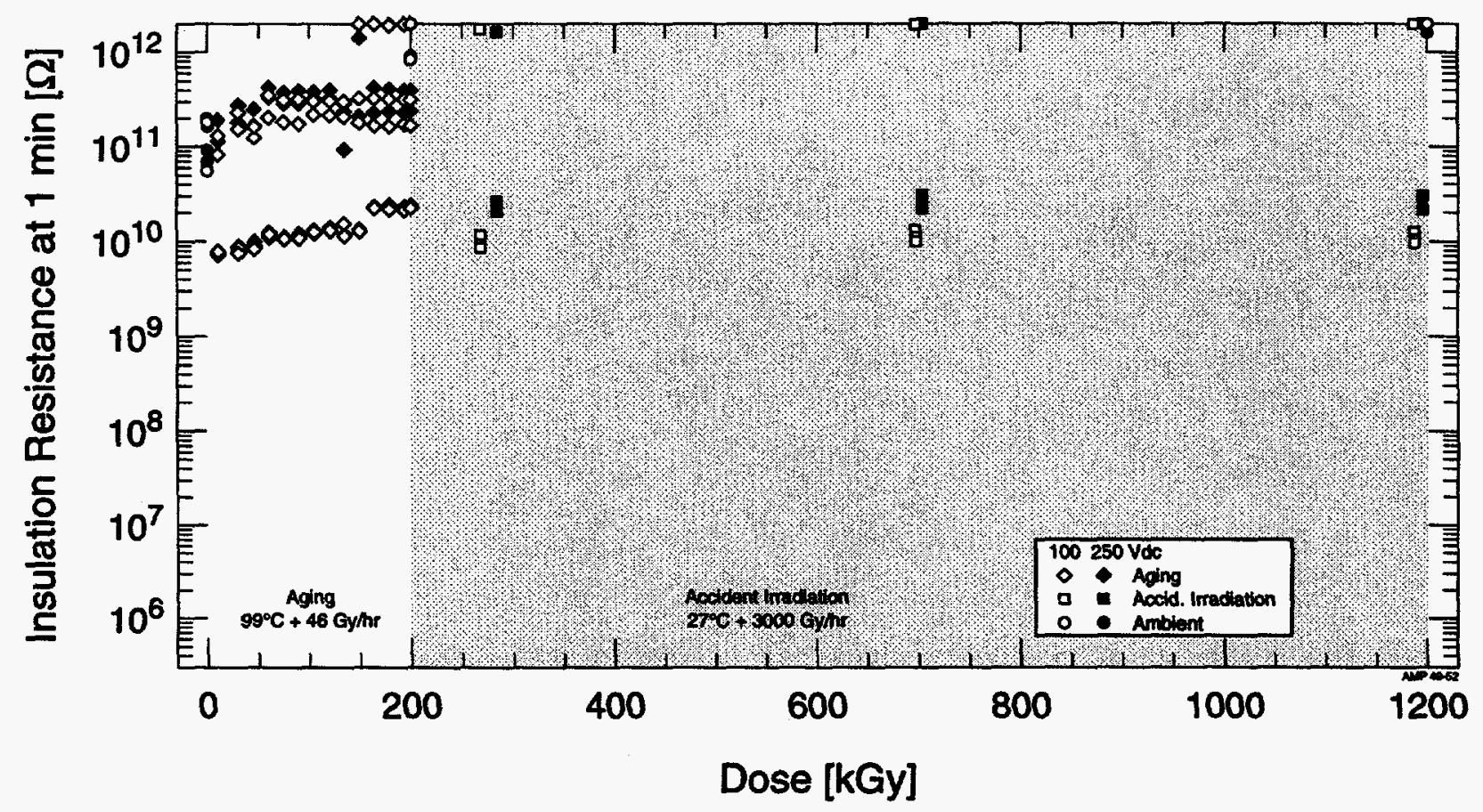

Figure 3.1: IR of the Amphenol coaxial connector conductors during aging and accident irradiation.

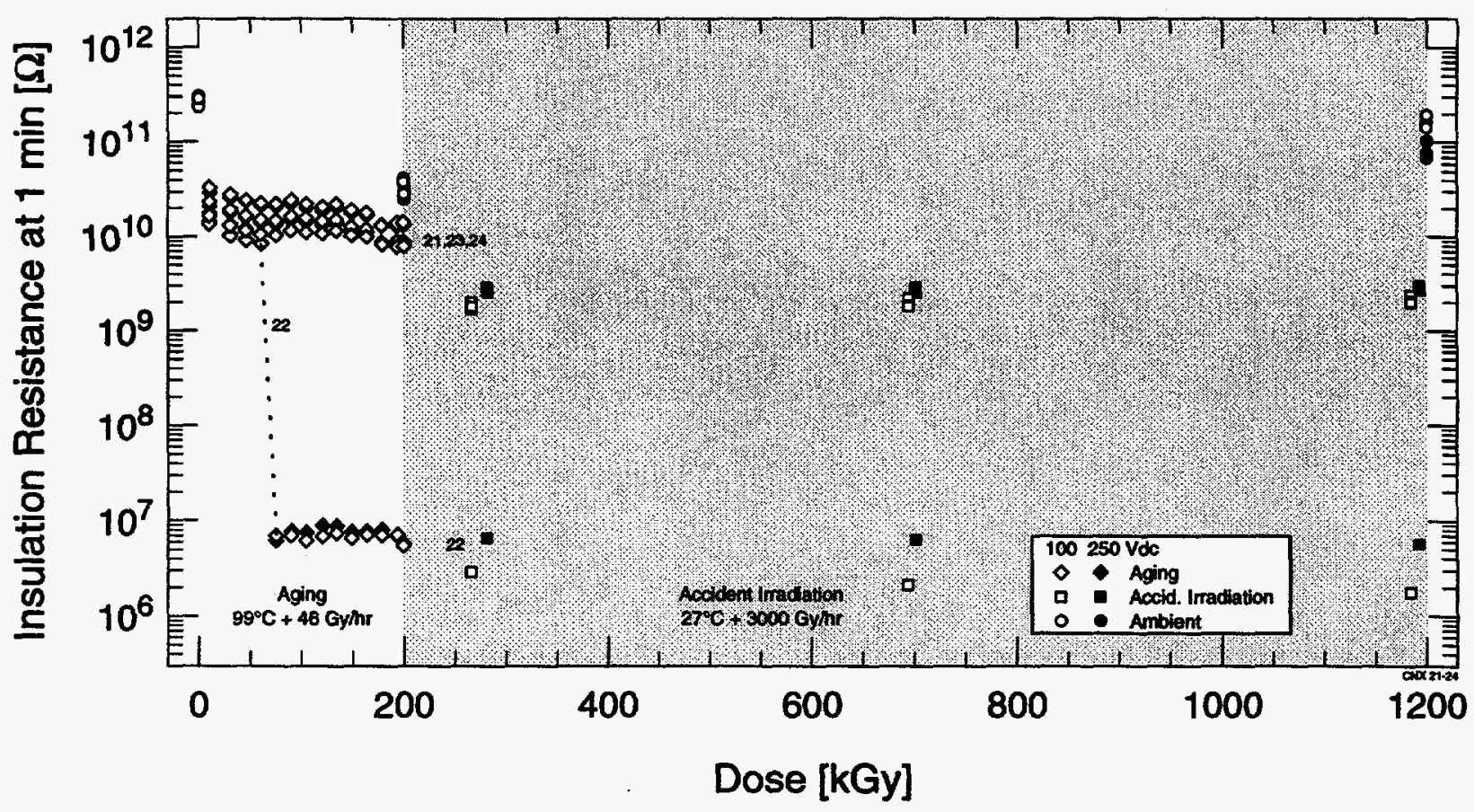

Figure 3.2: IR of the Conax Buffalo ECSA conduit seal conductors during aging and accident irradiation. 


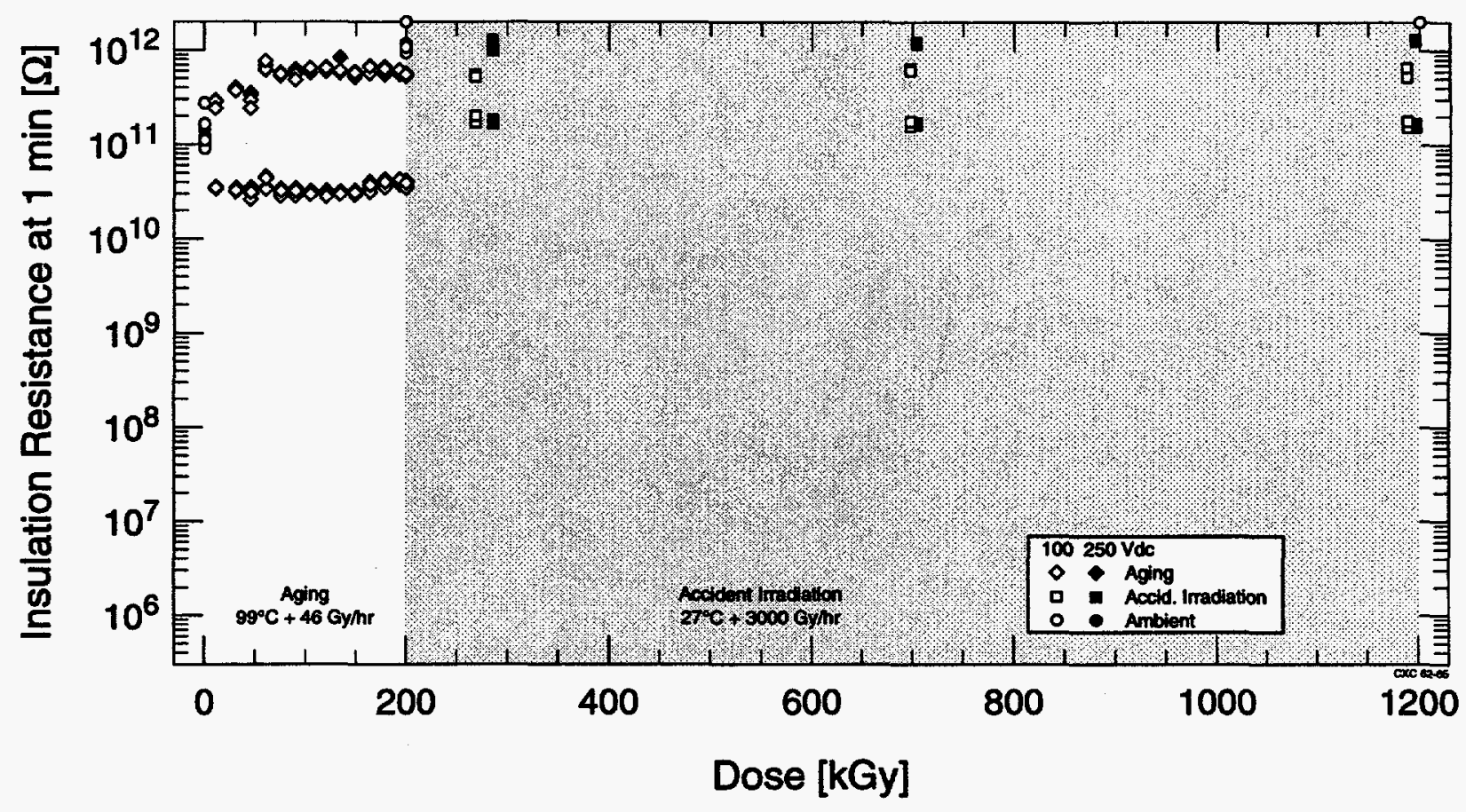

Figure 3.3: IR of the Rockbestos coaxial cable conductors during aging and accident irradiation.

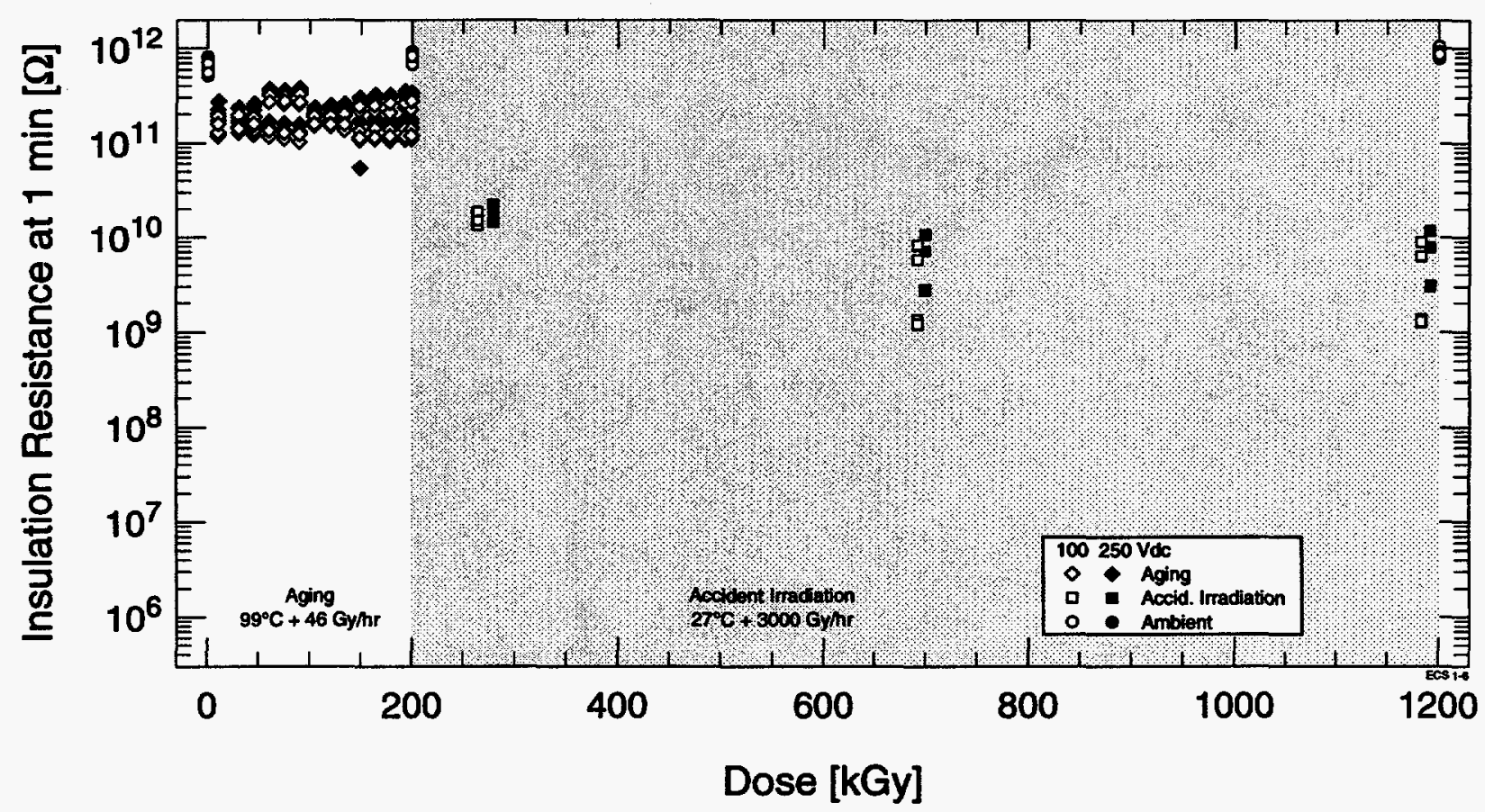

Figure 3.4: IR of the EGS conduit seal conductors during aging and accident irradiation. 


\section{EXPERIMENTAL RESULTS}

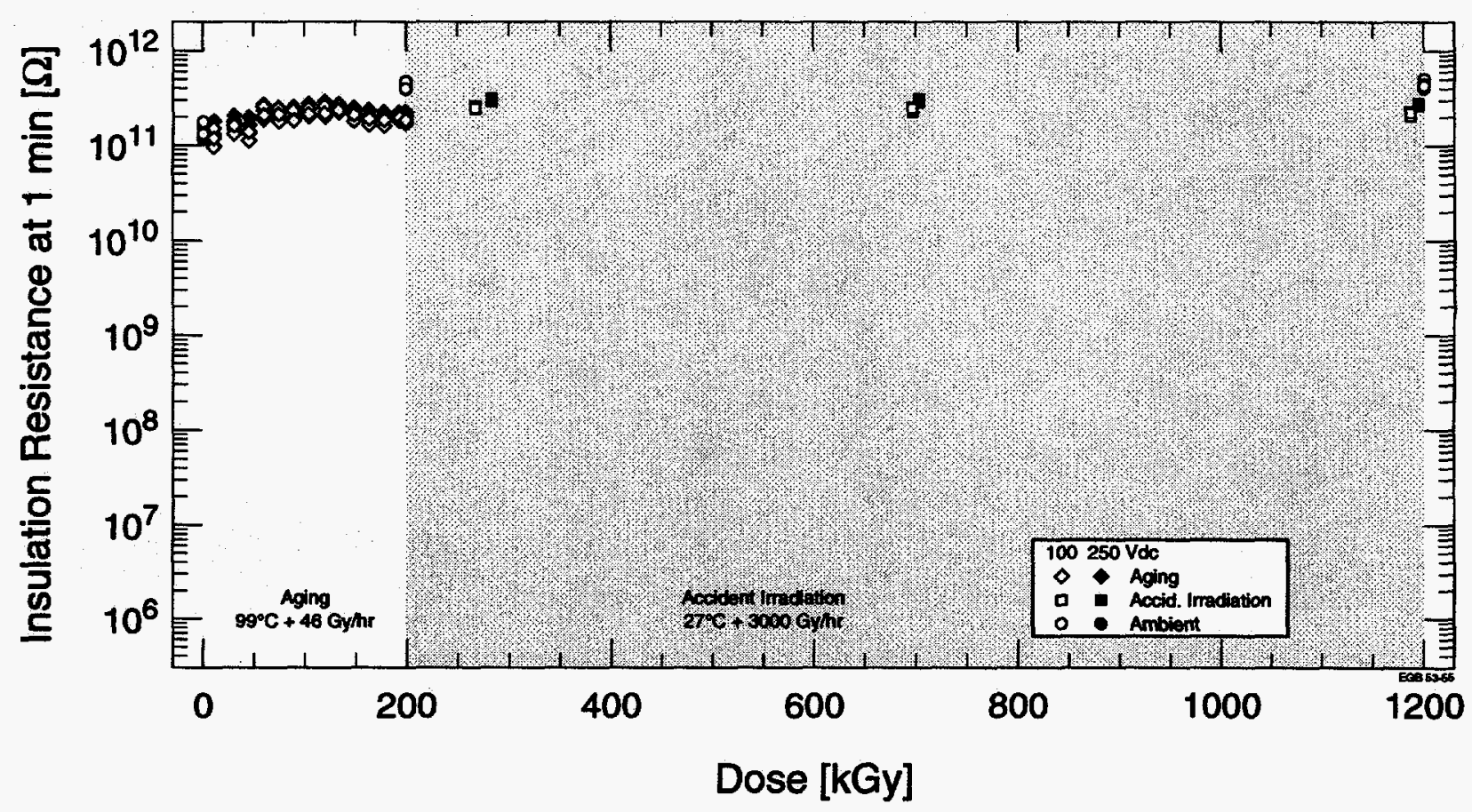

Figure 3.5: IR of the EGS Grayboot connector conductors during aging and accident irradiation.

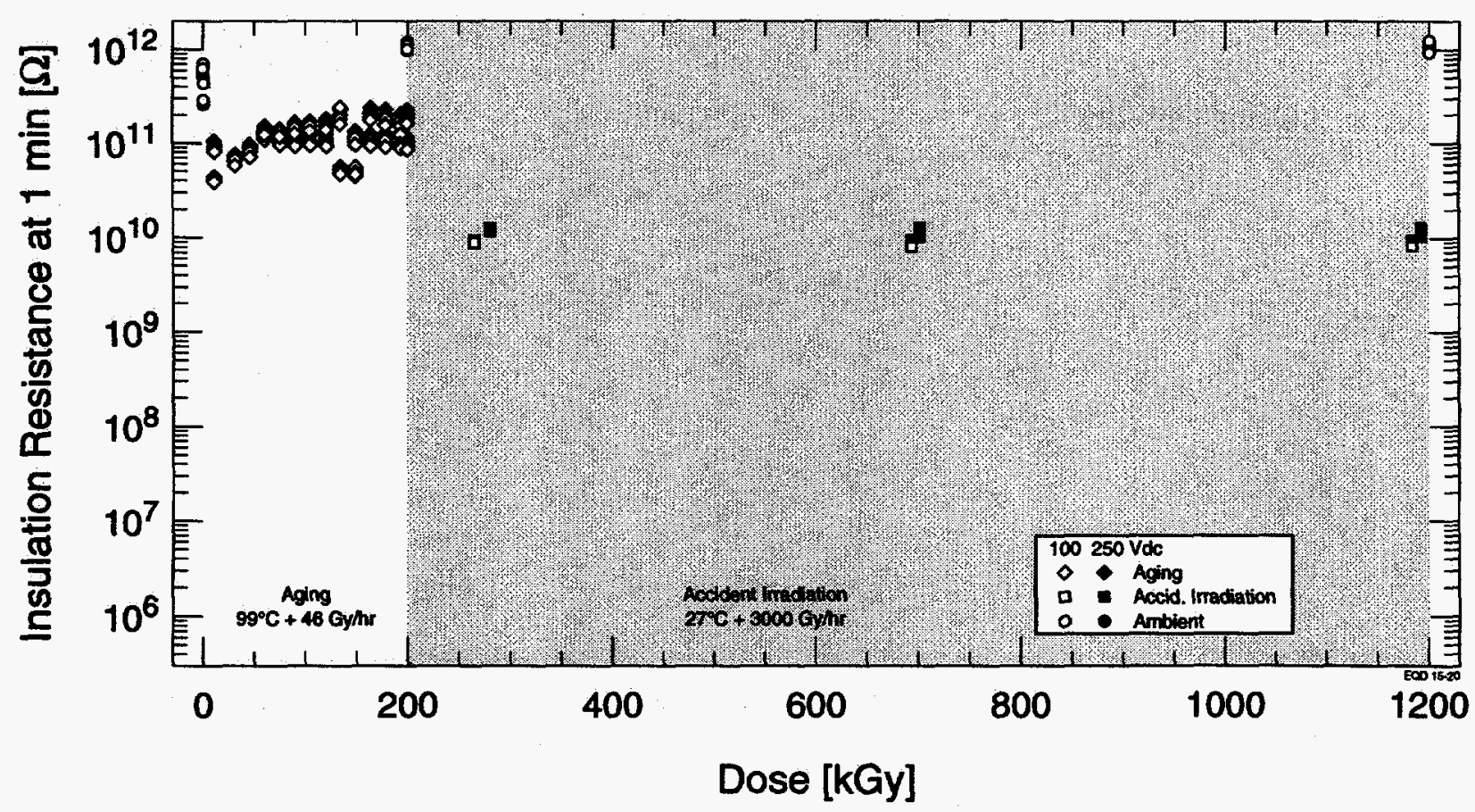

Figure 3.6: IR of the EGS quick-disconnect connector conductors during aging and accident irradiation. 


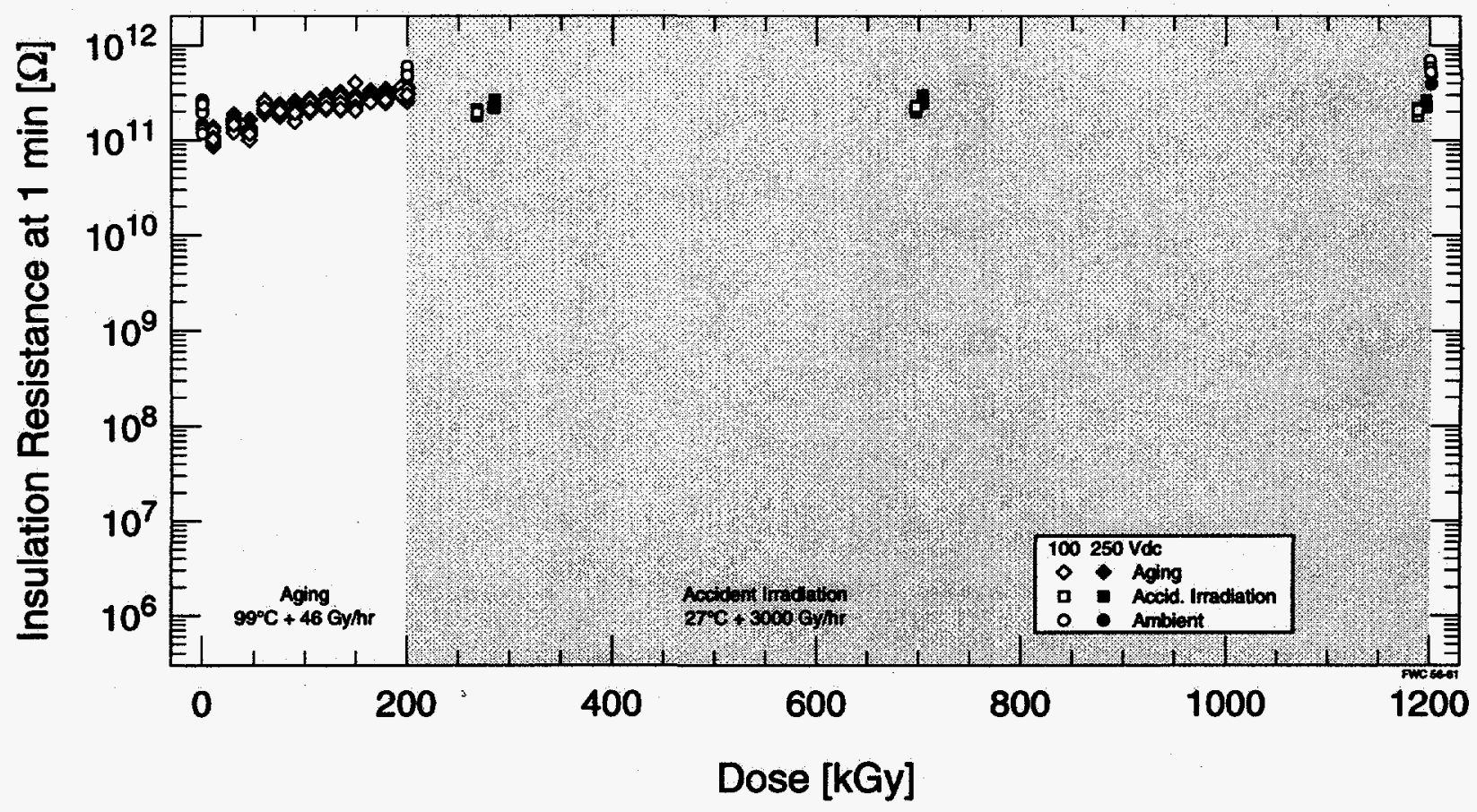

Figure 3.7: IR of the Rockbestos Firewall III cable conductors during aging and accident irradiation.

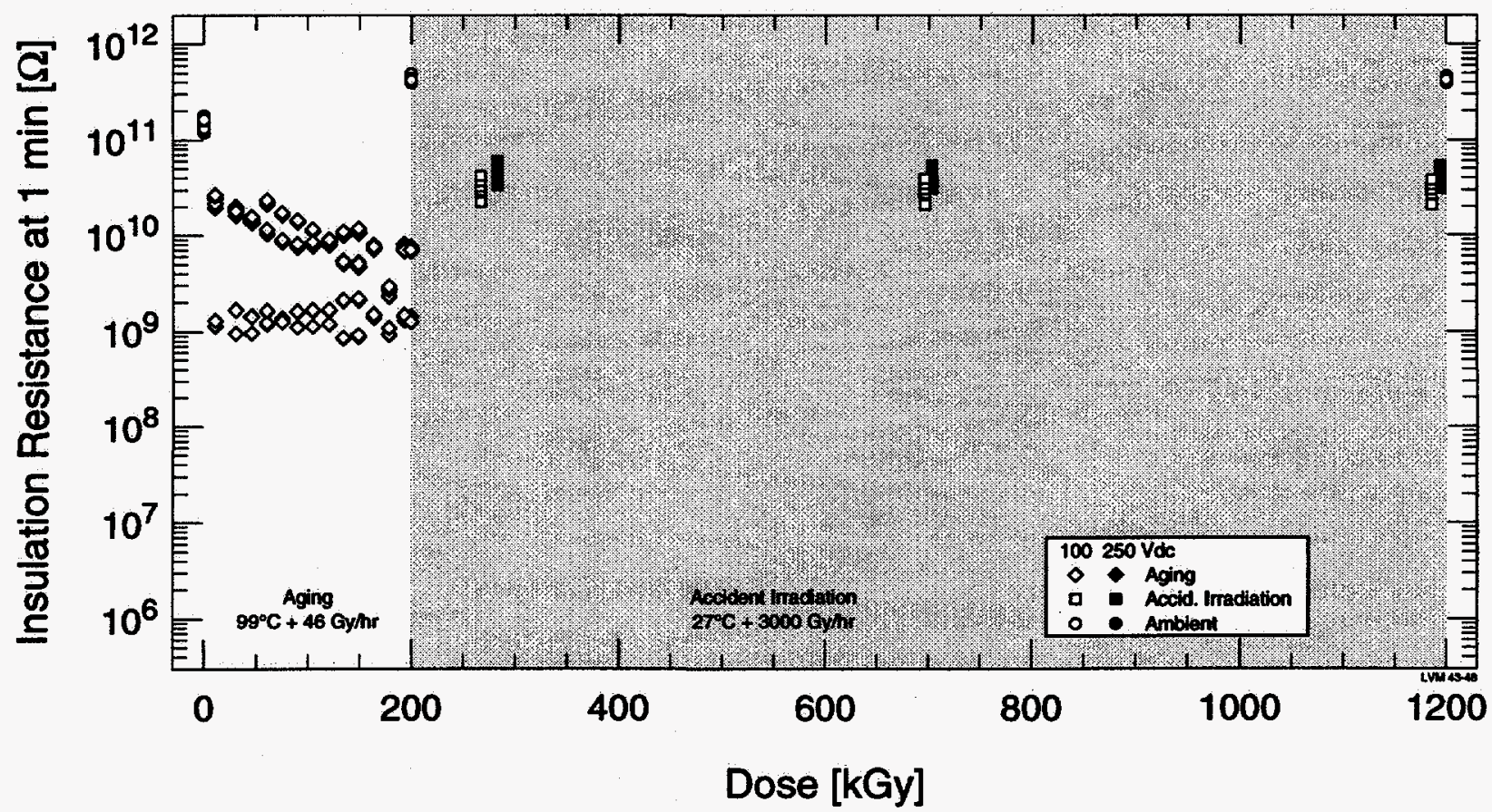

Figure 3.8: IR of the Litton-VEAM connector conductors during aging and accident irradiation. 


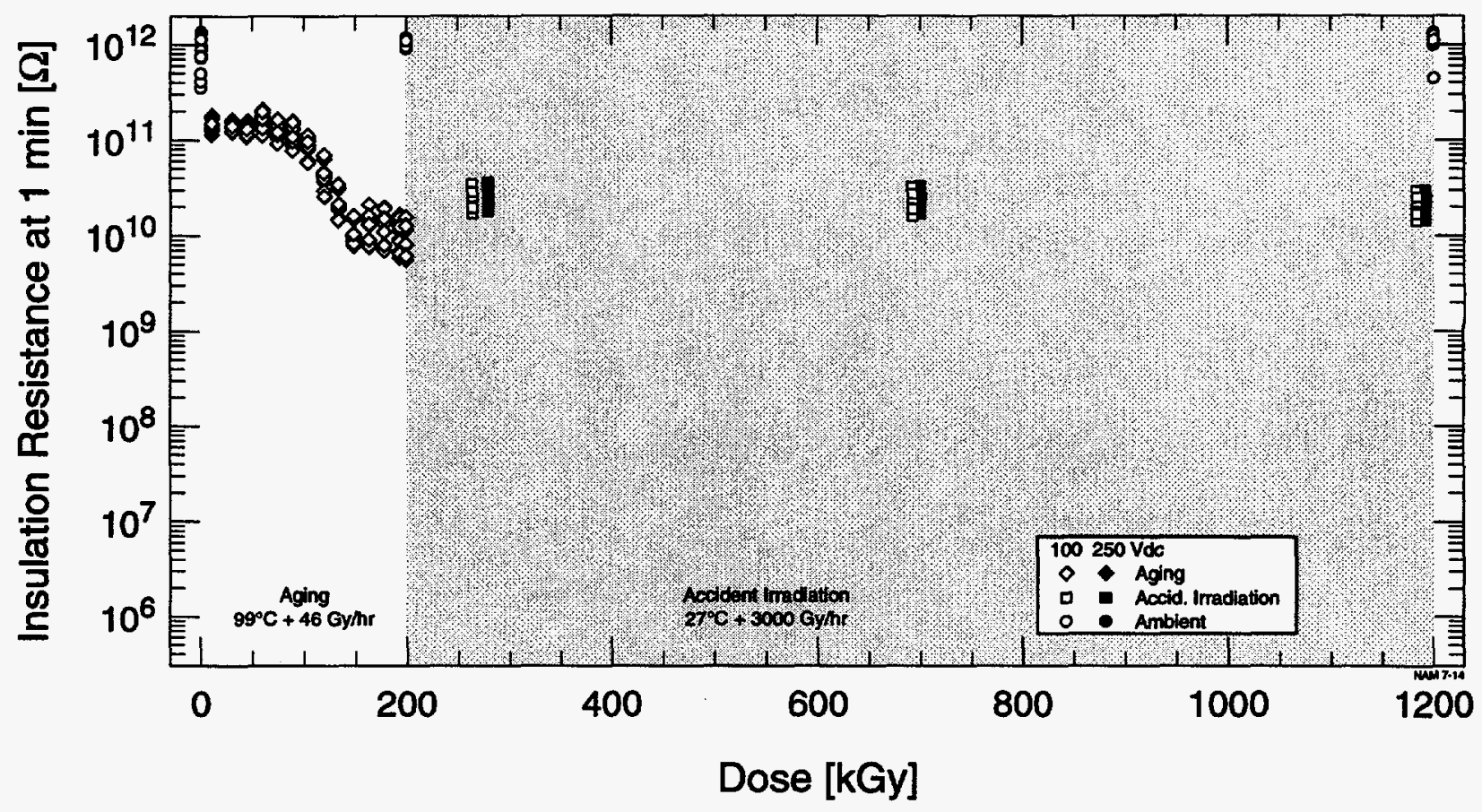

Figure 3.9: IR of the NAMCO EC210 connector conductors during aging and accident irradiation.

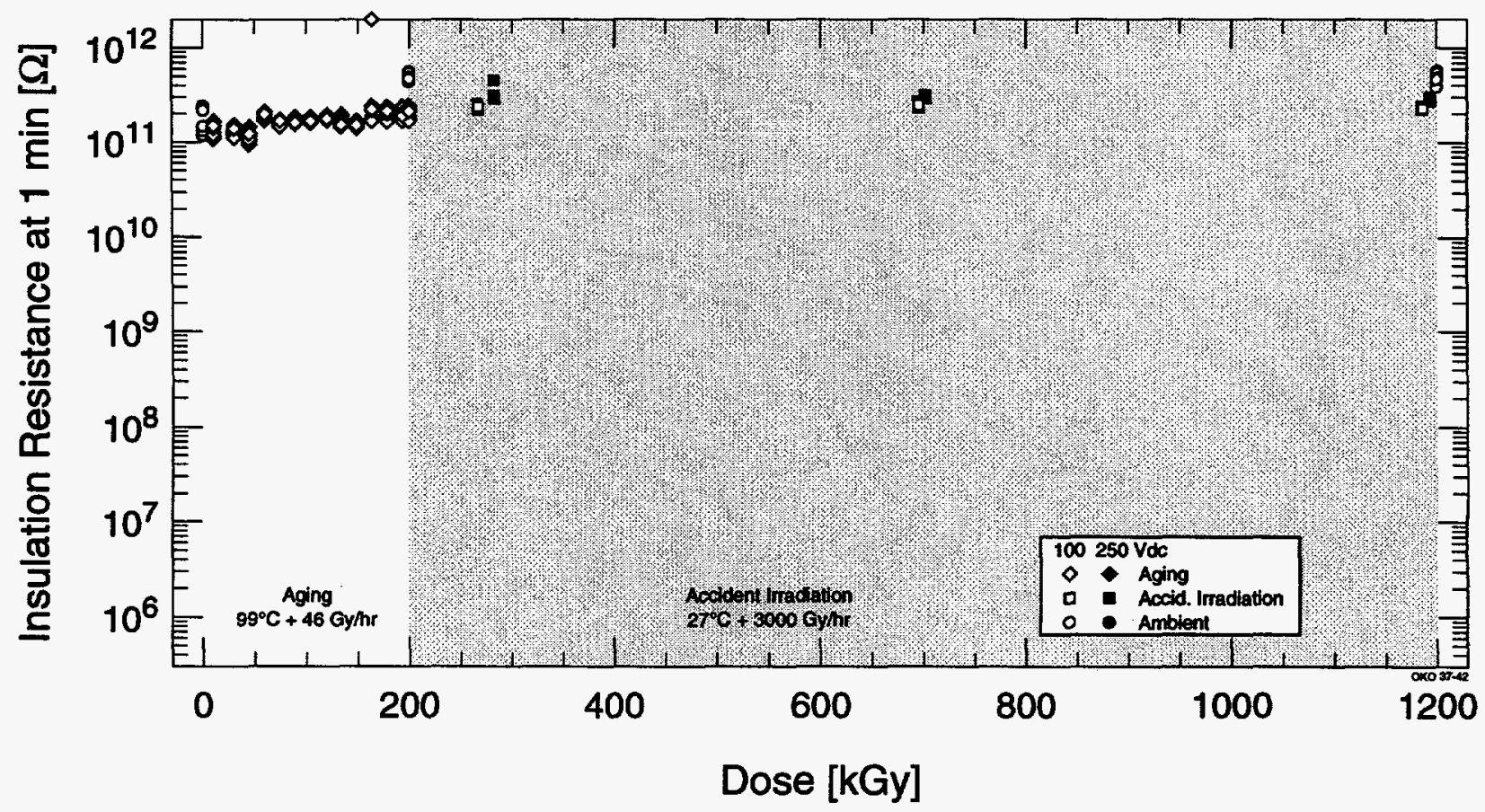

Figure 3.10: IR of the Okonite tape splice conductors during aging and accident irradiation. 


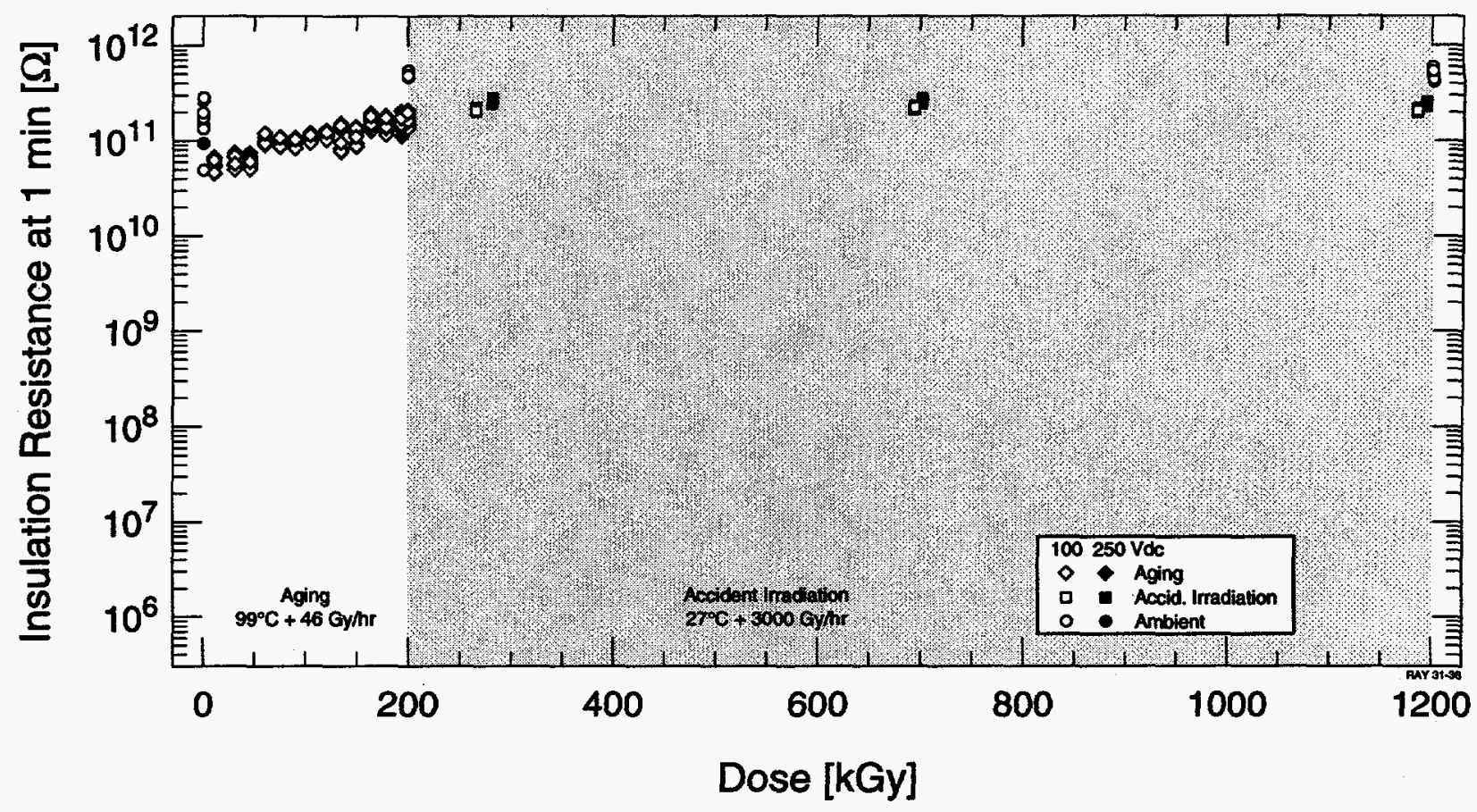

Figure 3.11: IR of the Raychem heat-shrink splice conductors during aging and accident irradiation.

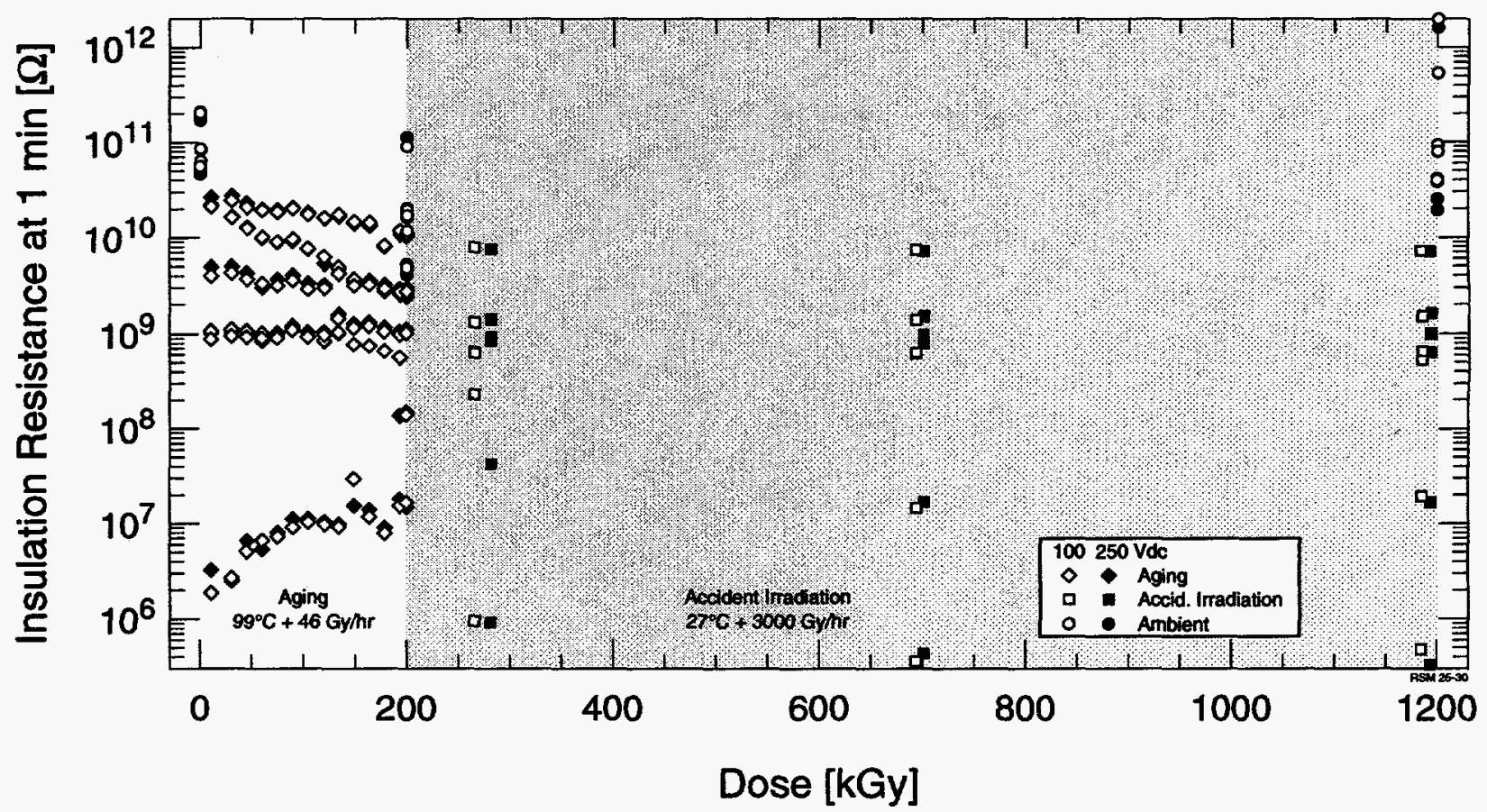

Figure 3.12: IR of the Rosemount 353C conduit seal conductors during aging and accident irradiation. 


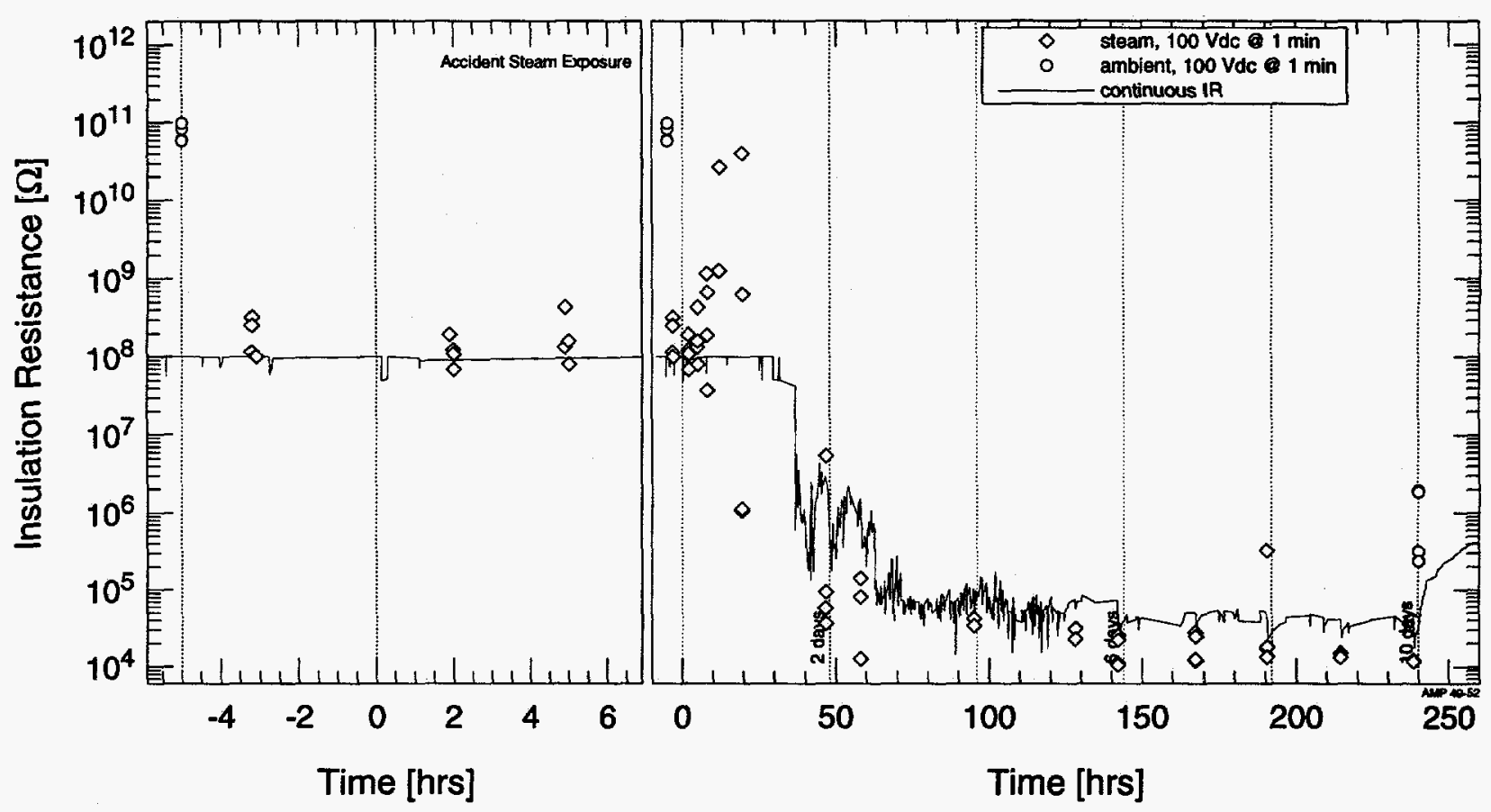

Figure 3.13: IR of the Amphenol coaxial connector conductors during the accident steam exposure.

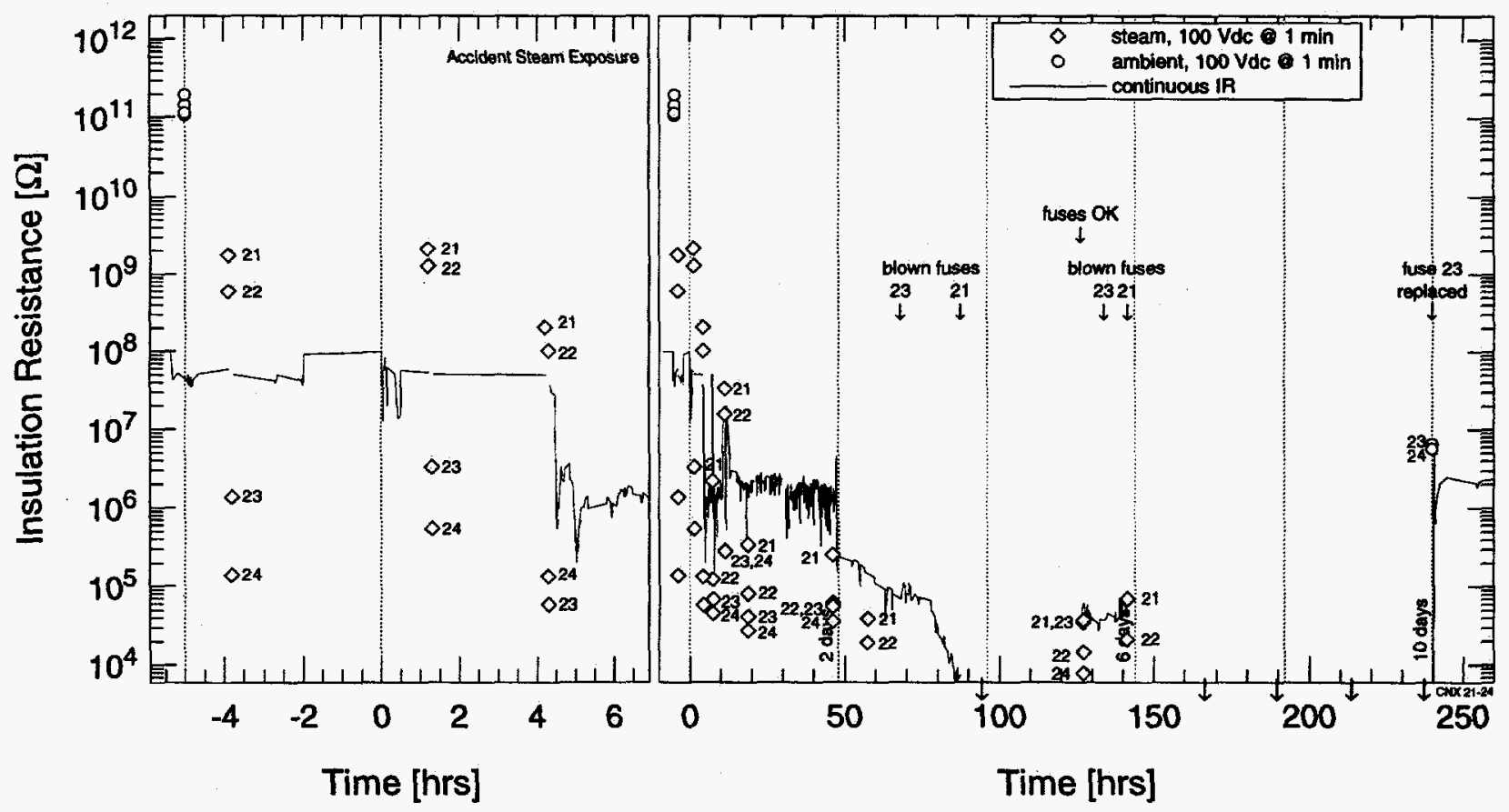

Figure 3.14: IR of the Conax Buffalo ECSA conduit seal conductors during the accident steam exposure. 


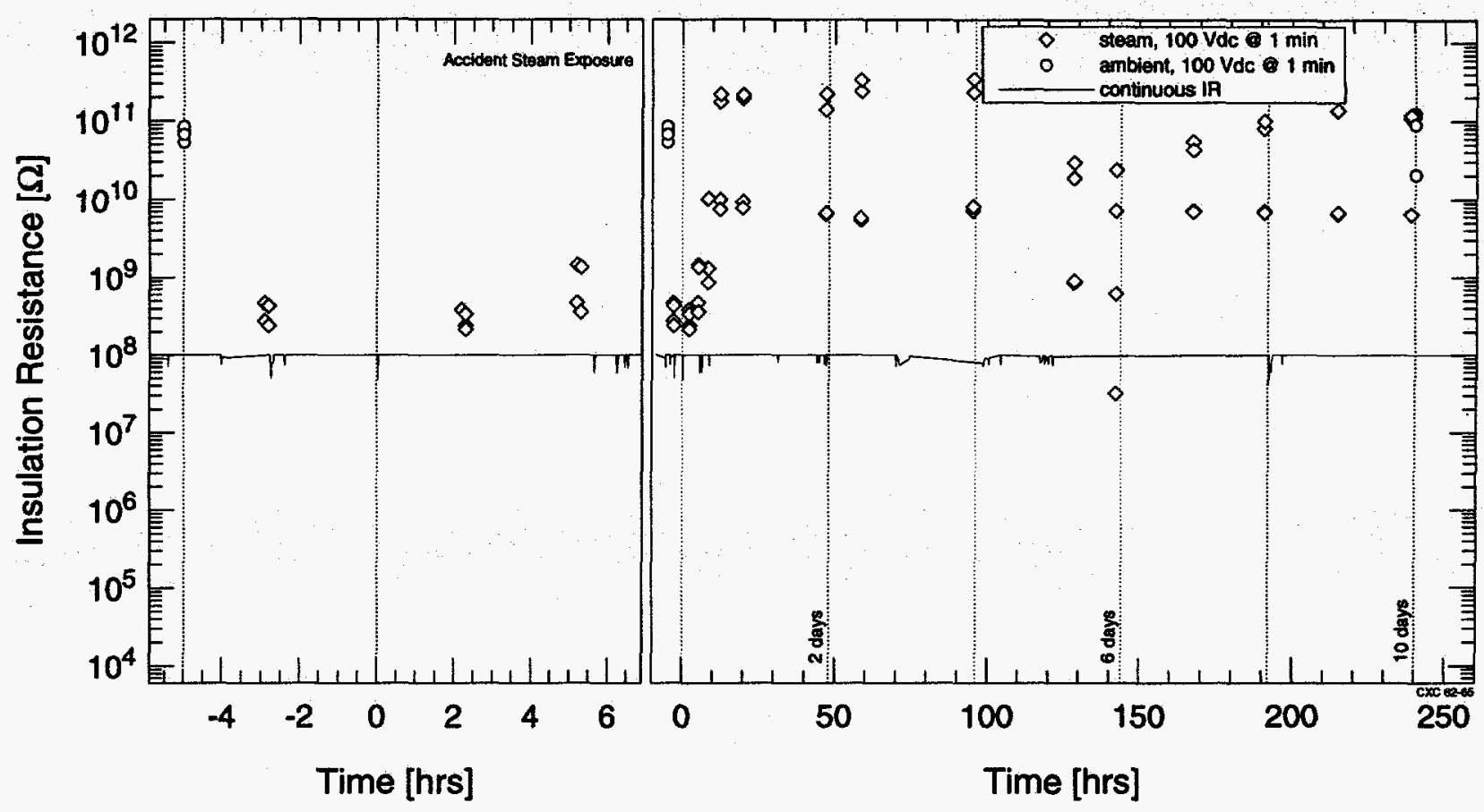

Figure 3.15: IR of the Rockbestos coaxial cable conductors during the accident steam exposure.

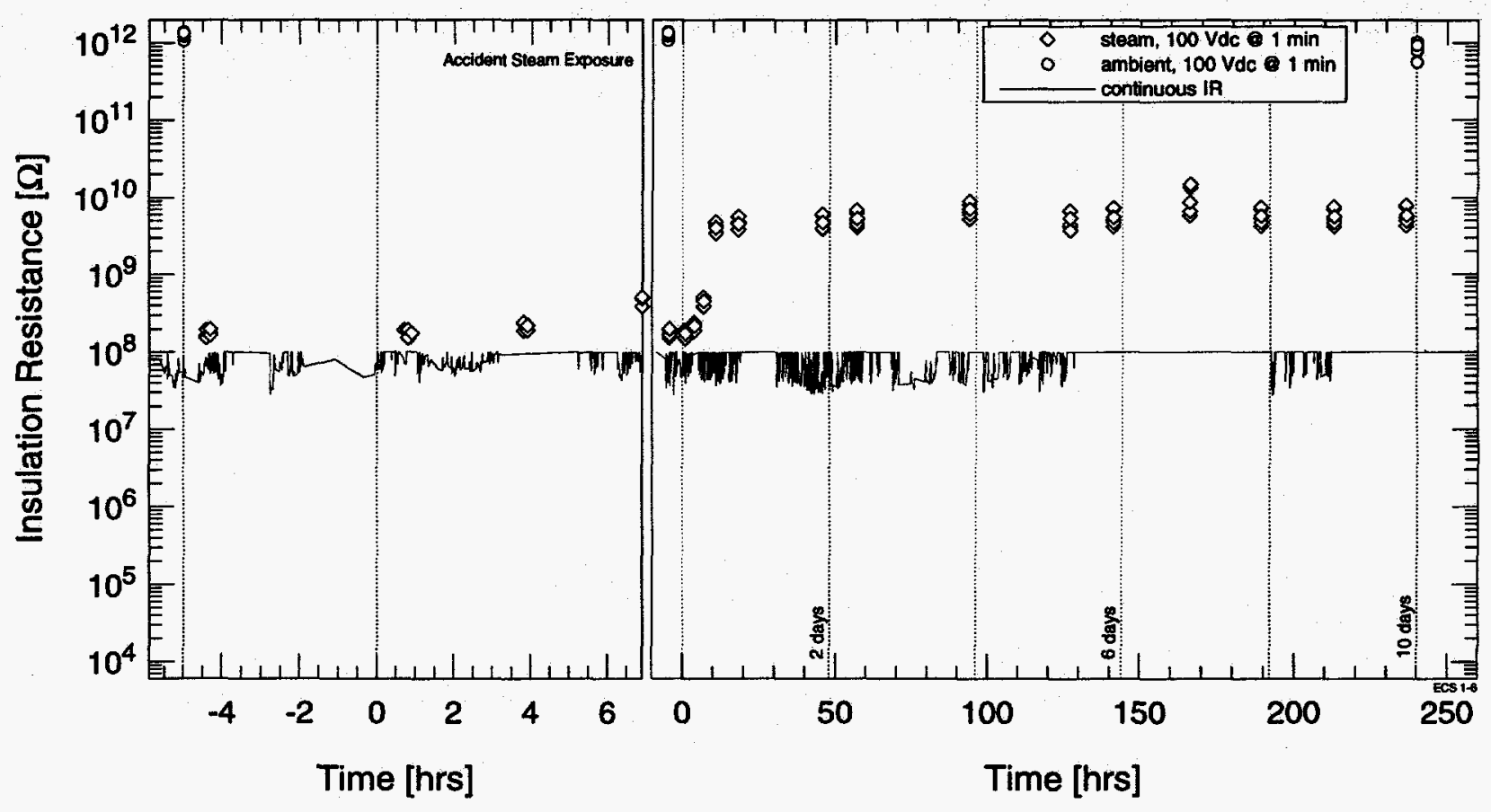

Figure 3.16: IR of the EGS conduit seal conductors during the accident steam exposure. 


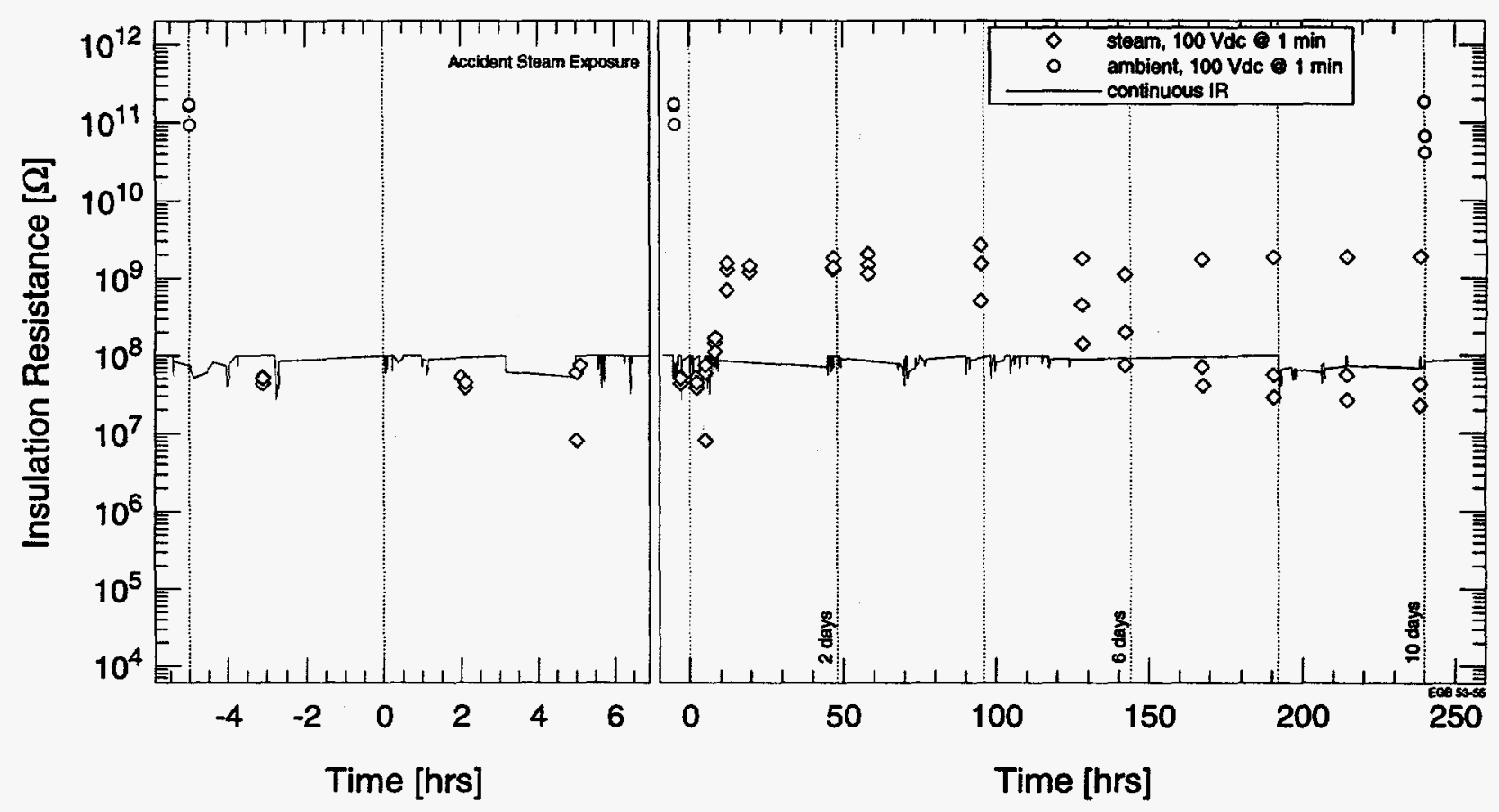

Figure 3.17: IR of the EGS Grayboot connector conductors during the accident steam exposure.

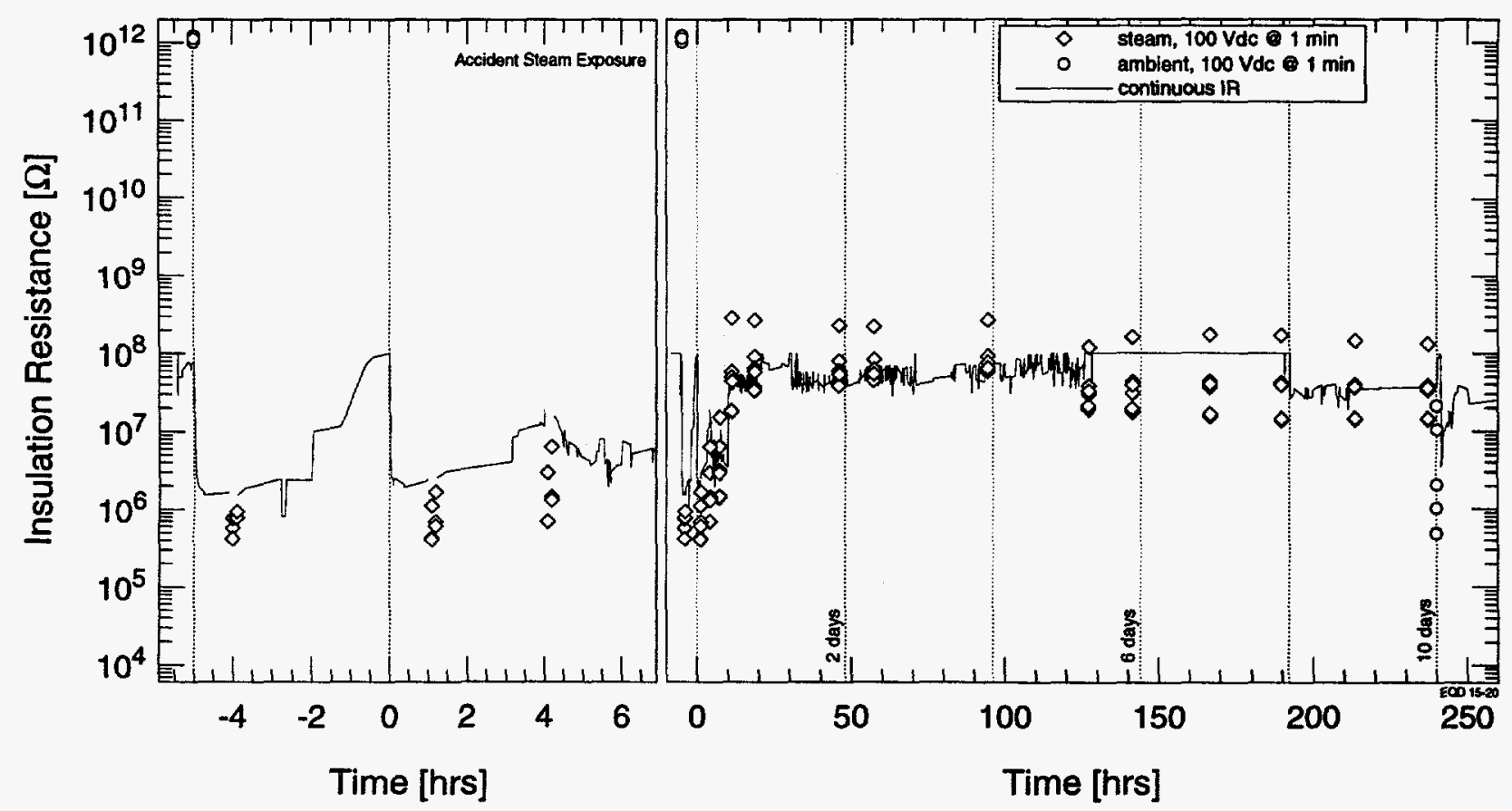

Figure 3.18: IR of the EGS quick-disconnect connector conductors during the accident steam exposure. 

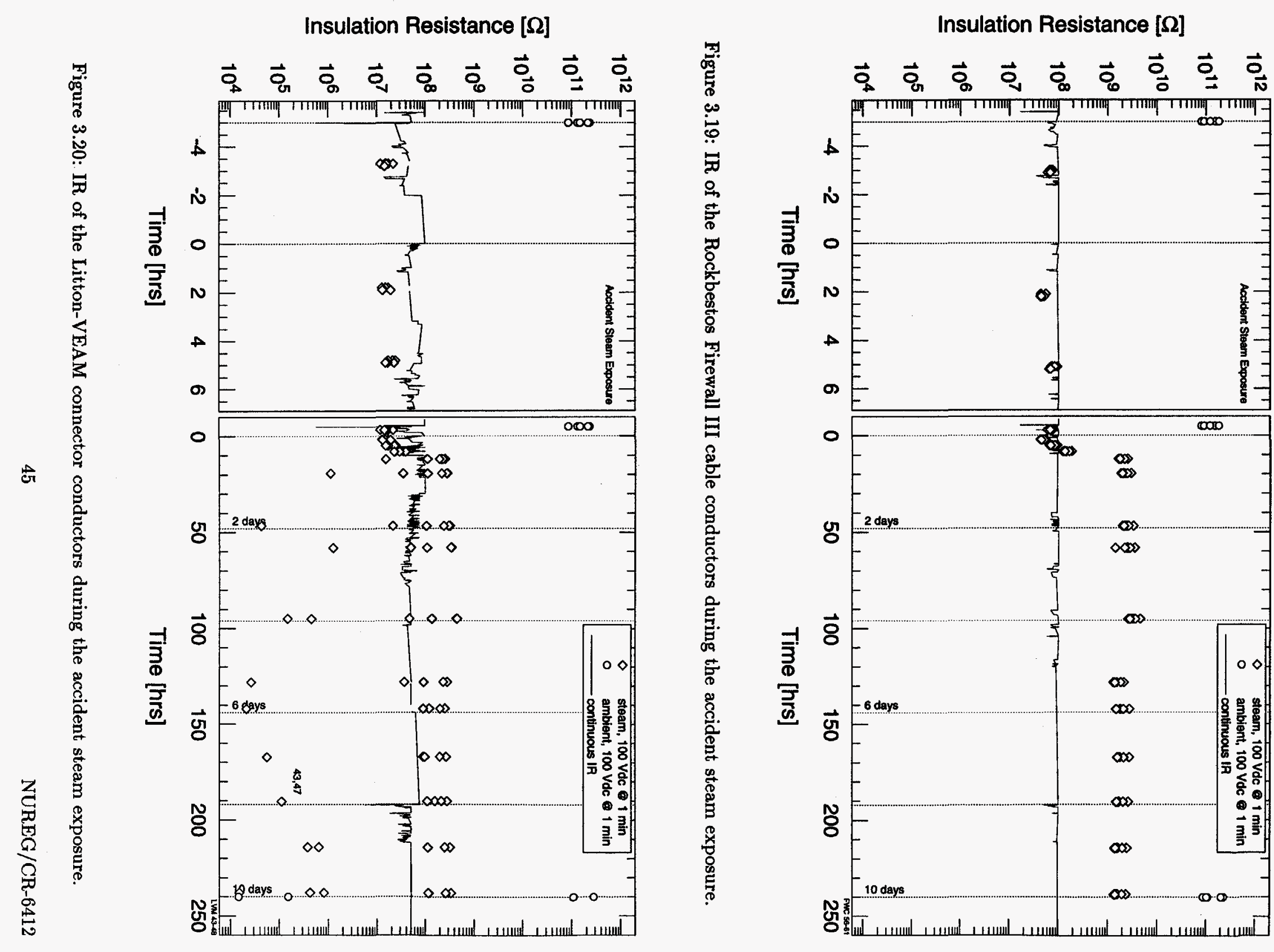


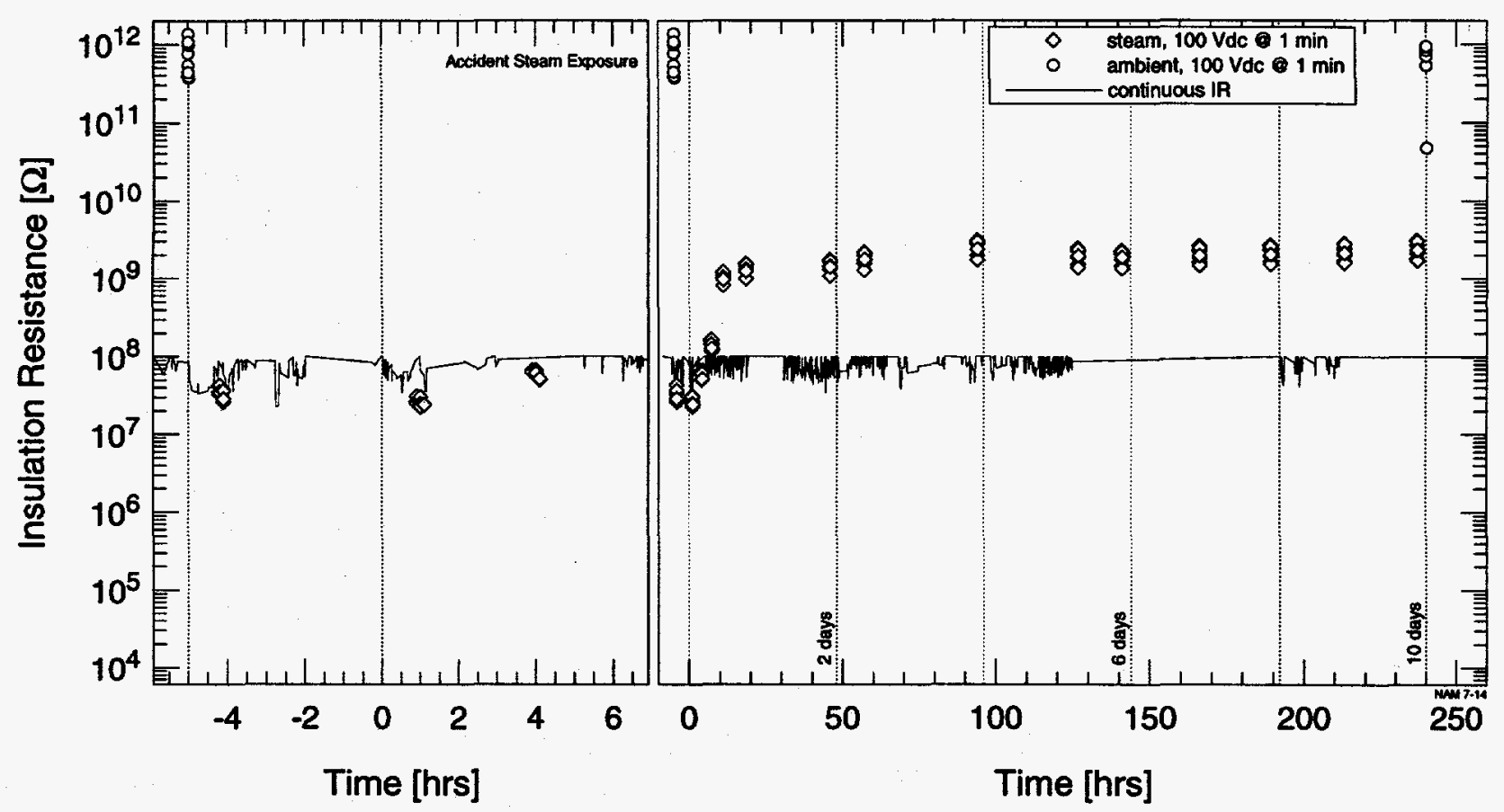

Figure 3.21: IR of the NAMCO EC210 connector conductors during the accident steam exposure.

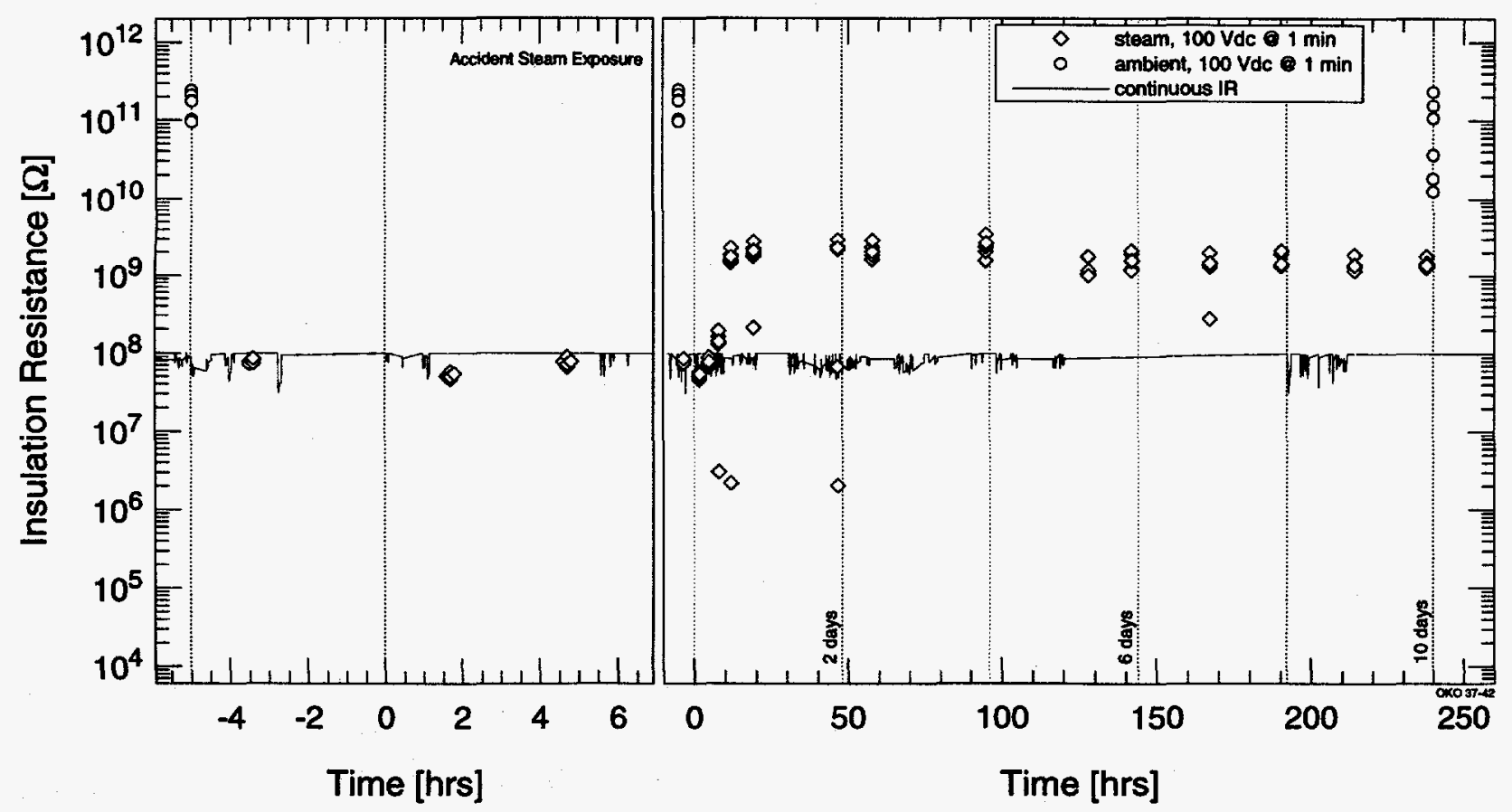

Figure 3.22: IR of the Okonite tape splice conductors during the accident steam exposure. 


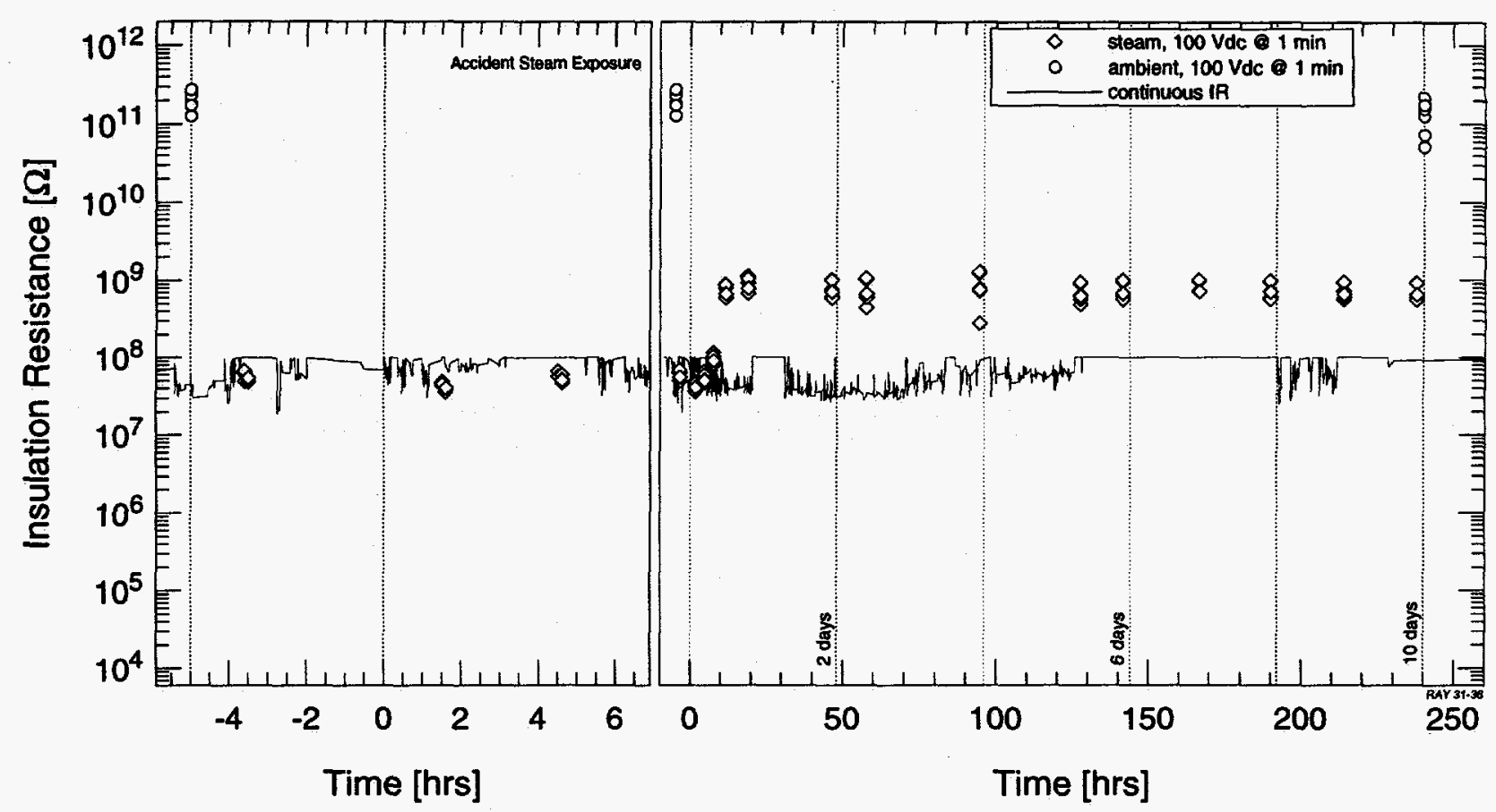

Figure 3.23: IR of the Raychem heat-shrink splice conductors during the accident steam exposure.

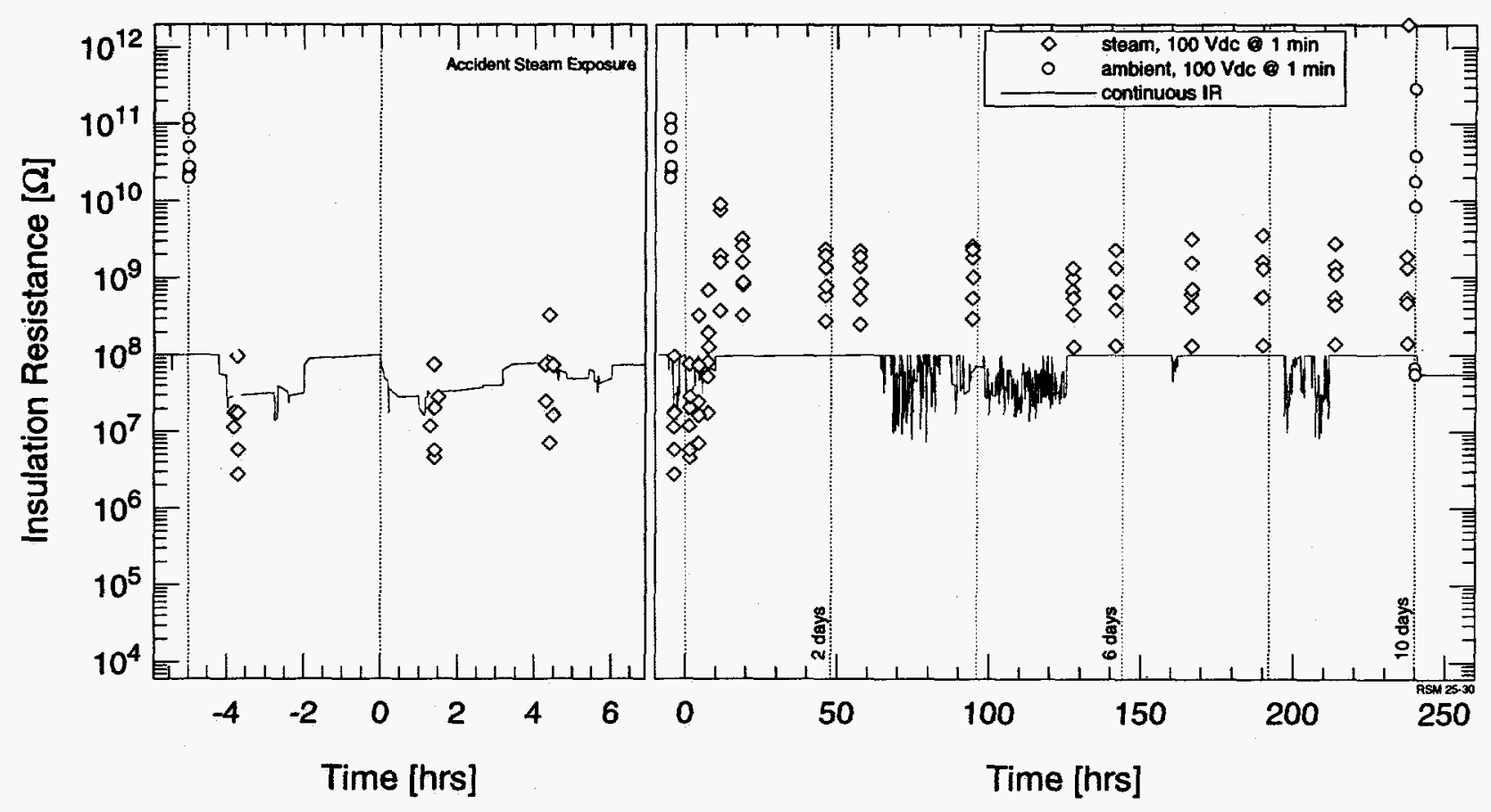

Figure 3.24: IR of the Rosemount 353C conduit seal conductors during the accident steam exposure. 


\section{EXPERIMENTAL RESULTS}

Table 3.2: Post-LOCA Test Results for Conductors 1 to 36 .

\begin{tabular}{|c|c|c|c|c|c|c|c|c|}
\hline \multirow[b]{4}{*}{ Conductor $^{a}$} & \multicolumn{4}{|c|}{$100 \mathrm{Vdc} I R$ at $1 \mathrm{~min}$} & \multirow{2}{*}{\multicolumn{4}{|c|}{$\begin{array}{c}\text { Dielectric Withstand (1-min hold period) } \\
\text { LOCA + } 23 \text { months }\end{array}$}} \\
\hline & \multirow{3}{*}{$\begin{array}{c}\text { LOCA } \\
+3 \text { days } \\
\text { Dry } \\
{[\Omega]}\end{array}$} & \multirow{2}{*}{\multicolumn{3}{|c|}{$\frac{\text { LOCA }+13 \text { months }}{\text { Submerged }}$}} & & & & \\
\hline & & & & & \multicolumn{2}{|c|}{ Dry } & \multicolumn{2}{|c|}{ 2-hr Submergence } \\
\hline & & $\begin{array}{l}\text { Dry } \\
{[\Omega]}\end{array}$ & $\begin{array}{l}30 \mathrm{~min} \\
{[\Omega]}\end{array}$ & $\begin{array}{c}3 \mathrm{hr} \\
{[\Omega]}\end{array}$ & $\begin{array}{l}\text { Voltage } \\
{[\mathrm{kVac}]}\end{array}$ & $\begin{array}{l}\text { Current } \\
{[\mathrm{mAac}]}\end{array}$ & $\begin{array}{l}\text { Voltage } \\
{[\mathrm{kVac}]}\end{array}$ & $\begin{array}{l}\text { Current } \\
{[\mathrm{mAac}]}\end{array}$ \\
\hline \multicolumn{9}{|c|}{ EGS conduit seal } \\
\hline 1 & $5.7 \mathrm{e} 11^{b}$ & $9.0 \mathrm{e} 11$ & $7.0 \mathrm{e} 11$ & 7.0e11 & 1.0 & 0.4 & 2.4 & 1.0 \\
\hline 2 & $7.9 \mathrm{e} 11$ & $1.1 \mathrm{e} 12$ & $9.1 \mathrm{e} 11$ & $9.2 \mathrm{e} 11$ & 1.0 & 0.4 & 2.4 & 1.0 \\
\hline 3 & $9.2 \mathrm{e} 11$ & $1.2 \mathrm{e} 12$ & $6.7 \mathrm{e} 11$ & $7.9 \mathrm{e} 11$ & 1.0 & 0.4 & 2.4 & 1.0 \\
\hline 4 & $1.0 \mathrm{e} 12$ & $9.2 \mathrm{e} 11$ & $2.1 \mathrm{e} 12$ & $1.1 \mathrm{e} 12$ & 1.0 & 0.4 & 2.4 & 1.1 \\
\hline 5 & $8.0 \mathrm{e} 11$ & $1.2 \mathrm{e} 12$ & $1.7 \mathrm{e} 12$ & $1.5 \mathrm{e} 12$ & 1.0 & 0.4 & 2.4 & 1.1 \\
\hline 6 & $9.4 \mathrm{e} 11$ & $1.1 \mathrm{e} 12$ & $1.6 \mathrm{e} 12$ & $1.7 \mathrm{e} 12$ & 1.0 & 0.4 & 2.4 & 1.1 \\
\hline \multicolumn{9}{|c|}{ NAMCO EC210 connector } \\
\hline 7 & $7.7 \mathrm{e} 11$ & $2.5 \mathrm{e} 06$ & $4.2 \mathrm{e} 06$ & $1.0 \mathrm{e} 07$ & 1.0 & 0.4 & 2.4 & 1.1 \\
\hline 8 & $7.4 \mathrm{e} 11$ & $2.7 \mathrm{e} 11$ & $1.9 \mathrm{e} 11$ & $1.7 \mathrm{e} 11$ & 1.0 & 0.4 & 2.4 & 1.2 \\
\hline 9 & $5.3 \mathrm{e} 11$ & $2.0 \mathrm{e} 09$ & $7.6 \mathrm{e} 08$ & $6.2 \mathrm{e} 08$ & 1.0 & 0.4 & 2.4 & 1.2 \\
\hline 10 & $6.9 \mathrm{e} 11$ & $1.9 \mathrm{e} 09$ & $8.8 \mathrm{e} 08$ & $7.3 \mathrm{e} 08$ & 1.0 & 0.4 & 2.4 & 1.1 \\
\hline 11 & $4.7 \mathrm{e} 10$ & 3.1e11 & $1.3 \mathrm{e} 11$ & $1.3 e 11$ & 1.0 & 0.4 & 2.4 & 1.1 \\
\hline 12 & $8.3 \mathrm{e} 11$ & $4.9 \mathrm{e} 11$ & $3.2 \mathrm{e} 11$ & $3.3 e 11$ & 1.0 & 0.4 & 2.4 & 1.1 \\
\hline 13 & $9.1 \mathrm{e} 11$ & $1.4 \mathrm{e} 11$ & $3.2 \mathrm{e} 10$ & $5.1 \mathrm{e} 10$ & 1.0 & 0.4 & 2.4 & 1.1 \\
\hline 14 & $9.3 \mathrm{e} 11$ & $3.8 \mathrm{e} 11$ & 2.1e11 & $2.2 \mathrm{e} 11$ & 1.0 & 0.4 & 2.4 & 1.1 \\
\hline \multicolumn{9}{|c|}{ EGS quick-disconnect connector } \\
\hline 15 & $5.0 \mathrm{e} 05$ & $3.3 \mathrm{e} 11$ & $3.9 \mathrm{e} 04$ & $1.1 \mathrm{e} 05$ & 1.0 & 0.4 & 2.4 & Trip \\
\hline 16 & $1.0 \mathrm{e} 06$ & $2.0 \mathrm{e} 10$ & $2.8 \mathrm{e} 04$ & $9.1 \mathrm{e} 04$ & 1.0 & 0.4 & 2.4 & Trip \\
\hline 17 & $1.1 \mathrm{e} 07$ & $2.5 \mathrm{e} 10$ & $2.0 \mathrm{e} 04$ & $6.5 \mathrm{e} 04$ & 1.0 & 0.4 & 2.4 & Trip \\
\hline 18 & $4.9 \mathrm{e} 05$ & $1.9 \mathrm{e} 10$ & $1.7 \mathrm{e} 05$ & $7.1 \mathrm{e} 04$ & 1.0 & 0.4 & 2.4 & 1.0 \\
\hline 19 & $2.1 \mathrm{e} 06$ & $2.6 \mathrm{e} 10$ & $6.3 \mathrm{e} 04$ & $3.3 e 04$ & 1.0 & 0.4 & 2.4 & Trip \\
\hline 20 & $2.1 \mathrm{e} 07$ & $1.2 \mathrm{e} 10$ & $6.7 \mathrm{e} 05$ & $3.5 \mathrm{e} 05$ & 1.0 & 0.4 & 2.4 & Trip \\
\hline \multicolumn{9}{|c|}{ Conax Buffalo ECSA conduit seal } \\
\hline 21 & $5.2 \mathrm{e} 01$ & $8.8 \mathrm{e} 05$ & $3.6 \mathrm{e} 03$ & $2.4 \mathrm{e} 03$ & 1.0 & Trip & 2.4 & Trip \\
\hline 22 & $1.5 \mathrm{e} 01$ & $1.2 \mathrm{e} 06$ & $2.2 \mathrm{e} 03$ & $2.0 \mathrm{e} 03$ & 1.0 & Trip & 2.4 & Trip \\
\hline 23 & $6.5 \mathrm{e} 06$ & $5.4 \mathrm{e} 06$ & $3.0 \mathrm{e} 04$ & $3.2 \mathrm{e} 04$ & 1.0 & Trip & 2.4 & Trip \\
\hline 24 & $5.7 \mathrm{e} 06$ & $6.2 \mathrm{e} 06$ & $8.1 \mathrm{e} 03$ & $7.5 \mathrm{e} 03$ & 1.0 & Trip & 2.4 & Trip \\
\hline \multicolumn{9}{|c|}{ Rosemount 353C conduit seal } \\
\hline 25 & $2.9 \mathrm{e} 11$ & $1.8 \mathrm{e} 11$ & $2.4 \mathrm{e} 11$ & $3.0 \mathrm{e} 11$ & 1.0 & 0.4 & 2.4 & 1.1 \\
\hline 26 & $1.8 \mathrm{e} 10$ & $3.4 \mathrm{e} 10$ & $8.1 \mathrm{e} 10$ & $1.9 \mathrm{e} 07$ & 1.0 & 0.4 & 2.4 & Trip \\
\hline 27 & $3.8 \mathrm{e} 10$ & $6.5 \mathrm{e} 10$ & $1.6 \mathrm{e} 11$ & $1.7 \mathrm{e} 11$ & 0.6 & 0.4 & 0.6 & 0.4 \\
\hline 28 & $6.7 \mathrm{e} 07$ & $5.2 \mathrm{e} 09$ & $3.5 \mathrm{e} 09$ & $4.7 \mathrm{e} 05$ & 1.0 & 0.4 & 2.4 & Trip \\
\hline 29 & $5.6 \mathrm{e} 07$ & $1.1 \mathrm{e} 10$ & $6.4 \mathrm{e} 10$ & $6.0 \mathrm{e} 05$ & 1.0 & 0.4 & 2.4 & Trip \\
\hline 30 & $8.4 \mathrm{e} 09$ & $1.4 \mathrm{e} 10$ & $6.3 \mathrm{e} 10$ & $4.1 \mathrm{e} 06$ & 0.6 & 0.4 & 0.6 & 0.6 \\
\hline \multicolumn{9}{|c|}{ Raychem heat-shrink splice } \\
\hline 31 & $1.3 \mathrm{e} 11$ & $2.5 \mathrm{e} 11$ & $2.7 \mathrm{e} 11$ & $3.1 \mathrm{e} 11$ & 1.0 & 0.8 & 2.4 & 2.1 \\
\hline 32 & $5.2 \mathrm{e} 10$ & $2.0 \mathrm{e} 11$ & $2.7 \mathrm{e} 11$ & $3.2 \mathrm{e} 11$ & 1.0 & 0.8 & 2.4 & 2.1 \\
\hline 33 & $1.6 \mathrm{e} 11$ & $2.5 \mathrm{e} 11$ & $3.9 \mathrm{e} 11$ & $3.8 \mathrm{e} 11$ & 1.0 & 0.8 & 2.4 & 2.1 \\
\hline 34 & $2.2 \mathrm{e} 11$ & $3.2 \mathrm{e} 11$ & 3.3e11 & $3.8 \mathrm{e} 11$ & 1.0 & 0.9 & 2.4 & 2.3 \\
\hline 35 & $7.4 \mathrm{e} 10$ & $9.4 \mathrm{e} 10$ & $1.5 \mathrm{e} 11$ & $2.1 \mathrm{e} 11$ & 1.0 & 0.9 & 2.4 & 2.2 \\
\hline 36 & $1.8 \mathrm{e} 11$ & $2.2 \mathrm{e} 11$ & $3.1 \mathrm{e} 11$ & $3.0 \mathrm{e} 11$ & 1.0 & 0.9 & 2.4 & 2.3 \\
\hline
\end{tabular}

${ }^{a}$ See Table 2.3 for additional information about each conductor.

${ }^{b}$ The entry $5.7 \mathrm{e} 11$ is a shorthand notation for the value $5.7 \times 10^{11}$. 
Table 3.3: Post-LOCA Test Results for Conductors 37 to 65 .

\begin{tabular}{|c|c|c|c|c|c|c|c|c|}
\hline \multirow[b]{4}{*}{ Conductor $^{a}$} & \multicolumn{4}{|c|}{$100 \mathrm{Vdc} I R$ at $1 \mathrm{~min}$} & \multirow{2}{*}{\multicolumn{4}{|c|}{$\begin{array}{c}\text { Dielectric Withstand (1-min hold period) } \\
\text { LOCA }+23 \text { months }\end{array}$}} \\
\hline & \multirow{3}{*}{$\begin{array}{c}\text { LOCA } \\
+3 \text { days } \\
\text { Dry } \\
{[\Omega]}\end{array}$} & \multirow{2}{*}{\multicolumn{3}{|c|}{$\begin{array}{r}\text { LOCA }+13 \text { months } \\
\text { Submerged }\end{array}$}} & & & & \\
\hline & & & & & \multicolumn{2}{|c|}{ Dry } & \multicolumn{2}{|c|}{ 2-hr Submergence } \\
\hline & & $\begin{array}{l}\text { Dry } \\
{[\Omega]}\end{array}$ & $\begin{array}{c}30 \mathrm{~min} \\
{[\Omega]}\end{array}$ & $\begin{array}{l}3 \mathrm{hr} \\
{[\Omega]}\end{array}$ & $\begin{array}{l}\text { Voltage } \\
{[\mathrm{kVac}]}\end{array}$ & $\begin{array}{l}\text { Current } \\
\text { [mAac] }\end{array}$ & $\begin{array}{l}\text { Voltage } \\
{[\mathrm{kVac}]}\end{array}$ & $\begin{array}{l}\text { Current } \\
\text { [mAac] }\end{array}$ \\
\hline \multicolumn{9}{|c|}{ Okonite tape splice } \\
\hline 37 & $2.3 \mathrm{e} 11^{b}$ & $1.9 \mathrm{e} 11$ & $4.8 \mathrm{e} 11$ & $4.8 \mathrm{e} 11$ & 1.0 & 0.9 & 2.4 & 2.3 \\
\hline 38 & $3.6 \mathrm{e} 10$ & $1.0 \mathrm{e} 11$ & $2.3 \mathrm{e} 11$ & $3.0 \mathrm{e} 11$ & 1.0 & 0.8 & 2.4 & 2.3 \\
\hline 39 & $1.3 \mathrm{e} 10$ & $1.3 \mathrm{e} 11$ & $2.5 \mathrm{e} 11$ & 3.1e11 & 1.0 & 0.9 & 2.4 & 2.3 \\
\hline 40 & $1.8 \mathrm{e} 10$ & $1.0 \mathrm{e} 11$ & $1.9 \mathrm{e} 11$ & $2.3 \mathrm{e} 11$ & 1.0 & 0.9 & 2.4 & 2.4 \\
\hline 41 & 1.1e11 & $1.1 \mathrm{e} 11$ & $2.5 \mathrm{e} 11$ & $3.0 \mathrm{e} 11$ & 1.0 & 0.9 & 2.4 & 2.3 \\
\hline 42 & $1.5 \mathrm{e} 11$ & $2.1 \mathrm{e} 11$ & $5.1 \mathrm{e} 11$ & $4.4 \mathrm{e} 11$ & 1.0 & 0.9 & 2.4 & 2.4 \\
\hline \multicolumn{9}{|c|}{ Litton-VEAM connector } \\
\hline 43 & $1.0 \mathrm{e} 03$ & $9.2 \mathrm{e} 05$ & $2.2 \mathrm{e} 02$ & $7.0 \mathrm{e} 01$ & 1.0 & Trip & 2.4 & Trip \\
\hline 44 & $2.8 \mathrm{e} 11$ & $3.6 \mathrm{e} 07$ & $5.6 \mathrm{e} 03$ & $7.9 \mathrm{e} 03$ & 1.0 & 0.7 & 2.4 & Trip \\
\hline 45 & $6.0 \mathrm{e} 03$ & $6.5 \mathrm{e} 05$ & $8.8 \mathrm{e} 01$ & $6.9 \mathrm{e} 01$ & 1.0 & Trip & 2.4 & Trip \\
\hline 46 & $1.1 \mathrm{e} 11$ & $1.2 \mathrm{e} 11$ & $6.9 \mathrm{e} 04$ & $6.0 \mathrm{e} 04$ & 1.0 & 0.7 & 2.4 & Trip \\
\hline 47 & $1.5 \mathrm{e} 04$ & $2.0 e 10$ & $4.0 \mathrm{e} 03$ & $4.4 \mathrm{e} 03$ & 1.0 & 0.7 & 2.4 & Trip \\
\hline 48 & $1.5 \mathrm{e} 05$ & $2.1 \mathrm{e} 11$ & $1.2 \mathrm{e} 04$ & $2.1 \mathrm{e} 04$ & 1.0 & 0.7 & 2.4 & Trip \\
\hline \multicolumn{9}{|c|}{ Amphenol coaxial connector } \\
\hline 49 & $1.9 \mathrm{e} 06$ & $7.6 \mathrm{e} 07$ & $7.9 \mathrm{e} 07$ & $8.8 \mathrm{e} 07$ & 1.0 & 0.6 & 2.4 & Trip \\
\hline 50 & $1.9 \mathrm{e} 06$ & $8.0 \mathrm{e} 07$ & $3.6 \mathrm{e} 04$ & $3.6 \mathrm{e} 04$ & 0.6 & 0.8 & 0.6 & Trip \\
\hline 51 & $3.2 \mathrm{e} 05$ & $3.9 \mathrm{e} 05$ & $3.6 \mathrm{e} 05$ & $4.1 \mathrm{e} 05$ & 1.0 & Trip & 2.4 & Trip \\
\hline 52 & $2.4 \mathrm{e} 05$ & $7.7 \mathrm{e} 05$ & $1.3 \mathrm{e} 04$ & $1.1 \mathrm{e} 04$ & 0.6 & Trip & 0.6 . & Trip \\
\hline \multicolumn{9}{|c|}{ EGS Grayboot connector } \\
\hline 53 & $4.1 \mathrm{e} 10$ & $1.9 \mathrm{e} 11$ & $3.2 \mathrm{e} 11$ & $4.1 e 11$ & 1.0 & 0.7 & 2.4 & 2.1 \\
\hline 54 & $6.8 \mathrm{e} 10$ & $2.4 \mathrm{e} 11$ & 2.1e11 & $2.2 \mathrm{e} 11$ & 1.0 & 0.7 & 2.4 & 2.1 \\
\hline 55 & $1.9 \mathrm{e} 11$ & $2.5 \mathrm{e} 11$ & $1.9 \mathrm{e} 11$ & $1.9 \mathrm{e} 11$ & 1.0 & 0.7 & 2.4 & 2.1 \\
\hline \multicolumn{9}{|c|}{ Rockbestos Firewall III cable } \\
\hline 56 & $2.3 \mathrm{e} 11$ & $3.2 \mathrm{e} 11$ & $5.8 \mathrm{e} 11$ & $4.9 \mathrm{e} 11$ & 1.0 & 0.8 & 2.4 & 2.0 \\
\hline 57 & $1.0 \mathrm{e} 11$ & $2.1 \mathrm{e} 11$ & $3.8 \mathrm{e} 11$ & $4.0 \mathrm{e} 11$ & 1.0 & 0.8 & 2.4 & 2.0 \\
\hline 58 & $2.0 \mathrm{e} 11$ & $2.4 \mathrm{e} 11$ & $4.1 \mathrm{e} 11$ & $3.9 \mathrm{e} 11$ & 1.0 & 0.8 & 2.4 & 2.0 \\
\hline 59 & $8.8 \mathrm{e} 10$ & $2.2 \mathrm{e} 11$ & $3.9 \mathrm{e} 11$ & $4.7 \mathrm{e} 11$ & 1.0 & 0.8 & 2.4 & 2.1 \\
\hline 60 & $1.1 \mathrm{e} 11$ & $1.9 \mathrm{e} 11$ & $3.2 \mathrm{e} 11$ & $3.7 \mathrm{e} 11$ & 1.0 & 0.8 & 2.4 & 2.1 \\
\hline 61 & $1.0 \mathrm{e} 11$ & $3.3 \mathrm{e} 11$ & $4.9 \mathrm{e} 11$ & $4.1 \mathrm{e} 11$ & 1.0 & 0.8 & 2.4 & 2.1 \\
\hline \multicolumn{9}{|c|}{ Rockbestos coaxial cable } \\
\hline 62 & $1.3 \mathrm{e} 11$ & $2.5 \mathrm{e} 11$ & $9.7 \mathrm{e} 11$ & $5.8 \mathrm{e} 11$ & 1.0 & 0.7 & 2.4 & 1.7 \\
\hline 63 & $1.2 \mathrm{e} 11$ & 2.1e11 & $3.4 \mathrm{e} 11$ & $3.0 \mathrm{e} 11$ & 0.6 & 0.9 & 0.6 & 1.0 \\
\hline 64 & $2.1 \mathrm{e} 10$ & $9.2 \mathrm{e} 10$ & $2.9 \mathrm{e} 11$ & $2.3 \mathrm{e} 11$ & 1.0 & 0.7 & 2.4 & 1.7 \\
\hline 65 & $9.1 e 10$ & $2.1 \mathrm{e} 11$ & $3.8 \mathrm{e} 11$ & $3.5 \mathrm{e} 11$ & 0.6 & 0.8 & 0.6 & 1.0 \\
\hline
\end{tabular}

a See Table 2.3 for additional information about each conductor.

${ }^{b}$ The entry $2.3 e 11$ is a shorthand notation for the value $2.3 \times 10^{11}$. 



\section{SUMMARY AND CONCLUSIONS}

This report presents the results of an experimental program to determine the aging and loss-of-coolant accident (LOCA) behavior of electrical connections in order to obtain an initial scoping of their performance. Ten types of connections commonly used in nuclear power plants were tested. These included 3 types of conduit seals, 2 types of cable-to-device connectors, 3 types of cable-to-cable connectors, and 2 types of in-line splices.

While the 6-month period of simultaneous radiation and thermal aging at $99^{\circ} \mathrm{C}\left(210^{\circ} \mathrm{F}\right)$ and $46 \mathrm{~Gy} / \mathrm{hr}(4.6 \mathrm{krad} / \mathrm{hr})$ was chosen to nominally simulate a plant environment for 60 years at $55^{\circ} \mathrm{C}$ $\left(131^{\circ} \mathrm{F}\right)$ and a dose of $200 \mathrm{kGy}(20 \mathrm{Mrad})$, the actual equivalent thermal aging ranged from 60 years at $28^{\circ} \mathrm{C}\left(82^{\circ} \mathrm{F}\right)$ for the Okonite tape splice to 60 years at $85^{\circ} \mathrm{C}\left(185^{\circ} \mathrm{F}\right)$ for the Conax Buffalo ECSA conduit seal (Table 2.5 and Figure 2.8 give a complete listing of the equivalent aging for all the connections). While it would have been desirable to age each of the connections to exactly 60 years at $55^{\circ} \mathrm{C}$ based upon each manufacturer's claimed activation energy, this was not possible because of time and scope considerations. Instead, a compromise was made by aging all of the connections at the same time in a single test chamber; this led to some of the connections being aged to less than, and some being aged to more than, the nominal conditions of 60 years at $55^{\circ} \mathrm{C}$. The simultaneous aging was followed by a LOCA simulation consisting of a 1000-kGy (100-Mrad) accident radiation exposure followed by an accident steam exposure.

In general, there was no meaningful degradation in the measured insulation resistance (IR) of the connections during the aging and accident irradiation exposures. Of the 55 connection conductors, only the IR of one Conax Buffalo ECSA conduit seal conductor and two Rosemount 353C conduit seal conductors fell below $10^{7} \Omega$ during aging and the accident irradiation exposure. ${ }^{1}$ In addition, the snap-on plastic covers used on the EGS Grayboot connector quickly became very brittle during aging, and will easily break apart and fall off. This had no effect on the

\footnotetext{
${ }^{1}$ Whether degraded IR values will affect the operability of an electrical circuit is plant and circuit dependent, and is thus beyond the scope of this report.
}

measured IR values and the covers are not required by the manufacturer. However, if the covers are required for seismic reasons or to prevent the connector from pulling apart, then premature aging could lead to problems.

The IR for most of the connections also remained high during the accident steam exposure. Only the four Conax Buffalo ECSA conduit seal conductors gave extremely low IR values $(<100 \Omega)$; the two nongrounded conductors repeatedly blew 1-A fuses when energized at $110 \mathrm{Vdc}$. However, post-test examination showed that these low IR values were produced by degraded Kapton-insulated cable leads; the IR of the actual conduit seals remained at levels above $10^{10} \Omega$. After the initial steam transients, only 3 of 6 Litton-VEAM connector conductors and all four Amphenol coaxial connector conductors had IR values that fell below $10^{7} \Omega$ (in addition to the four Conax Buffalo ECSA conduit seal conductors).

Post-test examination showed that the O-ring seals used in the Litton-VEAM connector were brittle and had experienced compression set, thereby reducing their sealing ability and allowing moisture to enter the connector body. The Rockbestos coaxial cable used with the Amphenol coaxial connector appears to allow moisture to permeate its jacket and then get into the unsealed connector by wicking along the braided shield. No explanation for the behavior of the

Rosemount 353C conduit seal was found during the post-test examination.

After completion of the LOCA exposure, a large fraction of the cable jackets were cracked, allowing easy ingress of moisture into the cables and possibly into the connections. While the connections are designed to stop this from occurring, the moisture in the cables is an additional environmental stressor and also makes any failure of the connection's internal seals more likely to affect circuit performance. Generally, the main function of a cable jacket is to protect the insulation during cable installation and no credit is taken for the jacket during environmental qualification testing. In fact, cracks or other breaches of the cable jacket may not be reported during such tests because they do not affect the cable's functionality. Situations where cable jacket 


\section{SUMMARY AND CONCLUSIONS}

integrity may be significant include beta radiation shielding, retention of shield integrity for shielded cables, and the possibility of jacket-insulation interactions for bonded-jacket cables. The results of the tests indicate that cable jacket integrity may also be important for connections because of possible intrusion of moisture into the connection.

After completion of the aging and accident exposures, submerged dielectric withstand testing was performed on the connections as required in IEEE 383-1974 [17], which also requires that equipment be installed in a manner that simulates its expected installation when in actual use. Because research testing does not apply to any specific installation, it must be performed using environments and device configurations that represent a reasonable expectation of what might actually be encountered in a plant; there are many plausible scenarios where connections could be subjected to submergence. Splices and cable-to-cable connectors can be installed anywhere along a cable run; thus these devices are as likely as a cable to be subjected to submergence. Because conduits are normally vented to the environment through a junction box, conduit seals are used as a moisture barrier between the conduit and the inside of a component. Anecdotes abound of incidents where trapped water poured out when a conduit was opened.

Half of the 10 connection types did not pass the post-LOCA, submerged dielectric withstand test:

- Essentially all the conductors in the Conax Buffalo ECSA conduit seals, Rosemount 353C conduit seals, EGS quick-disconnect connectors, Amphenol coaxial connectors, and Litton-VEAM connectors tripped the dielectric test set.

- None of the conductors in the EGS conduit seals, NAMCO EC210 connectors, EGS Grayboot connectors, Okonite tape splices, or Raychem heat-shrink splices tripped the test set.

Note that the problems were not limited to any one family of electrical connections; at least one connection from each of several of the families (conduit seals, cable-to-device connectors, and cable-to-cable connectors) was unable to pass the submerged dielectric withstand test.

If connections are used in applications where there is no possibility of submergence, the results of the submerged dielectric withstand testing are not relevant to the connection's ability to perform its intended functions. One must always know what specific applications and environmental conditions are relevant before using the results of a specific test for all possible uses of a device. It should also be noted that:

- If the environmental conditions of interest are less severe than those described in this report, then conclusions based upon these results cannot be substantiated. By their very nature, connections are usually easy to replace or service and thus in many applications they will be exposed to much less aging than complete cable runs, which are usually intended to remain in service for the entire life of a plant.

- Even though some of the problems identified in this report appear to be caused by cabling instead of the connection itself, it is important to remember that a problem anywhere in the entire cable-connection system will keep a system from being able to perform its intended function. Connections with Kapton-insulated cable leads may be more susceptible to such system-level problems because Kapton is relatively fragile.

Further detailed investigation of electrical connections is warranted and is being initiated because of the reduced IR values that occurred during the simulated nominal life of 60 years and the ensuing LOCA exposure, and the fact that $50 \%$ of the connection types were unable to successfully pass the subsequent submerged dielectric withstand test. This additional research will provide information on the accident performance of unaged cable-connection systems and also systems aged to conditions less severe than those used in this report. 


\section{REFERENCES}

[1] American Society for Testing and Materials, "Standard Practice for Application of Thermoluminescence-Dosimetry (TLD) Systems for Determining Absorbed Dose in Radiation-Hardness Testing of Electronic Devices," ASTM E668-93, Philadelphia, PA.

[2] Amphenol Corp., "RF Connector Assembly Instructions," F122-00212 Issue 1A (Interim), Amphenol RF/Microwave Operations, Danbury, CT, Jan. 1988, 78 pp.

[3] Buckalew, W.H., "Cobalt-60 Simulation of LOCA Radiation Effects," NUREG/CR-5231, SAND88-1054, Sandia National Laboratories, Albuquerque, NM, July 1989.

[4] See p. 56.

[5] See p. 56 .

[6] Craft, C.M., "Screening Tests of Terminal Block Performance in a Simulated LOCA Environment," NUREG/CR-3418, SAND83-1617, Sandia National Laboratories, Albuquerque, NM, Aug. 1984, 260 pp.

[7] Craft, C.M., "An Assessment of Terminal Blocks in the Nuclear Power Industry," NUREG/CR-3691, SAND84-0422, Sandia National Laboratories, Albuquerque, NM, Sep. 1984, 127 pp.

[8] Dillard, C.R. and Goldberg, D.E., Chemistry, 2nd ed., Macmillan Publishing Co., Inc., New York, NY, ISBN 0-02-329580-5, 1978, 756 pp.

[9] EGS Corp. International, "Installation and Maintenance Instructions for Patel/EGS Conduit Seals," Report No. EGS-TR-841215-01, EGS Corp. International, Huntsville, AL, Apr. 1990.

[10] EGS Corp. International, "Instructions for Installation of EGS/Patel 880701-B Bayonet Connector," Report No. EGS-TR-880706-01, EGS Corp. International, Huntsville, AL, Sep. 1990.

[11] EGS Corp. International, "Test Report for EGS GRAYBOOT Connectors Models GB-1, GB-2, and GB-3," Report No.

EGS-TR-880707-04, EGS Corp. International, Huntsville, AL, Dec. 1990.
[12] EGS Corp. International, "Installation and Removal Instructions for EGS GRAYBOOT Connectors," Report No. EGS-TR-880707-02, Rev. C, EGS Corp. International, Huntsville, AL, Aug. 1991.

[13] Franklin Research Center, "A Review of Equipment Aging Theory and Technology," Electric Power Research Institute Report EPRI NP-1558, Palo Alto, CA, Sep. 1980.

[14] Gillen, K.T., R.L. Clough, G. Ganouna-Cohen, J. Chenion, G. Delmas, "Loss of Coolant Accident (LOCA) Simulation Tests on Polymers: The Importance of Including Oxygen," NUREG/CR-2763, SAND82-1071, Sandia National Laboratories, Albuquerque, NM, July 1982 .

[15] Gillen, K.T., R.L. Clough, G. Ganouna-Cohen, J. Chenion, G. Delmas, "The Importance of Oxygen in LOCA Simulation Tests," Nuclear Engineering and Design, Vol. 74, 1982, pp. 271-285.

[16] Institute of Electrical and Electronics Engineers, "IEEE Standard for Qualifying Class 1E Equipment for Nuclear Power Generating Stations," IEEE Std. 323-1974, New York, NY, June 1976 (corrected copy), $24 \mathrm{pp}$.

[17] Institute of Electrical and Electronics Engineers, "IEEE Standard for Type Test of Class 1E Electric Cables, Field Splices, and Connections for Nuclear Power Generating Stations," ANSI/IEEE Std. 383-1974 (ANSI N41.10-1975), New York, NY.

[18] Institute of Electrical and Electronics Engineers, "IEEE Standard for Qualification of Class 1E Connection Assemblies for Nuclear Power Generating Stations," ANSI/IEEE Std. 572-1985, New York, NY.

[19] Jacobus, M.J., "Aging of Cables, Connections, and Electrical Penetration Assemblies Used in Nuclear Power Plants," NUREG/CR-5461, SAND89-2369, Sandia National Laboratories, Albuquerque, NM, July 1990.

[20] Jacobus, M.J., and G.F. Fuehrer, "Submergence and High Temperature Steam Testing of Class 1E Electrical Cables," 
NUREG/CR-5655, SAND90-2629, Sandia National Laboratories, Albuquerque, NM, May 1991.

[21] Jacobus, M.J., "Aging, Condition Monitoring, and Loss-Of-Coolant (LOCA) Tests of Class 1E Electrical Cables-Crosslinked Polyolefin Cables," NUREG/CR-5772, Vol. 1, SAND91-1766/1, Sandia National Laboratories, Albuquerque, NM, Aug. 1992.

[22] Jacobus, M.J., "Aging, Condition Monitoring, and Loss-Of-Coolant (LOCA) Tests of Class 1E Electrical Cables-Ethylene Propylene Rubber Cables," NUREG/CR-5772, Vol. 2, SAND91-1766/2, Sandia National Laboratories, Albuquerque, NM, Nov. 1992.

[23] Jacobus, M.J., "Aging, Condition Monitoring, and Loss-Of-Coolant (LOCA) Tests of Class 1E Electrical Cables-Miscellaneous Cable Products," NUREG/CR-5772, Vol. 3, SAND91-1766/3, Sandia National Laboratories, Albuquerque, NM, Nov. 1992.

[24] Krane, K.S., Modern Physics, John Wiley \& Sons, New York, NY, ISBN 0-471-07963-4, 1983, 512 pp.

[25] Litton/VEAM, "Assembly Procedure for: CIR01WN-16-10S(04) In-Line Receptacle, CIR065WN-16-10P(04) Straight Plug," VAP-368, Sep. 1991, 11 pp.

[26] Namco Controls, "Installation of EC210 Electrical Receptacles and Connector and Cable Assemblies into Various Control Devices," Report No. TMR 300, Rev. 0, Namco Controls, Mentor, OH, Apr. 1986.

[27] Namco Controls, "Installation Instructions: Receptacle and Connector Assemblies: EC210 Series," EC219-90002, Namco Controls, Mentor, OH, 14 pp.

[28] National Oceanic and Atmospheric Administration, U.S. Standard Atmosphere, 1976, NOAA-S/T 76-1562, Washington, D.C., Oct. $1976,227 \mathrm{pp}$.

[29] The Okonite Company, "The Fundamentals of Splicing and Terminating Electrical Cables," Bulletin 22.9.0, The Okonite Company, Ramsey, NJ, 1982, 16 pp.

[30] The Okonite Company, "Instructions for a Straight Splice for Multiconductor, Rubber
Insulated, Okolon Jacketed Nuclear Station Control Cable," Drawing No. D-11547, The Okonite Company, Ramsey, NJ, Oct. 1980, $3 \mathrm{pp}$.

[31] The Okonite Company, "Nuclear Environmental Qualification Report for Okoguard Insulated Cables and T-95 and No. 35 Splicing Tapes," Okonite Report No. NQRN-3, Rev. 4, The Okonite Company, Ramsey, NJ, 10/24/88. Activation energy of $0.65 \mathrm{eV}$ for the No. 35 jacketing tape was calculated from the Arrhenius plot for neoprene given in Appendix 2, Chart \#2.

[32] Patel Engineers, "Final Test Report on Patel Conduit Seals Manufactured by Patel Engineers for Use in Nuclear Power Plants," Patel Report No. PEI-TR-841203-12, Rev. A, Patel Engineers, Huntsville, AL, Jan. 1987.

[33] Patel Engineers, "Test Report for Nuclear Environmental Qualification of Patel 1/2 Inch Electrical Connector," Report No. PEI-TR-880701-04, Patel Engineers, Huntsville, AL, Mar. 1989.

[34] Pozar, David M., Microwave Engineering, Addison-Wesley, Reading, MA, 1990, $726 \mathrm{pp}$. (ISBN 0-201-50418-9).

[35] Raychem Energy Division, "Raychem Nuclear Splicing Kit Installation Instructions for Coaxial Splicing Kit NPKX-CCKN-06-01," NPKI 10100-2 (082188), 10/81.

[36] Raychem Energy Division, "Nuclear Plant Splice Kit Installation Instructions for In-Line Control Cable Splice," PII-57015-A, Nov. 1981, 2 pp. (included as part of the splice kit).

[37] Raychem Energy Division, "Analysis of Heat Aging Data on WCSF Material to Determine Pre-Aging Conditions for Nuclear Qualification Testing," Report Number EDR-5046, Mar. 1982.

[38] Raychem Corp., "WCSF-N Heavy Wall, Flame-retarded Nuclear Cable Sleeves: Product Installation and Inspection Guide," PII 57100E, Raychem Corporation, Electrical Products Group, Menlo Park, CA, Effective Date: Feb. 1991, (E2475) H51293 3/91.

[39] Raychem Corp., "WCSF-N In-Line Splice Application Guide," Raychem Corporation, Electrical Products Group, Menlo Park, CA, (E2425) H51211 3/91. 
[40] The Rockbestos Company, "Report on Qualification Tests for Firewall III Chemically Cross-Linked Polyethylene Constructions for Class 1E Service in Nuclear Generating Stations," The Rockbestos Company, New Haven, CT, Report \#QR-5804, 1-Aug-1985 (revised 27-Aug-1985).

[41] The Rockbestos Company, "Report on Qualification Tests for Rockbestos Adverse Service Coaxial, Twinaxial, and Triaxial Cable - Generic Nuclear Incident for Class 1E Service in Nuclear Generating Stations," The Rockbestos Company, New Haven, CT, Report \#QR-6802, 12-Mar-1986.

[42] Rosemount Inc., "Qualification Report for Conduit Seal Model 353C," Rosemount Report D8300152, Rev. C, Rosemount Inc., Eden Prairie, MN, Jul. 1987.

[43] Rosemount Inc., "Model 353C Conduit Seal," Instruction Manual 4498, Rosemount Inc., Eden Prairie, MN, Dec. 1990, 4 pp.

[44] Sorrento Electronics, "Installation Notes Low-Level Current Monitoring," SE-1001, Sorrento Electronics, San Diego, CA, 4 pp.

[45]. Toman, G.J., and P.J. Lindsay, "Review of Polyimide Insulated Wire in Nuclear Power Plants," Electric Power Research Institute EPRI NP-7189, ERC Environmental and Energy Services Company, Plymouth Meeting, PA, Feb. 1991.

[46] United States Nuclear Regulatory Commission, Office of Nuclear Reactor Regulation, "Degradation of Kapton Electrical Insulation," NRC Information Notice No. 88-89, Nov. 21, 1988.

[47] United States Nuclear Regulatory Commission, Office of Nuclear Reactor Regulation, "Environmental Qualification of Litton-VEAM CIR Series Electrical Connectors," NRC Information Notice No. 89-23, Mar. 3, 1989.

[48] United States Nuclear Regulatory Commission, Office of Nuclear Reactor Regulation, "Environmental Qualification Deficiency for Cables and Containment Penetration Pigtails," NRC Information Notice No. 97-45, July 2, 1997.

[49] Wyle Laboratories, "Nuclear Environmental Qualification: Qualification Test Program for
Terminal Blocks," Test Report 45603-1, Feb. 1982.

[50] Phone call to George Hageman, Quality Assurance for Multi-Amp Corporation, on Dec. 11, 1991. He gave States ZWM-25004 terminal block activation energies of $1.27 \mathrm{eV}$ for the barrier, $1.93 \mathrm{eV}$ for the base, and $2.2 \mathrm{eV}$ for the Melamine marker strip.

[51] Phone call to Douglas A. Coe, Sales Application Engineer for Namco Controls, on Dec. 13,1991 . He gave the minimum activation energy for Namco EC210 connectors as $0.8 \mathrm{eV}$ for the replaceable o-rings; the next lowest activation energy was $1.13 \mathrm{eV}$ for the lead wire jacket (these values are from Namco Report No. QTR 145, Rev. 2).

[52] Facsimile from A.J. Bernardini, General Manager for Litton-VEAM, on Aug. 23, 1991 (TF\# 8690/91). Activation energy of $1.15 \mathrm{eV}$ is for the silicon elastomers used in the connector. 


\section{PROPRIETARY SOURCES OF INFORMATION ${ }^{1}$}

[4] Conax Buffalo Corp., "Installation Manual for Electric Conductor Seal Assemblies with Long Body for Pipe Thread Equipment Interface," Conax IPS-725, Rev. H, Conax Buffalo Corporation, Buffalo, NY, Jul. 1987.

[5] Conax Buffalo Corp., "Design Qualification Test Report for Electric Conductor Seal Assembly (ECSA) for Conax Corporation (W/O 6-7E060)," Conax IPS-1079, Rev. F, Conax Buffalo Corporation, Buffalo, NY, Jan. 1988.

\footnotetext{
${ }^{1}$ Documents are not publicly available.
} 


\section{A TERMINAL BLOCKS}

This section describes the 2 types of terminal blocks tested; the experimental apparatus, techniques, and test conditions used to measure terminal blocks; and the results of the measurements. ${ }^{1}$ The terminal blocks were chosen to address issues related to a previous study of terminal blocks by Craft $[6,7]$, namely

1. The terminal blocks were not aged before the LOCA test in the previous study.

2. The terminal blocks were constantly powered in the previous study. The heat caused by this probably reduced the amount of surface moisture on the blocks during the accident test. To more closely mimic the behavior of a typical safety system, it would be useful to see what happens if the initially unpowered terminal blocks have power switched on after the steam exposure has started.

\section{A.1 Experimental Apparatus and Technique}

\section{A.1.1 Terminal Blocks Tested}

Two types of terminal blocks were tested:

- Marathon 1604 NUC

- States ZWM-25004

The two types of terminal blocks are Class $1 \mathrm{E}$ qualified and were supplied with a Certificate of Compliance that indicates the standards to which they have been qualified, the relevant qualification documents, and the manufacturing lot and date. Further details on the terminal blocks are given in Table A.1. Activation energy data for the terminal blocks are given in Table A.2, which also tabulates the temperatures for 40 and 60 years that are equivalent to the 6 months of thermal aging at $98.8^{\circ} \mathrm{C}$ that was performed.

Two of each type of terminal block were installed in the test chamber using 6 cables (18 conductors), as indicated in Table A.3. Of these 18 conductors,

\footnotetext{
${ }^{1}$ In addition to the figures and tables included in this section, all the raw data are available upon request from the author.
}

4 supplied power to the 4 terminal blocks, 4 were the return legs for the power, and the remaining 10 were connected to adjacent terminal block terminals or the terminal block ground planes to serve as possible leakage paths. Rockbestos Firewall III XLPE multiconductor cable (12 AWG, 3 conductor, see FWC in Table 2.2) was used for all the terminal block connections.

\section{A.1.2 Test Conditions}

All environmental exposures were performed in the same test chamber and at the same time as the connections, as described in Section 2. Figure 2.6 shows a top view of the arrangement of connections in the test chamber. Two Hoffman A-806CHNF enclosures, each containing one Marathon and one States terminal block, were mounted inside the mandrel; the top of each enclosure was located approximately $32 \mathrm{~mm}$ (1.25 in) above the centerline of the cobalt-60 sources. As shown in Figure A.1, the Marathon terminal block was installed at the top of each of the two enclosures. A 0.25 -in diameter weep hole was located at the bottom of each enclosure. The cables entered and exited each enclosure through an elbow and a short section of conduit located inside the test chamber.

During the aging and accident radiation exposures, the terminal blocks were energized with $110 \mathrm{Vdc}$ and no current; all other terminal block conductors were grounded as indicated in Table A.3. During the accident steam exposure, the terminal block conductors were energized using the circuit shown in Figure A.2 as follows:

- The Marathon terminal block in enclosure 1 and the States terminal block in enclosure 2 were energized continuously with 45 to $110 \mathrm{Vdc}$. The actual dc energization is shown in Figure A.3.

- The States terminal block in enclosure 1 and the Marathon terminal block in enclosure 2 were switched between $110 \mathrm{Vac}, 220 \mathrm{Vac}$, and unenergized. This allowed measurement of terminal block transient leakage currents during the accident steam exposure. The actual ac energization is shown in Figure A.4. 


\section{A. TERMINAL BLOCKS}

Table A.1: Terminal Blocks Tested.

\begin{tabular}{ll}
\hline \hline TBM & Marathon 1604 NUC \\
& Marathon 1604 NUC Terminal Block, 4 poles (F\&H Part Number 1604505) \\
& Farwell and Hendricks Inc., 1000 Ford Circle, Milford, OH 45150 \\
& Purchase Requisition 67-6168, 6-6-91 \\
& Supplied with Certificate of Compliance \\
& Installed using Rockbestos Firewall III cable (see FWC in Table 2.2) \\
TBS & States ZWM-25004 \\
& States ZWM-25004 Terminal Block (4 poles) \\
& Multi-Amp Corp., 4271 Bronze Way, Dallas, TX 75237 \\
& Purchase Requisition 67-6229, 6-11-91 \\
& Supplied with Certificate of Compliance (Part No. 9417) \\
Installed using Rockbestos Firewall III cable (see FWC in Table 2.2) \\
\hline \hline
\end{tabular}

Table A.2: Activation Energies and Equivalent Thermal Aging to 6 Months at $98.8^{\circ} \mathrm{C}$ for the Terminal Blocks Tested.

\begin{tabular}{lcccc}
\hline \hline & \multicolumn{2}{c}{ Activation Energy } & \multicolumn{2}{c}{ Temperature $\left[{ }^{\circ} \mathrm{C}\right]$} \\
Terminal Block & $E_{a}$ & Reference & 40 years & 60 years \\
\hline Marathon 1604 NUC & $1.21 \mathrm{eV}$ & {$[49$, p.XII-34] } & 60.1 & 56.9 \\
States ZWM-25004 & $1.27 \mathrm{eV}$ & {$[50]$} & 61.8 & 58.7 \\
\hline \hline
\end{tabular}

Table A.3: Terminal Block Conductor Numbers.

\begin{tabular}{|c|c|c|c|}
\hline$\overline{\text { Enclosure } 1}$ & red conductor & white conductor & black conductor \\
\hline cable 1 & $66^{a}$ & $71 \mathrm{a}$ & $72 \mathrm{a}$ \\
\hline cable 2 & 67 & $71 b^{b}$ & 68 \\
\hline cable 3 & 69 & $72 \mathrm{~b}$ & 70 \\
\hline Enclosure 2 & red conductor & white conductor & black conductor \\
\hline cable 4 & 73 & $78 \mathrm{a}$ & $79 a$ \\
\hline cable 5 & 74 & $78 \mathrm{~b}$ & 75 \\
\hline cable 6 & 76 & $79 \mathrm{~b}$ & 77 \\
\hline
\end{tabular}




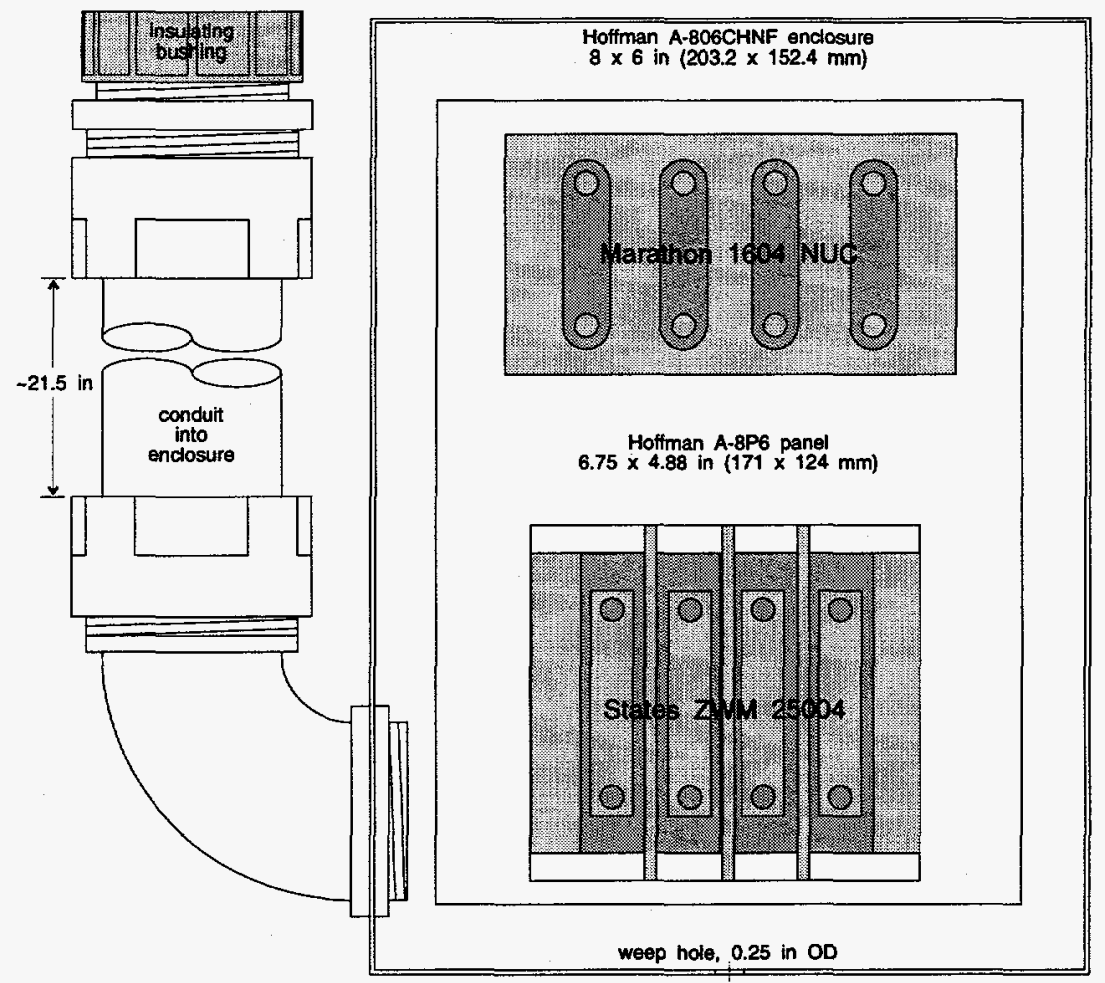

Figure A.1: Sketch of the two terminal blocks inside an enclosure.

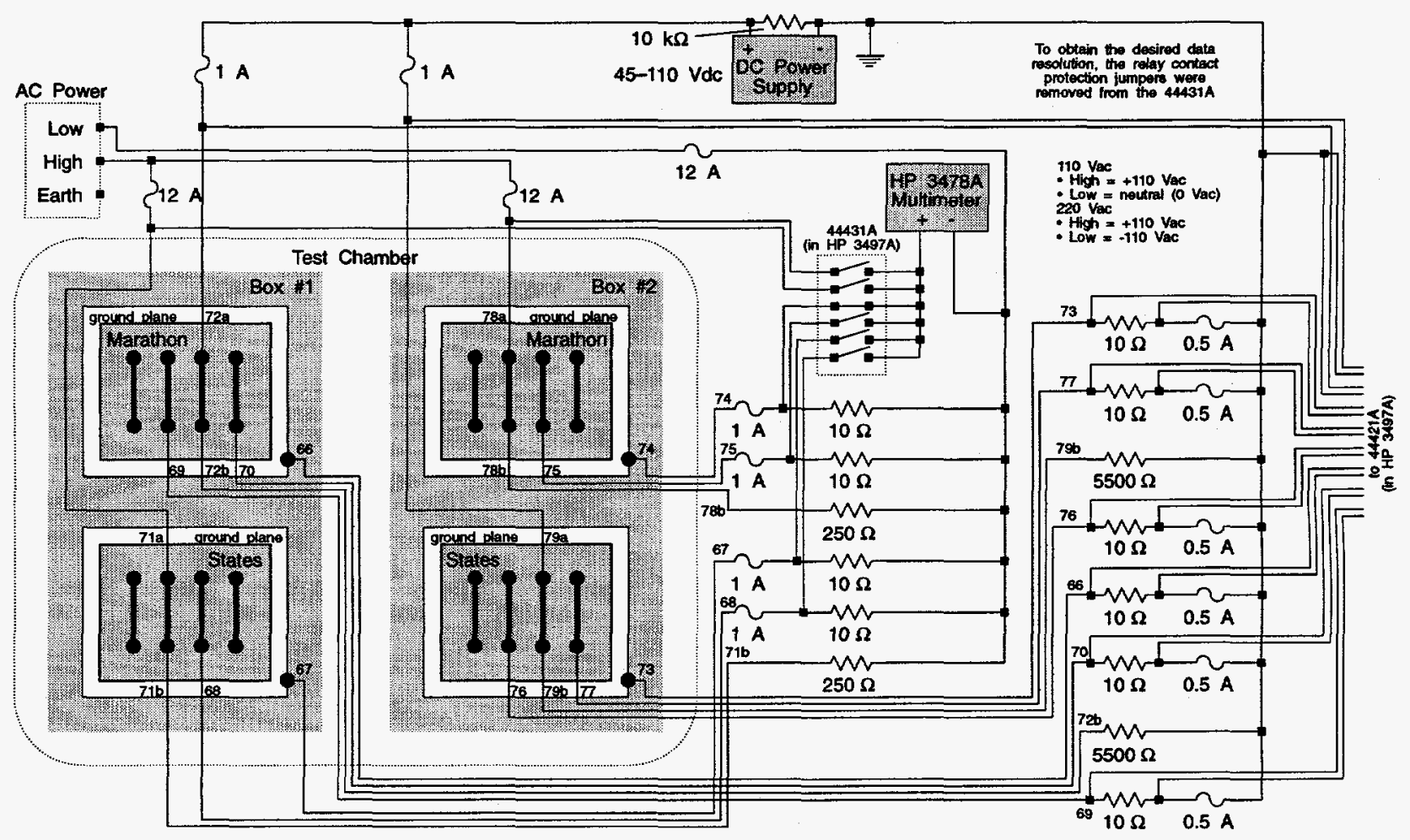

Figure A.2: Circuit used for dc and ac excitation of the terminal block conductors and to measure their "continuous" IRs during the accident steam exposure. 


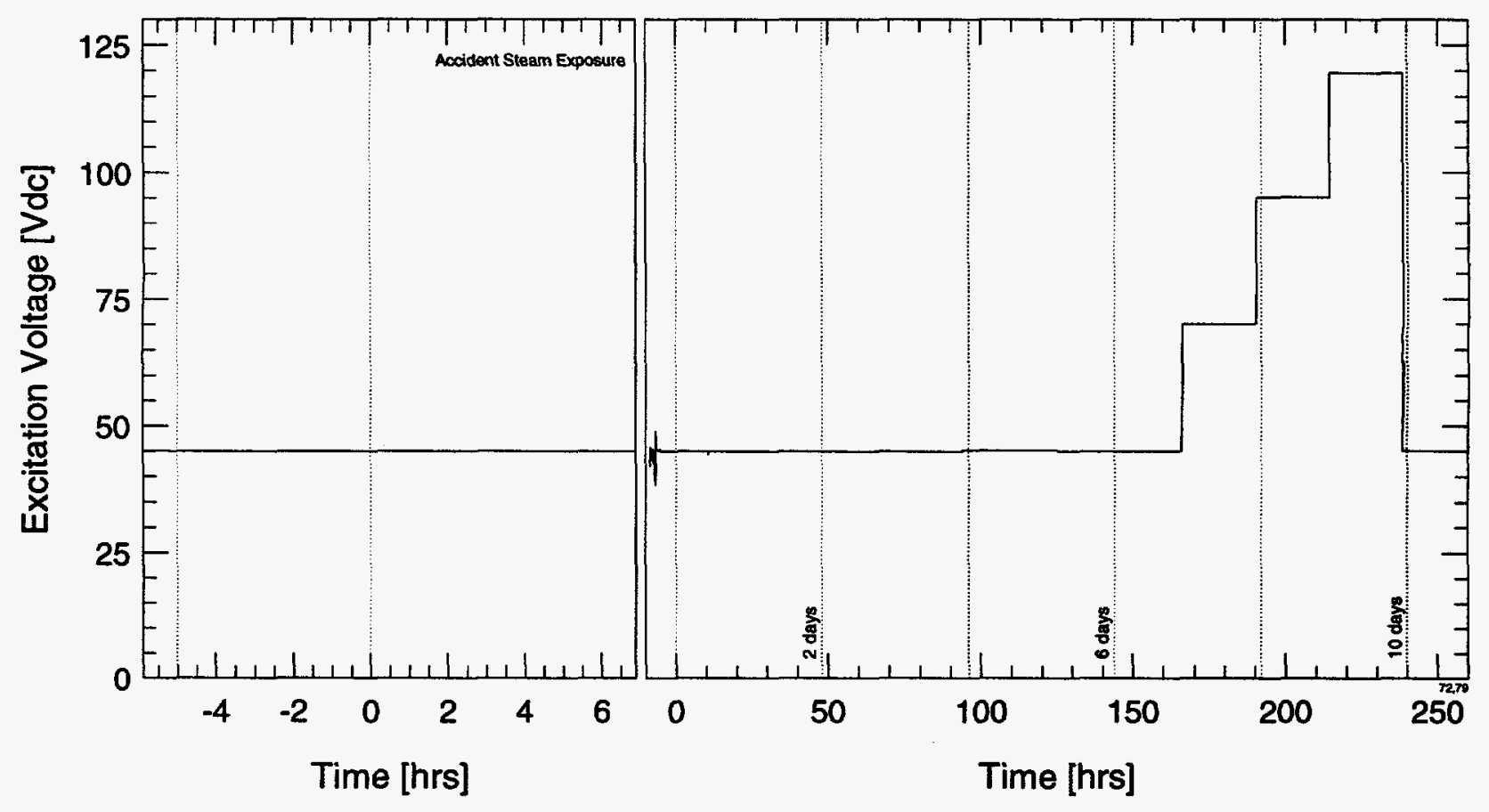

Figure A.3: Direct current excitation for the terminal block conductors during the accident steam exposure.

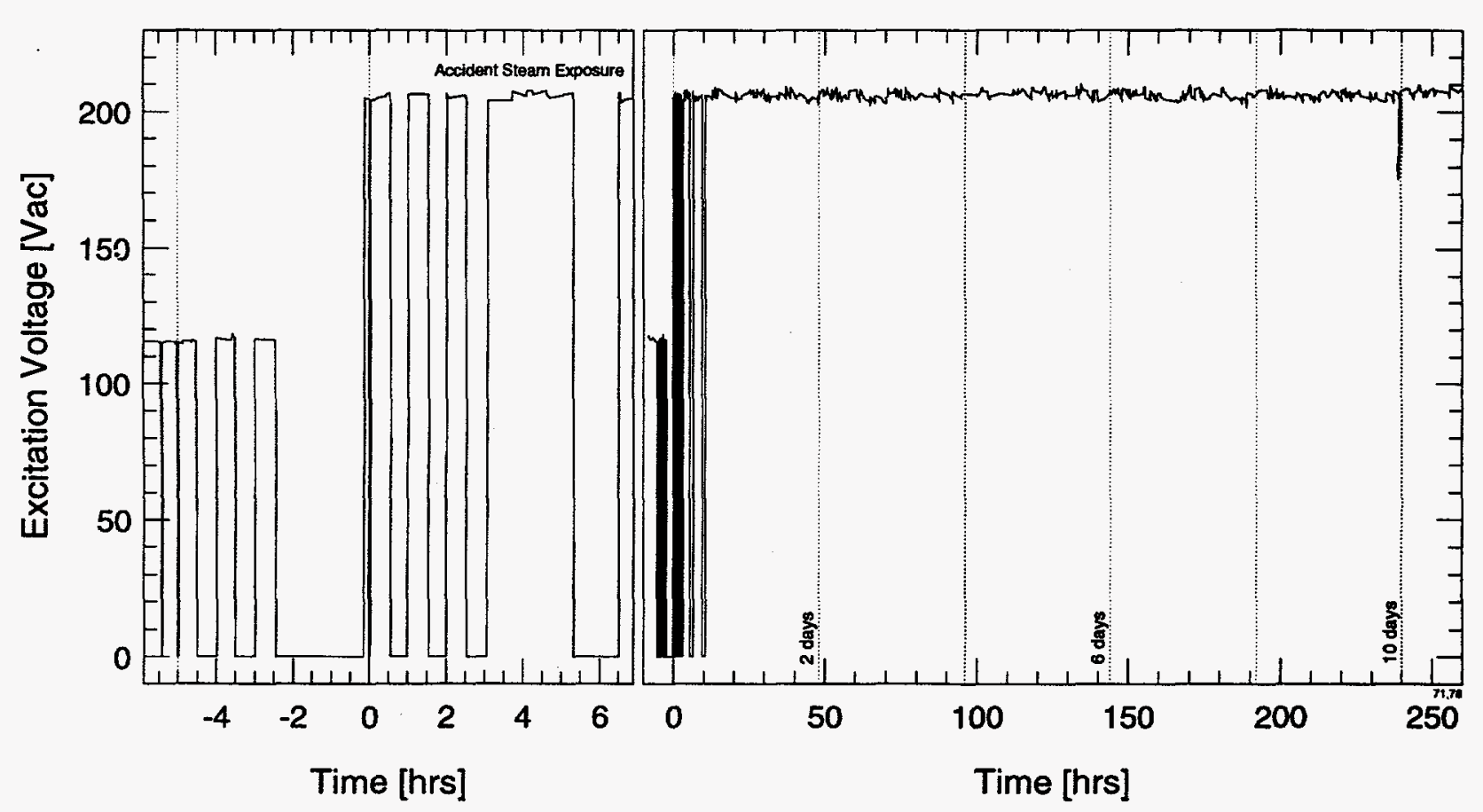

Figure A.4: Alternating current excitation for the terminal block conductors during the accident steam exposure. 
Table A.4: Alternating Current Excitation for Terminal Block Conductors During the Accident Steam Exposure.

\begin{tabular}{ccl}
\hline \hline Time & AC Voltage & Notes \\
\hline First transient & & \\
before start & $110 \mathrm{Vac}$ & obtain baseline values \\
$-26 \mathrm{~min}$ & off & \\
$-24 \mathrm{~min}$ & $110 \mathrm{Vac}$ & aborted transient \\
$-1 \mathrm{~min}$ & off & \\
$1 \mathrm{~min}$ & $110 \mathrm{Vac}$ & \\
$30 \mathrm{~min}$ & off & \\
$1 \mathrm{hr}$ & $110 \mathrm{Vac}$ & \\
$1.5 \mathrm{hr}$ & off & \\
$2 \mathrm{hr}$ & $110 \mathrm{Vac}$ & \\
$2.5 \mathrm{hr}$ & off & \\
$5 \mathrm{hr}$ & - & end of first transient \\
Second transient, reset time to 0 \\
$-9 \mathrm{~min}$ & $220 \mathrm{Vac}$ & obtain baseline values \\
$-1 \mathrm{~min}$ & off & \\
$1 \mathrm{~min}$ & $220 \mathrm{Vac}$ & \\
$30 \mathrm{~min}$ & off & \\
$1 \mathrm{hr}$ & $220 \mathrm{Vac}$ & \\
$1.5 \mathrm{hr}$ & off & \\
$2 \mathrm{hr}$ & $220 \mathrm{Vac}$ & \\
$2.5 \mathrm{hr}$ & off & \\
$3 \mathrm{hr}$ & $220 \mathrm{Vac}$ & end of transient peak \\
$5.5 \mathrm{hr}$ & off & \\
$6.5 \mathrm{hr}$ & $220 \mathrm{Vac}$ & \\
$9.5 \mathrm{hr}$ & off & \\
$10.5 \mathrm{hr}$ & $220 \mathrm{Vac}$ & \\
end of test & - & \\
\hline \hline & \multicolumn{3}{c}{} \\
\hline
\end{tabular}

\section{A.1.3 Electrical Measurement Techniques}

In addition to the discrete IR measurements described in Section 2.4.2, the continuous IR of the terminal block conductors was measured (only during the accident steam exposure) using the circuit shown in Figure A.2. Continuous IR measurements were performed for all terminal block conductors except the 4 conductors that energized the terminal blocks.

Note that all the discrete IR measurements were dc measurements. However, only the continuous IR measurements for the conductors from the dc energized terminal blocks were dc measurements. The continuous IR measurements for the ac energized terminal block conductors were ac measurements; these give the leakage and charging current for these conductors, much like what would occur for a low-voltage ac dielectric test set measurement.

Dielectric withstand (high potential) and TDR testing were performed as described in Section 2.

\section{A.2 Experimental Results}

Measured IR values during aging and accident irradiation are shown in Figures A.5 and A.6 for the Marathon and States terminal block conductors, respectively. For all the conductors, the IR remained essentially unchanged during the aging exposure and the ambient IR values measured at the end of aging were all higher than those measured prior to aging. The IR values also remained relatively unchanged during the accident irradiation, albeit at values somewhat lower than during the aging exposure. ${ }^{2}$ The ambient IR values measured at the end of the accident irradiation were all higher than those measured prior to aging.

Terminal block conductor IR data during the accident steam exposure are shown in Figures A.7-A.20. The IR fell to low values during the steam exposure due to the presence of moisture. The slow partial filling of the test chamber with condensate that occurred through

\footnotetext{
${ }^{2}$ The very high IR for the States terminal block conductor 73 at a dose of $698 \mathrm{kGy}$ was considered a test anomaly.
} 


\section{A. TERMINAL BLOCKS}

day 5 caused even larger reductions in the measured IR values because of the wet, saturated conditions in the test chamber that were imposed on the bare terminal blocks through the weep hole and unsealed conduit entry. ${ }^{3}$ The terminal block enclosures were also mounted lower in the test chamber than the other connections, which put them closer to this ever-growing pool of condensed steam. The data do not show any change in the measured IR when an initially unpowered terminal block has power suddenly applied while in a steam environment; it had been hypothesized that this might cause electrical shorting because of surface moisture that might form on the cold terminal block. Previous testing had utilized continuously powered terminal blocks, and the resulting $I^{2} R$ heat generation might have reduced the amount of surface moisture that formed on the blocks.

A post-LOCA IR measurement was performed 3 days after completion of the accident steam exposure; these data are tabulated in Table A.5 and are also plotted as the ambient data at approximately $240 \mathrm{hr}$ in Figures A.7-A.20. These data show a recovery in IR from that of the steam exposure.

Because of the possibility that moisture still remained in and on the terminal block enclosures, the IR was retested approximately 13 months later, which provided sufficient time to ensure that everything had dried out; these results are also shown in Table A.5. The IR of all the terminal block conductors had increased by several orders of magnitude to values near $10^{9} \Omega$ and above.

Once the dry IR test was completed, the test chamber was flooded with tap water and additional IR measurements were performed. As expected, the IR of the conductors attached to the bare terminal block terminals fell to low levels for measurements performed after a minimum soak time of $30 \mathrm{~min}$ (see Table A.5). No measurements were performed on the terminal block conductors after a minimum soak time of $3 \mathrm{hr}$.

Following the submerged IR tests, the connections were allowed to dry and then dielectric withstand testing was performed. An initial withstand test on the dry conductors was performed at $1000 \mathrm{Vac}$

\footnotetext{
${ }^{3}$ It does not appear that any of the terminal blocks were ever actually submerged by the slow filling of the test chamber.
}

rms; all of the terminal block conductors had a resulting current of less than $1 \mathrm{mAac}$ as shown in Table A.5. No submerged dielectric withstand testing was performed on the terminal block conductors.

Physical examination of the terminal blocks at the end of the test showed severe degradation. The enclosures were severely rusted and it appears that there was a fair amount of moisture present in the enclosures during the test (even though they do not appear to have been submerged during the partial flooding of the test chamber); moisture may have accumulated by condensing inside the conduit and dripping down into the enclosures.

The 2 States terminal blocks were severely degraded. The plastic shields between each pair of terminals had melted and collapsed downward. The screw terminals and lugs were badly corroded and were often covered by the collapsed plastic shields and label plate. The copper from the conductors used for dc excitation (79A and 79B) formed large blue-green deposits; in fact, conductor $79 \mathrm{~A}$ was completely corroded away and was not connected to anything.

The two Marathon terminal blocks looked much better because they did not melt; however, they were stained a rusty color and the screw terminals and lugs were badly corroded. Just as for the States terminal blocks, the copper from the conductors used for dc excitation (72A and 72B) had formed large blue-green deposits and conductor 72B was corroded away and not connected to anything.

It is interesting to note that for both the Marathon and States terminal blocks, the block that was energized with an ac voltage had noticeably less corrosion than the block energized with a dc voltage. One can hypothesize that the greater self-heating due to ac excitation might have reduced the amount of condensation on the block, thereby reducing the amount of corrosion. 


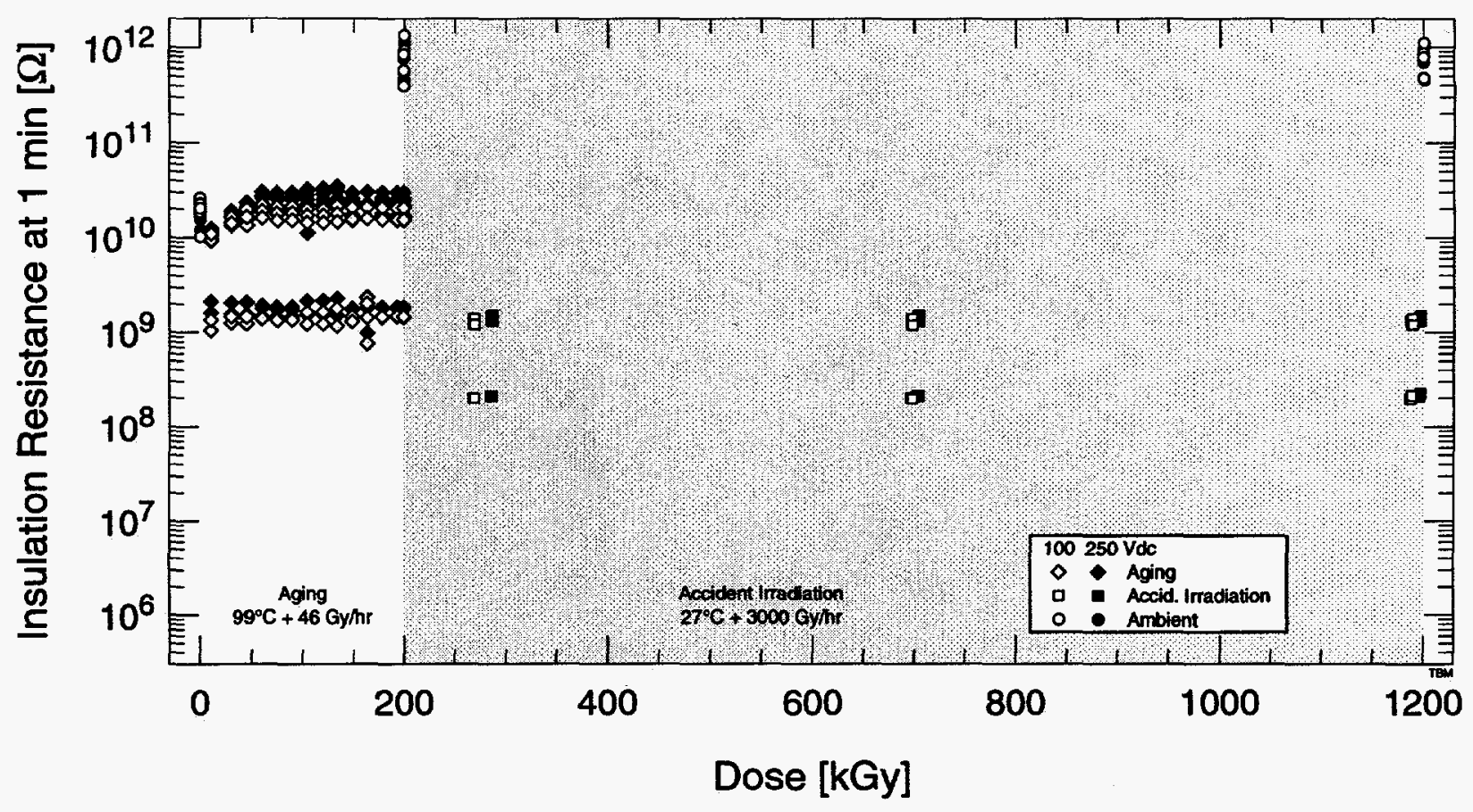

Figure A.5: IR of the 7 Marathon terminal block conductors during aging and accident irradiation.

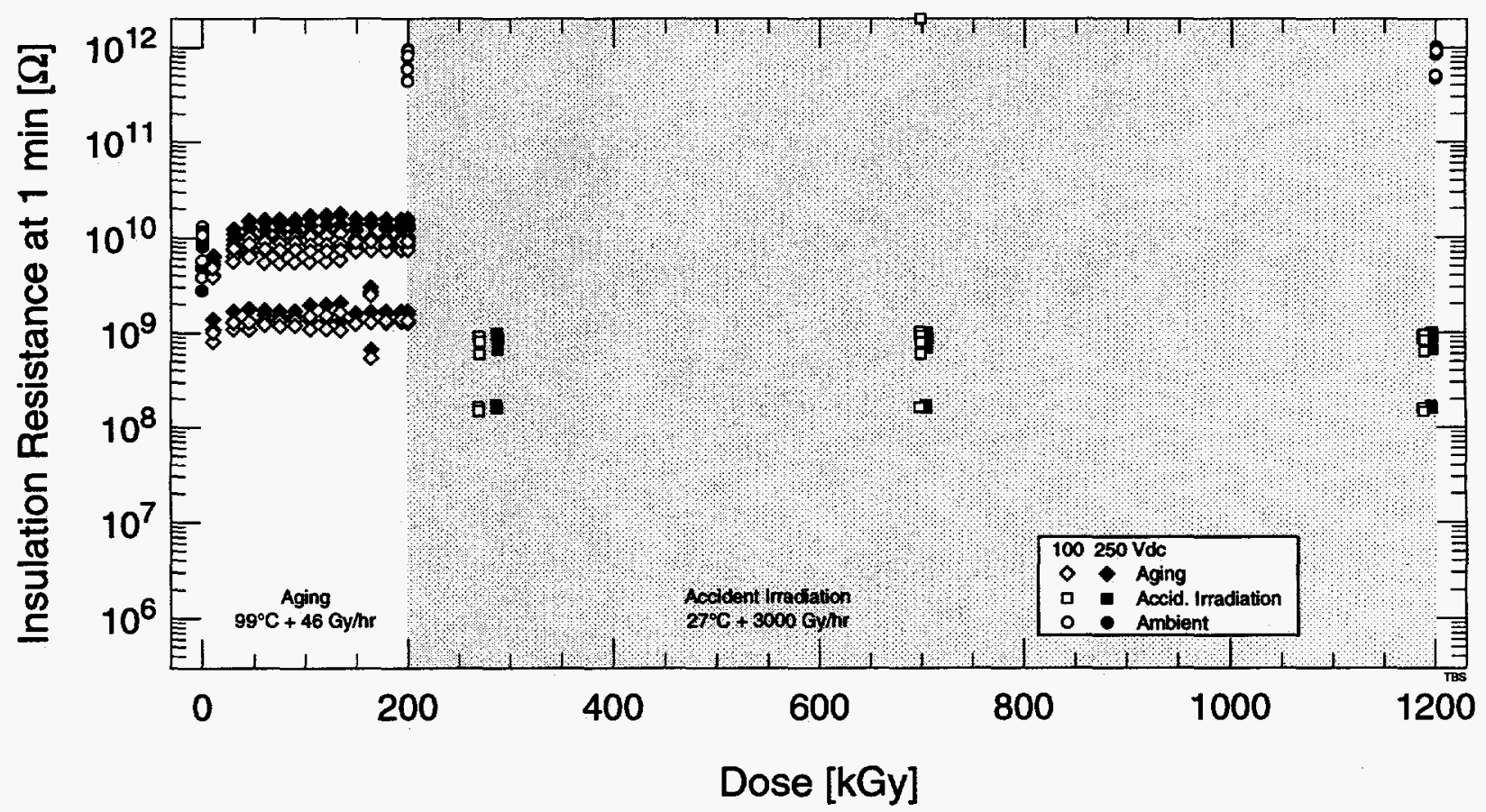

Figure A.6: IR of the 7 States terminal block conductors during aging and accident irradiation. 


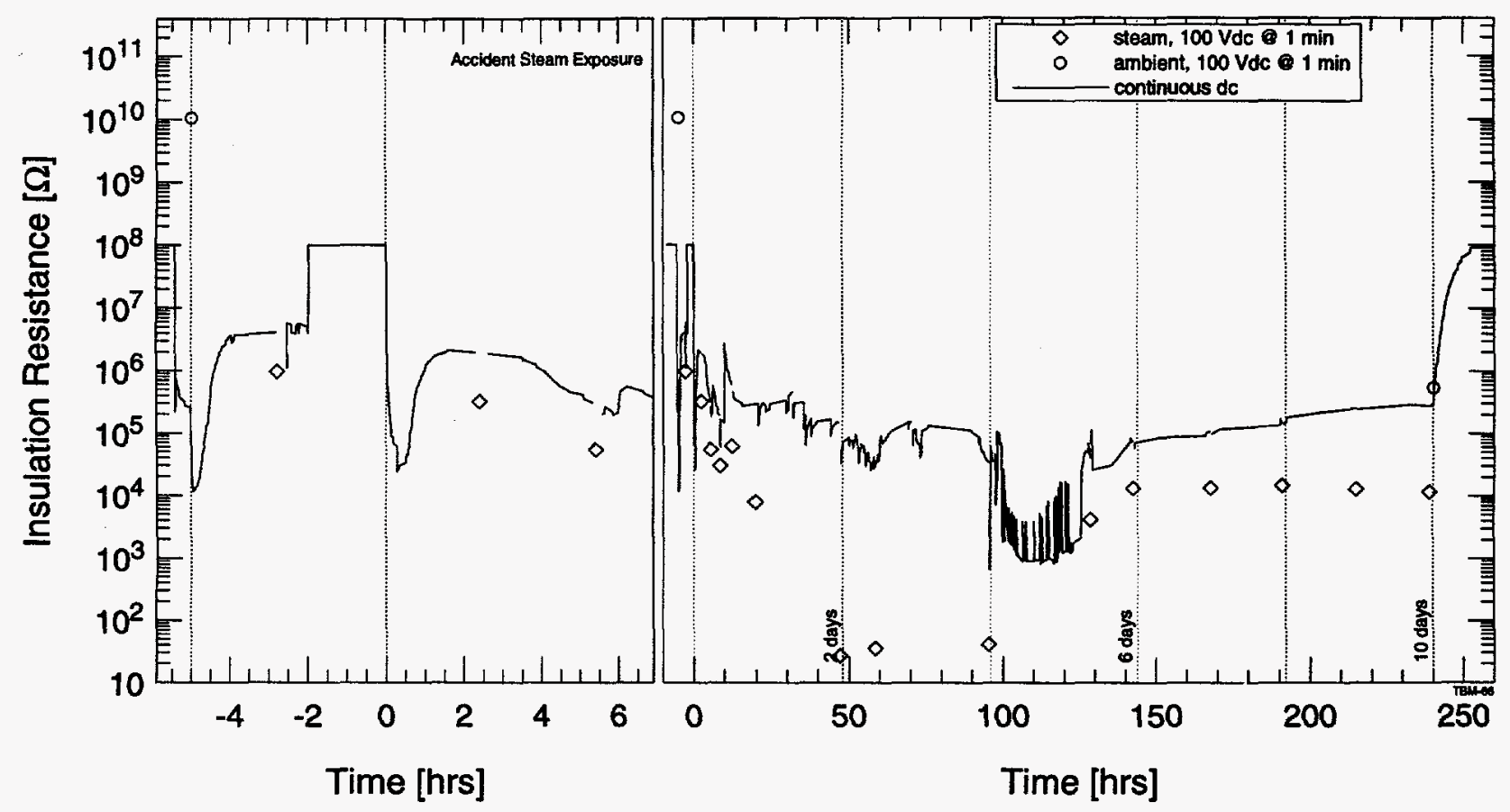

Figure A.7: IR of conductor 66 during the accident steam exposure (Marathon dc ground plane, enclosure 1).

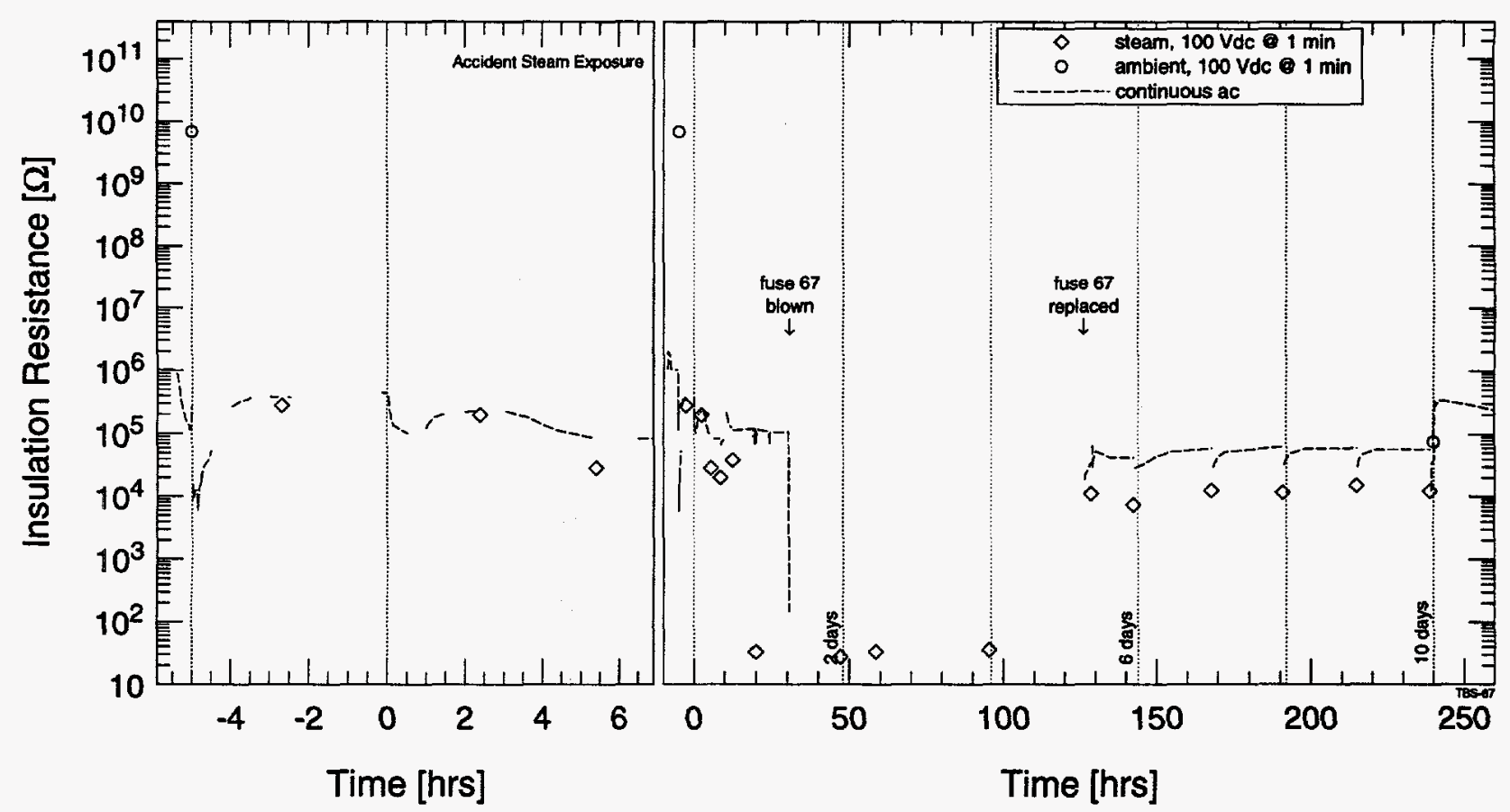

Figure A.8: IR of conductor 67 during the accident steam exposure (States ac ground plane, enclosure 1). 


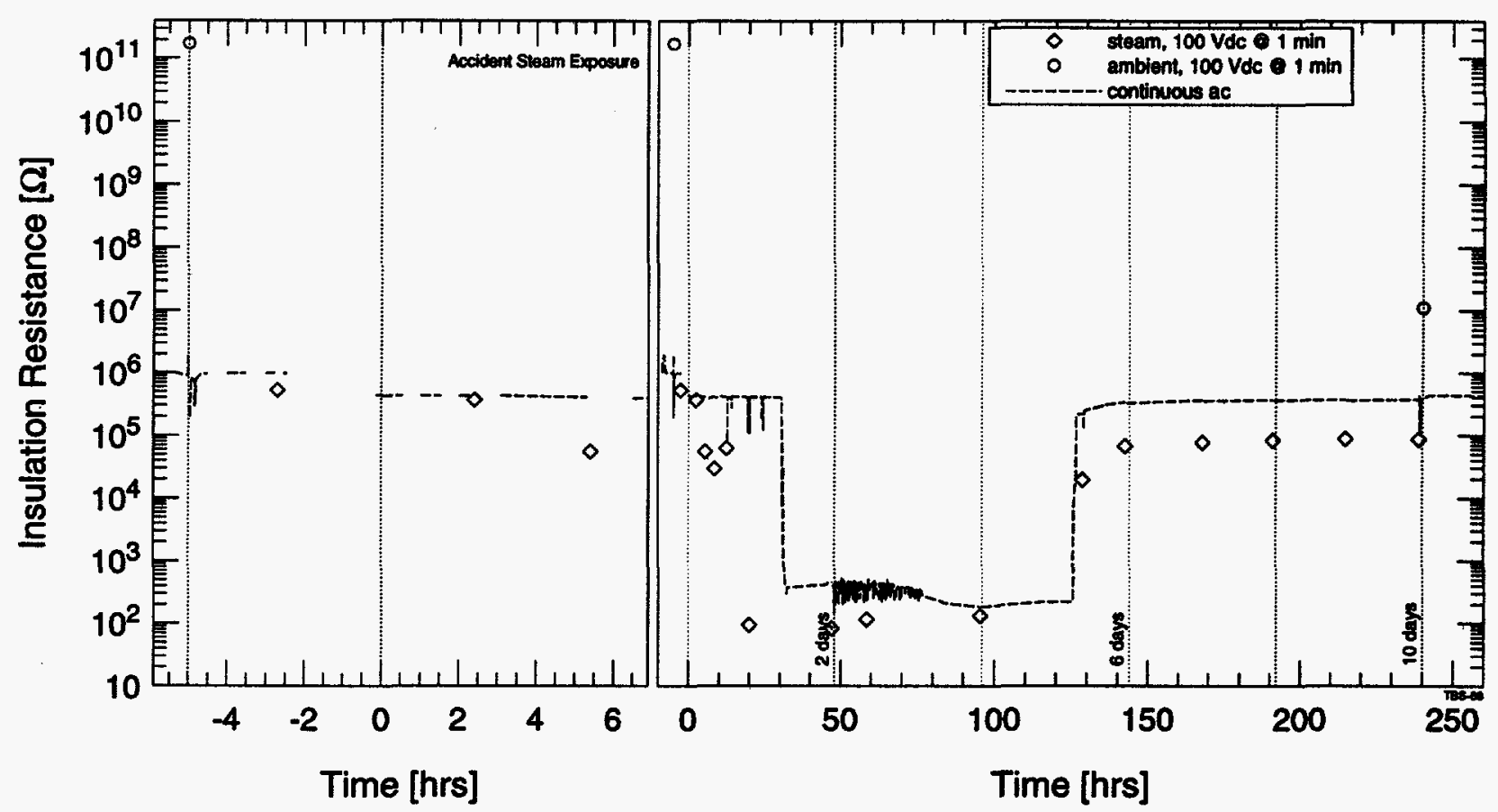

Figure A.9: IR of conductor 68 during the accident steam exposure (States ac adjacent terminal, enclosure 1).

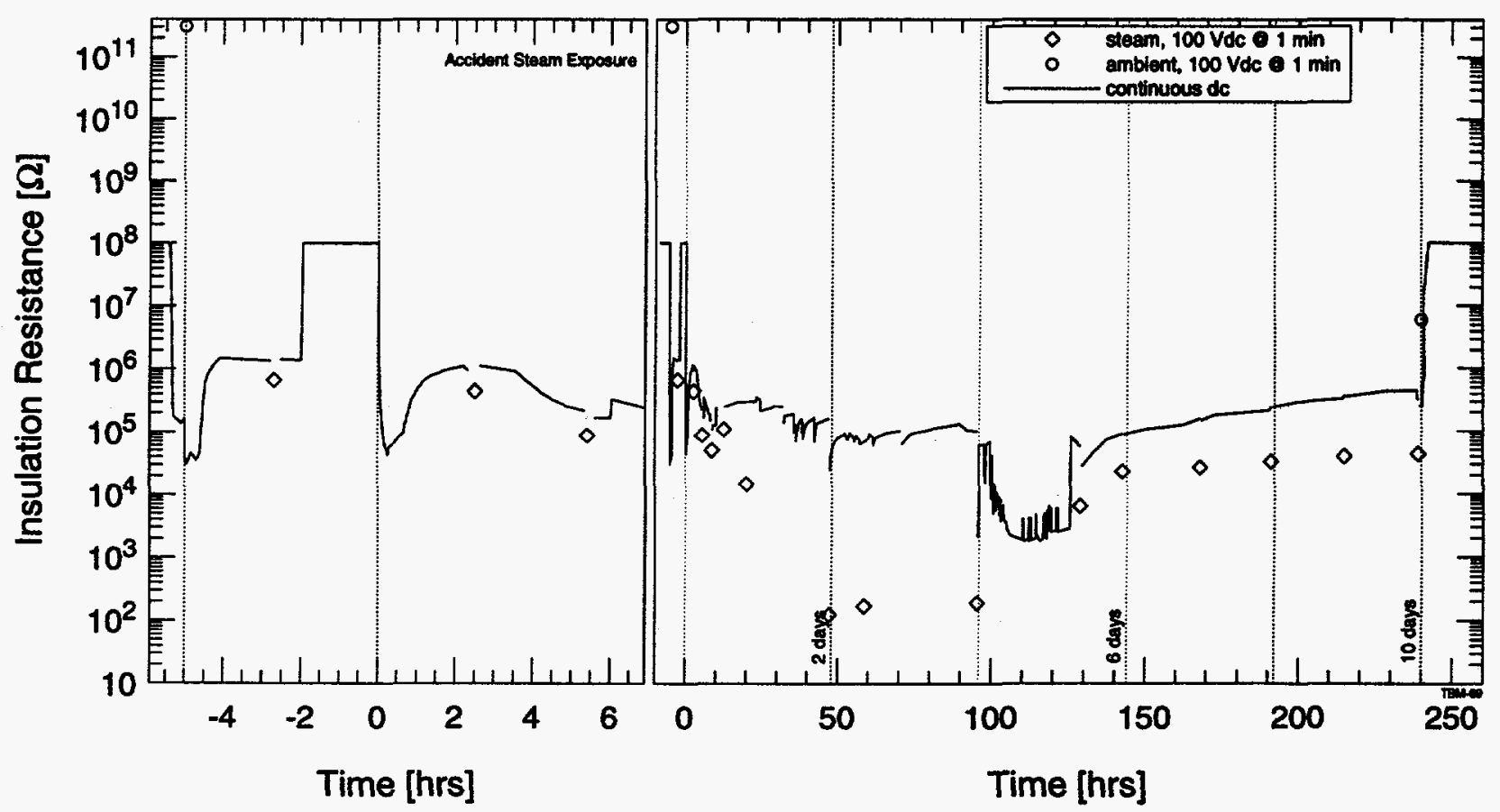

Figure A.10: IR of conductor 69 during the accident steam exposure (Marathon dc adjacent terminal, enclosure 1). 


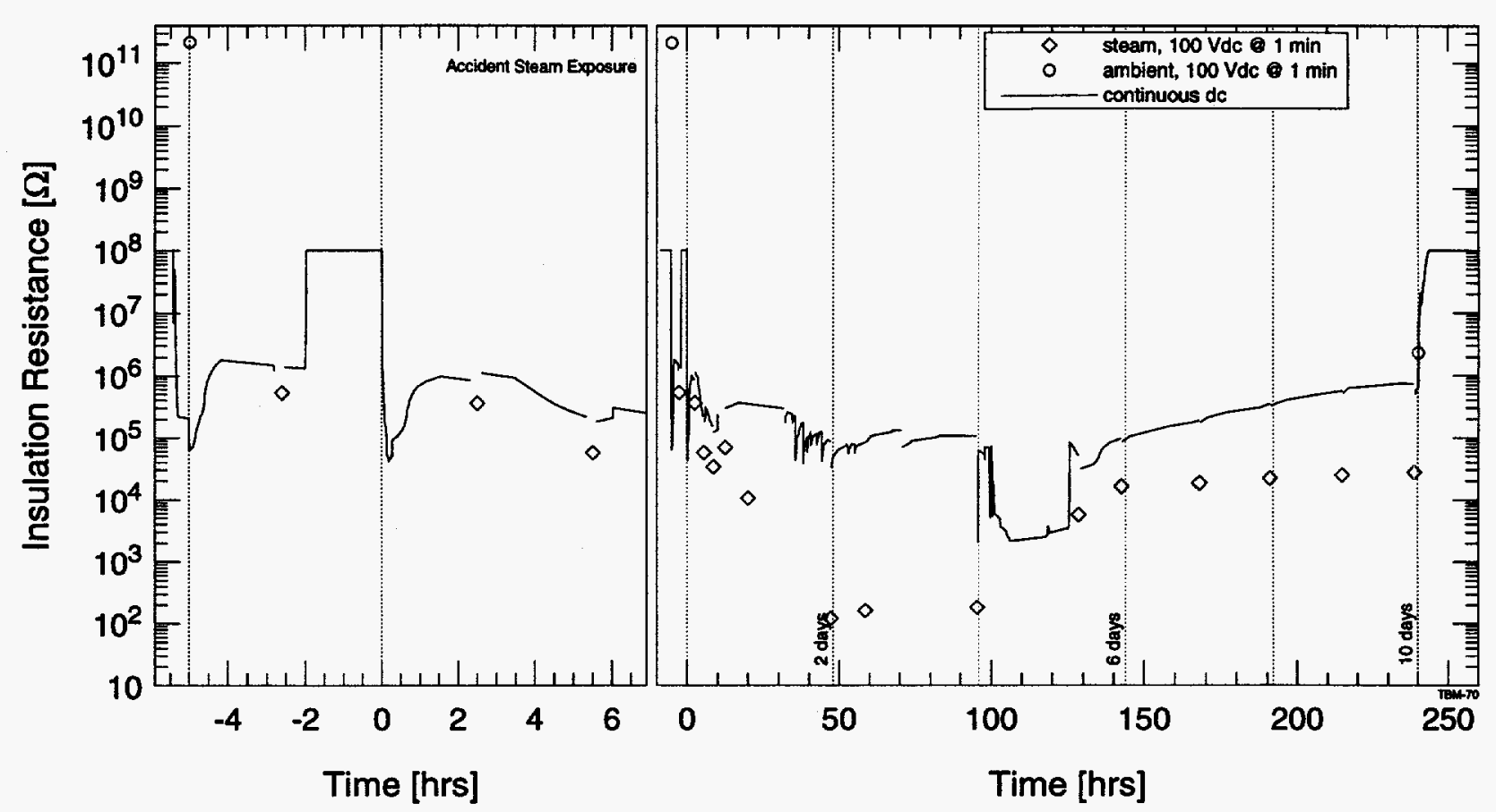

Figure A.11: IR of conductor 70 during the accident steam exposure (Marathon dc adjacent terminal, enclosure 1).

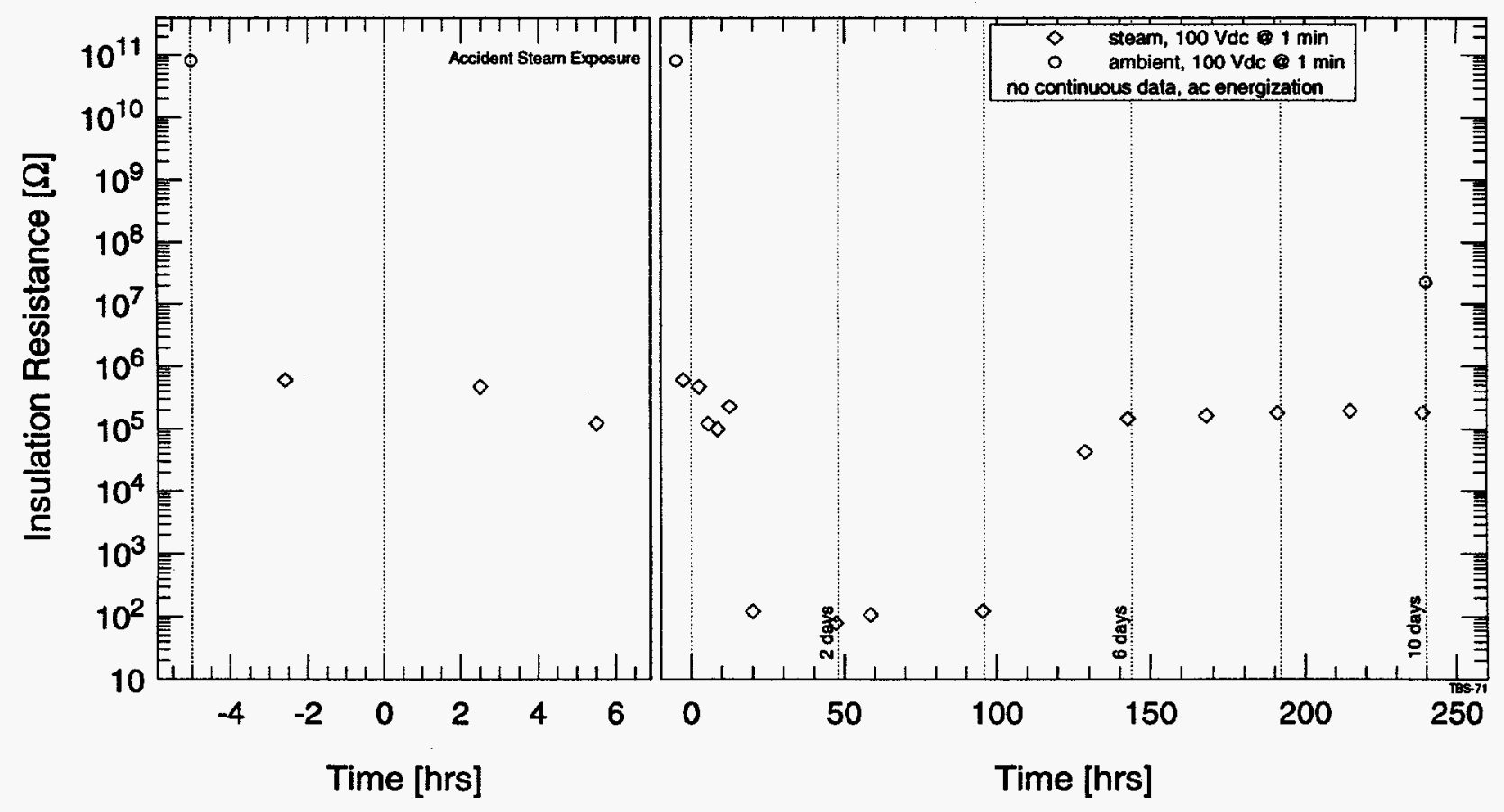

Figure A.12: IR of conductor 71 during the accident steam exposure (States ac energization, enclosure 1). 


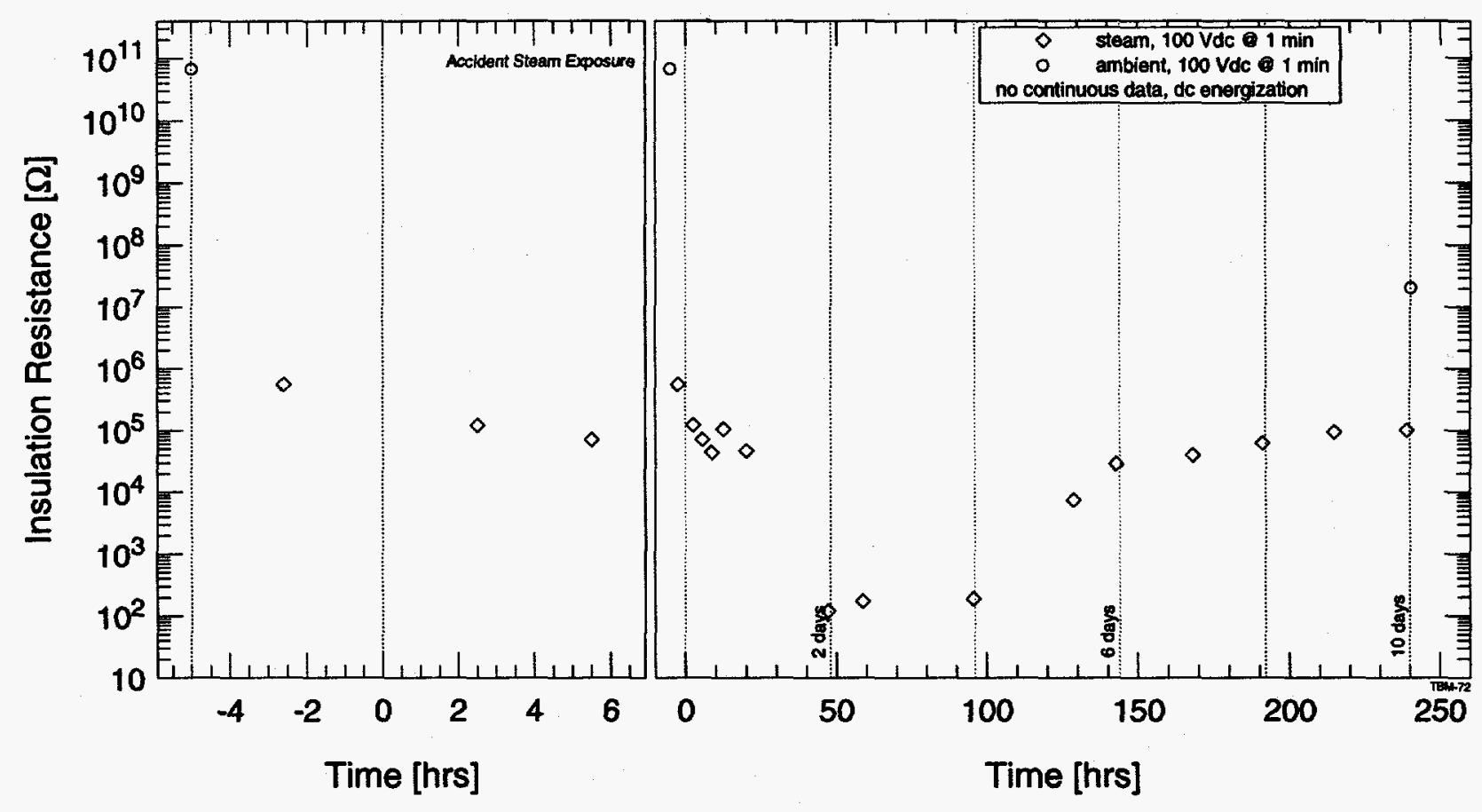

Figure A.13: IR of conductor 72 during the accident steam exposure (Marathon dc energization, enclosure 1).

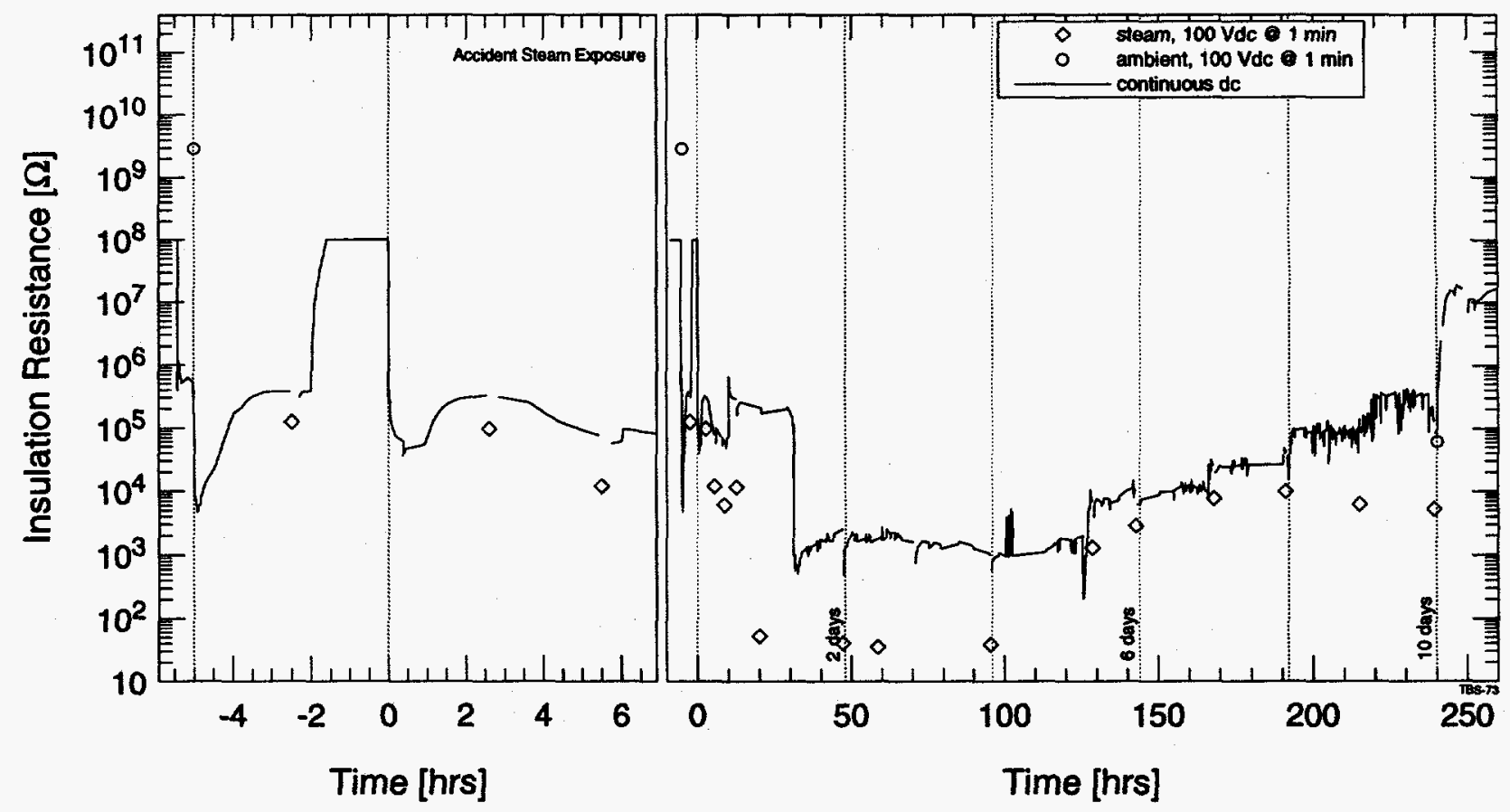

Figure A.14: IR of conductor 73 during the accident steam exposure (States dc ground plane, enclosure 2). 


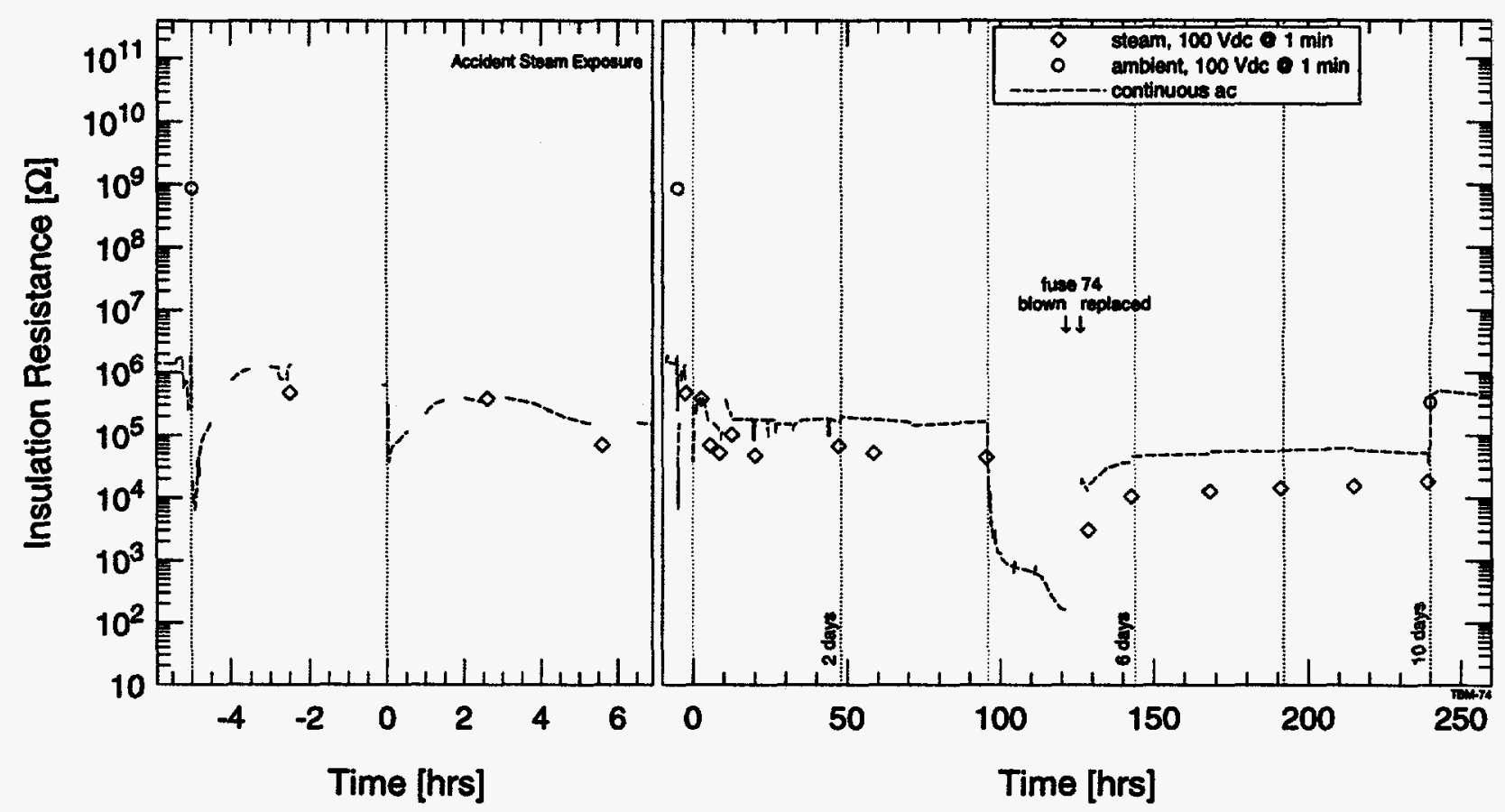

Figure A.15: IR of conductor 74 during the accident steam exposure (Marathon ac ground plane, enclosure 2).

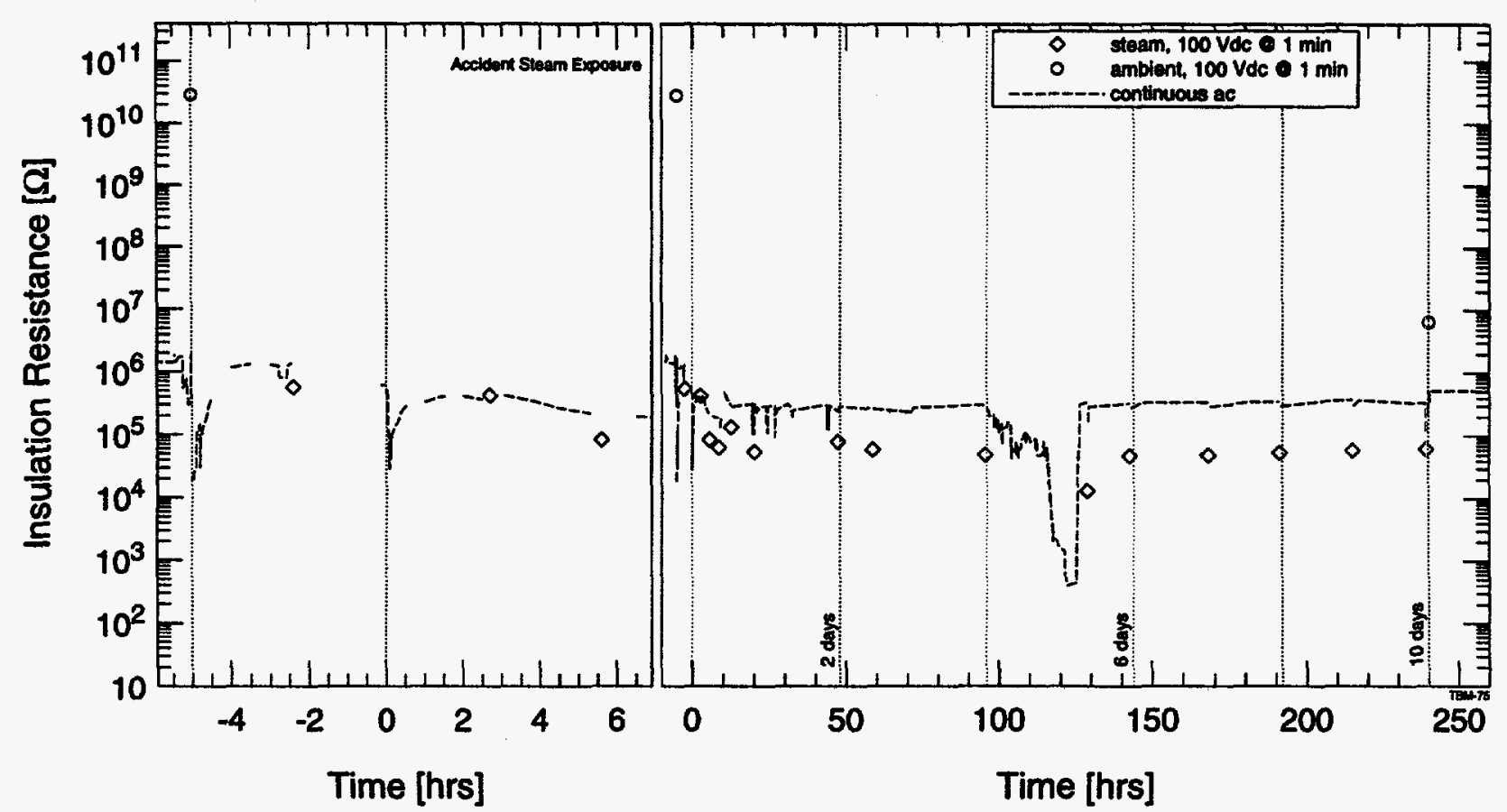

Figure A.16: IR of conductor 75 during the accident steam exposure (Marathon ac adjacent terminal, enclosure 2). 


\section{A. TERMINAL BLOCKS}

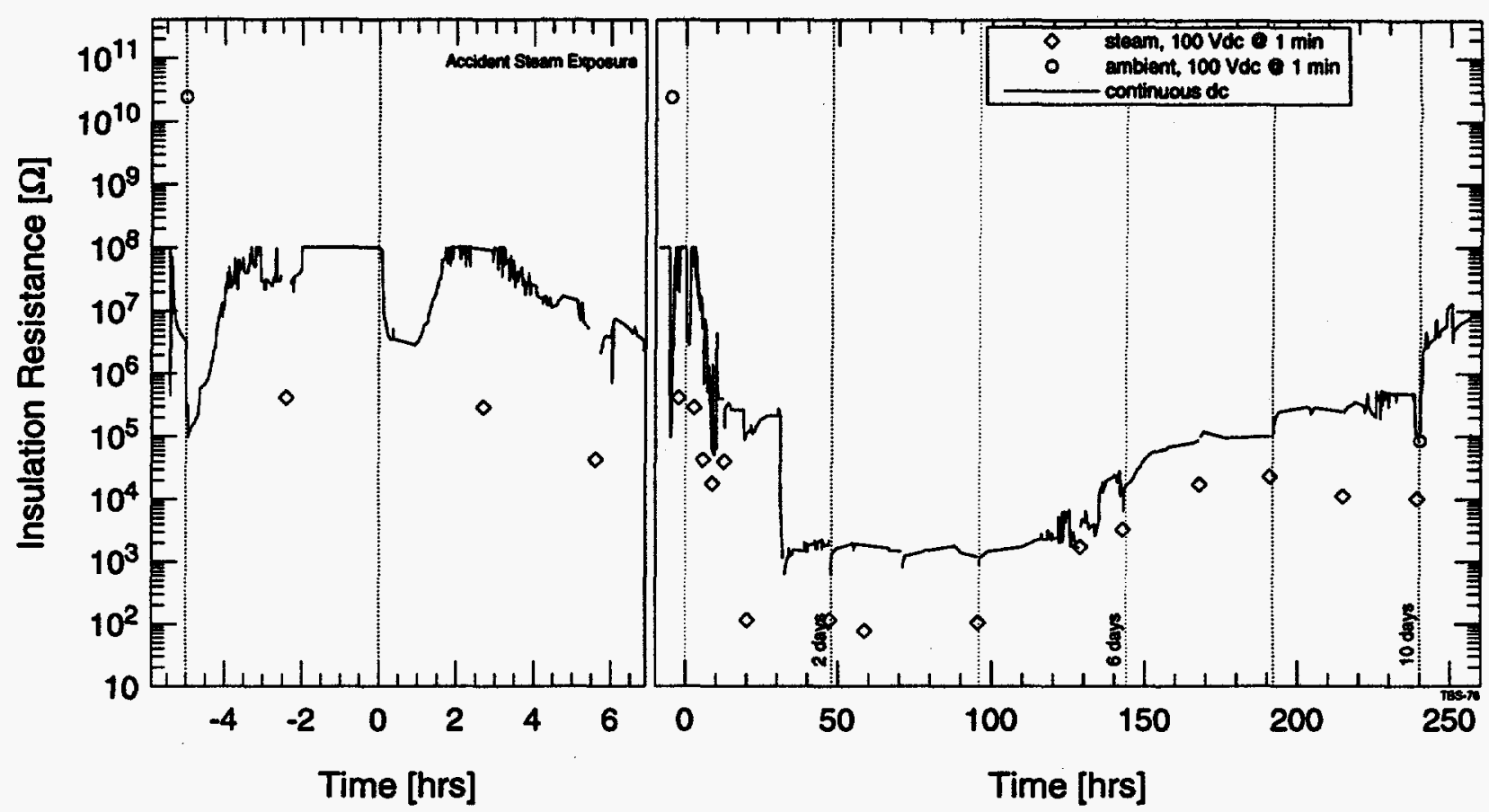

Figure A.17: IR of conductor 76 during the accident steam exposure (States dc adjacent terminal, enclosure 2).

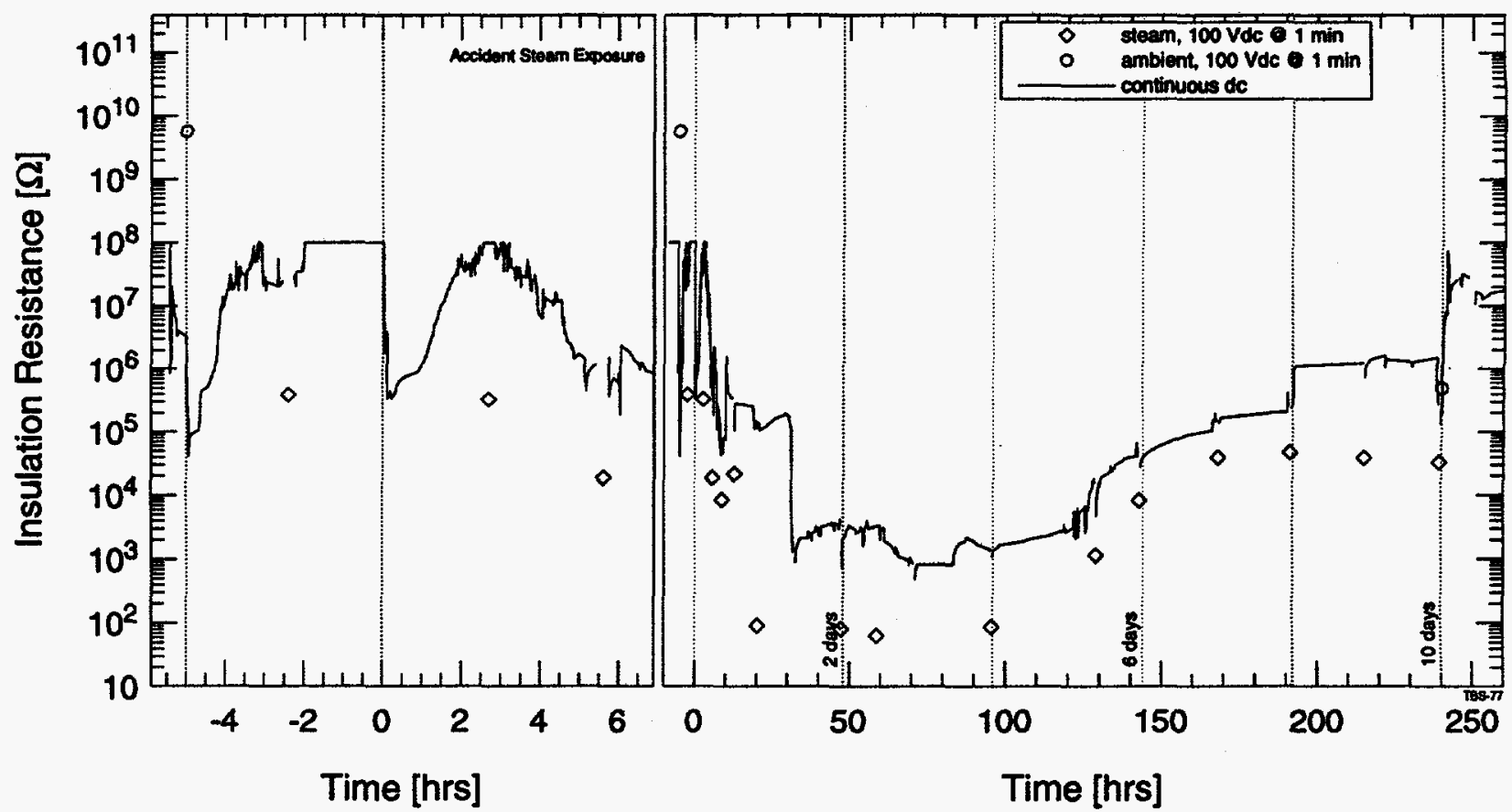

Figure A.18: IR of conductor 77 during the accident steam exposure (States dc adjacent terminal, enclosure 2). 


\section{A. TERMINAL BLOCKS}

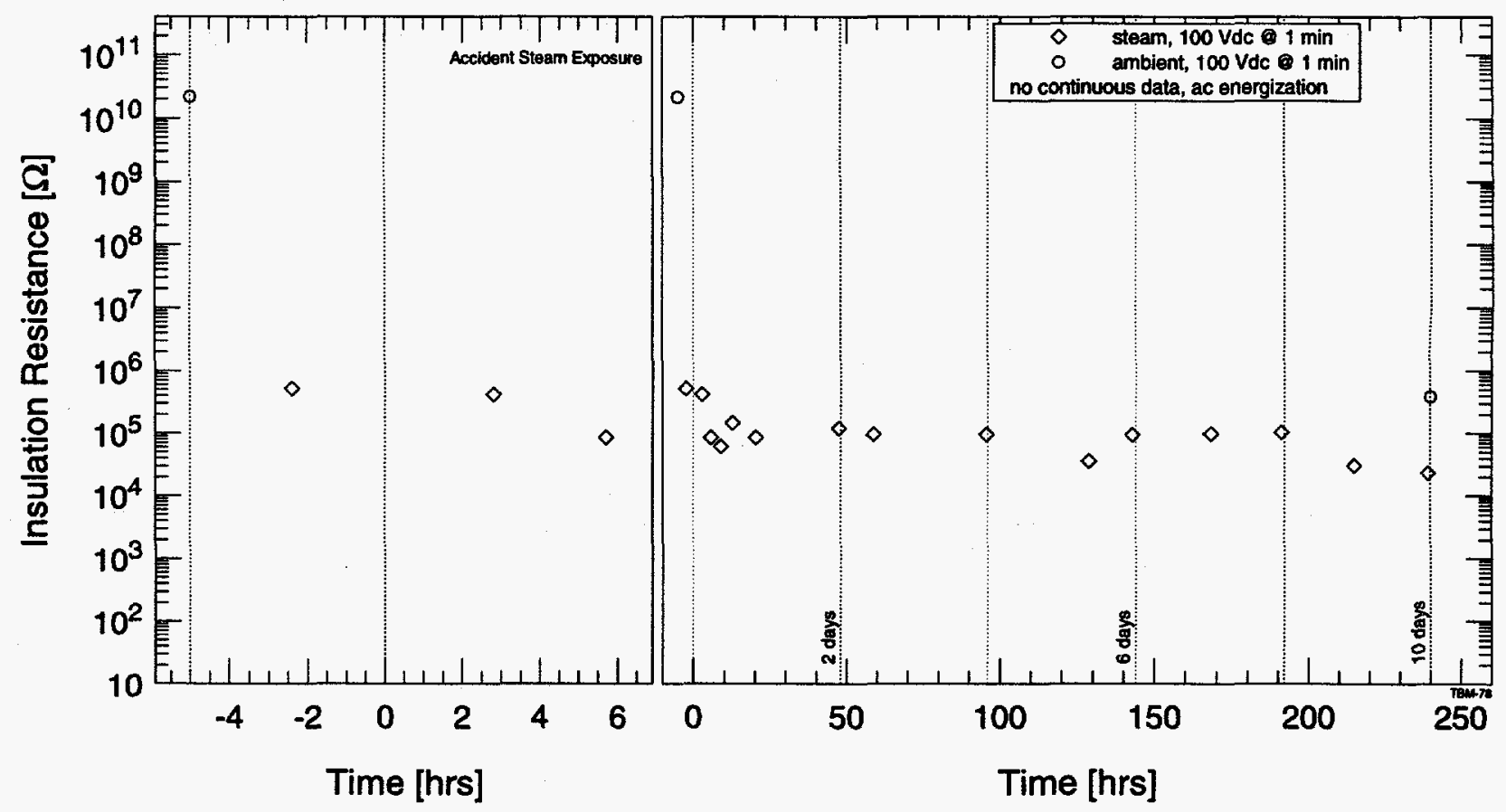

Figure A.19: IR of conductor 78 during the accident steam exposure (Marathon ac energization, enclosure 2).

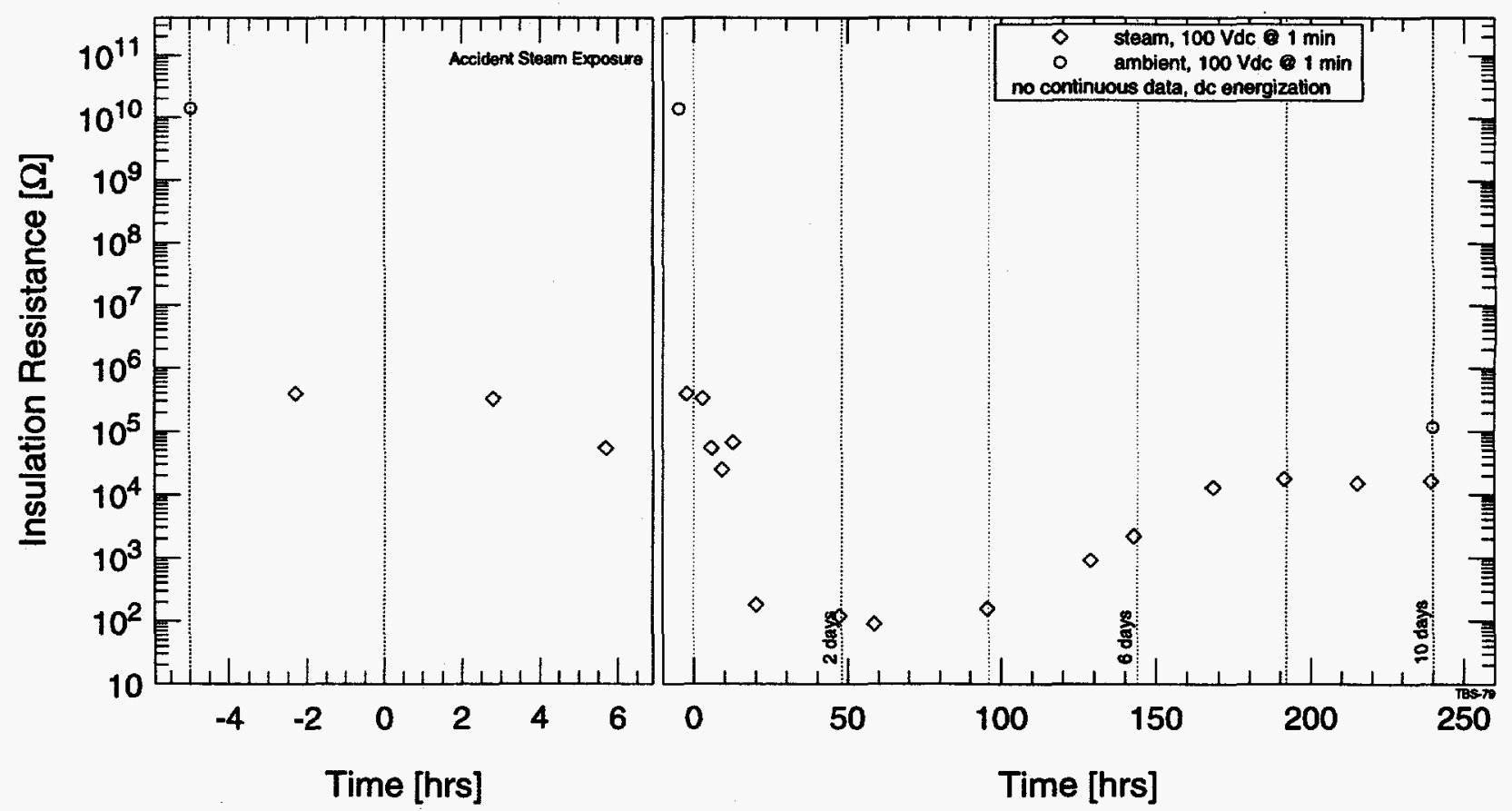

Figure A.20: IR of conductor 79 during the accident steam exposure (States dc energization, enclosure 2). 
Table A.5: Post-LOCA, Terminal Block Test Results.

\begin{tabular}{|c|c|c|c|c|c|c|c|c|}
\hline \multirow[b]{4}{*}{ Conductor $^{a}$} & \multicolumn{4}{|c|}{$100 \mathrm{Vdc}$ IR at $1 \mathrm{~min}$} & \multirow{2}{*}{\multicolumn{4}{|c|}{$\frac{\text { Dielectric Withstand (1-min hold period) }}{\text { LOCA }+23 \text { months }}$}} \\
\hline & \multirow{3}{*}{$\begin{array}{c}\text { LOCA } \\
+3 \text { days } \\
\text { Dry } \\
{[\Omega]}\end{array}$} & \multirow{2}{*}{\multicolumn{3}{|c|}{$\begin{array}{r}\text { LOCA }+13 \text { months } \\
\text { Submerged }\end{array}$}} & & & & \\
\hline & & & & & \multicolumn{2}{|c|}{ Dry } & \multicolumn{2}{|c|}{ 2-hr Submergence } \\
\hline & & $\begin{array}{l}\text { Dry } \\
{[\Omega]}\end{array}$ & $\begin{array}{l}30 \min \\
{[\Omega]}\end{array}$ & $\begin{array}{l}3 \mathrm{hr} \\
{[\Omega]}\end{array}$ & $\begin{array}{l}\text { Voltage } \\
{[\mathrm{kVac}]}\end{array}$ & $\begin{array}{l}\text { Current } \\
{[\mathrm{mAac}]}\end{array}$ & $\begin{array}{l}\text { Voltage } \\
{[\mathrm{kVac}]}\end{array}$ & $\begin{array}{l}\text { Current } \\
{[\mathrm{mAac}]}\end{array}$ \\
\hline \multicolumn{9}{|c|}{ Enclosure 1, Marathon terminal block, dc excitation during accident steam exposure } \\
\hline 66 & $5.5 \mathrm{e} 05^{b}$ & $5.0 \mathrm{e} 09$ & $1.1 \mathrm{e} 02$ & - & 1.0 & 0.4 & - & - \\
\hline 69 & $5.9 \mathrm{e} 06$ & $6.8 \mathrm{e} 09$ & $3.6 \mathrm{e} 02$ & - & 1.0 & 0.4 & - & - \\
\hline 70 & $2.3 \mathrm{e} 06$ & $7.9 \mathrm{e} 09$ & $3.6 \mathrm{e} 02$ & - & 1.0 & 0.4 & - & - \\
\hline 72 & $2.1 \mathrm{e} 07$ & $6.5 \mathrm{e} 09$ & $5.2 \mathrm{e} 02$ & - & 1.0 & 0.4 & - & - \\
\hline \multicolumn{9}{|c|}{ Enclosure 1, States terminal block, ac excitation during accident steam exposure } \\
\hline 67 & $7.7 \mathrm{e} 04$ & $6.3 \mathrm{e} 09$ & $6.6 \mathrm{e} 01$ & - & 1.0 & 0.4 & - & - \\
\hline 68 & $1.1 \mathrm{e} 07$ & $1.1 \mathrm{e} 10$ & $3.2 \mathrm{e} 02$ & - & 1.0 & 0.4 & - & - \\
\hline 71 & $2.3 \mathrm{e} 07$ & $1.5 \mathrm{e} 10$ & $2.7 \mathrm{e} 02$ & - & 1.0 & 0.7 & - & - \\
\hline \multicolumn{9}{|c|}{ Enclosure 2, States terminal block, dc excitation during accident steam exposure } \\
\hline 73 & $6.2 \mathrm{e} 04$ & $1.5 \mathrm{e} 09$ & $5.2 \mathrm{e} 01$ & - & 1.0 & 0.5 & - & - \\
\hline 76 & $8.6 \mathrm{e} 04$ & 4.5e09 & $1.9 \mathrm{e} 02$ & - & 1.0 & 0.4 & - & - \\
\hline 77 & $4.9 \mathrm{e} 05$ & $4.3 \mathrm{e} 09$ & $1.5 \mathrm{e} 02$ & - & 1.0 & 0.4 & - & - \\
\hline 79 & $1.2 \mathrm{e} 05$ & $1.4 \mathrm{e} 10$ & $1.3 \mathrm{e} 04$ & - & 1.0 & 0.5 & - & - \\
\hline \multicolumn{9}{|c|}{ Enclosure 2, Marathon terminal block, ac excitation during accident steam exposure } \\
\hline 74 & $3.4 \mathrm{e} 05$ & $7.6 \mathrm{e} 08$ & $6.4 \mathrm{e} 01$ & - & 1.0 & 0.5 & - & - \\
\hline 75 & $6.6 \mathrm{e} 06$ & $9.6 \mathrm{e} 08$ & $3.9 \mathrm{e} 02$ & - & 1.0 & 0.5 & - & - \\
\hline 78 & $3.9 \mathrm{e} 05$ & $1.5 \mathrm{e} 09$ & $3.5 \mathrm{e} 02$ & - & 1.0 & 0.9 & - & - \\
\hline
\end{tabular}

a See Table A.3 and Figure A.2 for identification of which cable the conductor came from and how the conductor was used.

b The entry $5.5 \mathrm{e} 05$ is a shorthand notation for the value $5.5 \times 10^{5}$. 



\section{B TEST FACILITIES AND RADIATION DOSIMETRY}

This appendix describes the test facilities, the techniques used to perform and measure the radiation exposures on the electrical connections tested, and presents the results of the radiation dosimetry.

\section{B.1 Test Facilities}

\section{B.1.1 LICA Facility}

The Low Intensity Cobalt Array (LICA) facility is located in the north end of Building 867 in Technical Area 1 at Sandia National Laboratories in Albuquerque, NM. It consists of radioactive sources and their associated test fixtures at the bottom of a $5.64-\mathrm{m}(18 \mathrm{ft}, 6 \mathrm{in})$ deep, water-filled pool as shown in Figure B.1. The LICA facility is used to perform radiation exposures for a wide variety of test specimens and components.

All the test fixtures are located at the bottom of the pool and all experiments take place at the bottom of the pool-the sources are never taken near the surface because the pool water provides radiation shielding. Radiation is produced by cobalt-60 (Co-60) sources; Co-60 is a source of gamma radiation that is nonactivating; thus exposed specimens and test fixtures do not become radioactive and can be removed from the LICA facility and handled with no further precautions.

The LICA pool contains 6 test fixtures; these are:

1. North Linear Array (fixed Co-60 configuration)

2. South Linear Array (fixed Co-60 configuration)

3. Circular Array (fixed Co-60 configuration)

4. High Intensity Cobalt Array (HICA) Fixture (movable Co-60 configuration)

5. Large Chamber Cobalt Fixture (movable Co-60 configuration)

6. Large Chamber Cobalt Fixture (movable Co-60 configuration)

As of January 1992, the 3 fixtures with fixed Co-60 configurations could provide dose rates ranging from 10 to $3,000 \mathrm{~Gy} / \mathrm{hr}(1-300 \mathrm{krad} / \mathrm{hr})$. The fixtures accept cylindrical test cans that have an interior diameter of $127 \mathrm{~mm}$ ( $5 \mathrm{in}$ ) and an interior height of $305 \mathrm{~mm}$ (12 in). These cans are typically used to irradiate samples of polymer materials, integrated circuits, electronic sensors, and other small items. The dose rate to the specimens is controlled by the location of the test can within the fixture.

The 3 fixtures with movable Co-60 configurations provide the capability for irradiation of larger specimens. There are $32 \mathrm{Co}-60$ sources, supplied by Neutron Products Inc. (Dickerson, MD), that can be used in the HICA and large chamber fixtures. Each source is $673.1 \mathrm{~mm}$ (26.5 in) long by $15.9 \mathrm{~mm}(0.625 \mathrm{in})$ outside diameter-cobalt is contained only in the middle $609.6 \mathrm{~mm}$ (24 in) of each source. The dose rate for these fixtures is set by changing the number and/or location of the cobalt sources installed in the fixture while the test chamber remains at a fixed location. The smaller test chamber, used in the HICA fixture, has an interior diameter of $254 \mathrm{~mm}$ (10 in) and an interior height of $667 \mathrm{~mm}$ (26.25 in). The test chambers used in the large chamber fixtures have an interior diameter of $521 \mathrm{~mm}(20.5 \mathrm{in})$ and an interior height in excess of $1219 \mathrm{~mm}$ (48 in). As of January 1992 , the total activity of the 32 sources was approximately $51 \mathrm{kCi}$, allowing dose rates in the large chamber fixtures of up to approximately $3,000 \mathrm{~Gy} / \mathrm{hr}(300 \mathrm{krad} / \mathrm{hr})$. The large test chambers are typically used to irradiate complete cable specimens or other large items of equipment from nuclear power plants. A side view of a large chamber fixture (and a test chamber) is shown in Figure B.2, and a top view of one of the fixtures is shown in Figure B.3, which gives the configuration of the tubes into which the Co-60 sources are placed. The two fixtures are identical except that one has only 16 source locations around the test chamber opening instead of the 32 locations shown in Figure B.3. The large chamber fixtures are made of aluminum and are watertight (i.e., they are filled with air) to minimize the amount of shielding between the cobalt sources and the test chamber.

All of the various test cans and chambers have the capability to simultaneously expose test specimens to controlled, elevated temperatures during the 


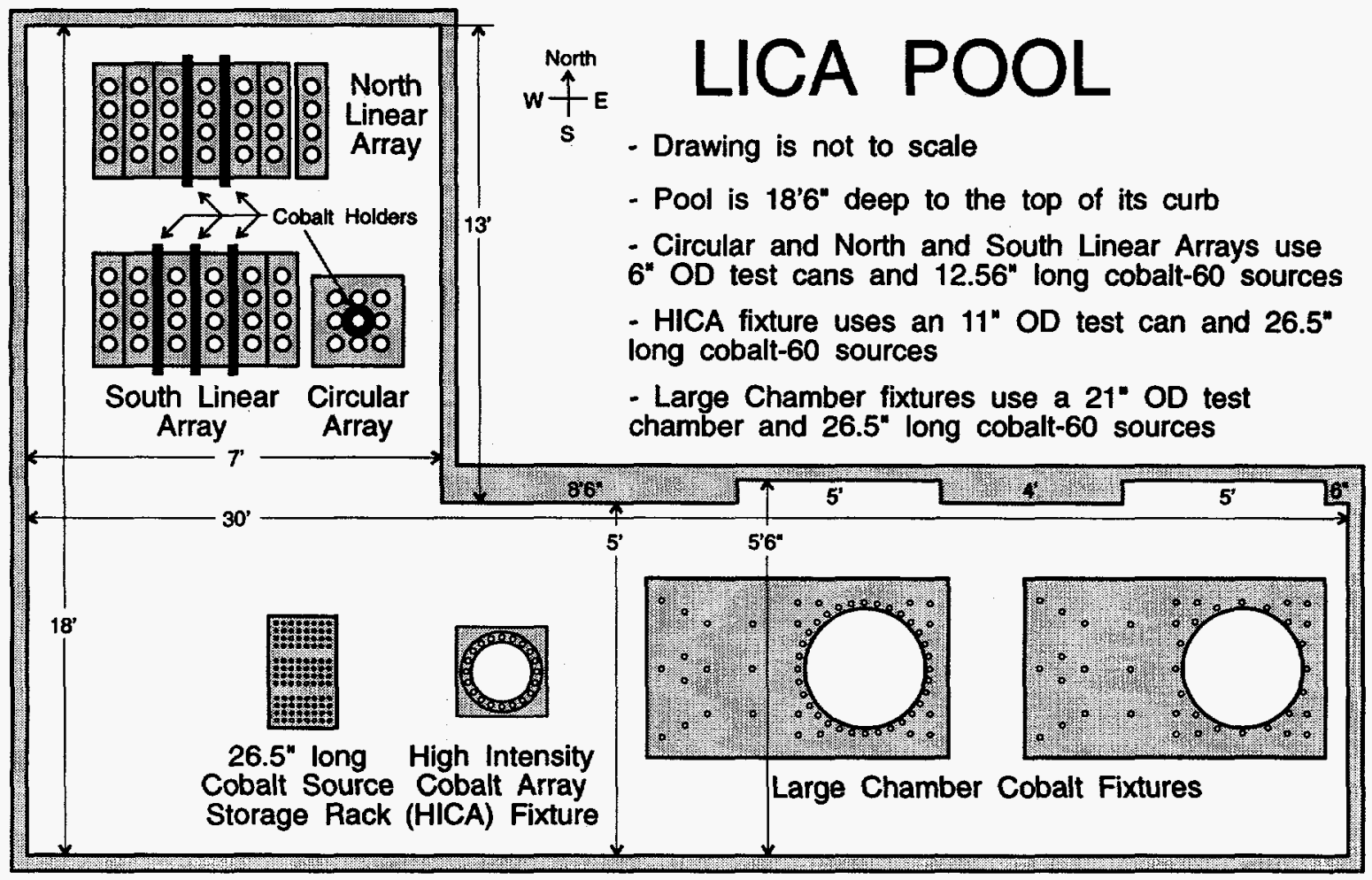

Figure B.1: Plan view of the LICA pool and fixtures.

irradiations in order to simulate simultaneous thermal and radiation aging conditions. Provisions are available for remote powering and monitoring of the items under test. Various gaseous environments can be introduced into the test chambers, with the greatest environment flexibility in the small test cans. Depending on the needs of the experiments being conducted, the test chambers can be exposed to positive or negative gauge pressures.

\section{B.1.2 Steam Exposure Facility}

The Steam Exposure Facility is located in the north end of Building 867 in Technical Area 1 at Sandia National Laboratories in Albuquerque, NM. It is used to simulate steam environments characteristic of loss-of-coolant accidents (LOCA) and severe accidents. This system incorporates superheaters and a large accumulator to produce the initial temperature-pressure transients required during simulation of an accident steam exposure. The schematics for this facility are shown in Figures B.4 and B.5.
The steam exposure facility uses the same test chambers as those in the LICA large chamber fixtures. Thus, test articles can be thermally and radiation aged in the LICA pool, then immediately exposed to a nuclear power plant LOCA simulation without being removed from the test chamber. This minimizes the possibility of damaging the test articles because of the handling necessary to transfer specimens between fixtures for the various stages of a test. The steam system can produce pressures of up to $1380 \mathrm{kPa}$ (200 psig) and temperatures of $400^{\circ} \mathrm{C}\left(752^{\circ} \mathrm{F}\right)$.

\section{B.1.3 Coordinate System}

In order to describe the location of objects, a coordinate system must be defined. The fixture coordinate system is based on the fixture that holds the cobalt sources and the test chamber. Figures B.2 and B.3 show this coordinate system. The $z$-axis is in the vertical direction, and thus the $x y$-plane is horizontal. The $x y$-origin is at the center of the opening into which the test chamber will fit, and the plane $z=0$ passes through the 
(1) Cobalt Fixture (Sandia Dwgs. S81456-S81459)

(2) Cobalt Fixture Rack (Sandia Dwg. S81460)

(3) Cobalt Fixture Test Chamber Support (Sandia Dwg. S81461) 20

(4) Cobalt-60 Source (Neutron Products Dwg. A200196)

(5) Test Chamber Head (Sandia Dwg. T56666)

(6) Test Chamber Bottom (Sandia Dwgs. T56667, T73614)

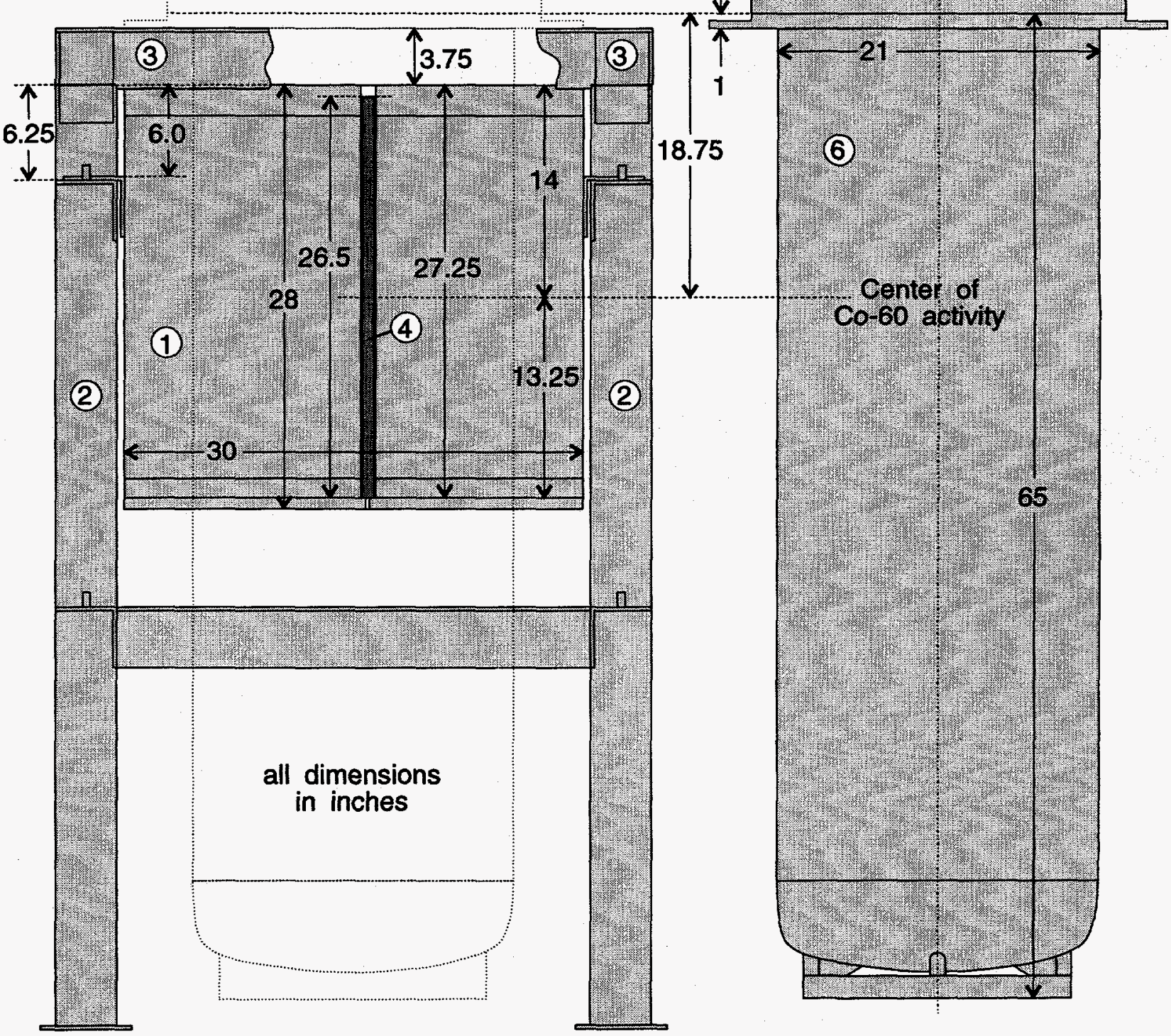

Figure B.2: Sketch of a test chamber and large chamber cobalt fixture. 


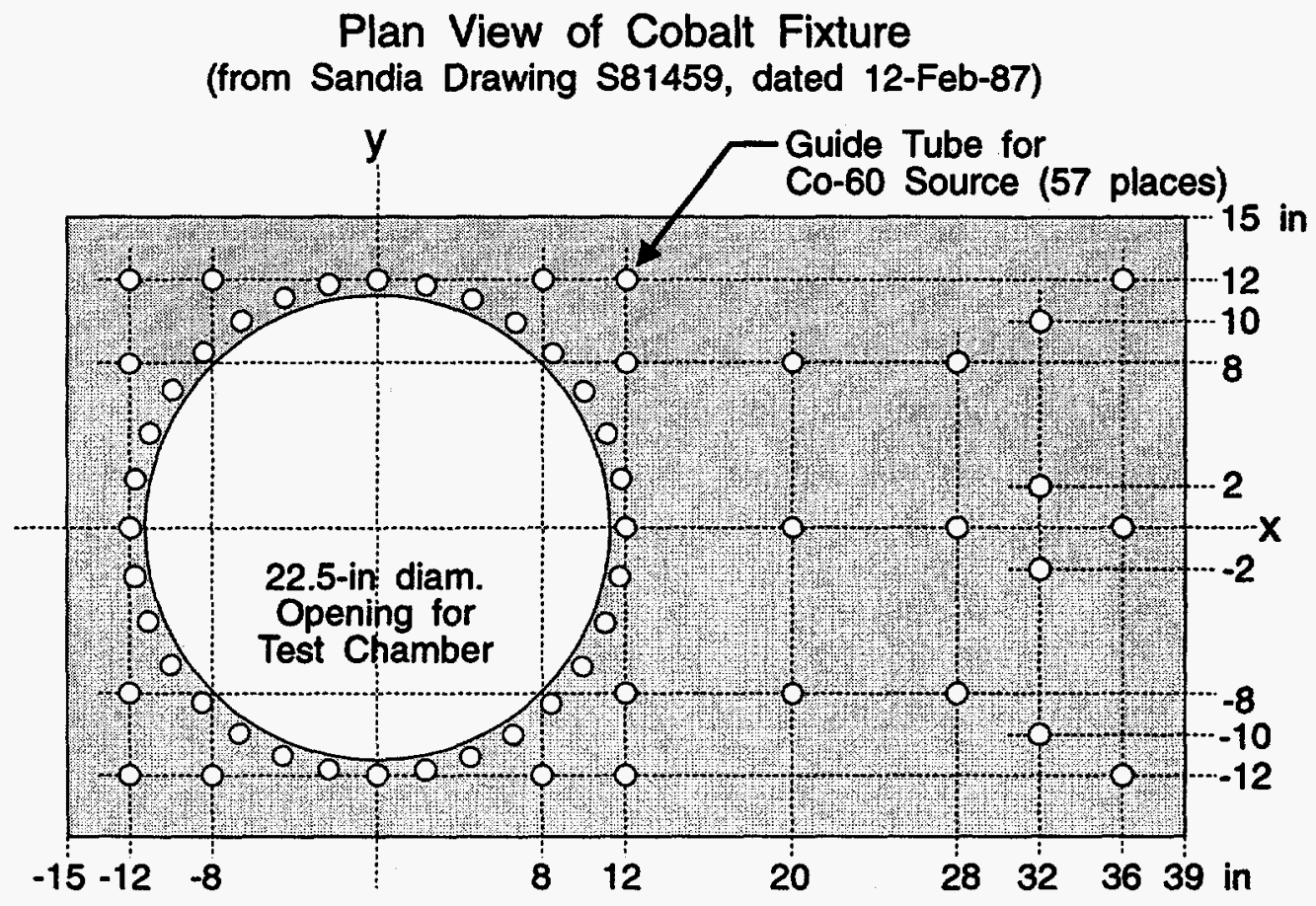

$z=0$ is at the centerline of the Co-60 sources in the vertical direction

Figure B.3: Plan view of large chamber cobalt fixture showing the fixture coordinate system and possible cobalt source locations.

vertical midpoint of the cobalt sources. The fixture coordinate system is used for all the figures in this appendix - an angle of $0^{\circ}$ is along the $x$-axis and $90^{\circ}$ is along the $y$-axis.

A second coordinate system is the chamber coordinate system, which is tied to the test chamber itself. This coordinate system can be rotated in relation to the fixture coordinate system by rotating the test chamber in its fixture.

\section{B.2 Radiation Dosimetry}

\section{B.2.1 Dosimetry Technique}

Thermoluminescent dosimetry was used to quantify the dose rates used in this test program. Dosimetry was performed using the following steps:

1. The specimens were installed in the test chamber in their radiation exposure configuration for the ensuing test.
2. Thermoluminescent dosimeters (TLDs) were then placed in the test chamber and on the test specimens at various locations.

3. The test chamber was then sealed and placed in the radiation environment to expose the TLDs to an optimum measurement dose (17-120 Gy was used for the aging dosimetry TLD exposures and the 1- $\sigma$ uncertainty in the measured dose was between $4 \%$ and $6 \%$; likewise, the accident dosimetry used 500-860 Gy with an uncertainty between $8 \%$ and $9 \%$ ).

4. After the proper exposure time, the test chamber was removed from the radiation field and the TLDs were rernoved and sent to be read.

5. The test chamber was then resealed and placed back in the radiation field to start the aging or accident radiation exposure of the connection samples.

Dosimetry was performed with the connections in their test configuration to give the most accurate measure of the as-tested dose rate. 


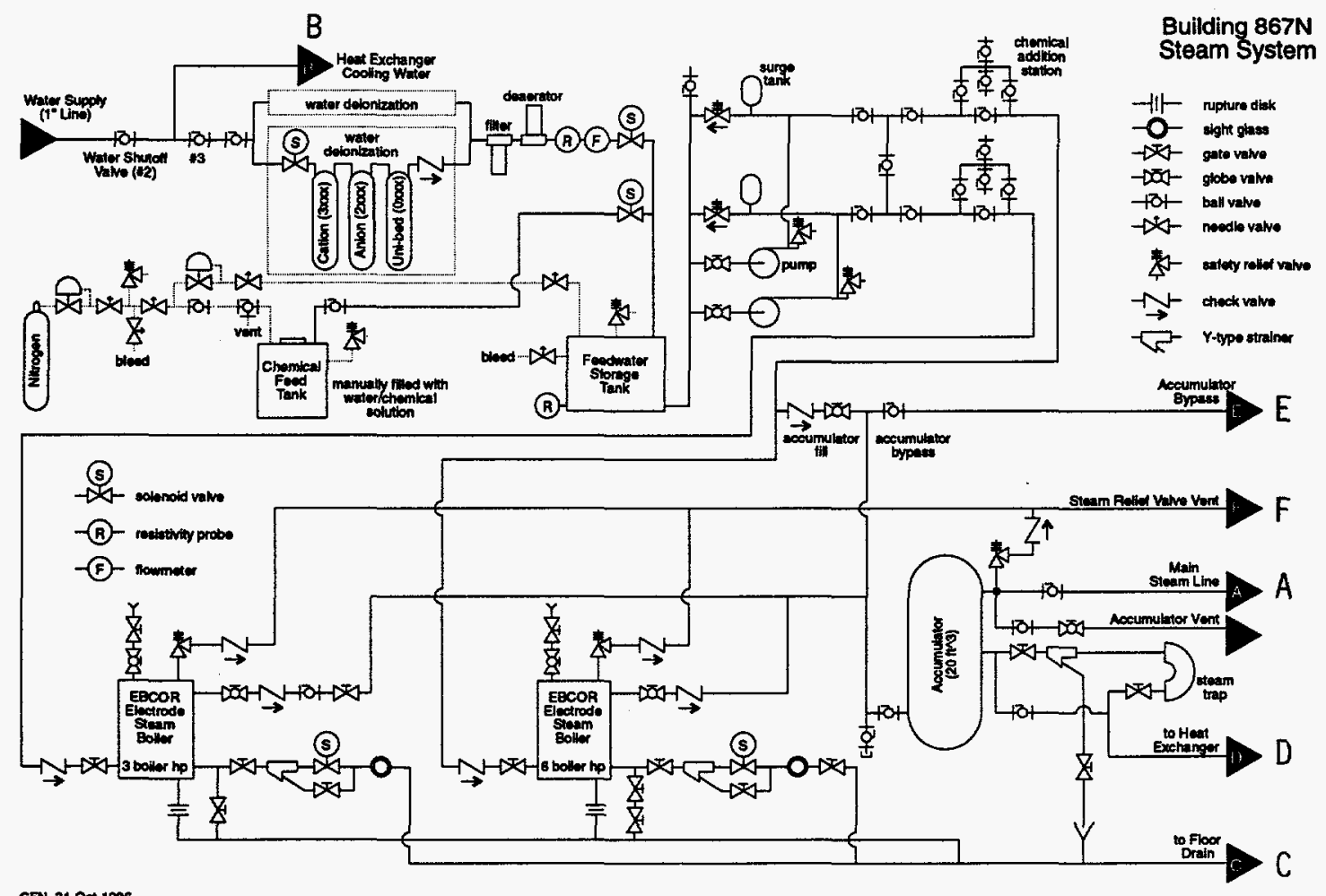

Figure B.4: Steam Exposure Facility-steam generation and storage.

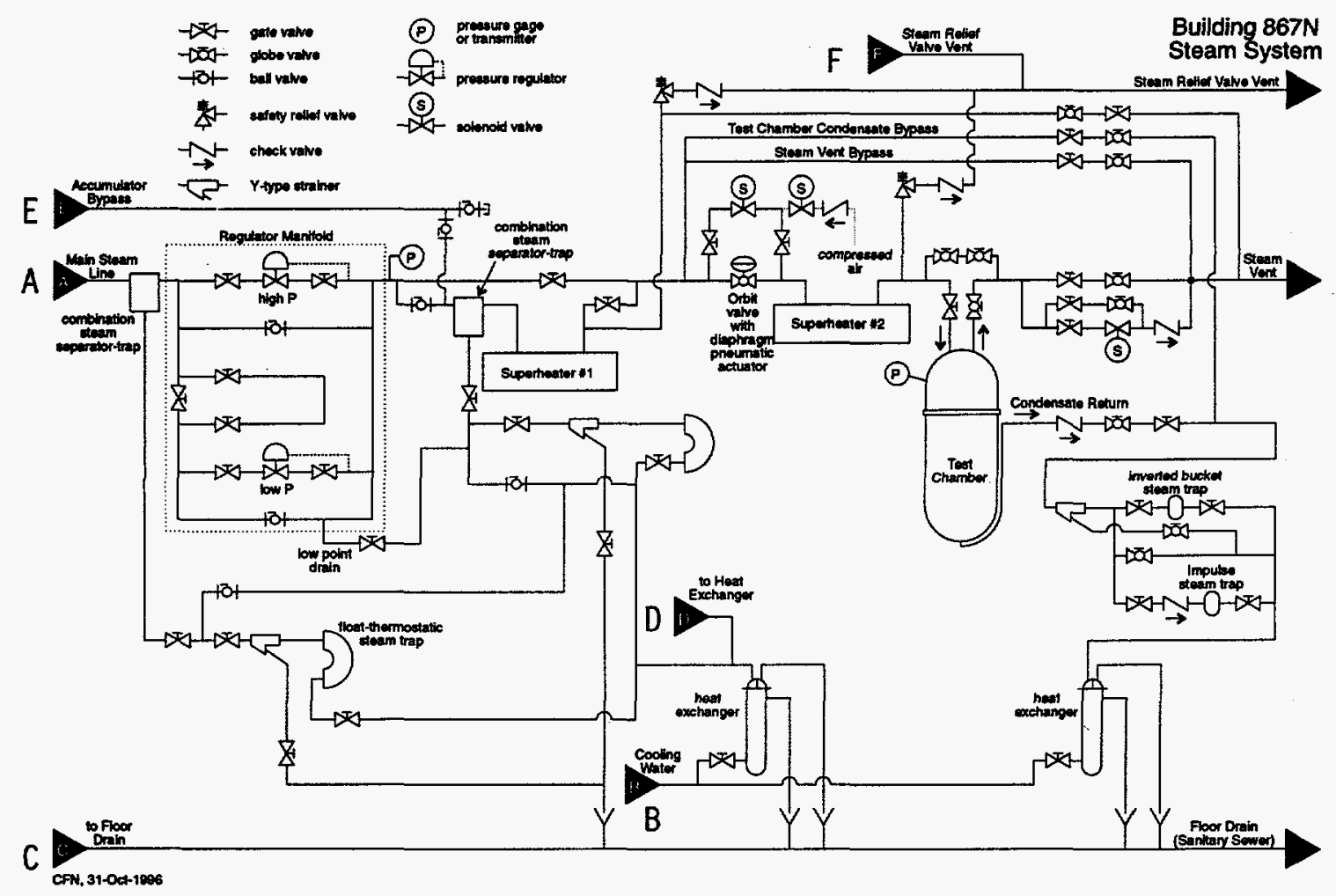

Figure B.5: Steam Exposure Facility-superheaters and steam delivery. 
The Radiation Dosimetry Laboratory at Sandia National Laboratories provided the TLDs and also read the TLD exposures. Their equipment and techniques follow ASTM E668 [1], and the resulting values for radiation exposure are traceable to the National Institute of Standards and Technology (NIST). Harshaw TLD 400 dosimeters were used. These are small (approximately $6 \mathrm{~mm}$ square by $5 \mathrm{~mm}$ thick) calcium fluoride $\left(\mathrm{CaF}_{2}\right)$ crystals doped with manganese (Mn). When a TLD is heated, it emits an amount of light that is proportional to its radiation exposure. A Harshaw Atlas hot gas reader was used to heat the TLD and the emitted light was measured using a photomultiplier tube connected to a picoammeter that integrated the amount of emitted light. The picoammeter reading was then converted to a radiation dose using the appropriate calibration.

\section{B.2.2 Aging Irradiation}

Radiation dosimetry was performed to quantify the aging radiation field to which the test samples were exposed. As shown in Figure B.6, three Co-60 sources were used to produce the aging radiation field for the connection test specimens in the test chamber; the dosimetry was performed using a single TLD at each of 92 different locations. The resulting aging dose rate at the outside of the mandrel is shown in Figure B.7.

\section{B.2.3 Accident Irradiation}

Radiation dosimetry was performed to quantify the accident radiation field to which the test samples were exposed. As shown in Figure B.8, 32 Co-60 sources were used to produce the accident radiation field; the dosimetry was performed using a single TLD at each of 40 different locations. The resulting accident dose rate is shown in Figure B.9. 


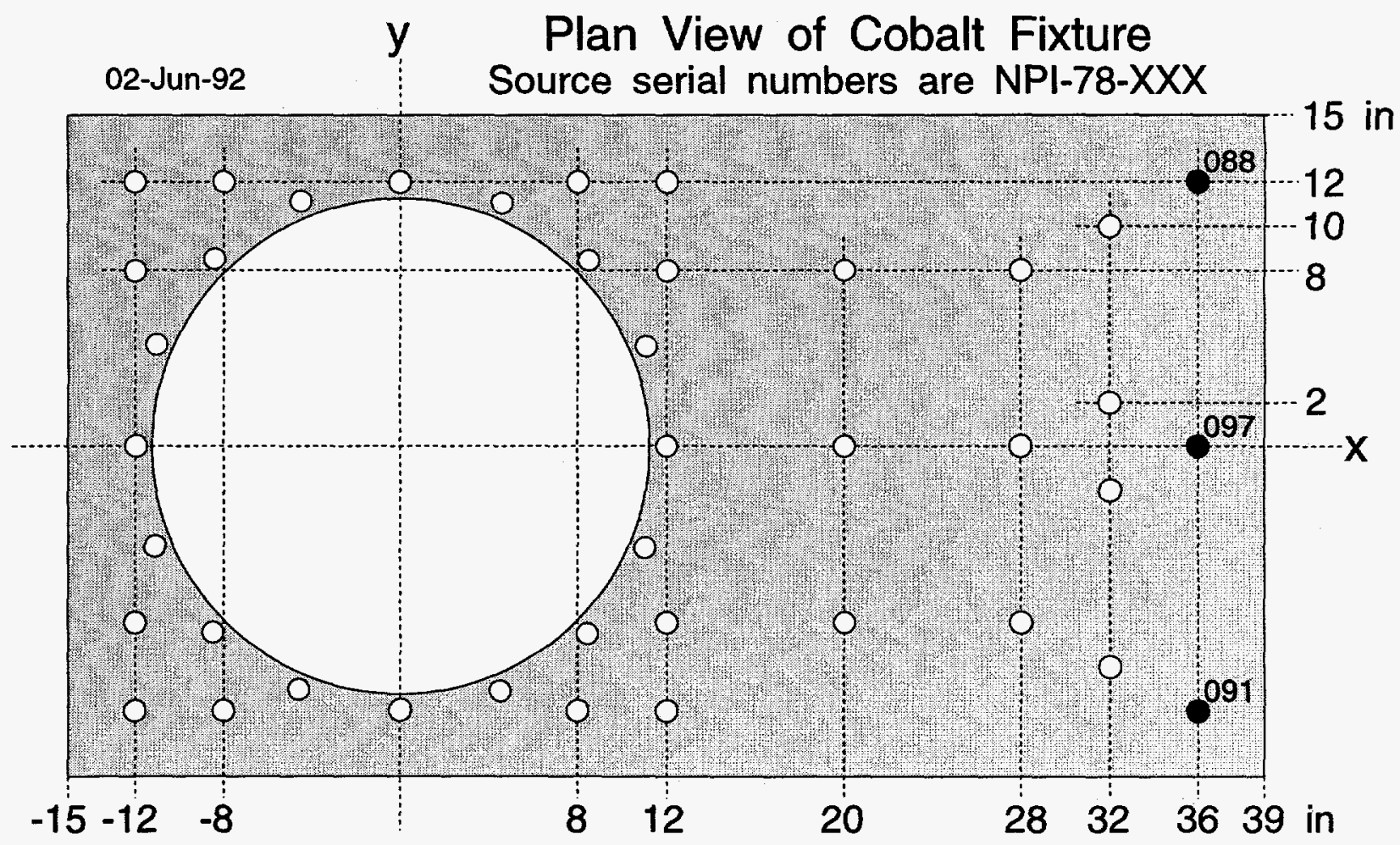

Figure B.6: Cobalt-60 source configuration for aging irradiation (black circles are guide tubes filled with a Co- 60 source and white circles are empty guide tubes).

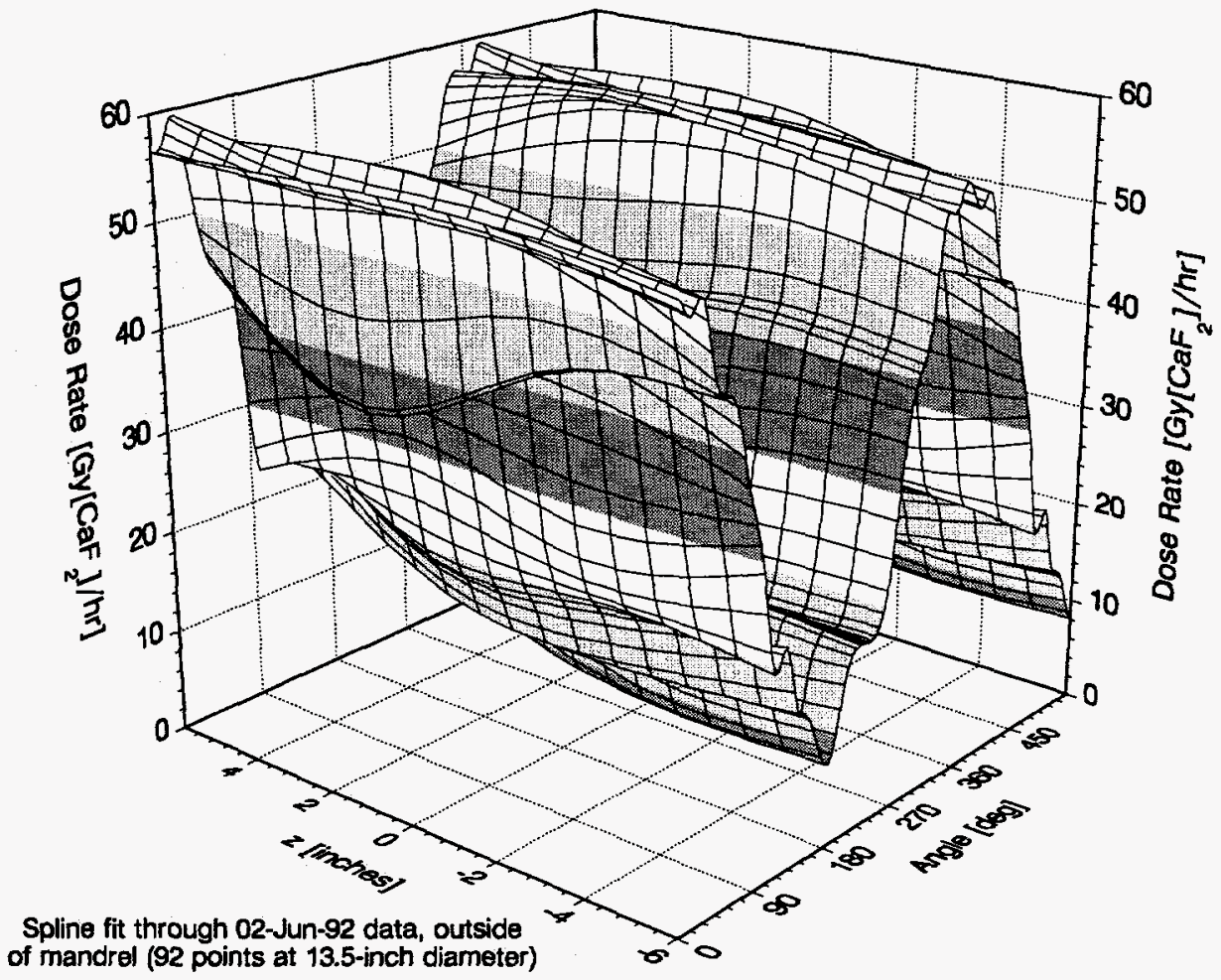

Figure B.7: Aging radiation dose rate-spline fit through data $\left(0^{\circ}\right.$ corresponds to $x=6.75$ inches, $y=$ 0 inches). 


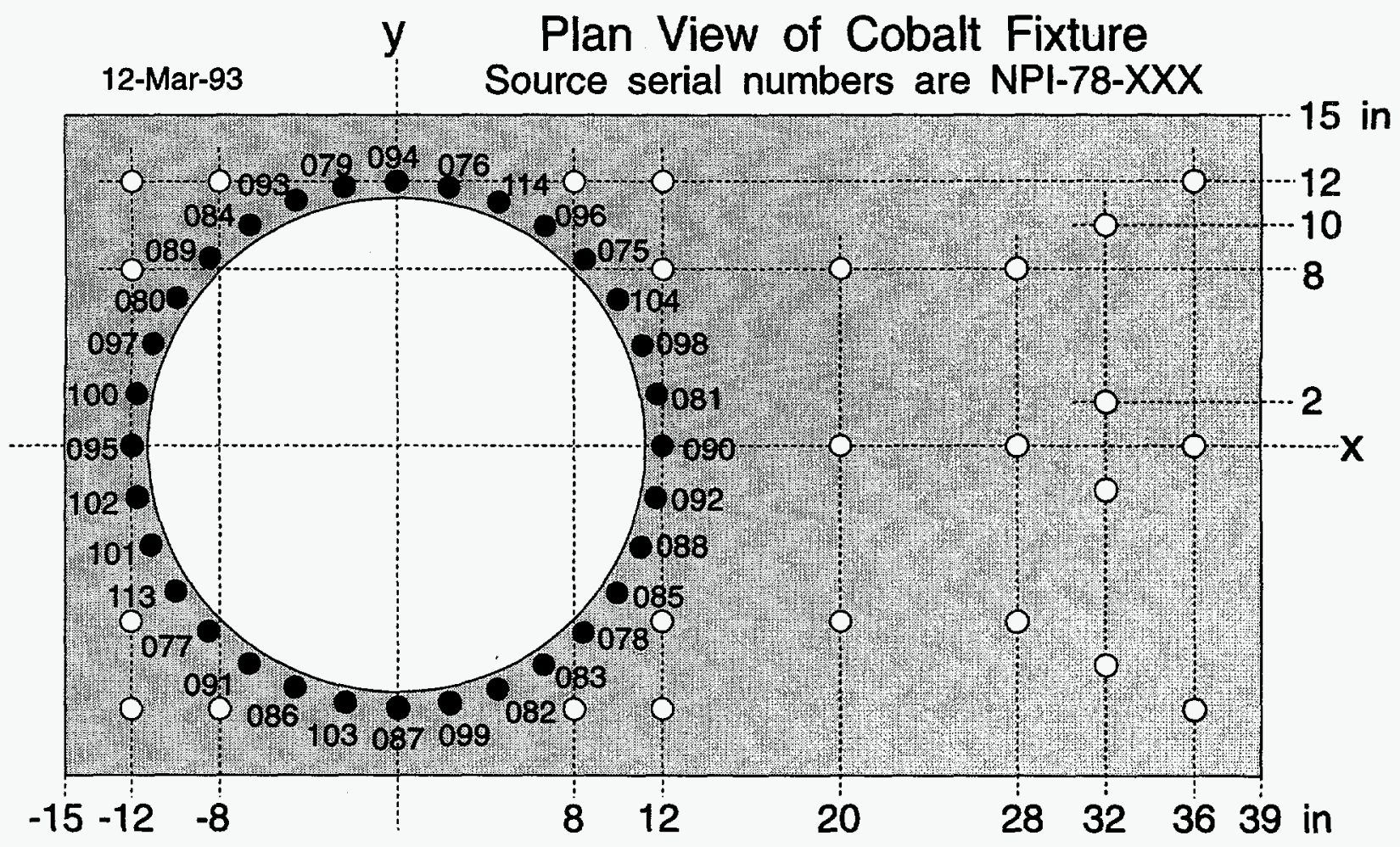

Figure B.8: Cobalt-60 source configuration for accident irradiation (black circles are guide tubes filled with a Co-60 source and white circles are empty guide tubes).

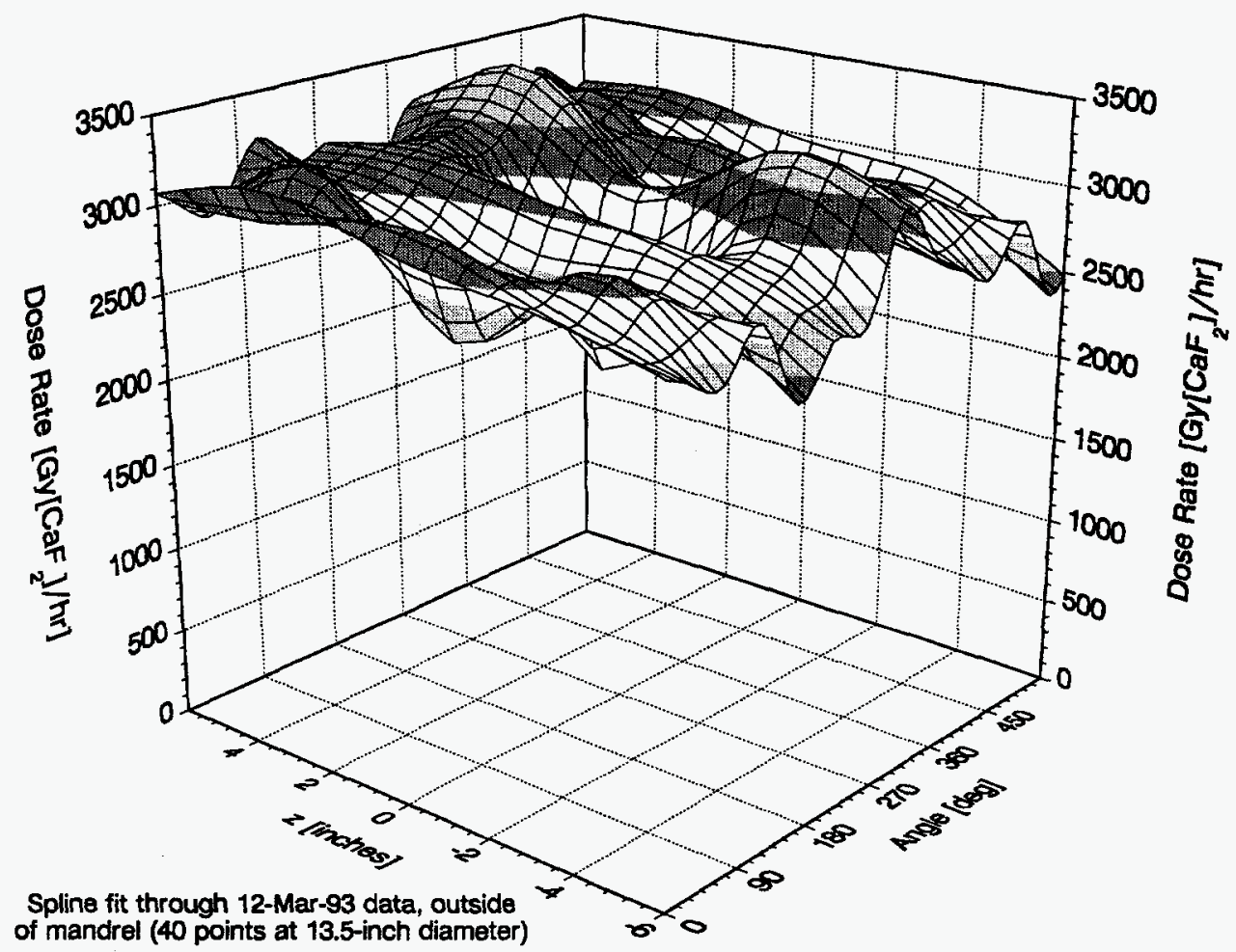

Figure B.9: Accident radiation dose rate- spline fit through data $\left(0^{\circ}\right.$ corresponds to $x=6.75$ inches, $y=0$ inches). 


\section{TIME DOMAIN REFLECTOMETRY RESULTS}

This section presents the experimental time domain reflectometry (TDR) data ${ }^{1}$ acquired for the 10 different types of connections and the 2 types of cables that were tested. TDR measurements were performed immediately before the accident steam exposure, immediately after the accident steam exposure (identified as "poststeam \#1" in Figures C.1-C.12), and approximately 26 months after the accident steam exposure (identified as "poststeam \#2" in Figures C.1-C.12) with identical test parameters. The connections were located approximately $9.1 \mathrm{~m}$ $(30 \mathrm{ft})$ down the cable.

The TDR data are presented as plots of reflection coefficient, $\rho$, versus distance down the cable, where:

$$
\rho=\frac{V_{\text {reflected }}}{V_{\text {incident }}}=\frac{Z_{L}-Z_{0}}{Z_{L}+Z_{0}}
$$

which can be rewritten as

$$
Z_{L}=Z_{0} \frac{1+\rho}{1-\rho}
$$

where

$$
\begin{aligned}
& \rho=\text { reflection coefficient, } \\
& Z_{0}=\text { characteristic impedance of cable } \\
& \text { (transmission line), and } \\
& Z_{L}=\text { load impedance. }
\end{aligned}
$$

The reflection coefficient is the ratio of the voltage applied to the cable divided by the voltage reflected back from the cable or circuit due to cable faults or changes in impedance. If there is an open circuit $\left(Z_{L}=\infty\right)$ in the cable, nearly all the energy will be reflected back when a pulse is sent down the cable. The reflected voltage will equal the incident pulse voltage and $\rho$ will be +1 . If there is a short circuit $\left(Z_{L}=0\right)$ in the cable, nearly all the energy will be delivered back to the instrument through a ground or return conductor instead of being sent on to the load. The polarity of the reflected pulse will be the opposite of the incident pulse and $\rho$ will be -1 . If there is no mismatch between the cable and the load $\left(Z_{L}=Z_{0}\right)$, almost no energy will be reflected back and $\rho$ will be 0 . In general, a load or fault with higher impedance than the cable will return a $\rho$ measurement of 0 to +1 , and a load or fault with a

\footnotetext{
${ }^{1}$ In addition to the figures included in this section, all the raw data are available upon request from the author.
}

lower impedance will return a $\rho$ measurement of 0 to -1 .

A value of 25,50 , or $100 \mathrm{~m} \rho(-25,-50$, or $-100 \mathrm{~m} \rho)$ corresponds to an impedance increase (decrease) of $5.1,10.5$, and $22.2 \%(4.9,9.5$, and $18.2 \%)$, respectively. 


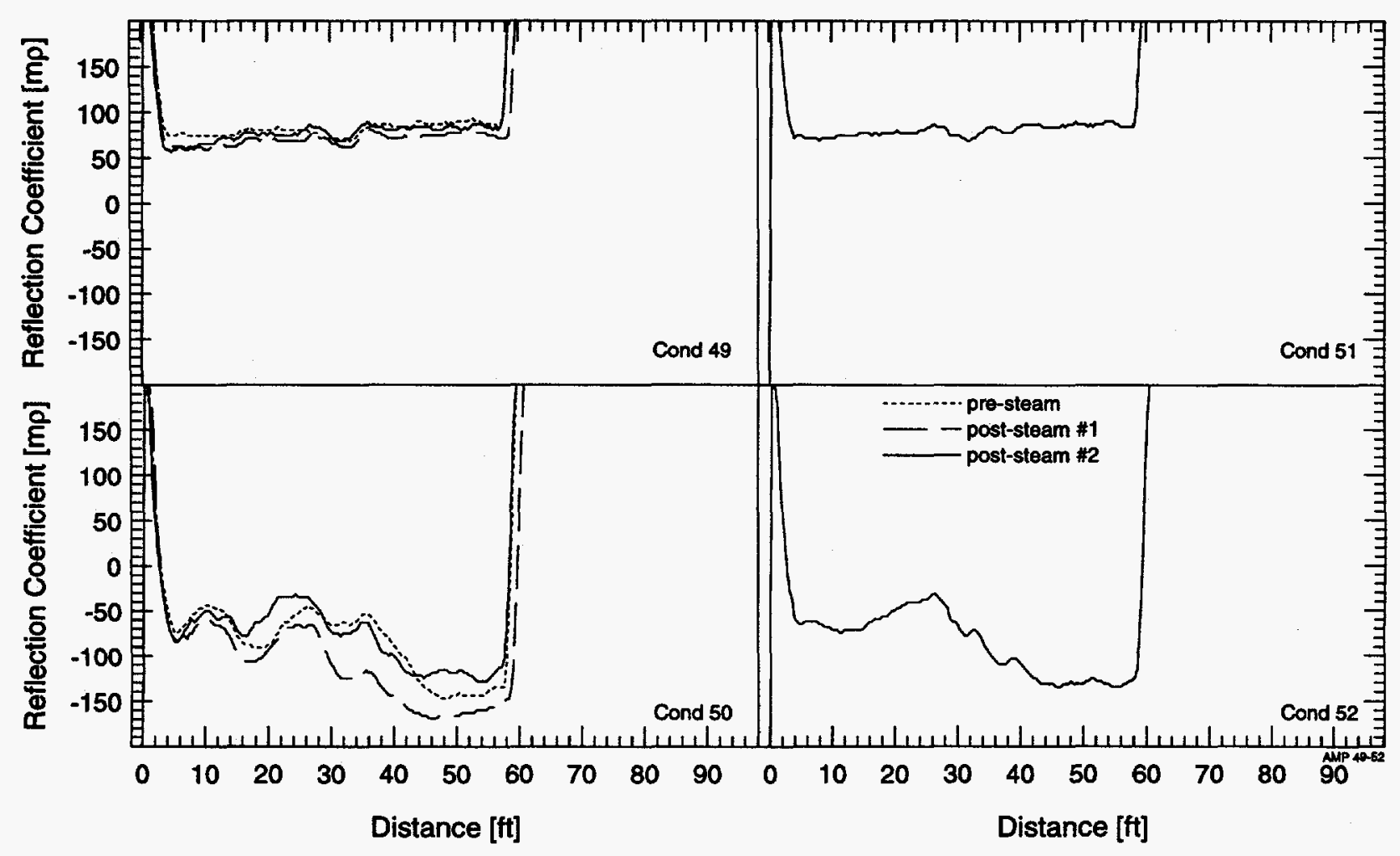

Figure C.1: TDR of the Amphenol coaxial connector conductors before and after the accident steam exposure. 


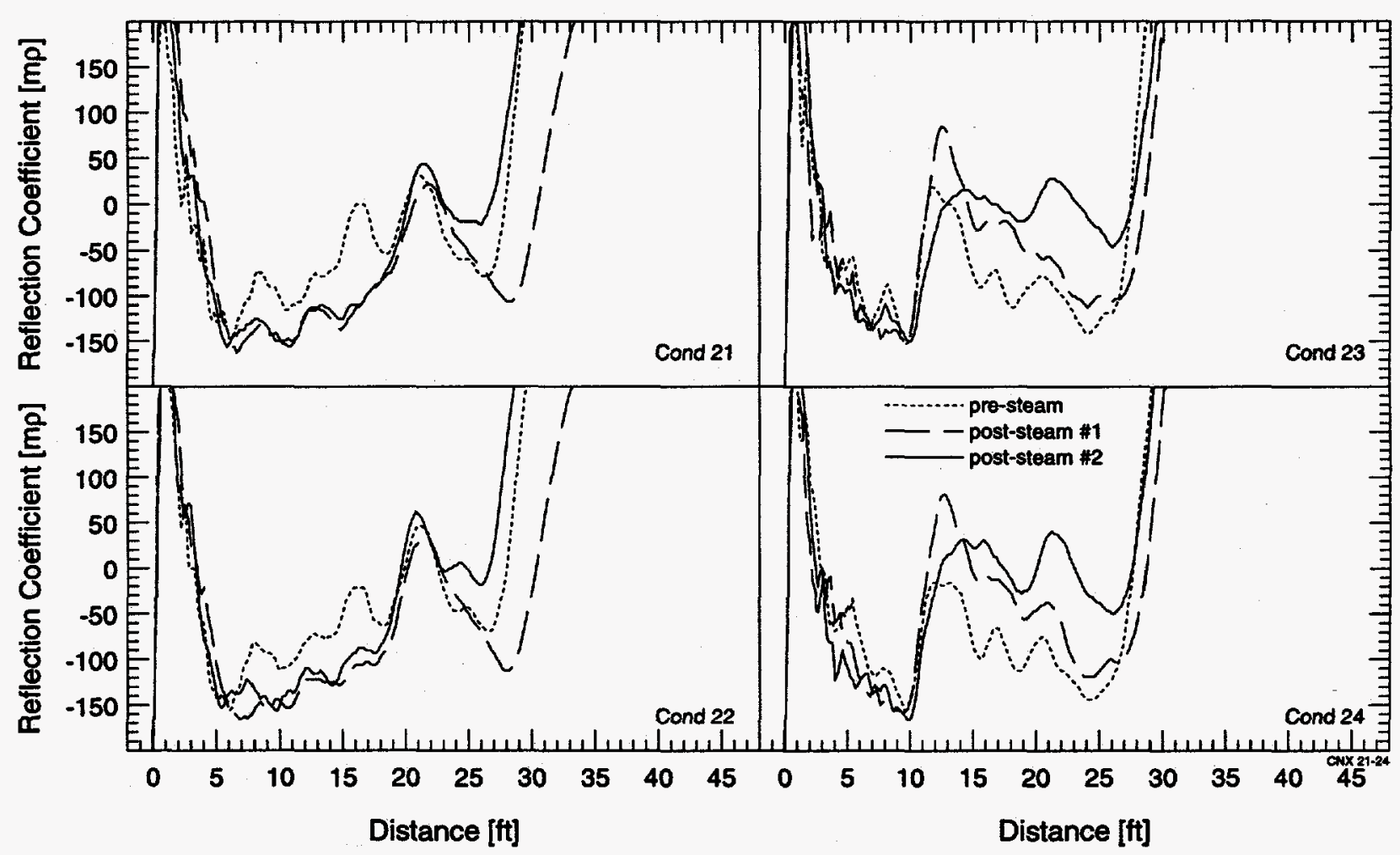

Figure C.2: TDR of the Conax Buffalo ECSA conduit seal conductors before and after the accident steam exposure. 
C. TIME DOMAIN REFLECTOMETRY RESULTS

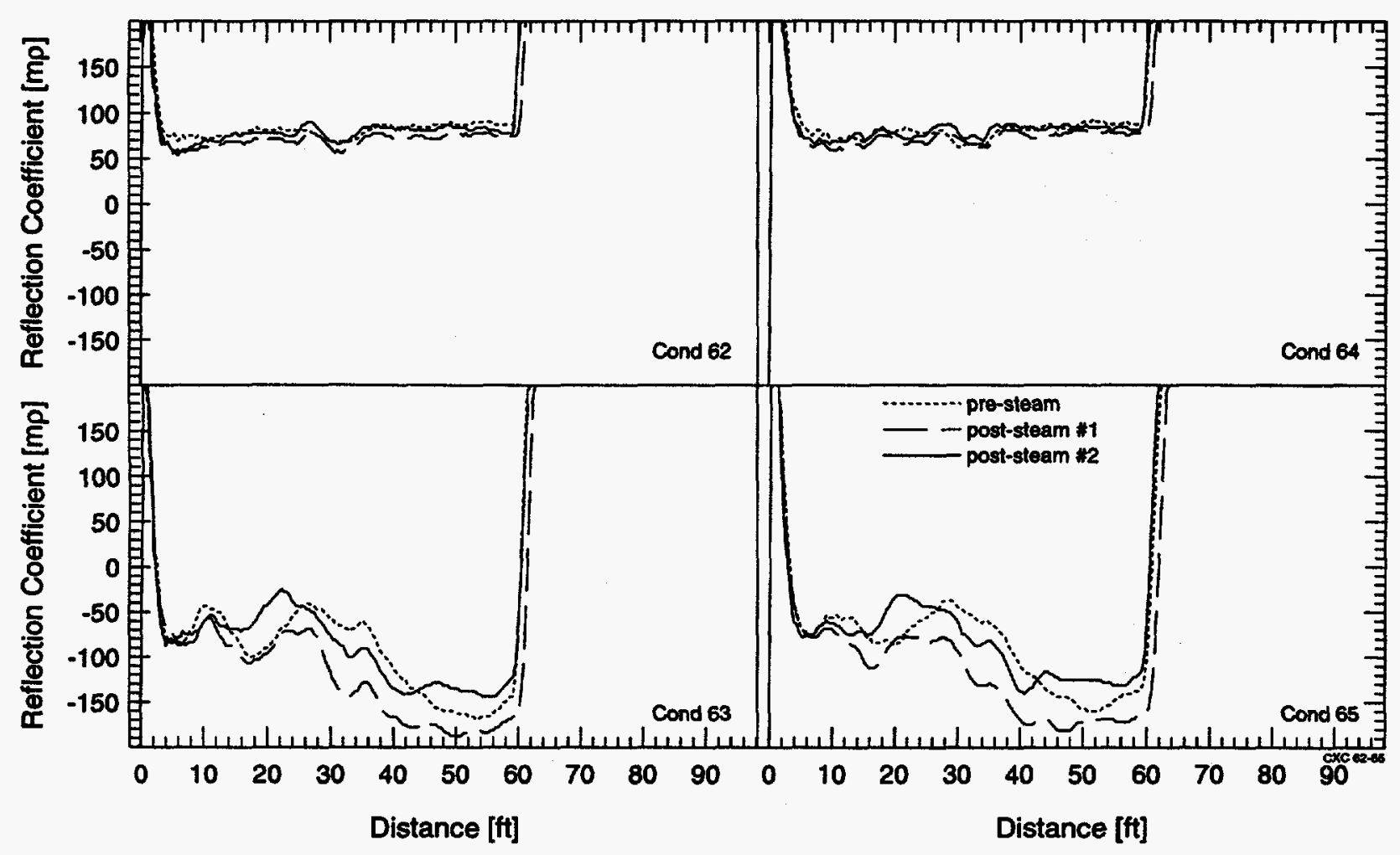

Figure C.3: TDR of the Rockbestos coaxial cable conductors before and after the accident steam exposure. 


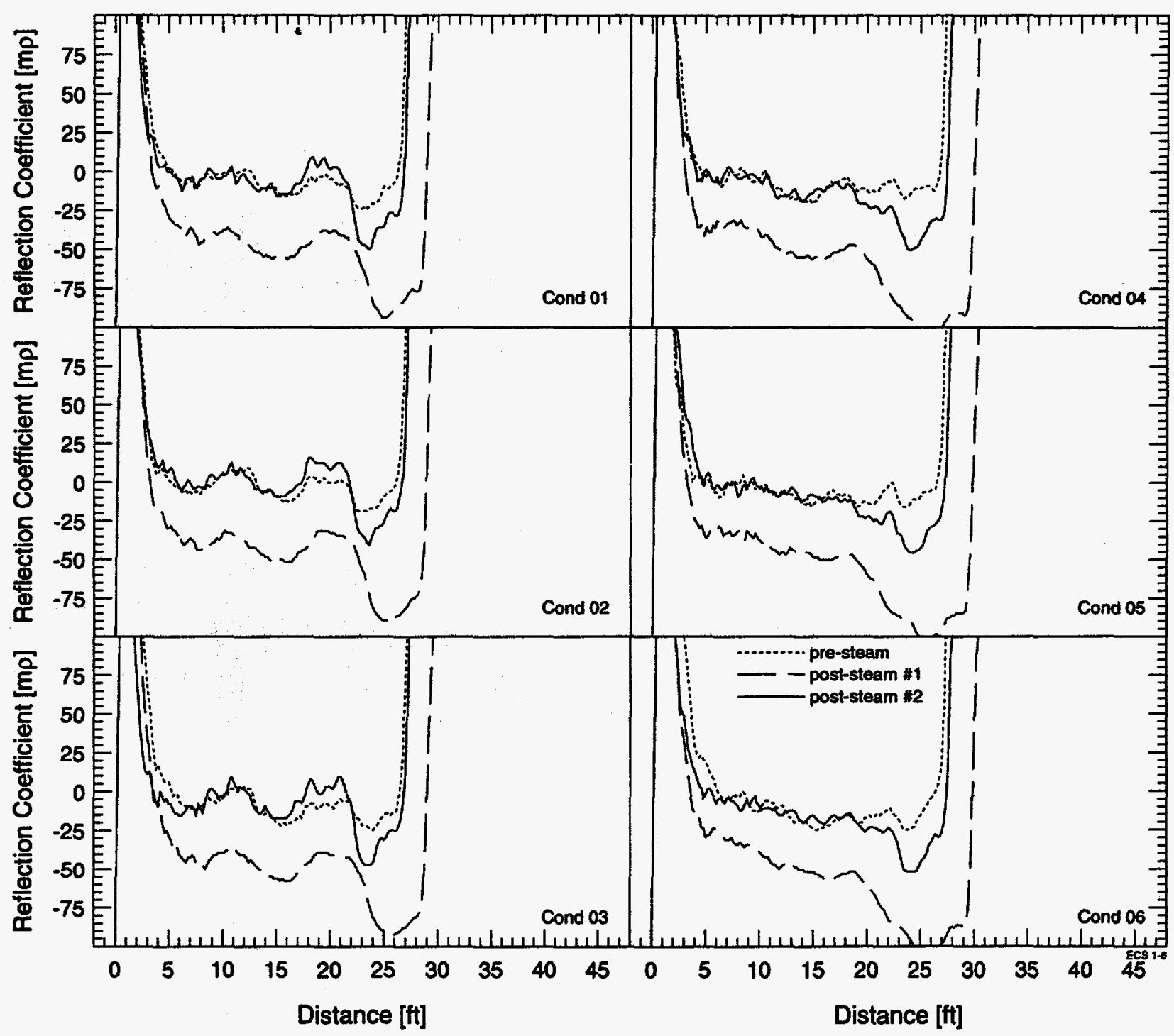

Figure C.4: TDR of the EGS conduit seal conductors before and after the accident steam exposure. 


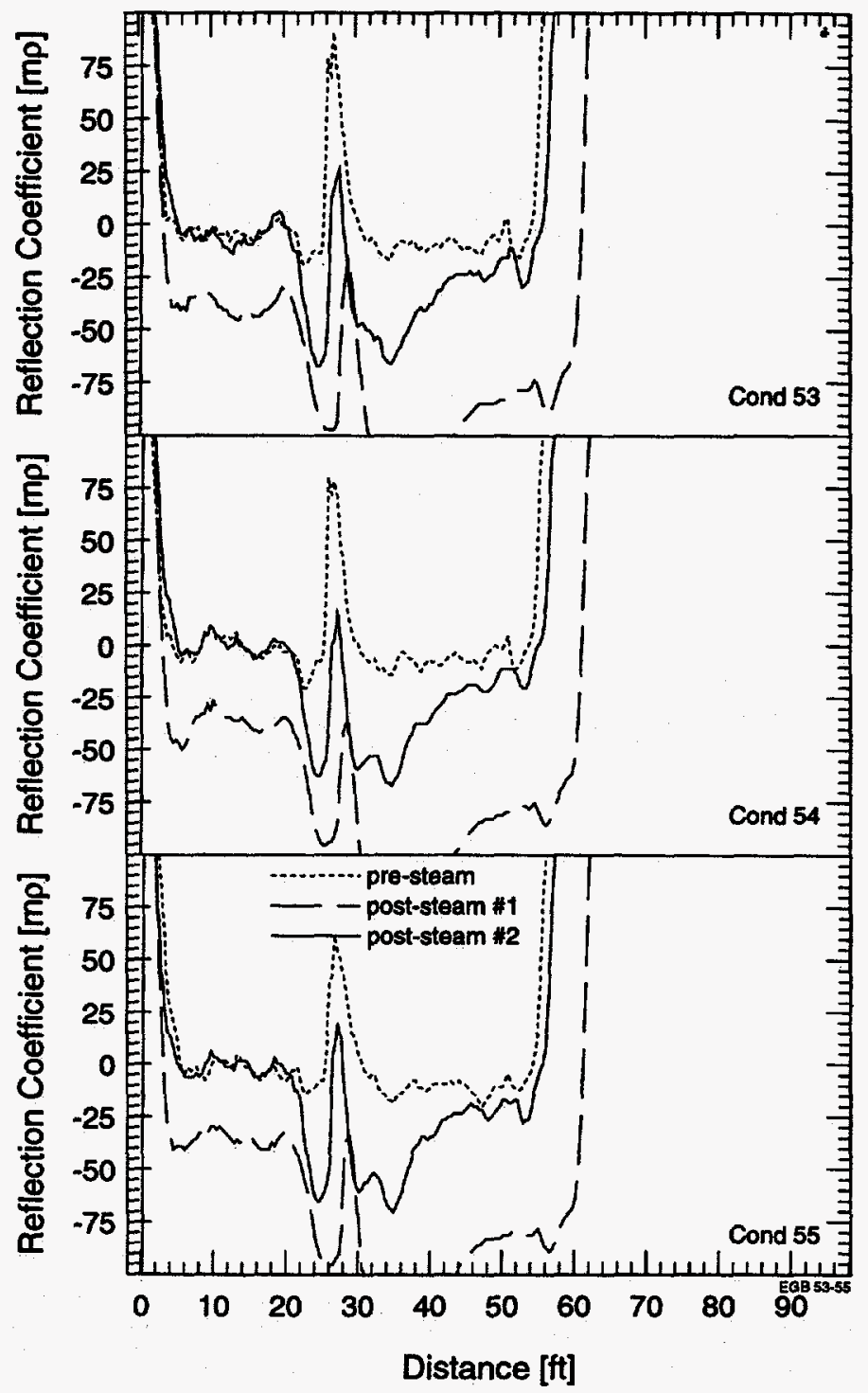

Figure C.5: TDR of the EGS Grayboot connector conductors before and after the accident steam exposure. 


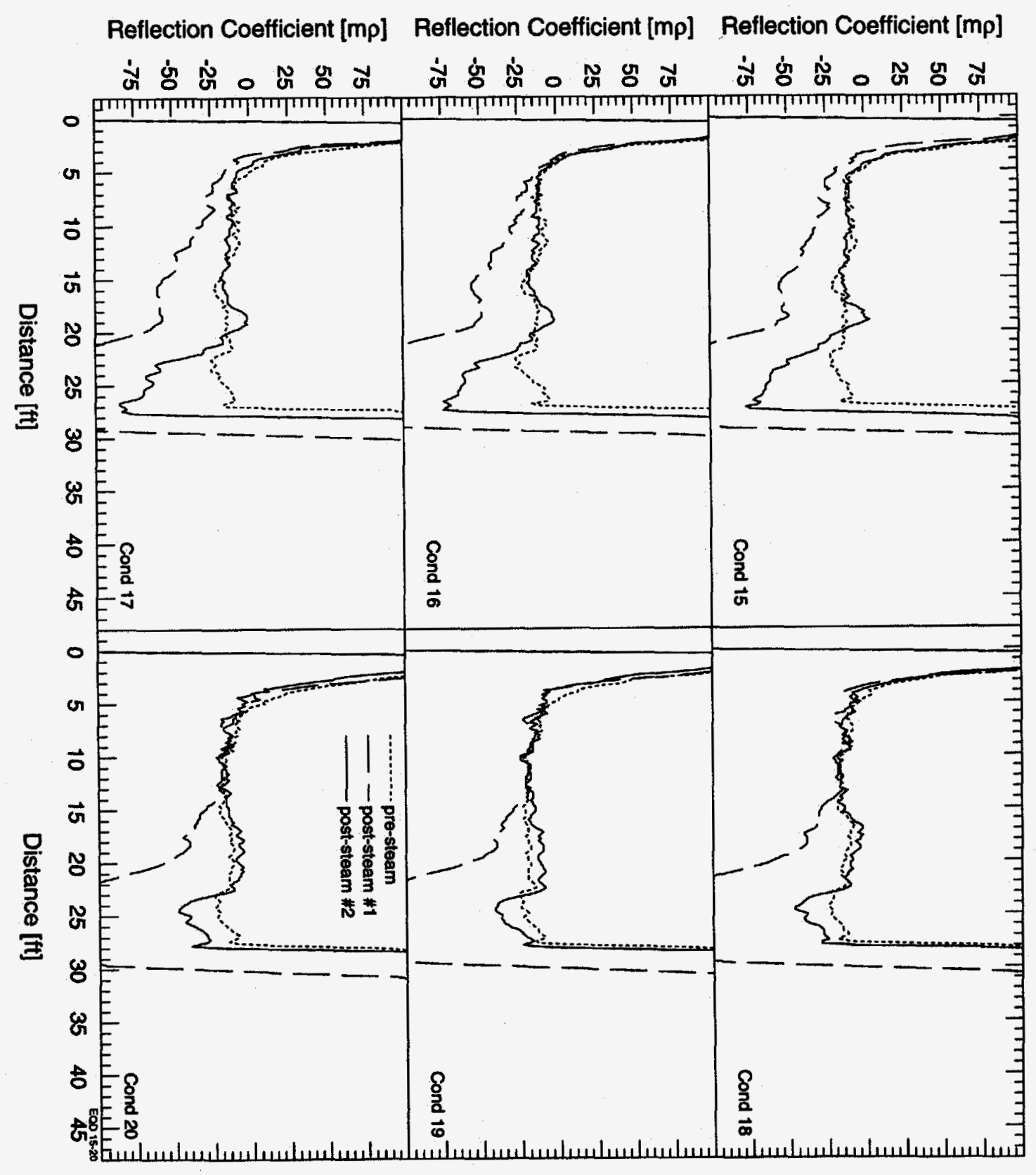




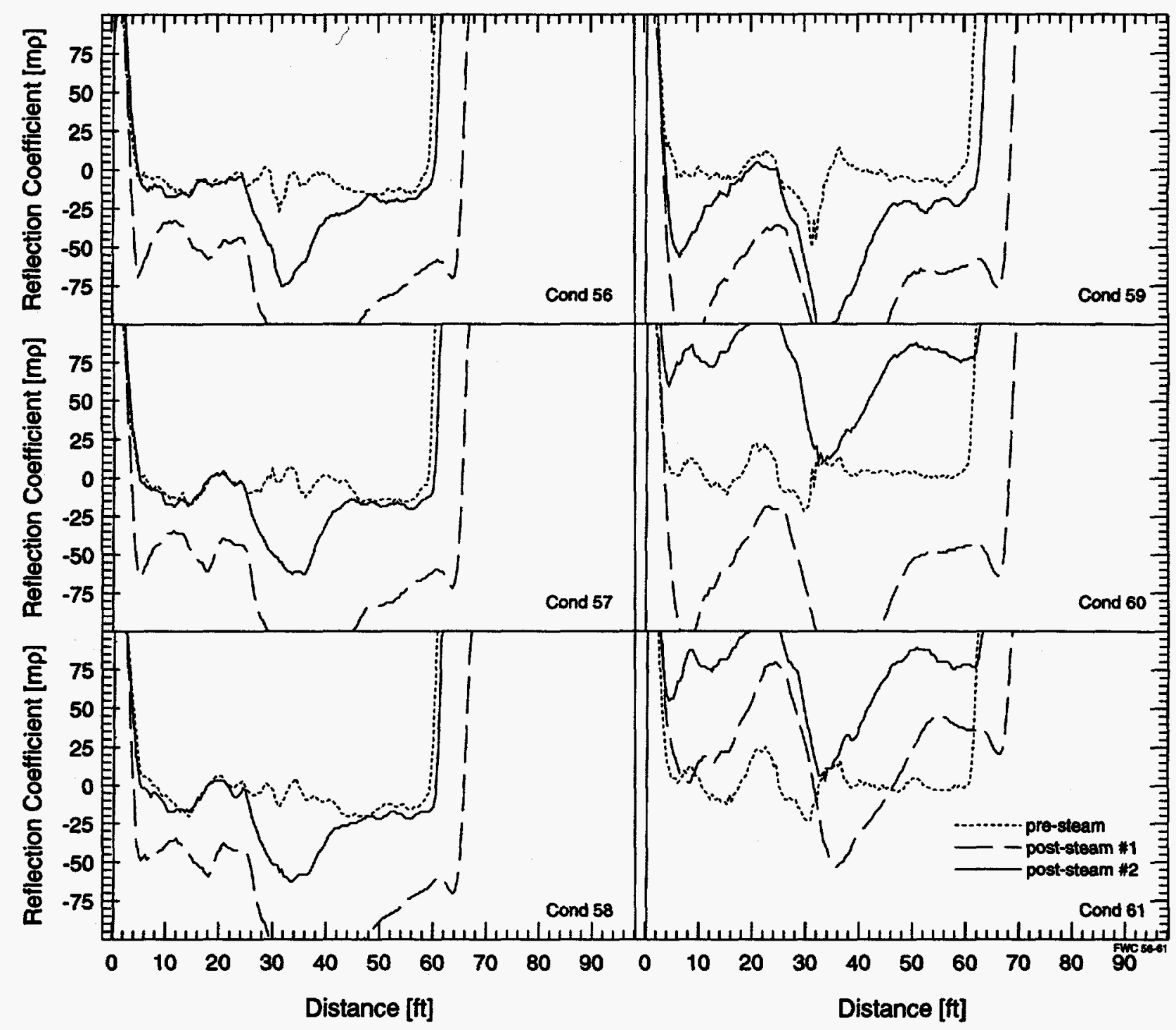

Figure C.7: TDR of the Rockbestos Firewall III cable conductors before and after the accident steam exposure. 
C. TIME DOMAIN REFLECTOMETRY RESULTS

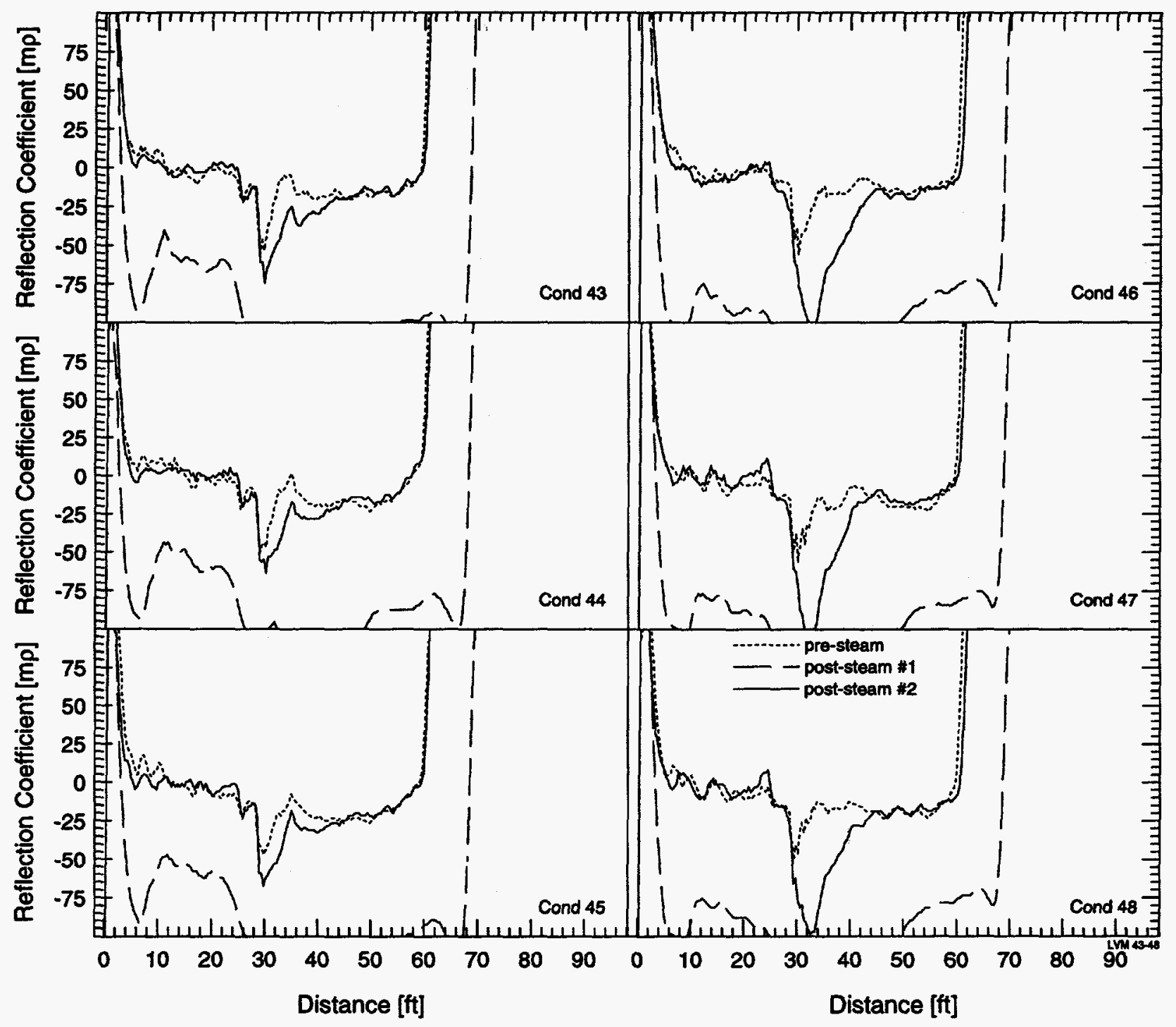

Figure C.8: TDR of the Litton-VEAM connector conductors before and after the accident steam exposure. 
C. TIME DOMAIN REFLECTOMETRY RESULTS

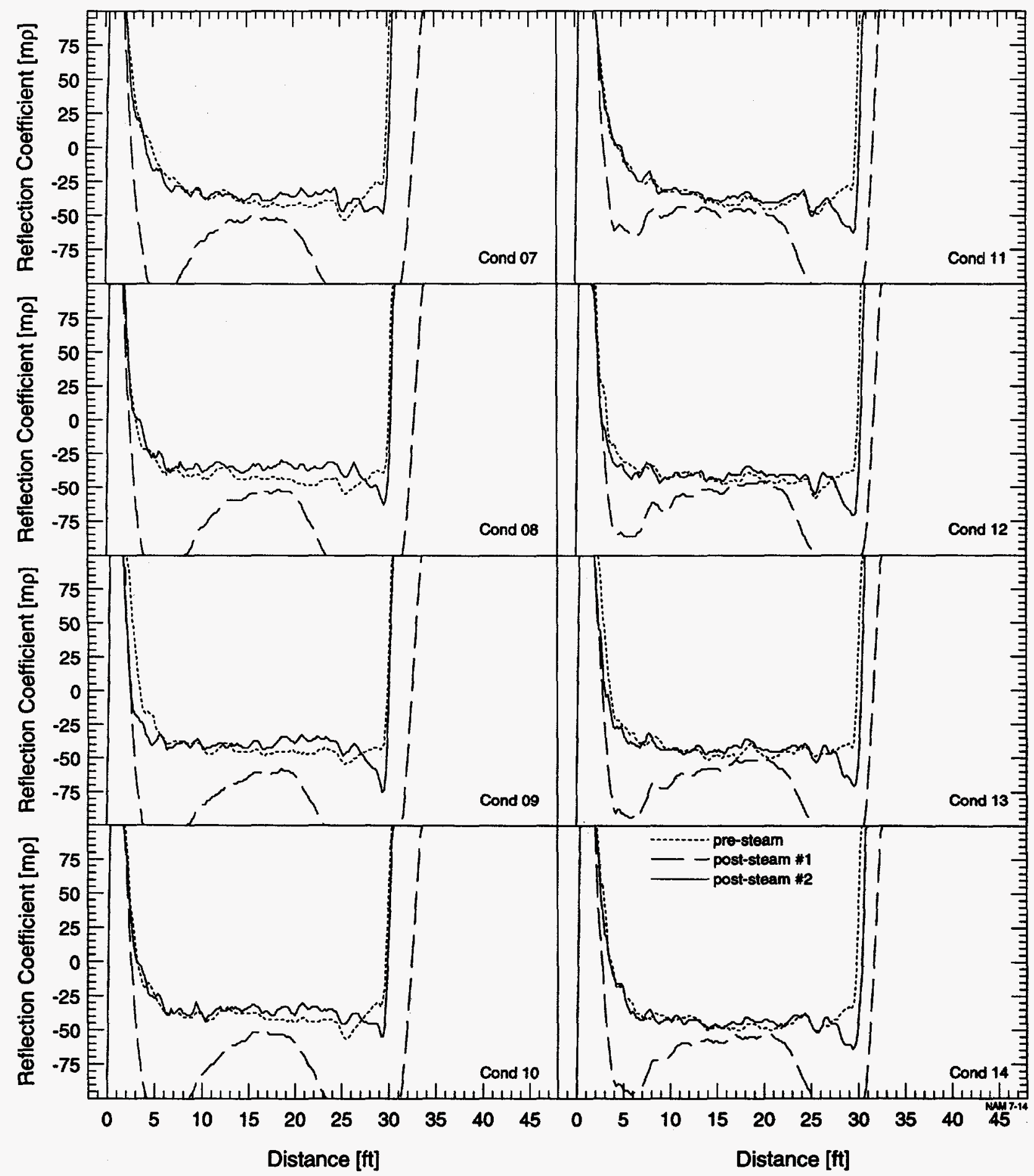

Figure C.9: TDR of the NAMCO EC210 connector conductors before and after the accident steam exposure. 
C. TIME DOMAIN REFLECTOMETRY RESULTS

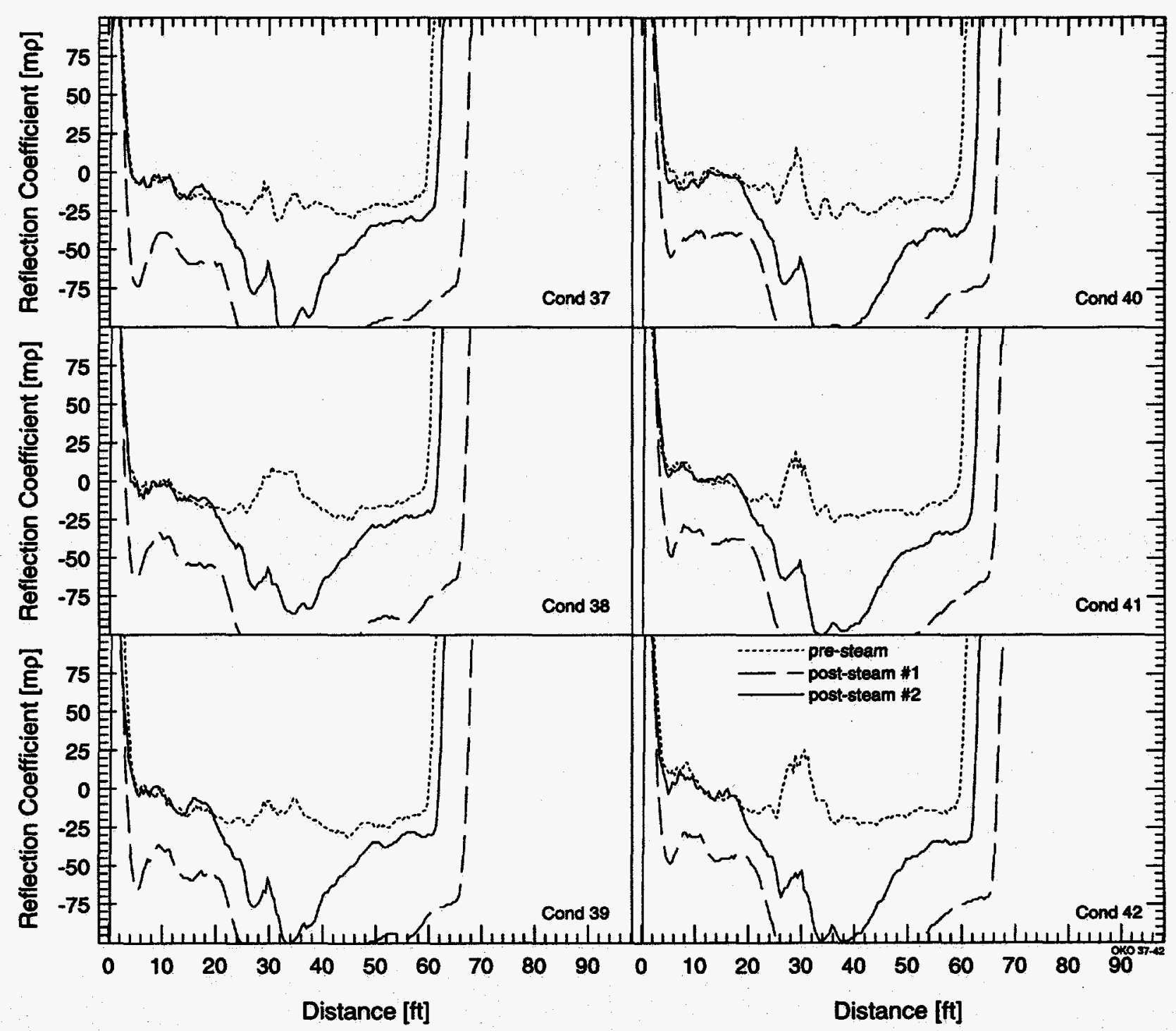

Figure C.10: TDR of the Okonite tape splice conductors before and after the accident steam exposure. 


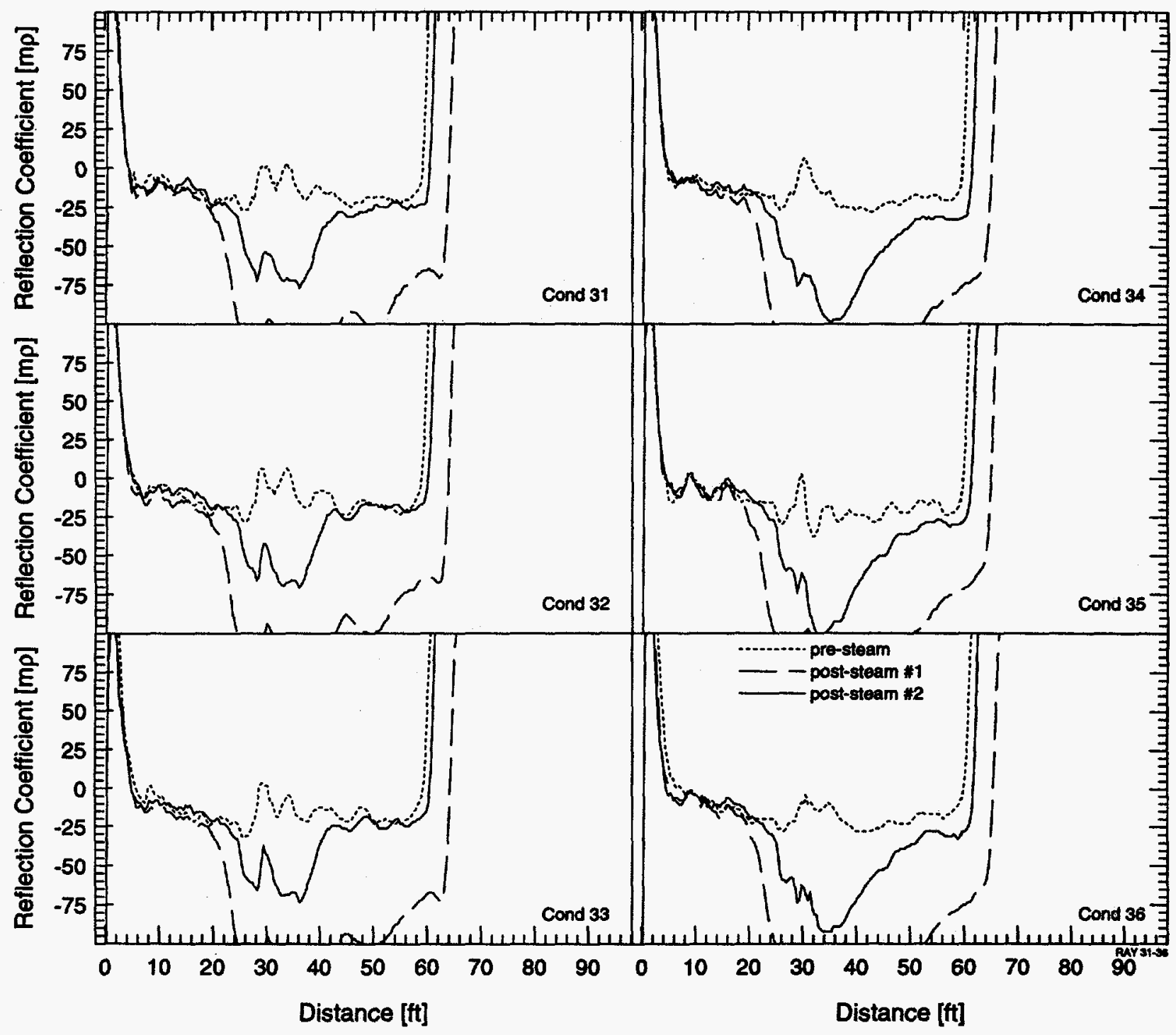

Figure C.11: TDR of the Raychem heat-shrink splice conductors before and after the accident steam exposure. 


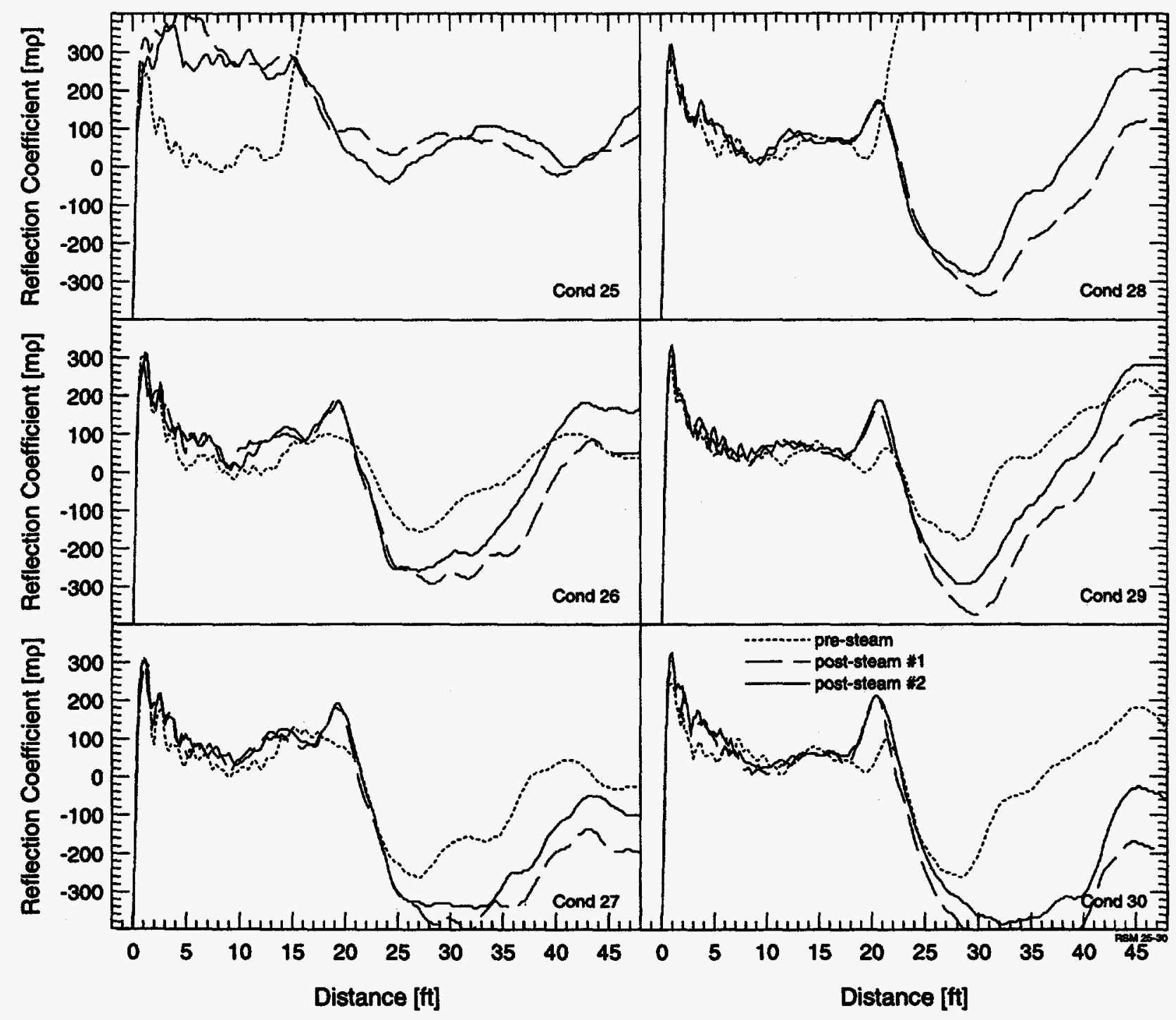

Figure C.12: TDR of the Rosemount 353C conduit seal conductors before and after the accident steam exposure. 
2. TITLE AND SUBTITLE

Aging and Loss-of-Coolant Accident (LOCA) Testing of

Electrical Connections

NUREG/CR-6412

SAND 97-3170

5. AUTHORISI

Curtis F. Nelson

Technical

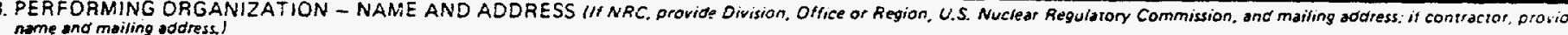

Sandia National Laboratories

P.0. Box 5800, Mail Stop 0742

Albuquerque, NM 87185-0742

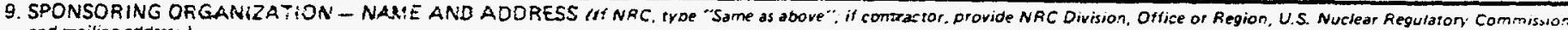
and mailing addres,

Division of Engineering Technology

Office of Nuclear Regulatory Research

U.S. Nuclear Regulatory Commission

Washington, DC 20555-0001

10. SUPPLEMENTARY NOTES

S. Aggarwal, NRC Program Manager

11. ABSTRACT 1200 wores or less?

This report presents the results of an experimental program to determine the aging and loss-of-coolant accident (LOCA) behavior of electrical connections in order to obtain an initial scoping of their performance. Ten types of connections commonly used in nuclear power plants were tested. These included 3 types of conduit seals, 2 types of cable-to-device connectors, 3 types of cable-to-cable connectors, and 2 types of inline splices. The connections were aged for 6 months under simultaneous thermal $\left(99^{\circ} \mathrm{C}\right)$ and radiation ( $46 \mathrm{~Gy} / \mathrm{hr}$ ) conditions. A simulated LOCA consisting of sequential high dose-rate irradiation ( $3 \mathrm{kGy} / \mathrm{hr}$ ) and high-temperature steam exposures followed the aging. Connection functionality was monitored using insulation resistance measurements during the aging and LOCA exposures. Because only 5 of the 10 connection types passed a post-LOCA, submerged dielectric withstand test, further detailed investigation of electrical connections and the effects of cable jacket integrity on the cable-connection system is warranted.

12. KEY WORDS'DESCR!PTORS / 2 is: wards ar phrases that will assist researchers in locating the report. 1

Radiation aging, thermal aging, condition monitoring, loss-ofcoolant accident (LOCA), cables, connectors, connections

\begin{tabular}{|c|}
\hline $\begin{array}{l}\text { 13. AVAILABILITY STRTEMENT } \\
\text { Un1imited }\end{array}$ \\
\hline 14. SECUAITY CLASSIFICATION \\
\hline (This Page) \\
\hline Unclassified \\
\hline TTres Reaort' \\
\hline Unclassified \\
\hline i5. NUMBER OF PAGES \\
\hline 16. PRICE \\
\hline
\end{tabular}

